\title{
Investigation of Intra/ply Shear Behavior of Out-of-Autoclave Carbon/Epoxy Prepreg
}

\author{
RAHUL PARAMBATH MOHAN
}

A thesis

in

The Department

of

Mechanical and Industrial Engineering

\author{
Presented in Partial Fulfillment of the Requirements \\ for the Degree of Master of Applied Science (Mechanical Engineering) \\ at Concordia University \\ Montreal, Quebec, Canada
}

February 2015

CRahul Parambath Mohan 2015 


\section{CONCORDIA UNIVERSITY}

\section{School of Graduate Studies}

This is to certify that the thesis prepared

\section{By: Rahul Parambath Mohan}

Entitled: Investigation of Intra/ply Shear Behavior of Out-of-Autolave Carbon/Epoxy

\section{Prepreg.}

and submitted in partial fulfillment of the requirements for the degree of

\section{Master of Applied Sciences (Mechanical Engineering)}

complies with the regulations of the University and meets the accepted standards with respect to originality and quality.

Signed by the final Examining Committee:

Chair

Dr. A.K. Waizuddin Ahmed

Examiner, External

Dr. M. Nokken, BCEE to the program

Examiner

Dr. S.V. Hoa, MIE

Examiner and

Dr. M. Hojjati

Supervisor

Approved by:

Dr. S. Narayanswamy, MASc Program Director

Department of Mechanical and Industrial Engineering

Dr. Christopher Trueman

Dean, Faculty of Engineering and Computer Science

Date: February 20, 2015 


\section{$\underline{\text { Abstract }}$ \\ Investigation of Intra/ply Shear Behavior of Out-of-Autoclave Carbon/Epoxy Prepreg. \\ Rahul Parambath Mohan}

The forming of a composite part without defects has been a challenging issue till date due to the complexity of the process. Lack of knowledge on the in- plane shear behavior of the composite during forming has always served as the prime reason for the defects. Still, a sound knowledge of diverse phenomena which make these flaws such as wrinkling, would help to optimize the performance. In addition, the possibility to form a composite part from out-of-autoclave prepreg without any defect would further enhance the process due to the cost reduction caused by eliminating the autoclave.

The work presented herein aims to investigate the intra-ply shear behavior of out- of- autoclave carbon epoxy thermoset prepreg and its effect on wrinkling using the picture frame and bias extension tests. Tests will be performed at varying temperatures and displacement rates in order to determine their contribution on deformability of the fabric. Digital image correlation was applied onto the set-up to take sequential images at various stages of deformation and capture the onset of wrinkling. Microstructural analysis was performed in order to observe the change in tow geometry throughout the shear deformation. In addition, the uni-directional and woven prepreg (8- harness and 5- harness) were compared to the scale of their deformability to determine the material which favors the forming the most. Finally, based on the response of the operating temperature (resin viscosity), displacement rate and layer counts (layer interactions) on the onset of wrinkling, an optimization method was generated using the Taguchi and Analysis of Variance technique to determine the parameter which influences, wrinkling the most.

\section{Keywords}

Out of autoclave prepreg, picture frame, intra-ply shear, tow geometry, Taguchi method. 


\section{Acknowledgements}

I would like to express my sincere gratitude to my supervisor, Dr. Mehdi Hojjati for his support throughout the course of the thesis project. It would not have been possible for me to complete the thesis without his valuable guidance and motivation.

I would like to thank, Dr. S.V. Hoa for allowing me to access the facilities in the CONCOM laboratories. I am thankful to NSERC and Bombardier Aerospace for their financial support and providing the required material throughout this project.

I am extremely grateful to my lab partner and my friend, Mr. Hassan Alsharani for his guidance and technical support. I would also like to thank Mr. Farjad Shamderi, Mr. Dainius Juras, Mr. Henry, Mr. Robert, Mr. Heng Wang for their guidance and help throughout the project.

I would like to thank my friends, Sethu Madhavan Rangaswamy, Ganesh Kumar Elangovan, Ashoka Kalyanasundaram, Abishek Ramesh, Karthick Krishnan, Harish Iyengar, Ramkarthick, Sri Kumaran, Siddharthan and Kumar Mani for their support throughout my stay in Montreal.

Finally, I would like to thank my parents for their unconditional love and support. I would like to dedicate this thesis to my parents, Mr. Mohan Kumar Mepparambath and Mrs. Baby Padma Parambath, my uncle Jayaraj Parambath and my brother Rakesh Parambath. 


\section{TABLE OF CONTENTS}

LIST OF FIGURES .................................................................................................................. vii

LIST OF TABLES .............................................................................................................................. xii

CHAPTER 1: INTRODUCTION................................................................................................... 1

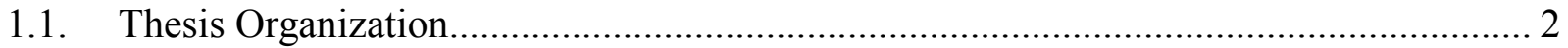

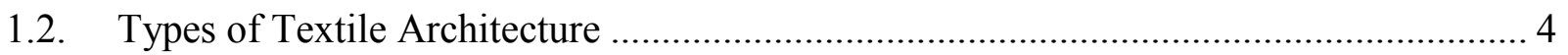

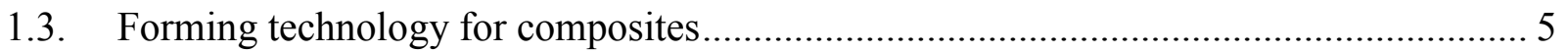

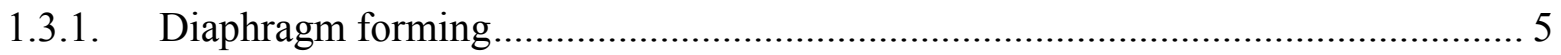

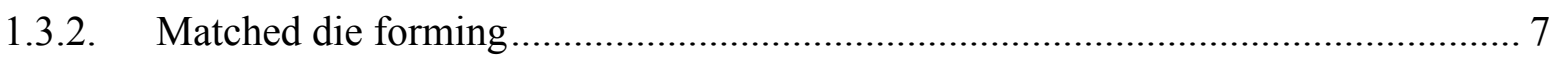

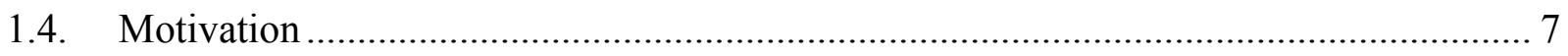

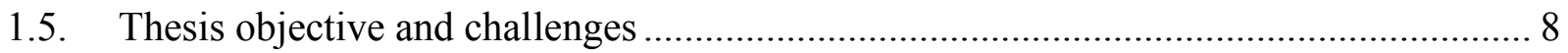

Chapter 2: Literature Review.................................................................................................... 10

2.1. Deformation mechanisms of textile composites ........................................................... 10

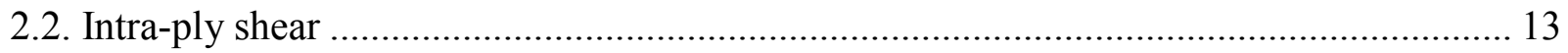

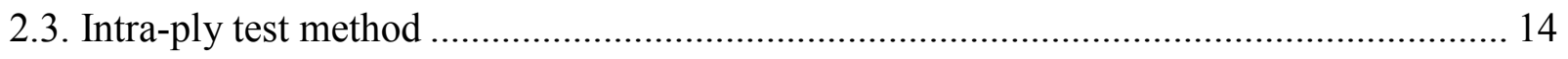

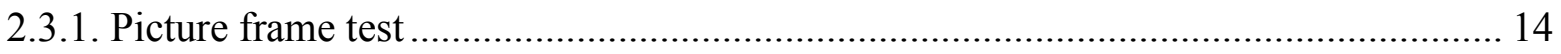

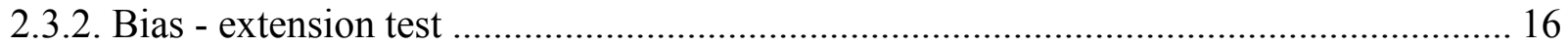

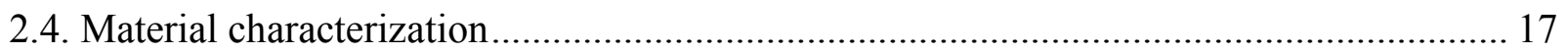

CHAPTER 3: MATERIALS AND RIG FABRICATION ............................................... 20

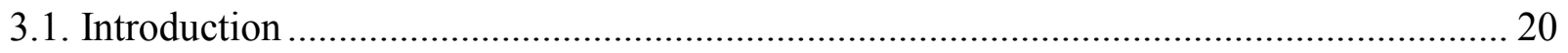

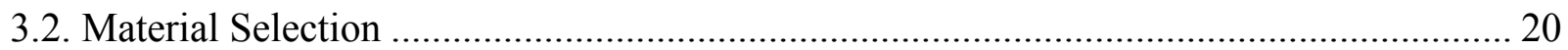

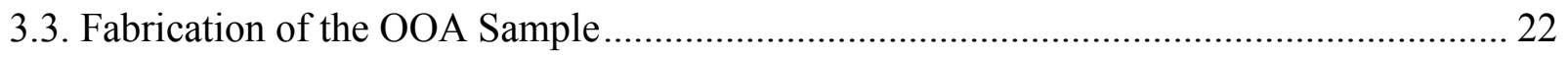

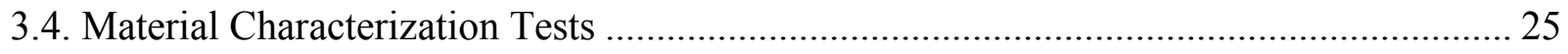

3.4.1. Differential Scanning Calorimeter (DSC) Analysis ..................................................... 25

3.4.1.1. Dynamic Cure Analysis ................................................................................ 25

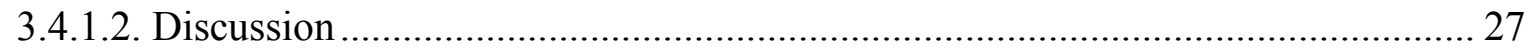

3.4.2. Rheological characterization of the prepreg ........................................................... 28

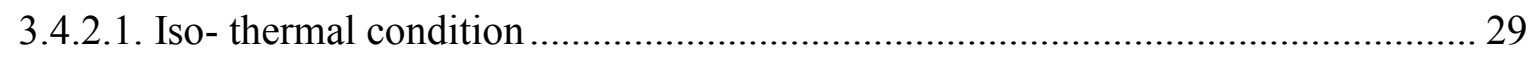




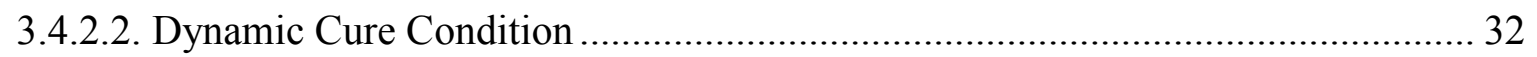

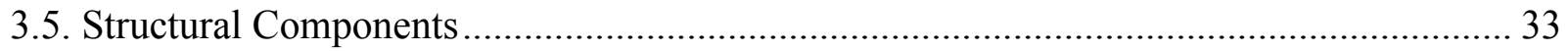

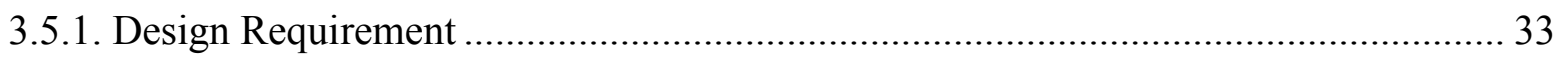

3.5.2 Clamping plate ......................................................................................................... 34

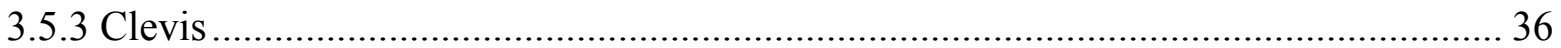

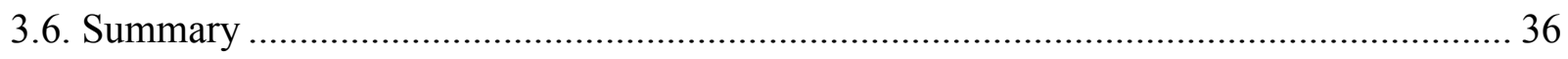

CHAPTER 4: TEST RESULTS AND DISCUSSION ........................................................ 37

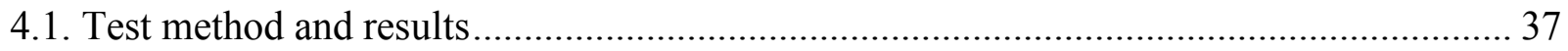

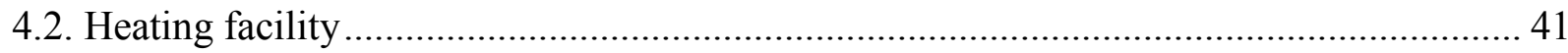

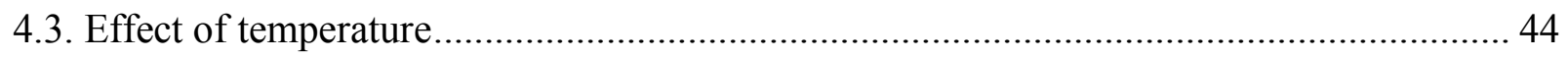

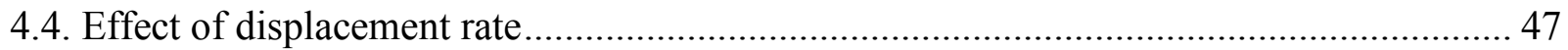

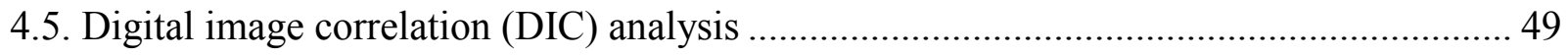

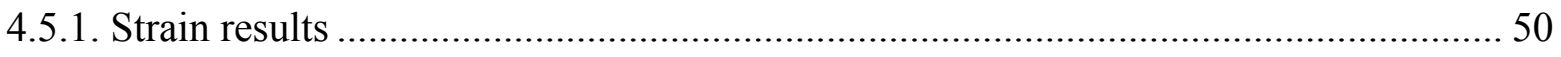

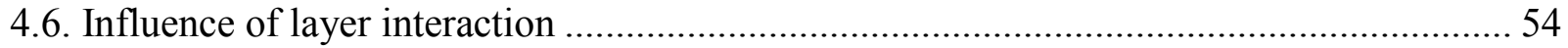

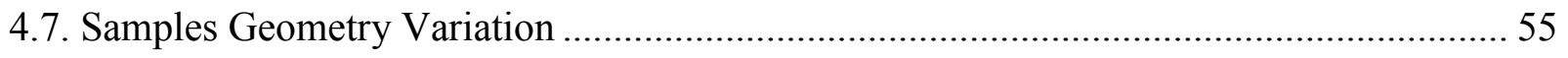

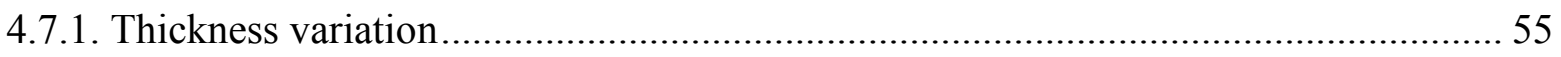

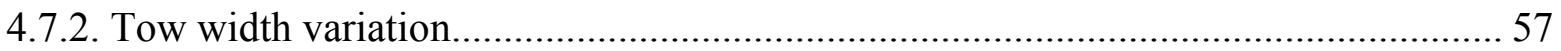

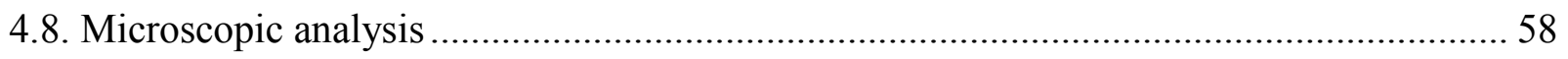

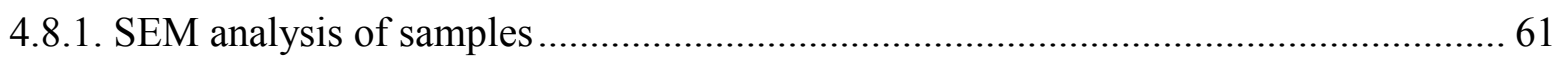

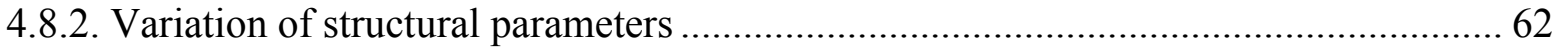

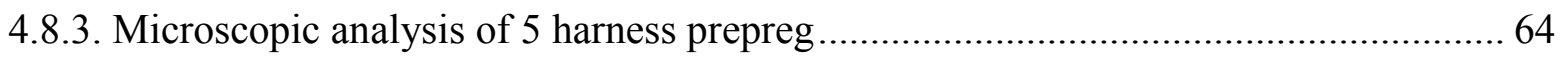

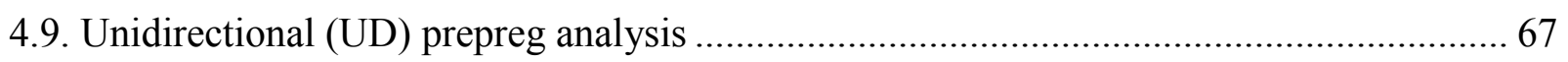

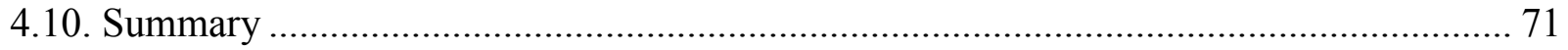

CHAPTER 5: Bias extension and optimization technique........................................................ 72

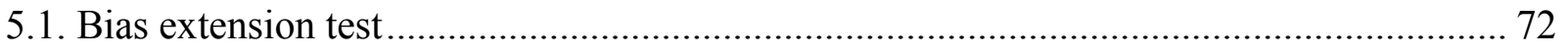

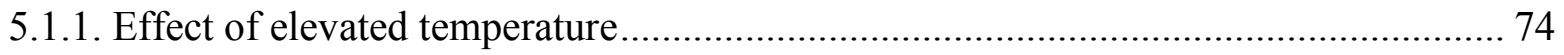

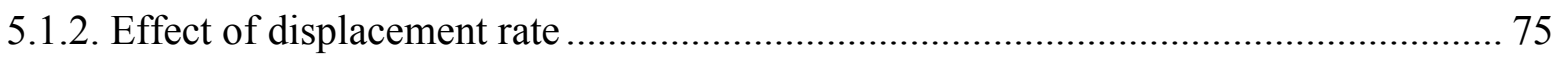

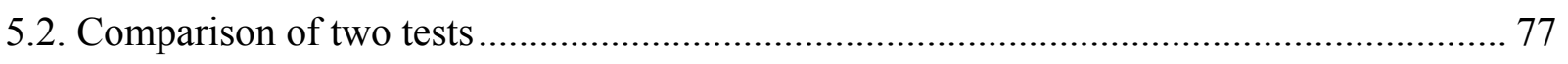

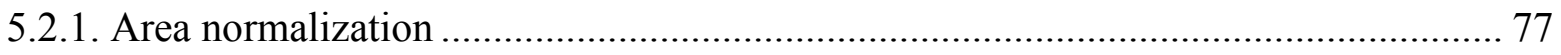

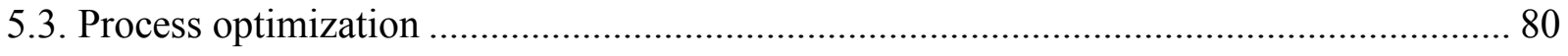




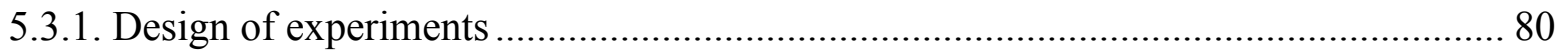

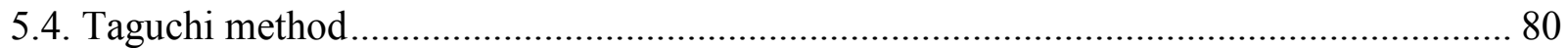

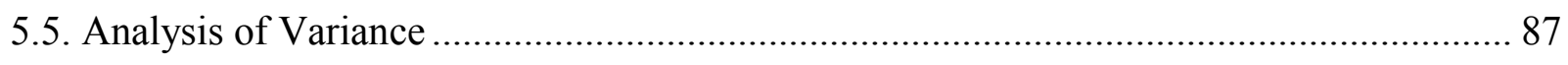

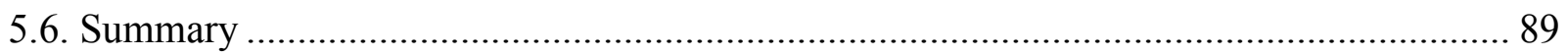

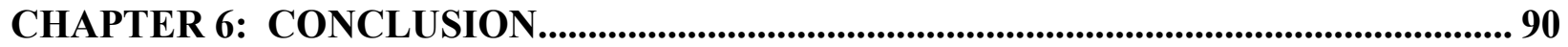

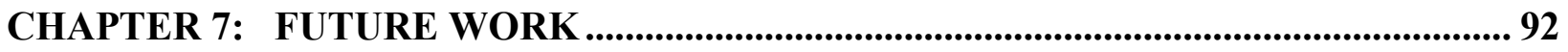

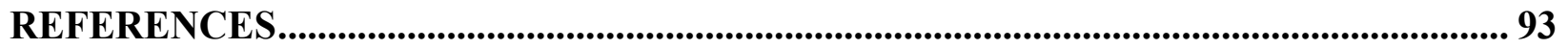




\section{LIST OF FIGURES}

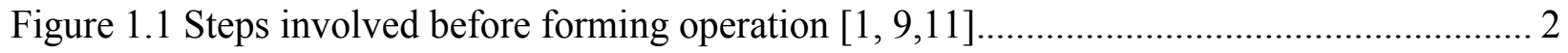

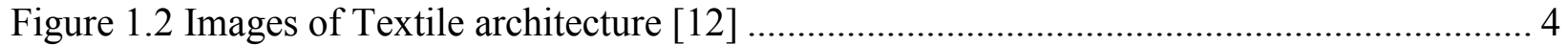

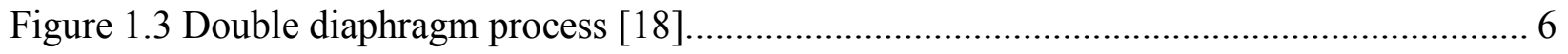

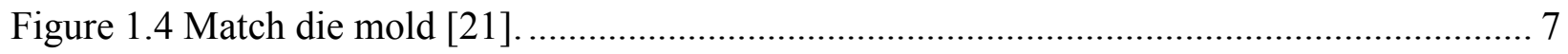

Figure 2.1 Deformation modes; (a) intra-ply shear, (b) intra-ply extension, (c) inter ply slippage,

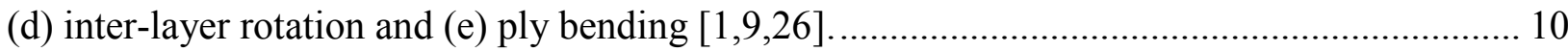

Figure 2.2 Inter- ply slip during double curvature forming [26] ......................................... 11

Figure 2.3 Test set-up; (a) inter-ply friction apparatus [9] and (b) ASTM D1388-08 bending test

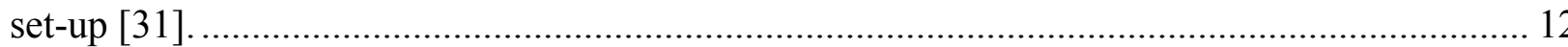

Figure 2.4 Types of intra-ply shear; (a) in-plane shear and (b) through thickness shear [35]..... 13

Figure 2.5 The pin-jointed net (PJN) model [37] ...................................................... 14

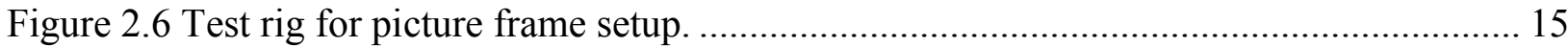

Figure 2.7 Bias- extension; (a) before deformation and (b) after deformation [45]................. 17

Figure 2.8 (a) shear inside the yarns [26] and (b) shear compliance graph [39]..................... 18

Figure 3.1 Pictograph of various composites (a) 5-harness woven, (b) 8-harness woven, (c) uni-

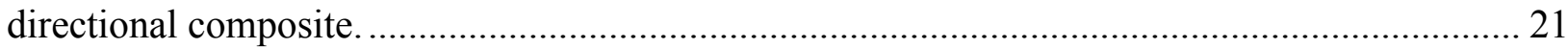

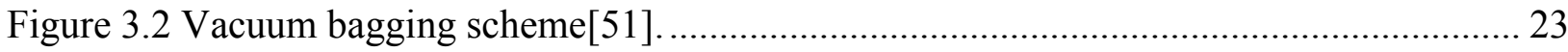

Figure 3.3 Initial sample made using Cycom-5320 8HS by hand lay-up process..................... 23

Figure 3.4 Final trimmed sample by hand lay-up process (a) 5-harness (5HS) sample, (b) 8-

harness (8HS) sample, (c) uni-directional (UD) sample................................................ 24

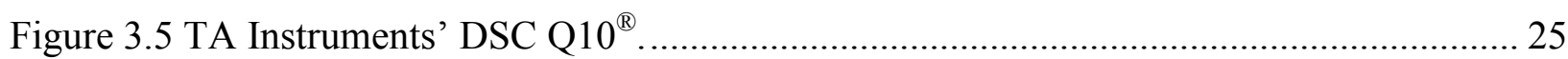

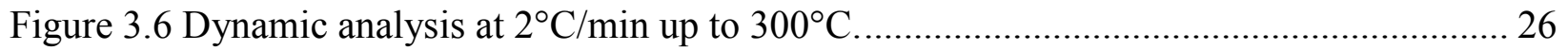

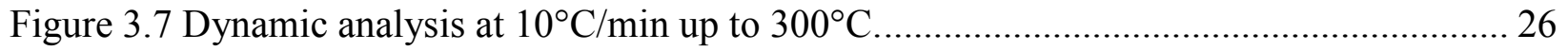

Figure 3.8 (a) MCR $500^{\circledR}$ Rheometer and (b) Thermostatting unit............................................ 28

Figure 3.9 Experimental viscosity at selected isothermal temperatures. ................................... 29

Figure 3.10 Variation of viscosity during the initial stage at selected temperatures.................. 30

Figure 3.11 Effect of storage modulus $\left(G^{\prime}\right)$ and loss modulus $\left(G^{\prime \prime}\right)$ on time at various temperatures. 
Figure 3.12 Viscosity vs. temperature at constant heating rate, $2^{\circ} \mathrm{C} / \mathrm{min}$.

Figure 3.13 Structural outline of the test set up: 1- clamping plate, 2- clevis, 3- shoulder bolts, 4-

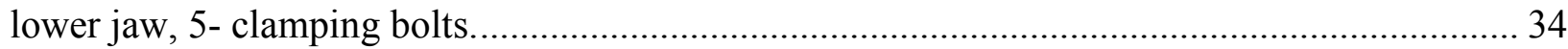

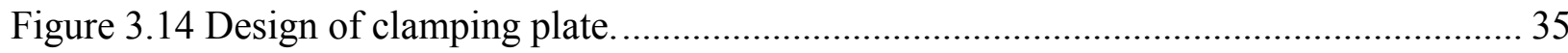

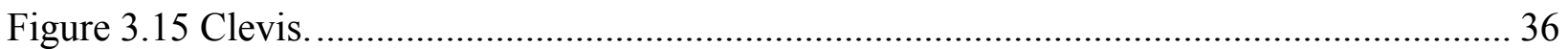

Figure 4.1 Set-up (a) initial sample, (b) un-deformed (square) frame and (c) deformed

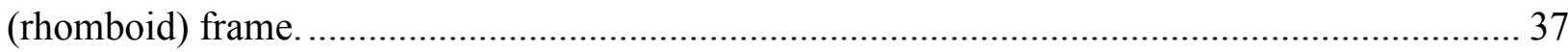

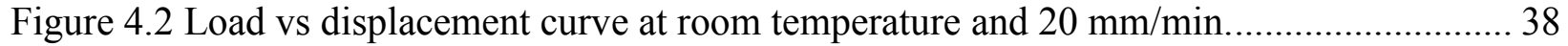

Figure 4.3 Shear load Vs calculated shear angle at room temperature and $20 \mathrm{~mm} / \mathrm{min}$............. 39

Figure 4.4 Comparison between calculated and experimental shear angle for 8HS. ............... 40

Figure 4.5 Comparison between calculated and experimental shear angle for 5HS. ................ 40

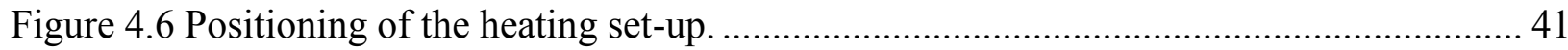

Figure 4.7 (a) Locations of thermocouples and (b) temperature recorded by thermocouples

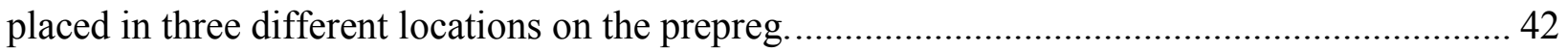

Figure 4.8 Photograph of the (a) IR temperature sensor and (b) FLIR ${ }^{\circledR}$ IR cameras. ............... 43

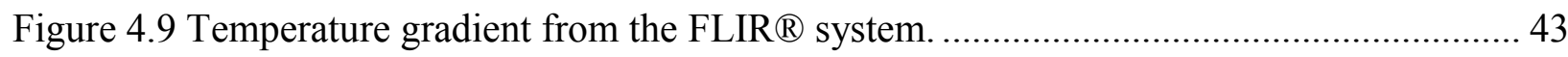

Figure 4.10 Picture frame on 8 harness at varying temperatures and $20 \mathrm{~mm} / \mathrm{min}$.................. 45

Figure 4.11 Picture frame test on 5 harness at varying temperatures and $20 \mathrm{~mm} / \mathrm{min}$............. 45

Figure 4.12 Locking angles of 8 harness and 5 harness at varying temperatures..................... 46

Figure 4.13 Picture frame test on 8 harness at varying ramp rates and $70^{\circ} \mathrm{C}$......................... 47

Figure 4.14 Picture frame test on 5 harness at varying ramp rates and $70^{\circ} \mathrm{C} \ldots \ldots \ldots \ldots \ldots \ldots \ldots \ldots . . . . . . . . . . . . .47$

Figure 4.15 Photos taken during the picture frame test. .................................................... 48

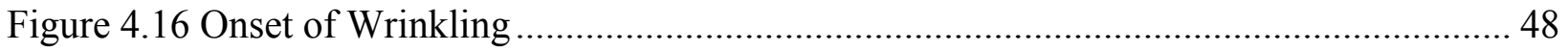

Figure 4.17 Locking angles of 8 harness and 5 harness at varying shear rates. ...................... 49

Figure 4.18 Experimental setup containing DIC and picture frame clamped on MTS............. 50

Figure 4.19 Strain fields at the end of the test (a) axial strain and (b) transverse strain............. 51

Figure 4.20 Shear strain field at varying measured shear angle (a) $\gamma \approx 8^{\circ}$, (b) $\gamma \approx 18^{\circ}$ and (c) $\gamma \approx$ $37^{\circ}$

Figure 4.21 Post processed 3D images from DIC (a) $\gamma \approx 0^{\circ}$, (b) $\gamma \approx 8^{\circ}$, (c) $\gamma \approx 15^{\circ}$, (d) $\gamma \approx 27^{\circ}$, (e)

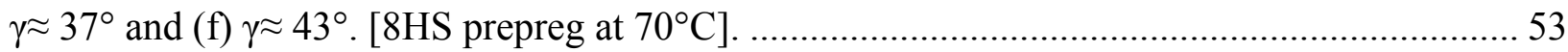

Figure 4.22 Effect of layer count on in-plane shear behavior................................................. 54 
Figure 4.23 Locking angles of 8 harness at varying layer count. ........................................ 55

Figure 4.24 Variation of sample thickness in (a) room temperature and (b) $70^{\circ} \mathrm{C} \ldots \ldots \ldots \ldots \ldots \ldots . . . . . . . . .56$

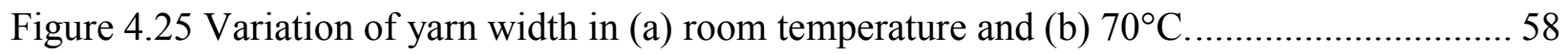

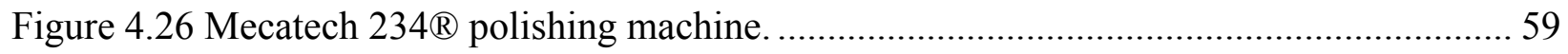

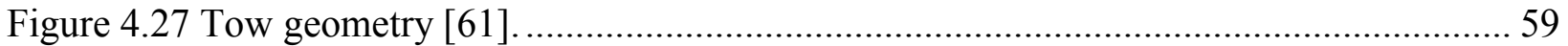

Figure 4.28 Microscopic image of the tow structure at various shear angles of 8HS samples (a) initial specimen, (b) $12^{\circ}$ sheared structure, (c) $24^{\circ}$ sheared structure and (d) $52^{\circ}$ sheared structure 60

Figure 4.29 SEM images at various stages of shear (a) before shear, (b) $24^{\circ}$ sheared structure and (c) $52^{\circ}$ sheared structure (end of shear).

Figure 4.30 The percentage of variation of various factors with shear angle (8HS) (a) tow thickness, (b) yarn width, (c) tow spacing $(\Delta \mathrm{Y})$, (d) amplitude and (e) wavelength. 63

Figure 4.31 Microscopic image of the tow structure at various shear angles of 5HS samples (a) initial specimen, (b) $16^{\circ}$ sheared structure and (c) $48^{\circ}$ sheared structure 64 Figure 4.32 The percentage of variation of various factors with shear angle (5HS) (a) tow thickness, (b) yarn width, (c) tow spacing $(\Delta \mathrm{Y})$, (d) amplitude and (e) wavelength. 66

Figure 4.33 Schematic representation of cross-ply laminates during shear............................... 67

Figure 4.34 Picture frame with UD fabric at varying temperatures and $20 \mathrm{~mm} / \mathrm{min}$............... 68

Figure 4.35 UD fabric (a) onset of wrinkling, and (b) shape of deformed sample.................... 69

Figure 4.36 Picture frame with UD fabric at varying ramp rates and $70^{\circ} \mathrm{C}$. ........................... 69

Figure 4.37 Wrinkling angles of 8HS, 5HS and UD at varying temperatures......................... 70

Figure 4.38 Wrinkling angles of 8HS, 5HS and UD at varying shear rates. .......................... 71

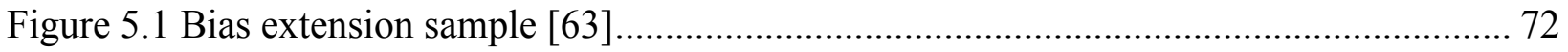

Figure 5.2 Photos taken during the bias extension test................................................... 73

Figure 5.3 Bias extension test on 8 harness at varying temperatures and $20 \mathrm{~mm} / \mathrm{min}$ [63] ....... 74

Figure 5.4 Bias extension test on 5 harness at varying temperatures and $20 \mathrm{~mm} / \mathrm{min}$ [63] ....... 74

Figure 5.5 Bias extension test on 8 harness at varying ramp rates and $70^{\circ} \mathrm{C}[63] \ldots \ldots \ldots \ldots \ldots \ldots . . . . . . . . .76$

Figure 5.6 Picture frame test on 5 harness at varying ramp rates and $70^{\circ} \mathrm{C}$ [63].................... 76

Figure 5.7 Indication of pure shear zones in picture frame and bias-extension samples............. 77

Figure 5.8 Comparison between picture frame and bias extension test for 8HS...................... 78

Figure 5.9 Comparison between picture frame and bias extension test for 5HS..................... 78 
Figure 5.10 Combination of parameters of 8HS at different levels (a) Temperature, (b)

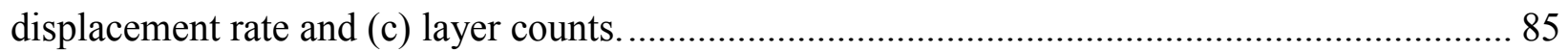

Figure 5.11 Combination of parameters of 5HS at different levels (a) Temperature, (b)

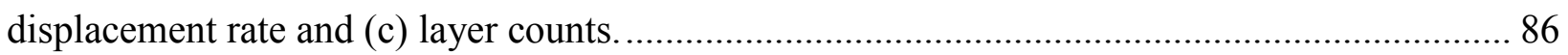




\section{LIST OF TABLES}

Table 3.1 Material properties of the composites used in the thesis $[51]$.

Table 3.2 Gel time at different temperatures

Table 4.1 Viscosity at elevated temperatures....................... 44

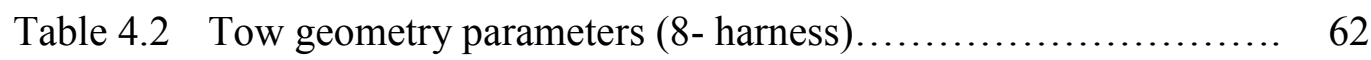

Table 4.3 Tow geometry parameters $(5$ - harness $) \ldots \ldots \ldots \ldots \ldots \ldots \ldots \ldots \ldots$

Table 5.1 Comparison between picture frame and bias- extension test..... 79

Table 5.2 Parameters and their levels $[66] \ldots \ldots \ldots \ldots \ldots \ldots \ldots \ldots \ldots \ldots . . \ldots$

Table $5.3 \quad$ L9 orthogonal array.................................. 81

Table 5.4 Summary of results of locking angles and $\mathrm{S} / \mathrm{N}$ values........... 82

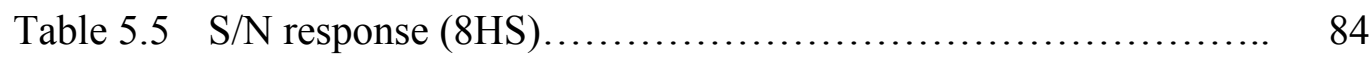

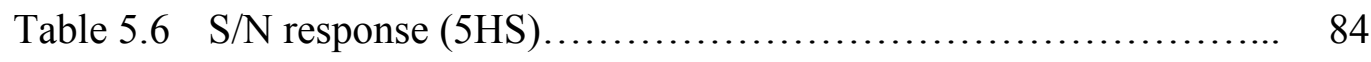

Table 5.7 Ideal parameter combinations............................ 84

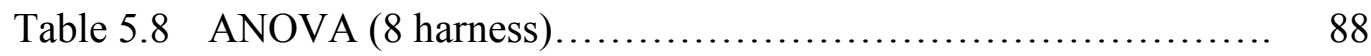

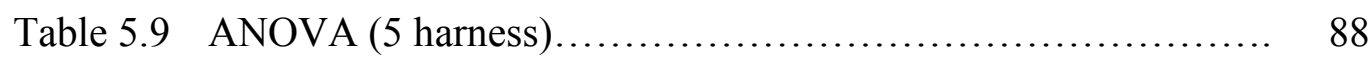




\section{CHAPTER 1: INTRODUCTION}

Textile technologies since their emergence many millennia ago have undergone revolutionary evolution to envisage a broad spectra from the term 'textile' emerged from woven fabrics to contemporary applications of fibres, filaments and yarns and most products derived from them [1]. Textile composites are very common these days in the automotive, aerospace, pipeline industries, etc., due to their superior properties such as high specific stiffness, high strength, low weight, low thermal expansion, good corrosion resistance [2,3]. These are also found to be resistant to crack propagation due to the interlacing tows which are found to be damaged tolerant [4]. Specifically, the textile thermoset composites made of textile reinforcement and thermoset matrix material have been of greater demand in the aerospace industry since they are widely used in manufacturing aircraft composite components. However, the mechanical behavior of the textile composites during deformation has been reported to be non-linear when compared to the individual carbon fibers which were seen to exhibit linear behavior [5].

In addition, the textile composites made up of out-of-autoclave (OOA) thermoset prepeg has come up as an increasingly used alternative to the traditional autoclave based material due to their reduced cost and space [6]. The OOA prepreg is manufactured by the application of only temperature and vacuum, without the requirement of much pressure, eliminating the need of the costly autoclave [7]. The OOA prepreg are designed in a way to remove the entrapped air by creating a porous medium which eases the removal of air during the debulking process [8].

Forming of textile composites by hot drape forming (HDF) integrated with automated fibre placement (AFP) and automated tape laying (ATL) has been a major area of research due to its ability to overcome the limitation of forming complex contours. However, while forming using HDF process the parts are found to be prone to defects such as wrinkling and out of plane buckling. These defects need to be overcome by analyzing different modes of deformation which tend to occur during forming [1,9].These deformation modes can be identified by various testing methods such as the picture frame test and the bias extension test. These tests help in modelling 
varying deformation mechanisms before proceeding with the actual forming operation [10]. Figure 1.1 explains the sequence of steps involved prior to the forming operation.

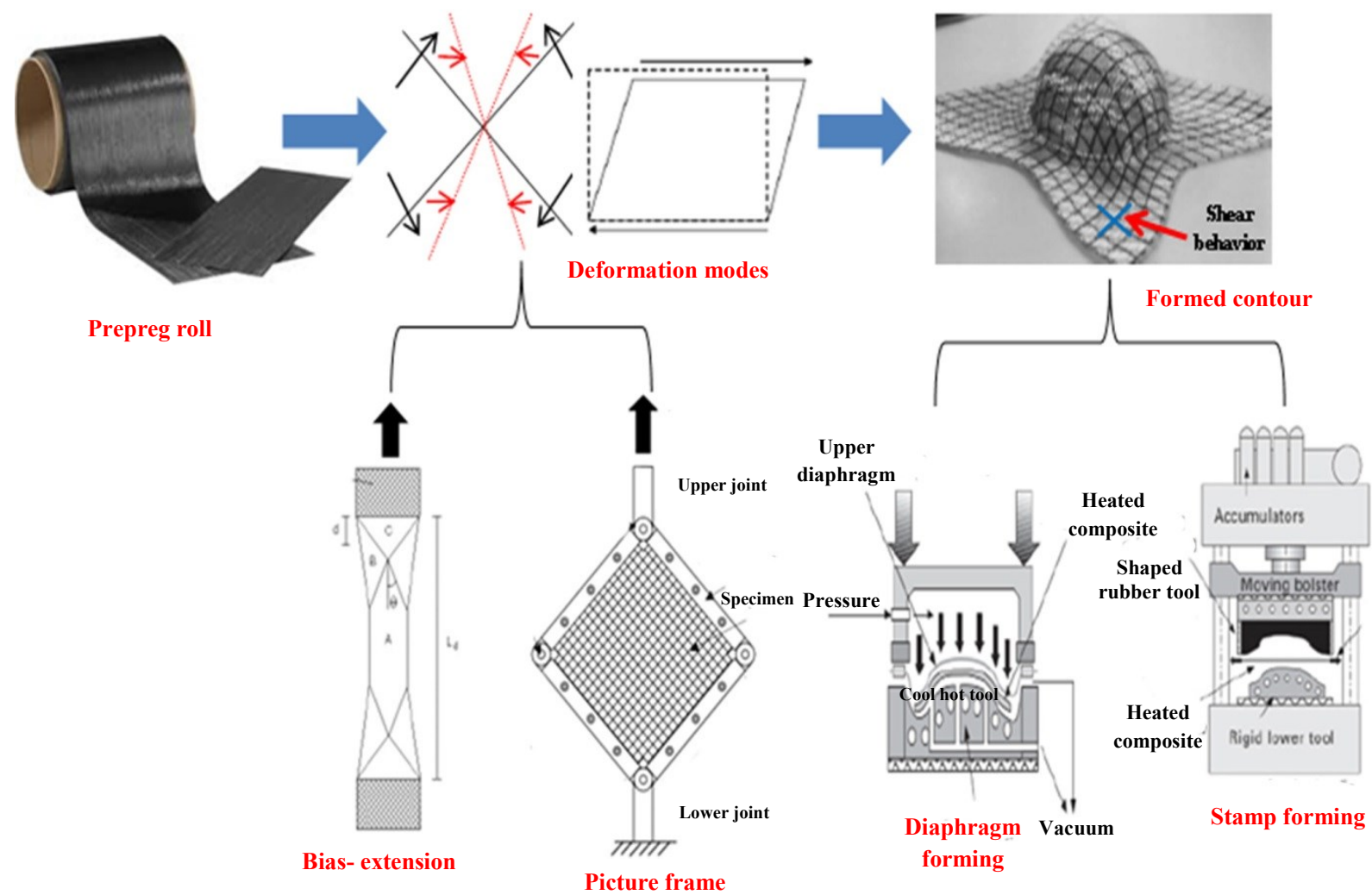

Figure 1.1 Steps involved before forming operation $[1,9,11]$.

This research will focus on the deformation mechanisms which occur during the forming operation. In particular, regarding the intra-ply shear of OOA prepreg, using the picture frame and bias-extension test. The effect of temperature (resin viscosity), displacement rate and layer count (layer interaction) on the in-plane shear deformation is investigated. In addition, the influence of these parameters on the onset of wrinkling has been studied.

\subsection{Thesis Organization}

The dissertation is divided into 7 chapters and a brief description of each chapter has been listed below.

Chapter 1 gives a brief description of the various types of textile architectures commonly used and introduces the principle behind the functioning of double diaphragm and match- die forming processes. 
Chapter 2 reviews the major work done regarding the various deformation mechanisms which occur during the forming operation. In particular, regarding the intra-ply shear deformation and the tests available to measure the intra-ply shear.

Chapter 3 deals with the material selection and fabrication of the picture frame rig. This chapter discuss the material properties of 8-harness (8HS), 5-harness (5HS) and UD Cycom 5320 carbon epoxy OOA prepreg and their fabrication process in detail. The procedure involved in determining the curing temperature of the resin using the DSC analysis is discussed. The rheological analysis performed to determine the time taken for the resin to cure is detailed in this chapter.

Chapter 4 discuss the effect of the temperature and displacement rate on the intra-ply shear of the $8 \mathrm{HS}$, 5HS and UD OOA prepreg using the picture frame test. The onset of wrinkling at these different conditions are observed using the DIC. The microscopic and SEM analysis performed to visualize the tow geometry during the shear deformation is explained in this chapter.

Chapter 5 introduce the bias extension test and its linearity with the picture frame test. Further, the Taguchi and Analysis of Variance (ANOVA) method of optimization is used to recommend the best parameter combination to reduce the onset of wrinkling.

Chapter 6 gives a conclusion to the work presented in this thesis.

Chapter 7 details the recommendations given regarding the implementation of the intra-ply shear results to the actual double diaphragm forming operation. 


\subsection{Types of Textile Architecture}

The most common types of the textile architecture are found to be; $2 \mathrm{D}$ woven, 3D woven, braided and non-crimp fabrics [12] (see Figure 1.2)

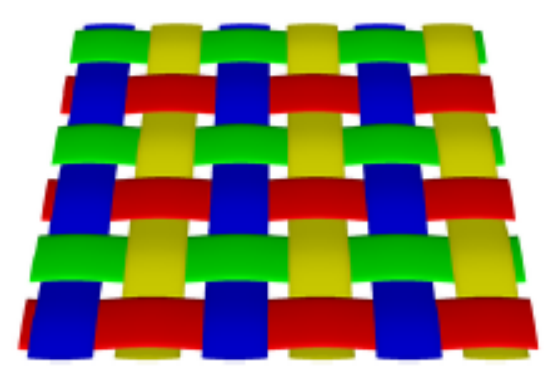

2D Weave

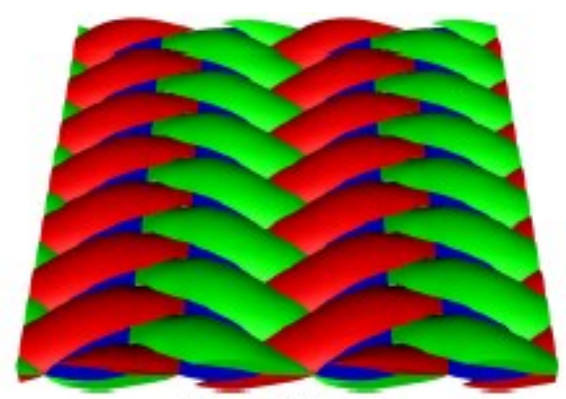

Triaxial braid

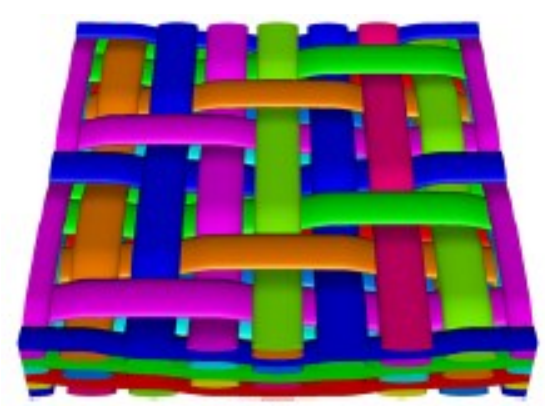

3D Weave

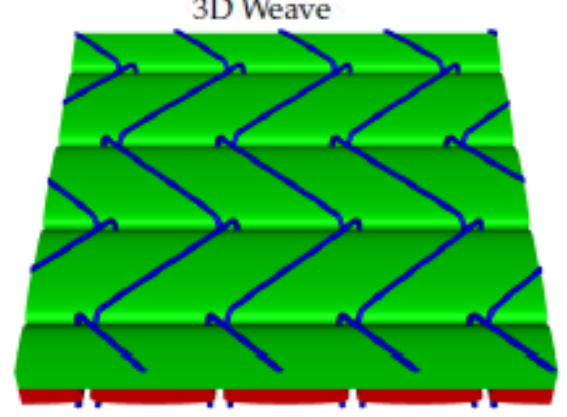

Non-crimp fabric

Figure 1.2 Images of Textile architecture [12]

The woven fabrics are more common in aerospace industries due to their superior properties and are found to be produced by interlacing warp and weft yarns. The fibers along the horizontal direction are called the warp, while the ones along the vertical direction are called the fill or weft. The woven fabrics are classified into various types; plain weave, $2 \times 2$ twill weave and harness weave $(3,4,5 \ldots$ harness $)$. Of the lot, the plain weaves are seen to be the simplest weaves made by interlacing alternate warp yarn over and beneath the weft yarns [13]. However, the plain weaves were witnessed to have low drapability. Whereas, the $2 \times 2$ twill weave pattern is generated by interlacing 2 warp threads beneath and over every two weft threads. Finally, the harness weave is made by interlacing minimum of three warp yarns over three weft yarns, enabling them to exhibit the high drapability [13].

The 3D weaves are used when the properties along the thickness direction are to be enhanced $[13,14]$. The $3 \mathrm{D}$ weaves consist of binder yarns interlaced in between the warp and weft tows. 
The 3D weaves are found to be used for application which require high damage tolerance [15] and fatigue resistance [14]. However, their application in the aerospace industry is low when compared to $2 \mathrm{D}$ fabrics due to their low shear and torsion properties and their difficulty to manufacture quasi-isotropic woven composites [14].

The braided fabrics involves interlacing of three or more threads with each other in a diagonal formation, creating tubular or solid construction [1]. The braided fabrics tend to have optimum properties in all directions and are found to be stronger than other reinforcement patterns $[1,12]$.

Non-crimp fabrics include several layers of uni-directional crimp-free fiber layers combined together by stitching - sewing or knitting - or by application of binders [1,12]. The layers involve $45^{\circ}$ and $90^{\circ}$ orientation of fibers. These are found to be economical for production and faster to process $[1,12]$. But as the layer count increases, the ability of the non-crimp fabrics to conform to complex contours decreases due to the restriction imparted by the stitching $[1,12]$.

\subsection{Forming technology for composites}

The forming of the composites involves sequential operations such as; heating, forming and consolidation (or) cooling of the material [9]. The various technologies of forming include; compression molding, vacuum forming, diaphragm forming, bladder molding, matched die molding and roll forming [9]. Among which, diaphragm forming and matched die molding are found to be the most common forming processes due to their improved quality of the products $[16,17]$. The forming of composites is either performed on dry fabrics by supplying the resin during the forming operation or by performing the forming on the pre-impregnated (prepreg) fabric in which the resin is already in the partially cured state [18].

\subsubsection{Diaphragm forming}

Diaphragm forming is a process which involves forming the pre-impregnated (prepreg) laminate into the desired shape using the diaphragms, similar to the compression molding process. The diaphragm forming is generally classified into two types; single diaphragm forming and double diaphragm forming. In the single diaphragm forming process, the prepreg is placed in between the sheets of release film and placed over the mold [18]. Further, a diaphragm is sealed at the top of the mold and air pressure is applied from the top of the diaphragm and a vacuum is applied from bottom of the diaphragm forcing the prepreg to deform to the mold geometry [1,9]. The 
diaphragms used are flexible enough to form complex contours and are made up of different materials depending upon the temperature to be operated. The polymeric materials such as polyimide (PI) films, silicon rubber sheets are used for high temperature applications due to their ability to resist rupture [9]. In addition, Bersee et al. [19] suggested that thicker and stiffer diaphragm reduces the onset of wrinkling, which however requires further investigation.

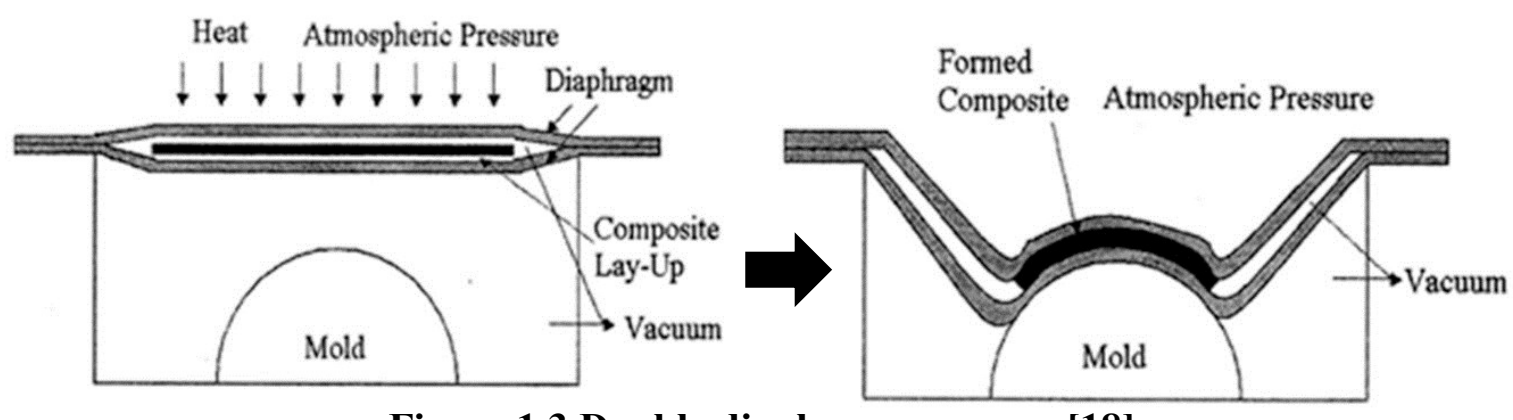

Figure 1.3 Double diaphragm process [18].

On the other hand, double diaphragm forming is somewhat similar to the single diaphragm forming except that the prepreg is placed between two diaphragms instead of one $[1,9,18]$, as shown in Figure 1.3. By this, it was made certain that the spring back that occurs during the single diaphragm is overcome [18]. Double diaphragm forming is seen to be much preferred these days in the aerospace industry due to its reduced cost and high quality of the output product $[18,20]$. However, the major disadvantages which set it apart are its long cycle time and limitation in forming complex contours [18], which require further research.

The double diaphragm forming process was originally developed for forming thermoplastic composites [19]. However, more recently much work has been carried out in the aerospace industry using thermoset composites, due to their preferable low operating temperature. During the forming of thermoset prepreg, the laminate is heated to decrease the resin viscosity and in turn to facilitate the forming operation. It's been reported by previous research [11] that thermoset composite must be operated at $90^{\circ} \mathrm{C}$ or lower to prevent curing during the operation. Whereas, the thermoplastic prepreg needs to be melted before it is formed, which in turn requires high temperature [19]. These discussions suggest that thermoset prepreg are much more preferable than the thermoplastic prepreg for the double diaphragm forming process. However, to date there is relatively less documented research regarding the diaphragm forming of thermoset prepreg, which therefore requires further investigation. 


\subsubsection{Matched die forming}

During the matched die forming, the composite sheet is heated to the required temperature until which the matrix melts and then the press is closed rapidly until the sheet conforms to the shape of the mold $[1,9,21]$. A pair of matched dies are used for the stamping process, as shown in Figure 1.4. In order to avoid the spring back of material and to ensure that the material takes the new shape, the pressure and temperature are to be maintained [21]. The surface finish of the output product formed by match die forming are of high quality enabling them to find a high demand in the automobile industry [22]. Previous studies have also reported that proper consolidation of the material during the forming would help to reduce the onset of buckling [22].

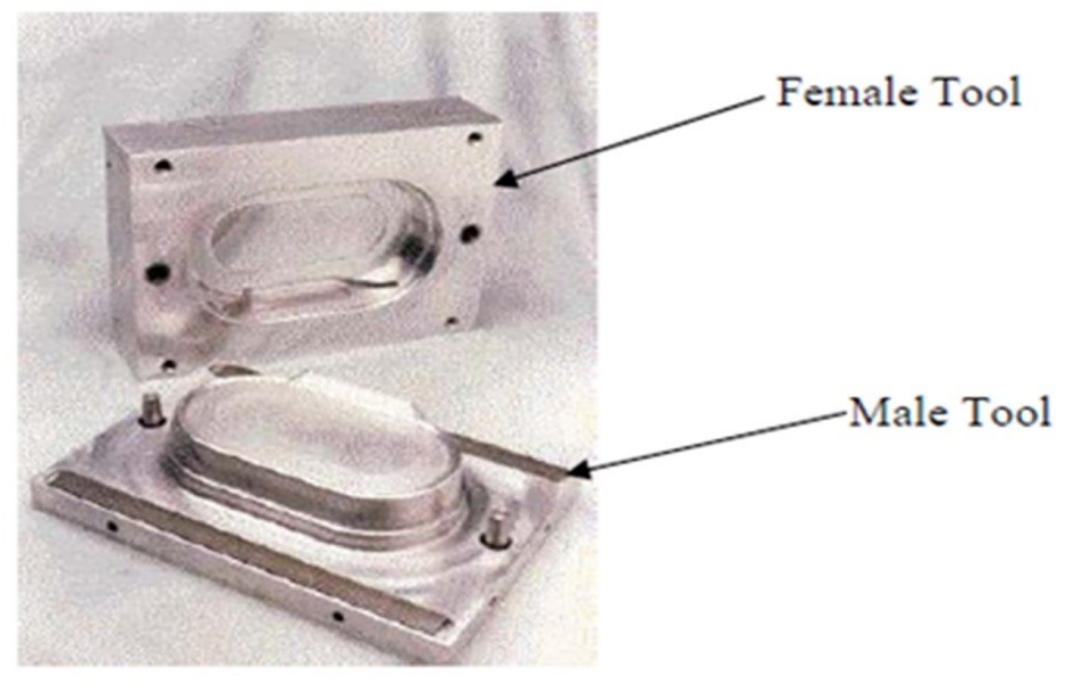

Figure 1.4 Match die mold [21].

In contrast to the double diaphragm forming operation, the matched die forming is a fast process with less cycle time. However, the matched die forming has been reported as an expensive set-up due to its high cost dies [16].

\subsection{Motivation}

The main motivation behind this study is to understand the in-plane shear behavior of the OOA carbon/epoxy prepreg. Forming of the OOA prepreg after proper understanding of the in-plane shear deformation mechanism could help in reducing the process induced defects, such as wrinkling. By this, the goal of forming a complex shape without any wrinkles could be achieved. 
The integration of the diaphragm forming and OOA technology can not only reduce the cost, but also can produce a high quality part with less void content. To facilitate this, the effect of temperature and strain rate on the in-plane shear behavior of OOA prepreg were studied using the picture frame and bias extension test. Apart from this, the recent advancements in the OOA technology has also fuelled the author.

The other motivation lies behind the lack of knowledge about the optimum operating conditions which could facilitate a forming operation without any defects. To study this, shear deformation was performed at varying parameter combinations (operating temperature, displacement rate and layer count) to determine the combination which could postpone wrinkling.

\subsection{Thesis objective and challenges}

The objective of this thesis is to characterize the intra-ply shear properties of the OOA carbon/epoxy thermoset prepreg. Many such experimental and analytical works have been carried out by researchers to characterize the in-plane shear behaviour of the woven fabrics using the picture frame test and the bias-extension test. The prime objective of this study is to characterize the drapability of low cost OOA thermoset prepreg before modelling and performing the actual forming operation.

The main objective of determining the ideal operating conditions to perform the forming operation by postponing the onset of wrinkling has been addressed in this thesis. By this, the contribution of these parameter conditions at the onset of wrinkling is been optimized.

In this present study, the three important challenges associated with forming a wrinkle free composite part that were identified by the research team to be resolved prior to actual production phase are as follows,

- To find the processing window for temperature while forming the Cycom 5320 OOA prepreg. The ideal operating temperature of the prepreg depends on the curing temperature of the resin which needs to be identified by performing DSC analysis. In addition, the time required for the forming operation before any curing (gelation time) is to be investigated by rheological analysis. 
- To characterize the effect of various parameters; operating temperature (resin viscosity), displacement rate and layer count (layer interactions) on the in-plane shear behavior of the OOA prepreg by performing the picture frame and bias- extension test. The effect of these parameters on the onset of wrinkling on the fabrics is studied. Further, the tow geometry of the prepreg during the shear deformation were to be investigated.

- To develop an optimization technique to determine the optimum conditions which facilitate wrinkle free forming. Further, the significant parameter which influence wrinkling the most is studied and analyzed. 


\section{Chapter 2: Literature Review}

A literature review was performed to introduce the various deformation modes that tend to occur during the forming of a composite. In particular, regarding the intra-ply shear that tends to occur when the material is subjected to in plane shear. The issues of the review include intra-ply test methods, material characterization during the picture frame and bias extension test and onset of wrinkling during the shear deformation.

\subsection{Deformation mechanisms of textile composites}

During the forming of the textile composite materials, various deformation mechanisms tend to occur, such as intra-ply shear, intra-ply extension, inter-layer rotation, inter-ply/inter tool slippage, ply bending and so on $[9,23]$, as depicted in Figure 2.1. However, intra-ply shear, interply slip and ply bending are considered as the selected deformations which play an important role in forming of double curvature [9].

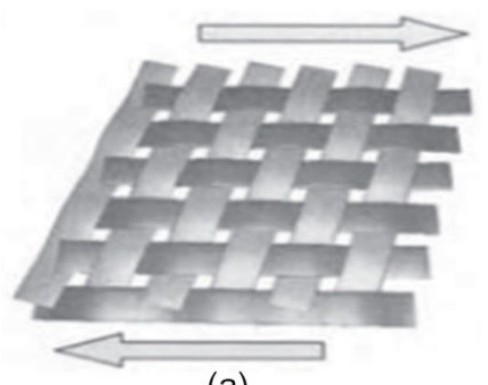

(a)

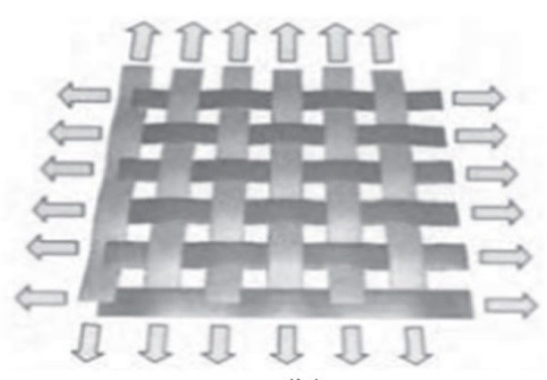

(b)

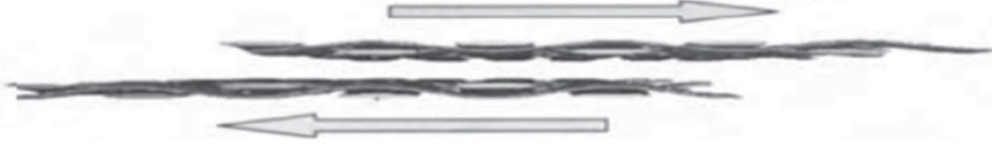

(c)

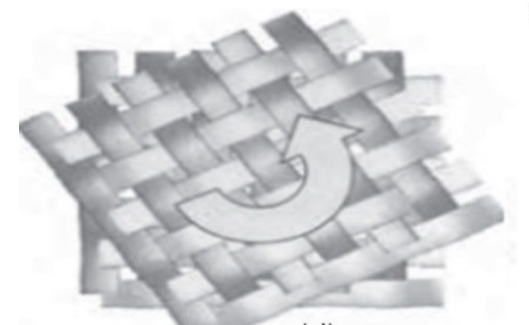

(d)

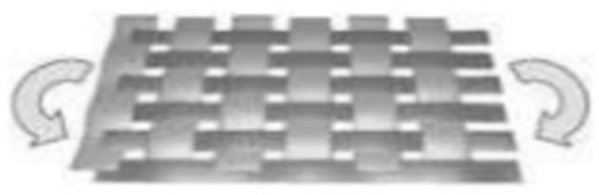

(e)

Figure 2.1 Deformation modes; (a) intra-ply shear, (b) intra-ply extension, (c) inter ply slippage, (d) inter-layer rotation and (e) ply bending $[1,9,26]$. 
Among these, intra-ply shear is found to be the predominant deformation when forming textile composites [1,9]. The intra-ply shear involves rotation between the parallel tows within the fabric layers at its crossover points, followed by compaction [1,9], as represented in Figure 2.1 (a). There is no standard ASTM test to measure the intra-ply shear behavior of the composite $[24,25]$. However, the two most common tests (picture frame and bias extension test) used to characterize the in-plane shear behavior of the fabric is discussed in detail in the forthcoming chapters 4 and 5. An overview of the works performed regarding to the intra-ply shear is explained in detail in section 2.2 .

The inter-ply slip, considered as an important deformation, tends to occur during the forming of the single curvature and double curvature contours [26]. The plies tend to slip over each other, resulting in inter-ply slippage. In turn, if the slippage is restricted, as in Figure 2.2, the innermost ply might tend to buckle out of the plane, as a result of high compressive strain [26]. The inter/ply friction is also termed as ply-ply friction and it also plays an important role in transferring of loads between the plies. In addition, researches by Vancalooster [26] and Konstantine et al. [27] revealed that friction between the tools and fabric plays an important role in the final product. If the friction is too much it might result in the tearing off of the material, whereas if it is too low it might lead to wrinkling of the material [26]. Similar to intra-ply shear, there is no standard ASTM test to measure the ply-ply friction. However, a similar setup, as in Figure 2.3 (a) has been used for years by researchers [27-30] (with some modifications) to measure the inter-ply friction. The set-up works by placing a layered prepregs in between two plates (which are pressurized using compressed air) and pulling them in the opposite directions to measure the frictional resistance of the prepreg.

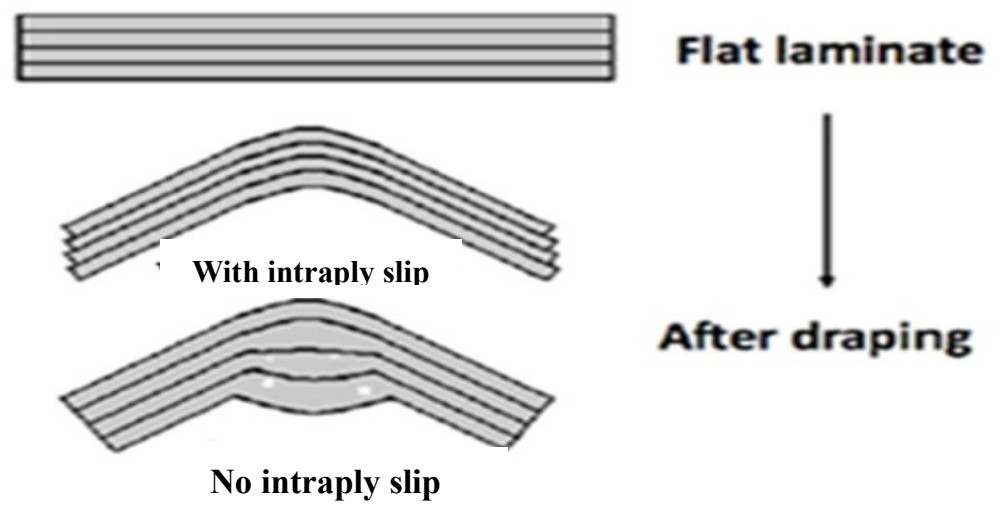

Figure 2.2 Inter-ply slip during double curvature forming [26]. 
Along with intra-ply shear, intra-ply bending (bending of individual layers) is also considered as one of the major deformation modes during the forming of complex contours with double curvatures [9]. It was observed by E.de Bilbao et al. [31] that the bending behavior of the composite plays a significant role in the out of plane deformation (wrinkling) of the laminates. The bending stiffness of the fabric was found to be dependent upon the yarn density and fabric linear density $[32,33]$. Unlike intra-ply shear and inter-ply slip, a standard cantilever bending test (ASTM D1388-08), see Figure 2.3 (b), is in practice to measure the bending stiffness of the fabric $[31,34]$. But not much research has been done to date to characterize the bending property during the forming.

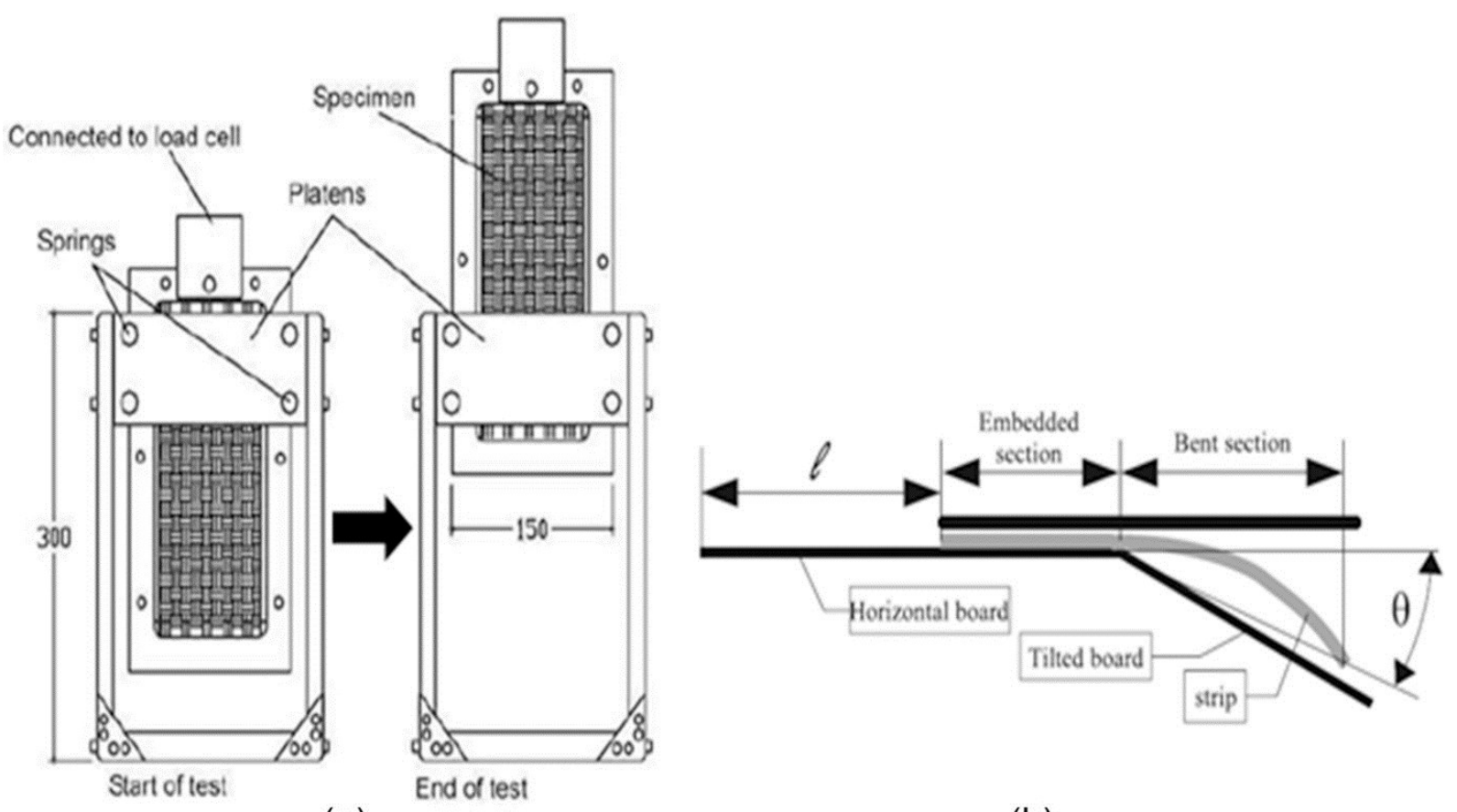

(a)

(b)

Figure 2.3 Test set-up; (a) inter-ply friction apparatus [9] and (b) ASTM D1388-08 bending test set-up [31].

This dissertation does not aim to discuss much regarding the inter-ply slip and ply bending that takes place during the deformation of the prepreg. The prime objective of this thesis is to investigate the intra-ply shear deformation during the forming of the composites. 


\subsection{Intra-ply shear}

Intra-ply shear is inferred to be the predominant deformation mechanism which tends to occur when the material is subjected to in-plane shear [9]. The two different mechanisms of intra-ply deformations: the in-plane deformation and through thickness deformation [35] are shown in Figure 2.4.

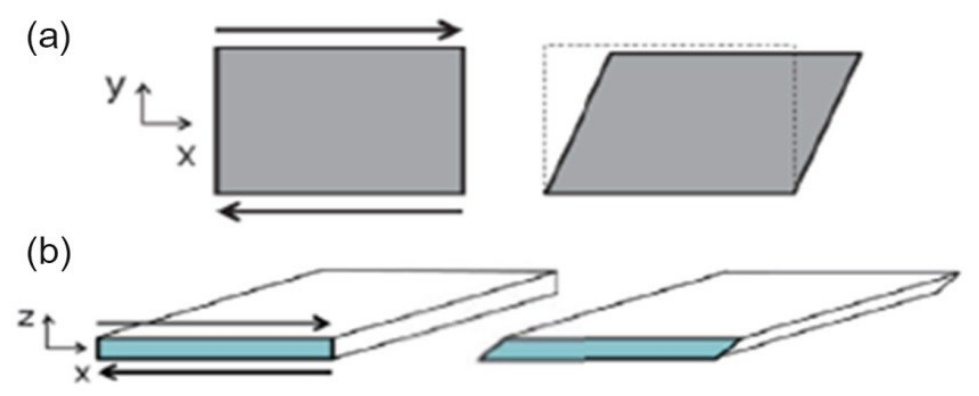

Figure 2.4 Types of intra-ply shear; (a) in-plane shear and (b) through thickness shear [35].

The intra-ply shear of commingled fabrics was investigated using picture frame and biasextension tests by Lebrun et al. [24]. The woven fabrics were assumed to deform based on the pin-jointed net (PJN) approximation which was originally proposed by Mack and Taylor [36]. The PJN theory is based on the assumption that during deformation, yarns are inextensible with no slippage possible at crossovers, but allows rotation of fibers [25,37]. In detail, the model assumes that the adjacent warp and weft yarns are connected to each other at the crossover points (pin-joints) by a fixed kinematic linkage. When deformed, they tend to remain straight, but free to rotate around the pin joints, as shown in Figure 2.5. The angle between the warp and weft yarns indicate the amount of in-plane shear. The woven fabrics tend to wrinkle when the adjacent yarns come in contact with each other and lock. The angle at which they tend to come in contact is stated as the locking angle [2,3]. Prodromou and Chen [38] arrived to the conclusion that when inter yarn space is more it means that tows can rotate larger angles before they come in contact with each other. Not much research has been performed to characterize the shear mechanisms of the UD fabrics in recent times. Lately (2000), Kevin Potter [37] worked on the UD prepreg and reported that PJN assumption was valid for UD prepreg during its initial stages of deformation; while at the later stages the PJN assumption was not reported to be in good agreement with results due to the occurrence of the slippage at the later stages. In addition, he also reported that kinematic linkage between the yarns might be ideal for the manual lay-up; but, while forming 
they might result in locking at earlier stages. Hence, to reduce the linkage he suggested to increase the operating temperature [25]. The deformation mechanism in the UD prepreg is parallel along the axis rather than the adjacent yarns crossing over each other, as in woven prepreg [9]. Zhang et al. [39] studied the intra-ply shear of fabrics with different areal density and reported that fabrics with lower density tend to have better deformability and that shear performance decreases with the increase in density.

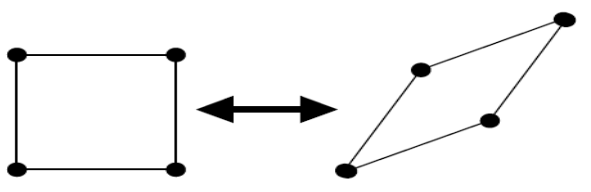

Figure 2.5 The pin-jointed net (PJN) model [37].

\subsection{Intra-ply test method}

As discussed before, there is no standardized ASTM technique available to measure the intra-ply shear $[24,25]$. The picture frame test and the bias-extension test, which are the common test methods to measure the intra-ply shear are explained in detail in the upcoming section.

\subsubsection{Picture frame test}

A picture frame test set-up, as shown in Figure 2.6, has been used by researchers to characterize the in-plane shear behavior of the woven fabrics [24, 39-41]. Numerous picture frame rig setup have been designed in the past to measure the intra-ply shear. Recently, Yifan Zhang [39] designed a new picture frame test setup in which bearings were used to connect the arms of the frame. He made sure by using the bearings, the arms of the rigs are structured to be free to rotate around the hinges which resulted in pure shear deformation. In this thesis, in order to impart pure shear, shoulder bolts were used to connect the arms which are discussed in detail in section 3.5.2. In turn, P. Harrison et al. [41] suggested that the axial load required to deform the sample recorded by the MTS system is directly proportional to the number of adjacent yarns undergoing deformation. On investigating the effect of the boundary condition on the in-plane shear, Wang [21] reported that serious wrinkling was visible at an early stages of the test when the samples were pinned onto the picture frame. In turn, he suggested that it is rather preferable to clamp the samples onto the rig to reduce the effect of wrinkling than testing them under the pinned boundary condition. Hence, in this case cross shaped samples are to be clamped onto the frame using C-clamps, such that the samples are parallel to the side of the frame. The corners of the 
samples were cut in order to restrict the corner effects and in turn to impart pure shear throughout the sample. A benchmark effort was undergone by a group of researchers by performing the picture frame test with different test ups and with samples of different sizes. At the end of the work they concluded that; the shear force increase as the size of the sample increases; however, the results can be compared when the shear force is normalized with respect to shear area [42]. Lastly, proper care must be taken to ensure that the fibers are properly clamped without any misalignment. If clamped tightly, misaligned tows might lead to either a severe bend at the point of clamping or slip out of clamping [41,43]. The effect of misalignment was studied by Milani et al. [44] by coming up with an arbitrary misalignment on the sample and it was seen that the obtained results were $80 \%$ lower than the actual test results. This variation in the results was reported due to the involvement of both shear and tension during the test.
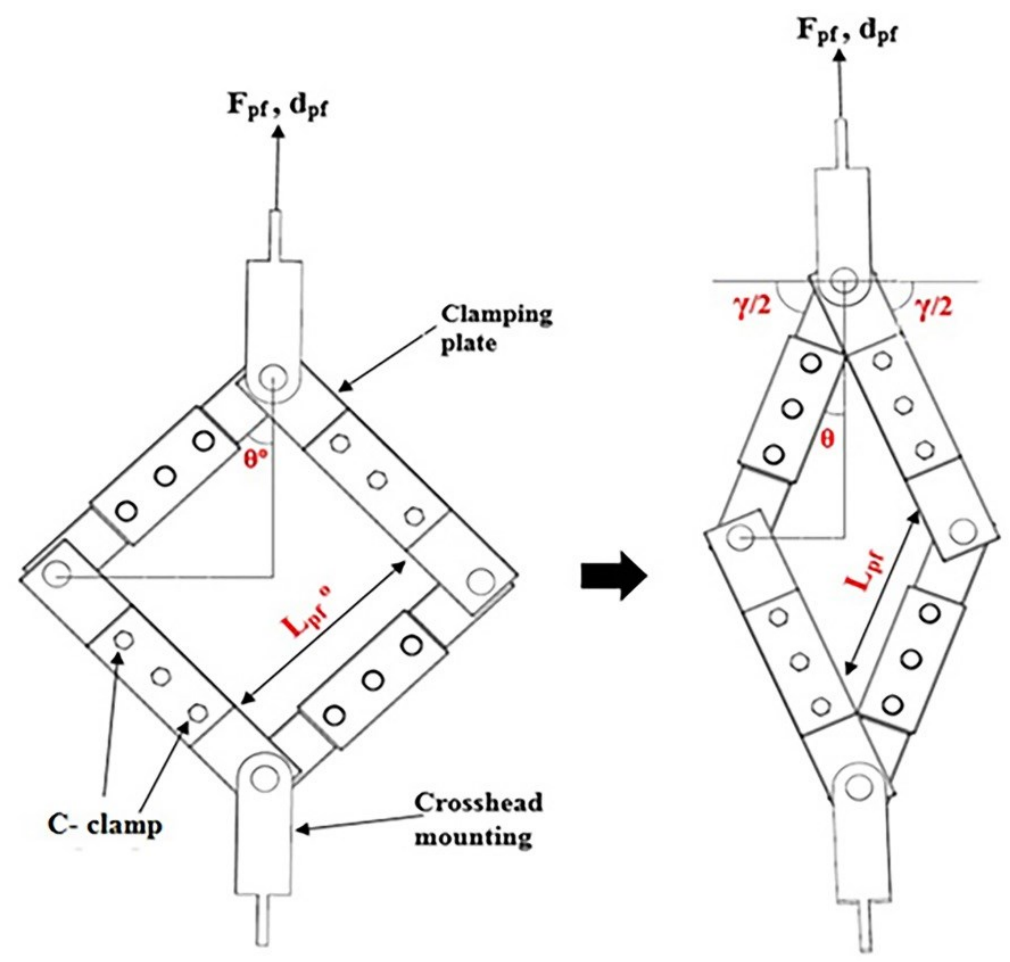

Figure 2.6 Test rig for picture frame setup.

The amount of shear possible between the warp and weft yarns before interlocking is determined by the plot of shear angle vs shear load. The force required to shear the sample $\left(\mathrm{F}_{\mathrm{s}}\right)$ can be calculated from the cross-head force $\left(\mathrm{F}_{\mathrm{pf}}\right)$ by the formulae, ([9], p. 5). 


$$
\mathrm{F}_{\mathrm{S}}=\frac{\mathrm{F}_{\mathrm{pf}}}{2 \cos \theta}
$$

Where $\theta$ is the frame angle and $F_{p f}$ is the measured axial load recorded. The shear angle can be deduced from the frame angle by the relation, ([9], p. 5)

$$
\gamma=90-2 \theta
$$

Where $\gamma$ is the shear angle, the shear angle can also be resolved from cross head displacement by Equation 1.3, ([9], p. 5)

$$
\gamma=\frac{\pi}{2}-2 \cos ^{-1}\left[\frac{1}{\sqrt{2}}+\frac{\mathrm{d}_{\mathrm{pf}}}{2 \mathrm{~L}_{\mathrm{pf}}}\right]
$$

Where, $d_{p f}$ is the cross head displacement, $L_{p f}$ is the length measured between the center of the hinges as indicated in Figure 2.6.

\subsubsection{Bias - extension test}

One of the earliest methods to characterize the trellising behavior is found to be the biasextension test [43]. When compared to the picture frame test, the bias extension is found to be a simple test since it doesn't require any special rig set-up, but analyzing the result is found to be complex due to the interaction of non-shear components [45]. In a bias extension test, the material is extended along the bias direction initially at $\pm 45^{\circ}$ to the direction of applied tensile force $[9,24,41]$.

The sample for the bias- extension test (see Figure 2.7 (a)) is observed to have three zones of deformation: zone A, Zone B and Zone C. When deformed, it has been reported that zone A experiences pure shear; since it has it's both the ends free without being clamped. Whereas, the zone $\mathrm{B}$ has been noted to experience half the shear of the zone A (since it has one of its end clamped) and in turn the zone $C$ experience no shear (both the ends clamped) [45]. It's been observed by previous studies that the aspect ratio $\left(K=1_{0} / \mathrm{w}_{0}\right)$ must be greater than or equal to two for zone A to experience pure shear [39]. In contrast to the picture frame test, the boundary condition doesn't have much effect in bias extension test even if clamped tightly [3]. 


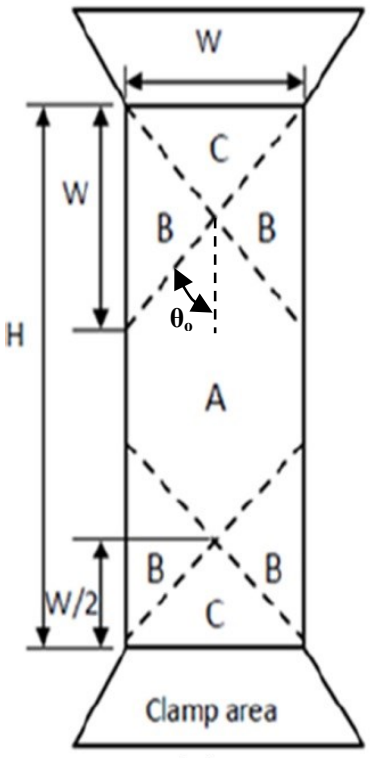

(a)

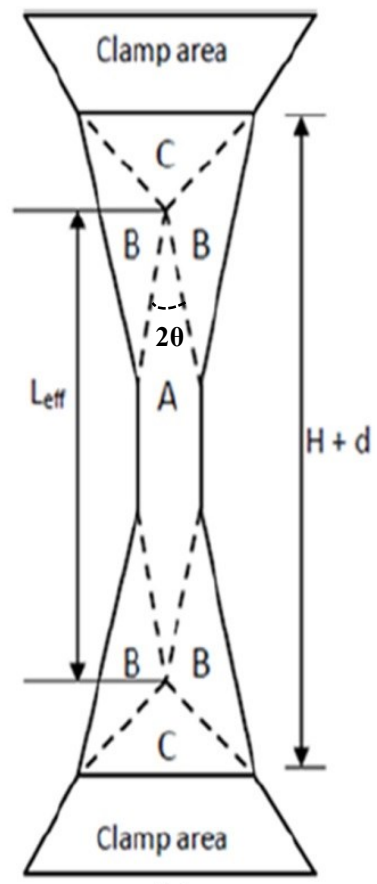

(b)

Figure 2.7 Bias- extension; (a) before deformation and (b) after deformation [45].

From Figure 2.7, it is seen that the initial angle $\theta_{0}$ is $45^{\circ}$ and the shear angle ' $\gamma$ ' can be determined by, [45]

$$
\gamma=90-2 \cos ^{-1}\left(\mathrm{~L}_{0}+\frac{\mathrm{d}}{\sqrt{2 \mathrm{~L}_{0}}}\right)
$$

Where ' $\mathrm{d}$ ' is the cross head displacement and the length $\mathrm{L}_{0}=\mathrm{H}-\mathrm{W}$. The term $\mathrm{H}$ and $\mathrm{W}$ represents the initial height and width of the specimen.

\subsection{Material characterization}

On performing the in-plane shear test using the picture frame and bias-extension test, the shear compliance graph is seen to be divided into 3 stages (see Figure 2.8(b)). In all the three stages, the shear force is seen to increase with the shear angle. At the initial stages, the average shear inside the yarn is found to be much less; while Willems et al. [46] suggested that at this stage only friction between the yarns serves as the major resistance. Further, at stage 2, the yarns tend to come in close contact with each other, resulting in the locking of the yarns. At this stage, lateral compression serves as the major resistance and a sharp increase in shear resistance is 
visualized [4]. Finally, any deformation beyond the locking zone would result in serious wrinkling which was evident on stage 3 . It can be seen that the locking angle separates the low stiffness and high stiffness region [47]. The wrinkling is found to occur when the compressive forces induced during the forming of the double curvatures cause gross buckling throughout the thickness of the composite causing out of plane buckling [48]. In practice, it was observed by Boisse et al. [49] that forming of double curvatures require large shear angles which in turn require large shear stiffness which eventually leads to wrinkling. This can be avoided by using blank holders which can create tension and reduce wrinkles at large shear angles [49]. Zhu et al. [2] investigated the intra-ply shear in the $2 \mathrm{D}$ fabric and concluded that reduction of yarn width is the key to wrinkling. On a whole, while forming it is suggested that; higher the locking angle, postponed the onset of wrinkling, which is favorable in terms of draping complex contours [39].

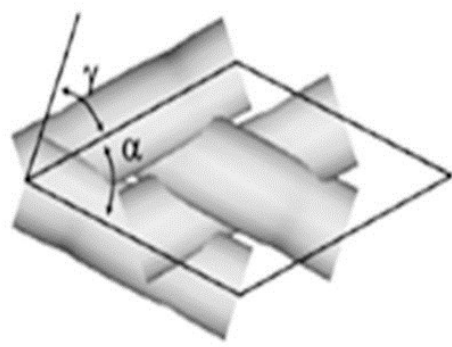

(a)

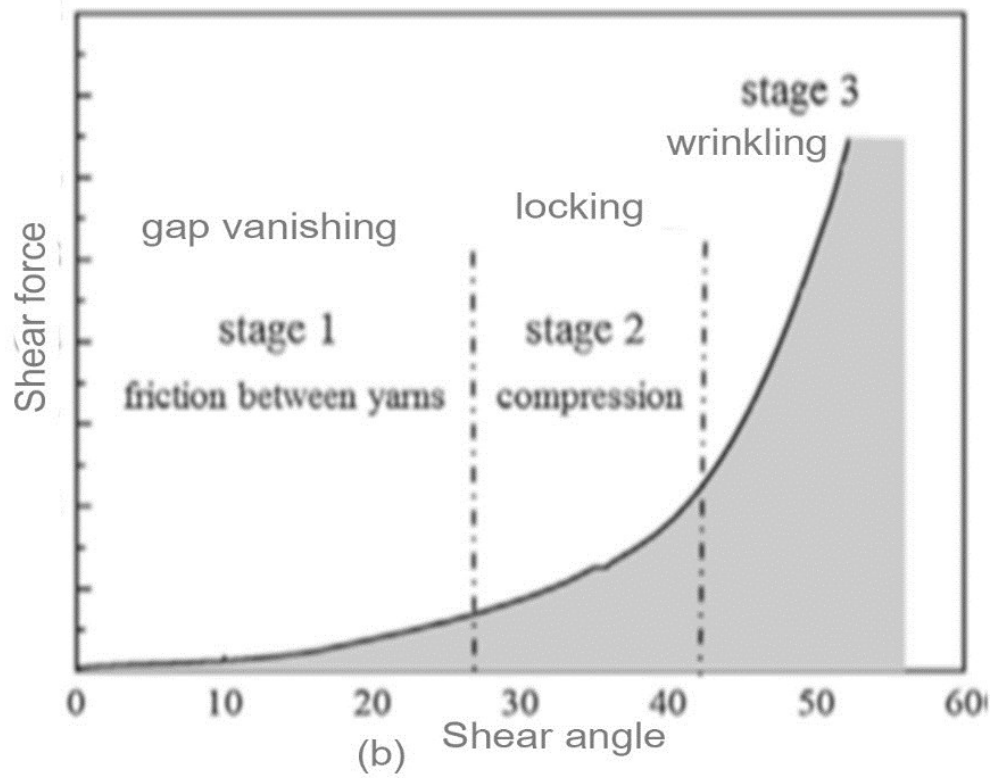

Figure 2.8 (a) shear inside the yarns [26] and (b) shear compliance graph [39].

The digital image analysis (DIC) has been used in the past to visualize the onset on wrinkling. However, when the fabrics are tested inside the environment chamber (capable of generating elevated temperatures) it was observed by Larberg et al. [11] that the DIC was not able to perform the $3 \mathrm{D}$ analysis due to the hindrance of the window in the environmental chamber. To overcome this, a system of non-contact infrared heater, capable of generating uniform temperature has been suggested in section 4.2. By this, the DIC was able to perform $3 \mathrm{D}$ analysis without any hindrance. 
From the literature, it is evident that a lot of research has been carried out to determine the inplane shear behavior of woven fabric; but however, not much work has been reported to date to characterize the intra-ply shear mechanism of the OOA prepreg, which serves as the prime objective of this dissertation. 


\section{CHAPTER 3: MATERIALS AND RIG FABRICATION}

\subsection{Introduction}

This chapter describes the selected OOA material used in this dissertation in detail and the fabrication of the picture frame used to perform the shear test. In the first part of this chapter, the fabrication technique employed for preparing OOA sample is discussed. Later, the material properties of the prepreg have been characterized by various testing methods. Finally, the various design requirements accomplished during the rig fabrication have been explained in detail.

\subsection{Material Selection}

The material chosen for this project was Cytec engineered materials, Cycom-5320-1. It is an OOA based prepreg used for aerospace application [50]. In particular, three different styled composites, two textile woven fabrics (5-harness and 8-harness carbon/epoxy satin prepreg) and a uni-directional (UD) composite made up of the same material were used for analysis. The primary ground for selecting three different styled composites is to characterize the difference in shear behavior between them. Picking out the samples made up of same resin system and same manufacturer makes the results comparable and much more reliable.

Table 3.1 Material properties of the composites used in the thesis [51].

\begin{tabular}{cccc}
\hline $\begin{array}{c}\text { Dissertation ID } \\
\text { Manufacturer }\end{array}$ & $\begin{array}{c}\text { 5HS OOA } \\
\text { Cyctec materials }\end{array}$ & $\begin{array}{c}\text { 8HS OOA } \\
\text { Cyctec materials }\end{array}$ & $\begin{array}{c}\text { UD OOA } \\
\text { Cyctec materials }\end{array}$ \\
\hline Fiber & T650-5HS carbon & T650-8HS carbon & T650-UD carbon \\
Resin & Cycom 5320 & Cycom 5320 & Cycom 5320 \\
Tow count (fiber/tow) & 6000 & 3000 & Nil \\
Yarn width (mm) & 2.03 & 0.99 & Nil \\
Thickness (mm) & 0.60 & 0.55 & 0.32 \\
Areal density (g/m $\left.\mathbf{m}^{\mathbf{2}}\right)$ & 1178.62 & 1164.36 & 882.34 \\
Resin content $(\mathbf{\%})$ & 36 & 36 & 36 \\
\hline
\end{tabular}


Table 3.1 summarizes the material properties of the composite-reinforcements. It is noted that the areal density and thickness of the 5HS samples is higher than the 8HS and UD samples. Figure 3.1 depicts the images of the three different styled prepreg materials under investigation.

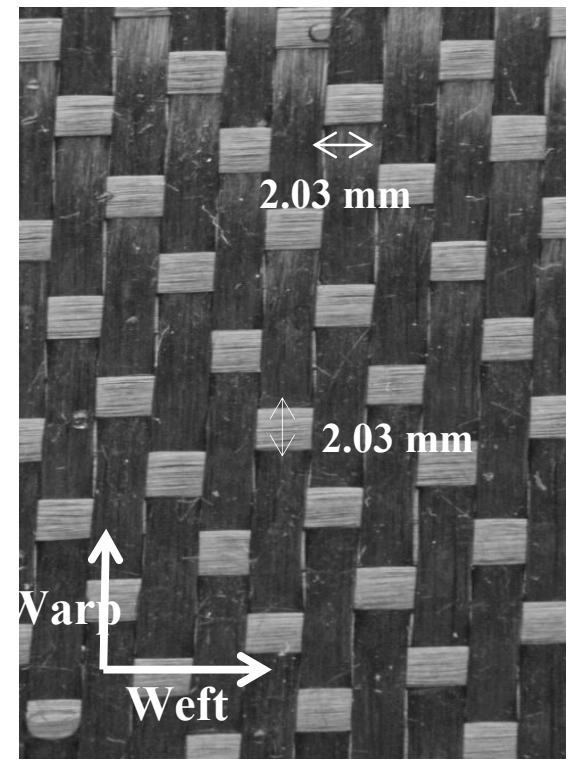

(a)

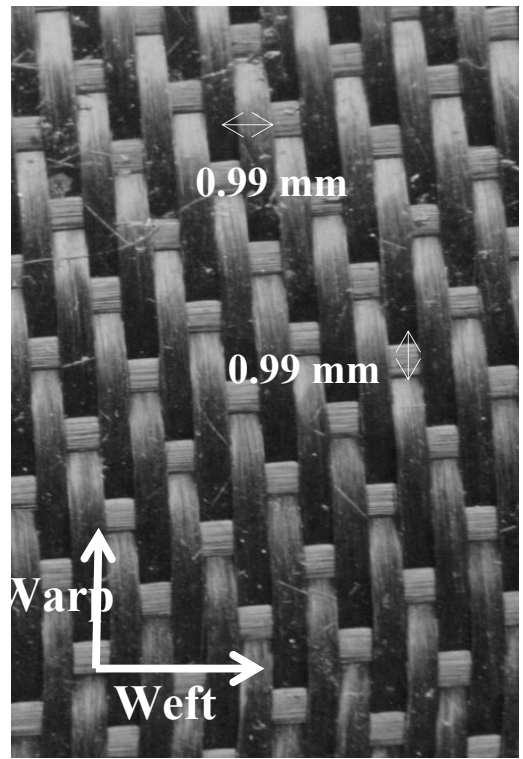

(b)

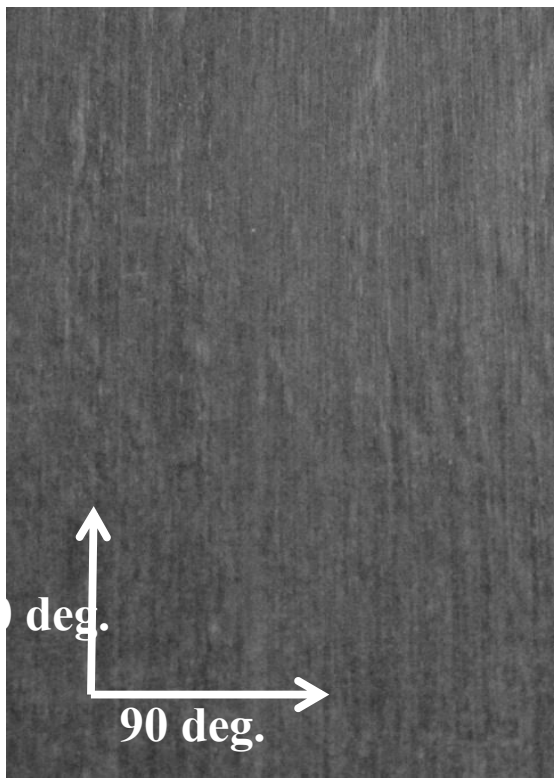

(c)

Figure 3.1 Pictograph of various composites (a) 5-harness woven, (b) 8-harness woven, (c) uni-directional composite. 


\subsection{Fabrication of the OOA Sample}

This section discuss regarding the various steps involved in the fabrication of the OOA prepreg. The samples were prepared by hand lay-up technique and the steps involved are as follows,

Step 1: The prepreg was first cut into a required dimension, in our case into $310 \times 310 \mathrm{~mm}^{2}$ cross section of the available prepreg roll of 42 meters. On account of investigating the shear behavior of cross ply laminate $[0,90]$ in this dissertation, two layers of prepreg were cut of the same dimension. Later, the samples were left at room temperature for 2 hours to improve its tackiness.

Step 2: The mold surface on which the stacking is to be done was first cleansed with acetone in order to improve the surface finish. Then a layer of release agent was applied to the mold and left to dry for 10 minutes to ease the demoulding process. Later, the samples were stacked over the mold by placing them one over the other using the rollers to increase the adherence between the layers.

Step 3: After the stacking of all the layers of the prepreg the mold was covered by a vacuum bag and sealed at the ends by sealant tapes. The reinforcements were then vacuumed at a pressure of $0.1 \mathrm{MPa}$ for 30 minutes. This debulking process helps in oozing out the entrapped air and moisture [13].

Figure 3.2 shows the bagging materials involved in the vacuum bag preparation. The bleeder shown in the setup has been only an optional since the material employed is in preconsolidated (prepreg) form. Figure 3.3 shows the final 8HS OOA sample obtained after debulking.

Step 4: Finally the debulked samples were cut cross shaped as shown in Figure 3.4 enabling them to clamp onto the picture frame rig set up. 


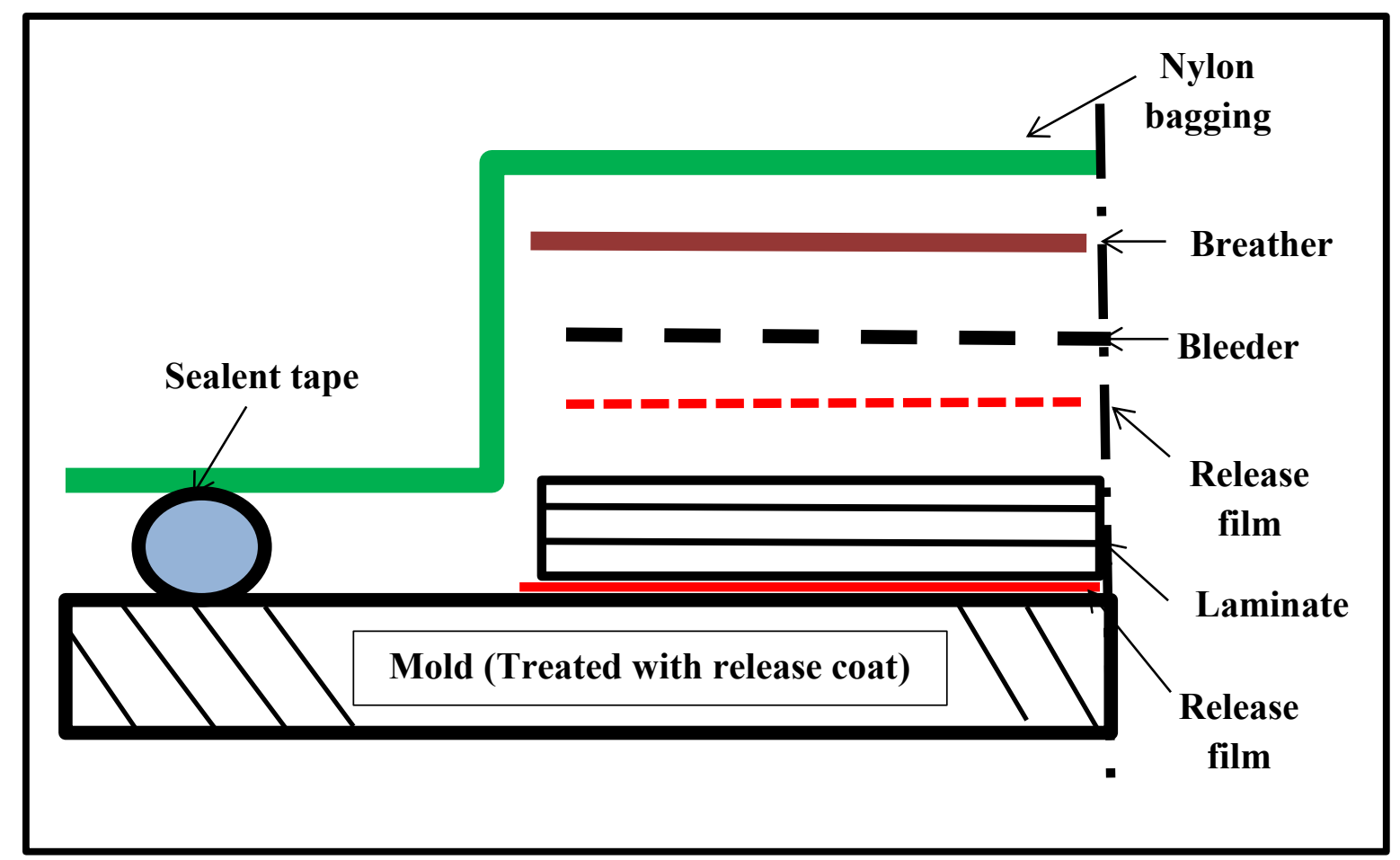

Figure 3.2 Vacuum bagging scheme [51].

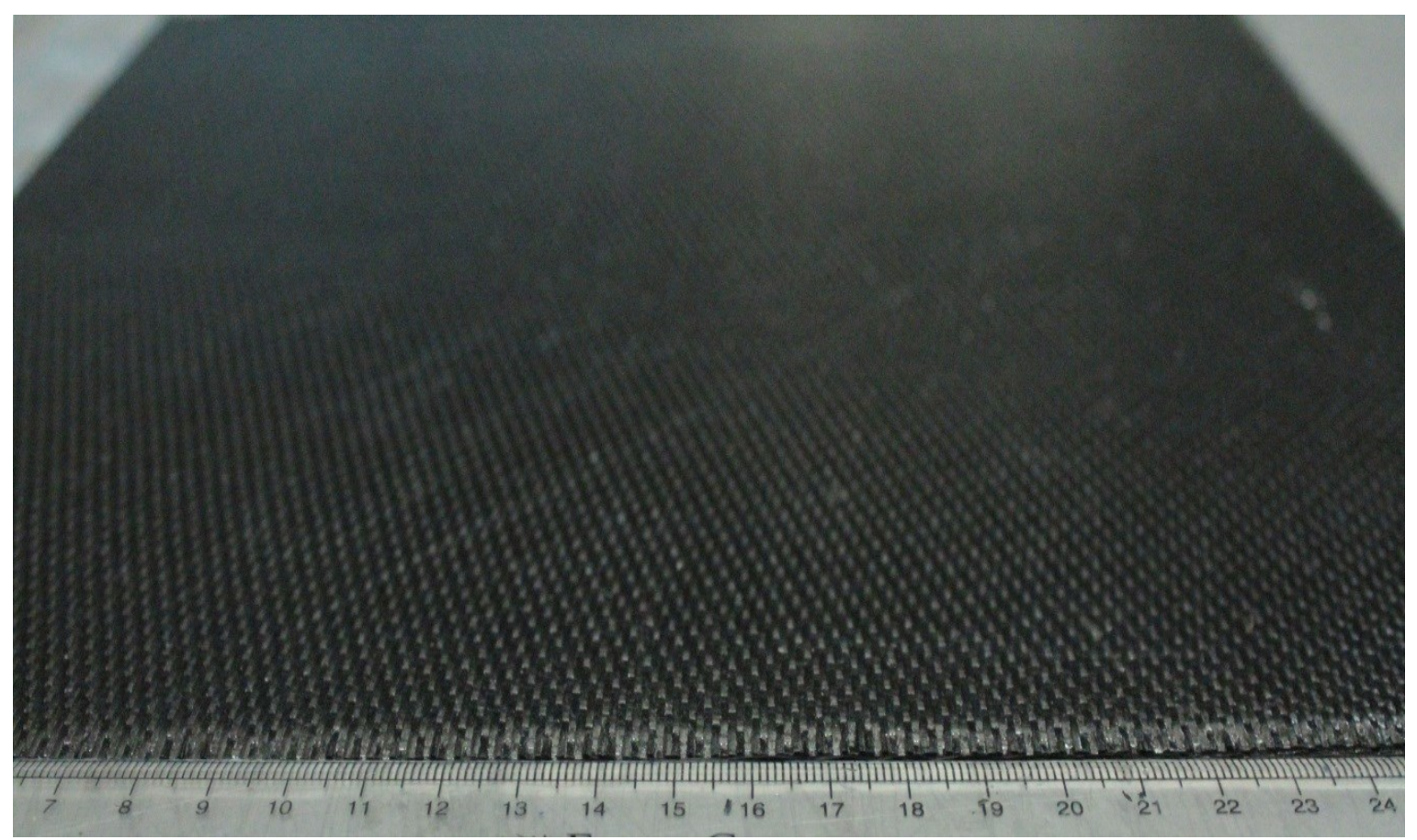

Figure 3.3 Initial sample made using Cycom-5320 8HS by hand lay-up process. 


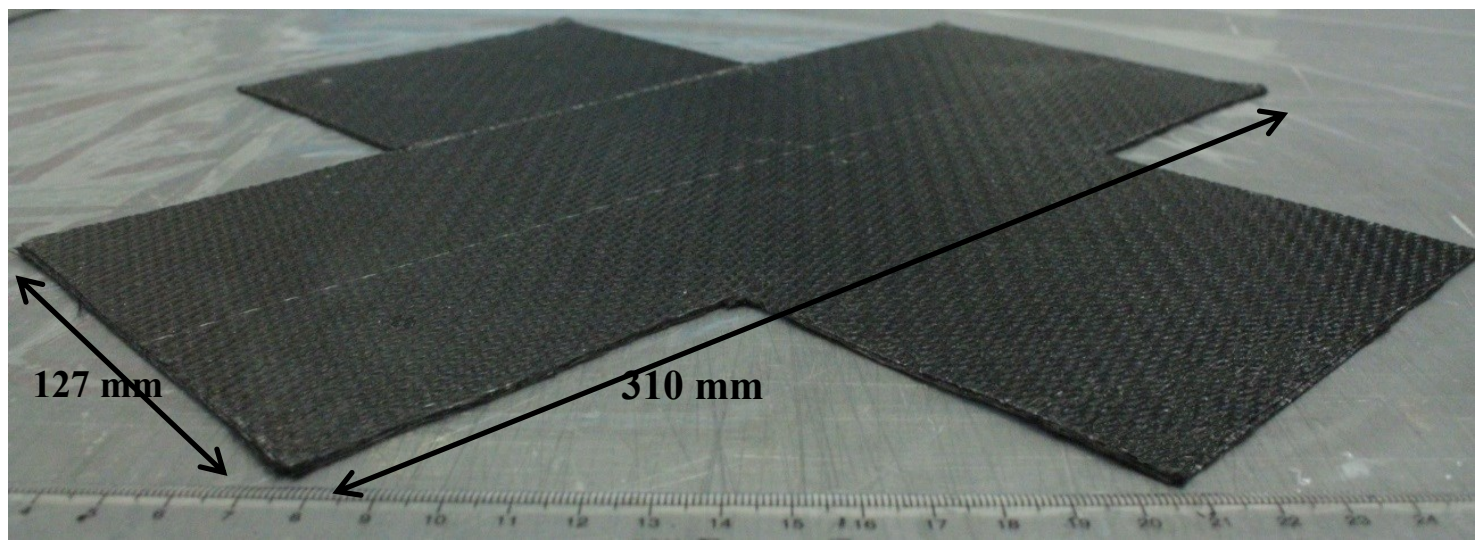

(a)

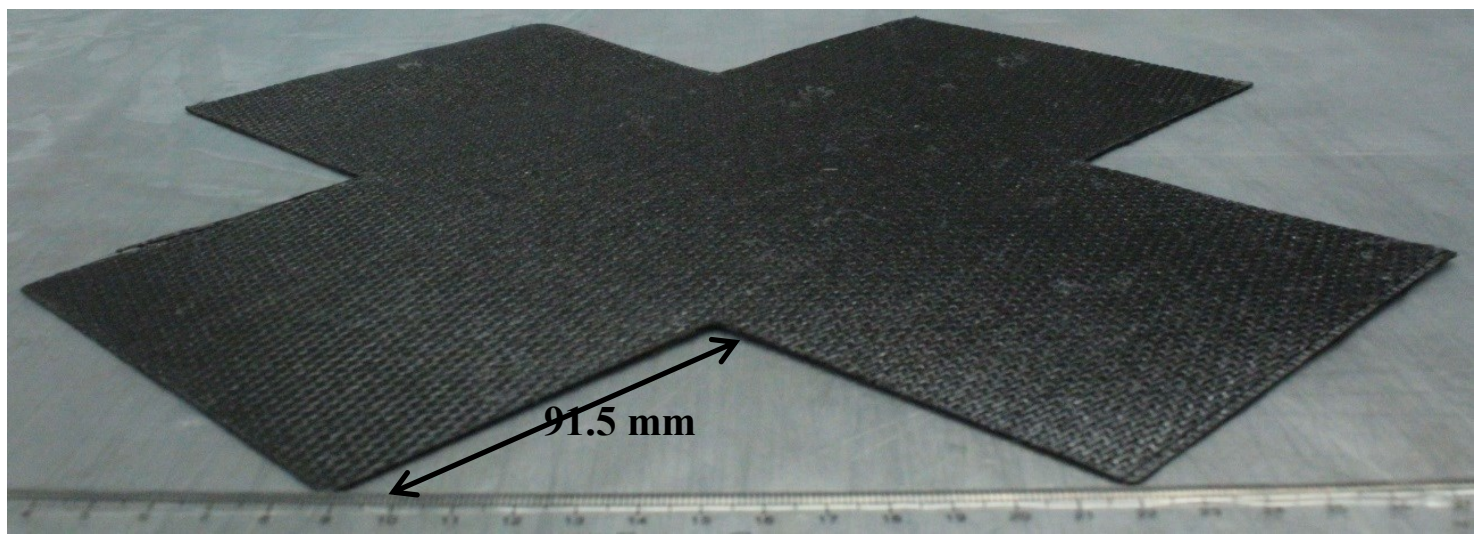

(b)

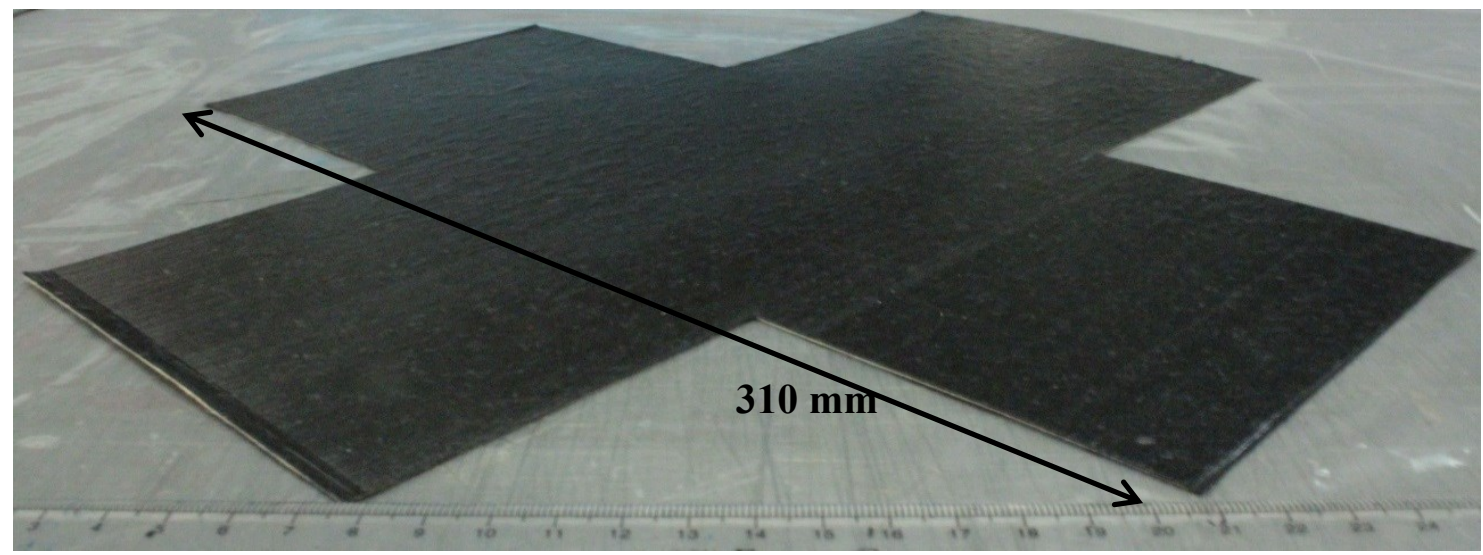

(c)

Figure 3.4 Final trimmed sample by hand lay-up process (a) 5-harness (5HS) sample, (b) 8harness (8HS) sample, (c) uni-directional (UD) sample. 


\subsection{Material Characterization Tests}

\subsubsection{Differential Scanning Calorimeter (DSC) Analysis}

The differential scanning calorimetry (DSC) is a thermal analysis technique which measures the heat flow and temperature during the thermal transition of the material [7]. The sample whose thermal analysis is to be investigated is weighed and placed inside a hermetic pan and sealed with a lid. In addition, an empty pan without any sample is sealed and marked as a reference pan.

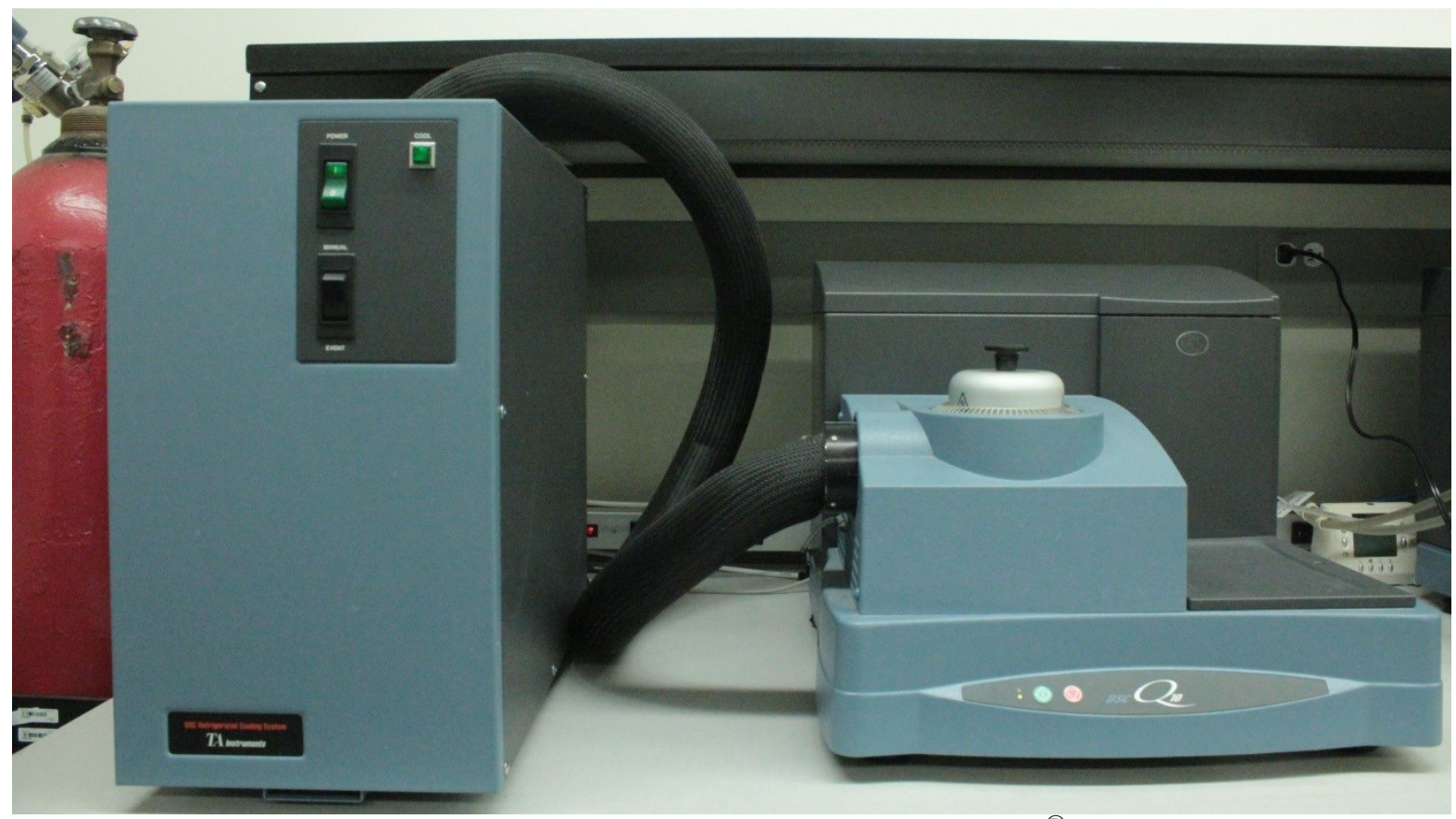

Figure 3.5 TA Instruments' DSC Q10 ${ }^{\circledR}$.

During the analysis, the difference in heat flow and temperature between the reference pan and the sample is recorded throughout the test. In this case, the TA Instruments DSC Q10 ${ }^{\circledR}$ device used for the thermal analysis is depicted in the Figure 3.5. The setup was to be provided with a nitrogen gas flow of $50 \mathrm{ml} / \mathrm{min}$. Dynamic cure analysis was performed on Cycom-5320 OOA prepreg in order to investigate the temperatures, which mark the onset of cure reaction.

\subsubsection{Dynamic Cure Analysis}

The dynamic runs were performed at rates, $2^{\circ} \mathrm{C} / \mathrm{min}$ and $10^{\circ} \mathrm{C} / \mathrm{min}$ from $30^{\circ} \mathrm{C}$ to $280^{\circ} \mathrm{C}$ to monitor the difference in heat flow at various ramp rates. This response is plotted in Figures 3.6 and 3.7 which interprets the exothermic heat released at different rates. Two trials were 
established at each condition, the first trial was performed on an uncured sample and the second trial was executed on the same sample after it was cured [52]. The graphs indicate that the heat flow of the cured sample intersects the uncured sample at $113.5^{\circ} \mathrm{C}\left(2^{\circ} \mathrm{C} / \mathrm{min}\right)$ and $145.2^{\circ} \mathrm{C}$ $\left(10^{\circ} \mathrm{C} / \mathrm{min}\right)$ respectively. Based on the literature [52], these temperatures were marked as the onset of the cure reaction.

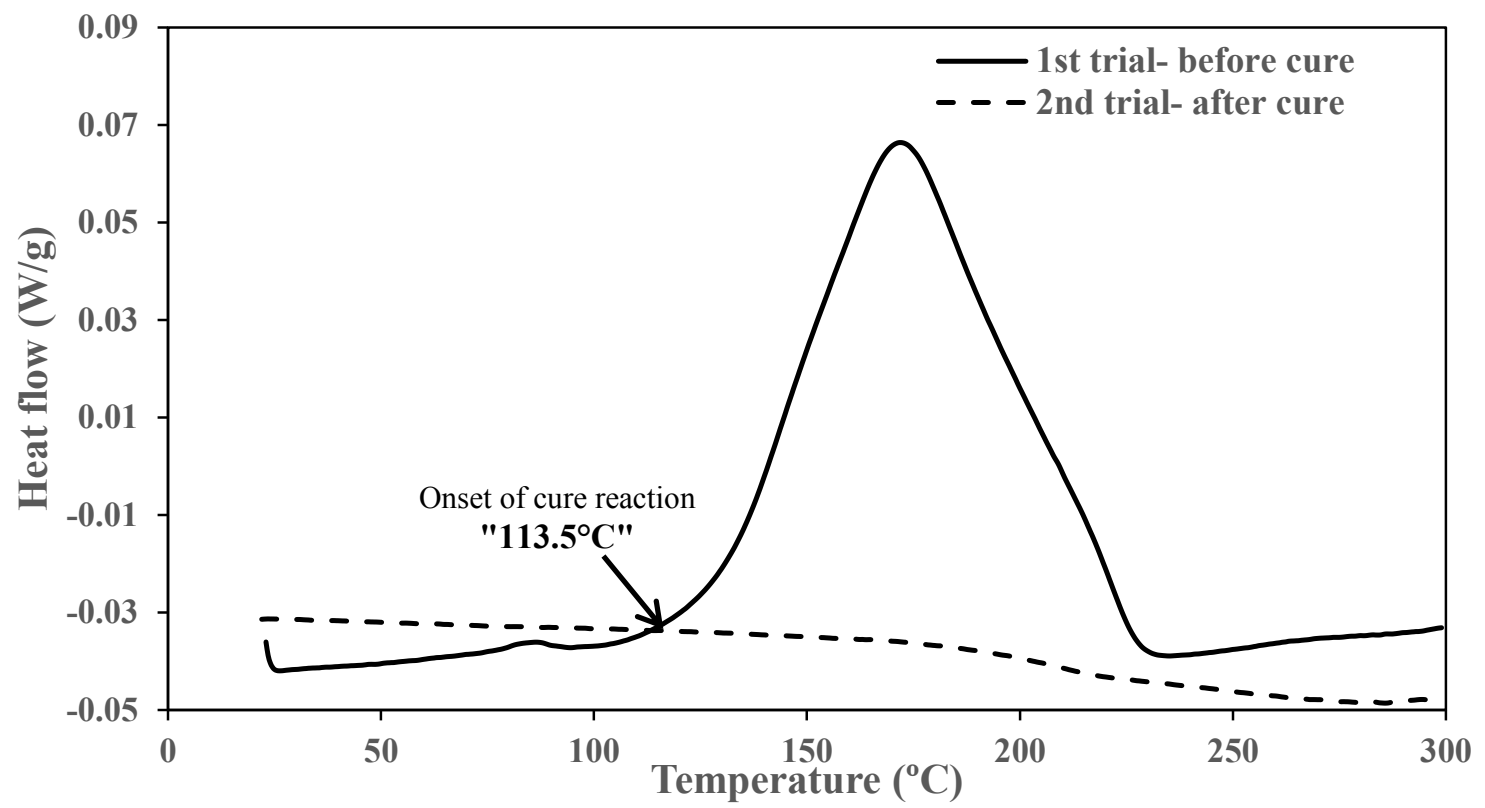

Figure 3.6 Dynamic analysis at $2^{\circ} \mathrm{C} / \mathrm{min}$ up to $300^{\circ} \mathrm{C}$.

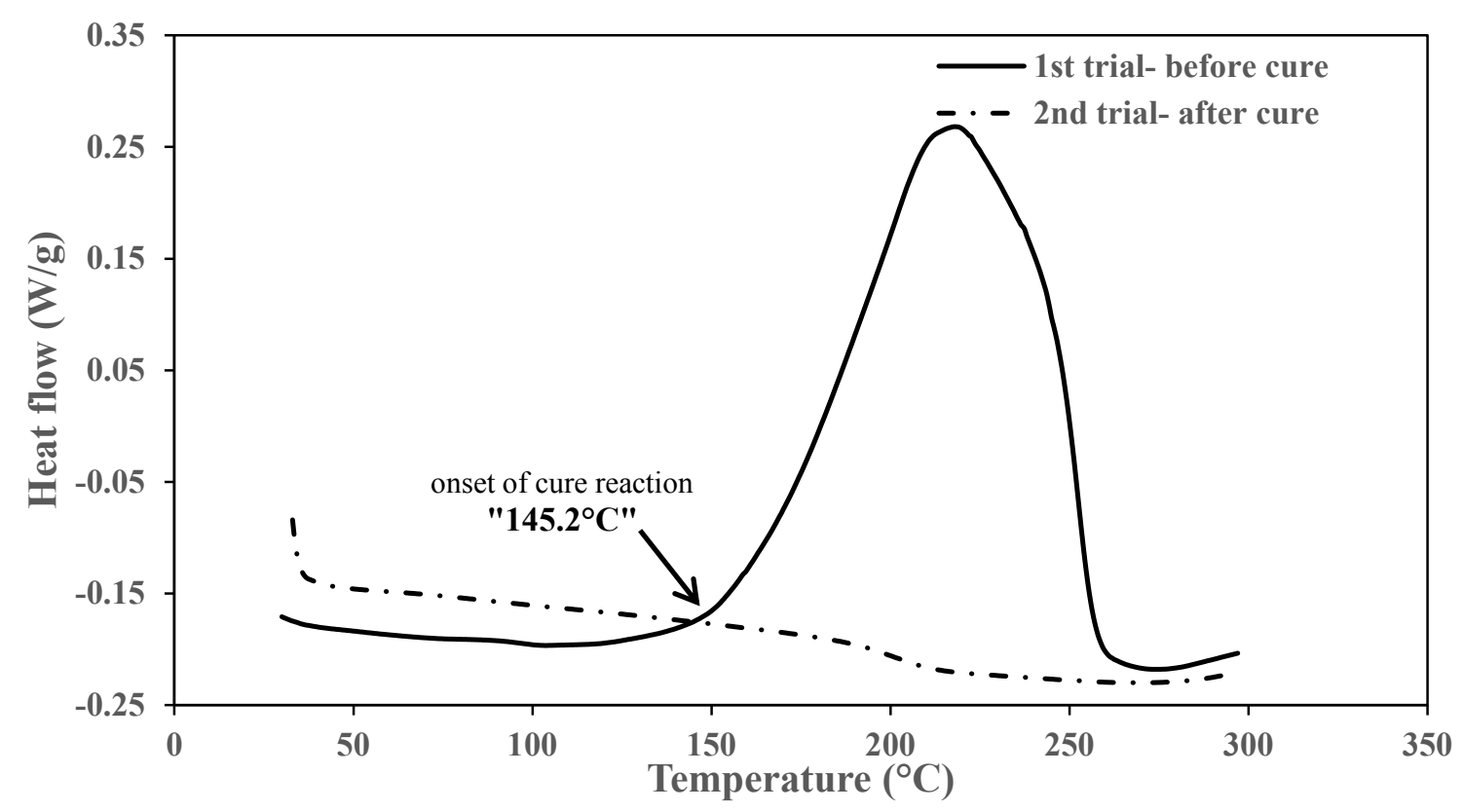

Figure 3.7 Dynamic analysis at $10^{\circ} \mathrm{C} / \mathrm{min}$ up to $300^{\circ} \mathrm{C}$. 
In addition, from both Figures 3.6 and 3.7, it is likewise visualized in common that the heat flow of the uncured sample is larger than the cured sample after the onset of cure reaction. While, the heat flow of the cured sample is seen to trace a baseline of the uncured sample after the onset of cure reaction. This shows that the sample is completely cured after the first trial resulting the second trial to trace the baseline. The onset temperature of the cure reaction at $2{ }^{\circ} \mathrm{C} / \mathrm{min}$ $\left(113.5^{\circ} \mathrm{C}\right)$ is found to be lower than at $10^{\circ} \mathrm{C} / \mathrm{min}\left(142.5^{\circ} \mathrm{C}\right)$. This shows that there is a nominal increase in the onset of cure reaction with the increase in the heating rate.

\subsubsection{Discussion}

These findings from the DSC helps us to conclude that the Cycom-5320 OOA epoxy resin starts to cure at $113.5^{\circ} \mathrm{C}\left(2^{\circ} \mathrm{C} / \mathrm{min}\right)$. This helps to fix the operating temperature range of the resin system (Cycom-5320) during the forming operation. While forming it is always necessary to operate within the onset temperature of cure since curing of the resin increases the shear rigidity of the prepreg and reduces the drapability of the fabric. Hence, with respect to Cycom-5320 material it is safer to operate within $113.5^{\circ} \mathrm{C}$ while forming. Further, rheological analysis was performed with the same resin system to verify the results from the DSC. 


\subsubsection{Rheological characterization of the prepreg}

The main objective here is to obtain the viscosity of the resin at different temperatures and to know how much time is available for forming before any curing (gelation) happens. The effect of temperature on viscosity was characterized using the MCR $500{ }^{\circledR}$ Rheometer, (see Figure 3.8).

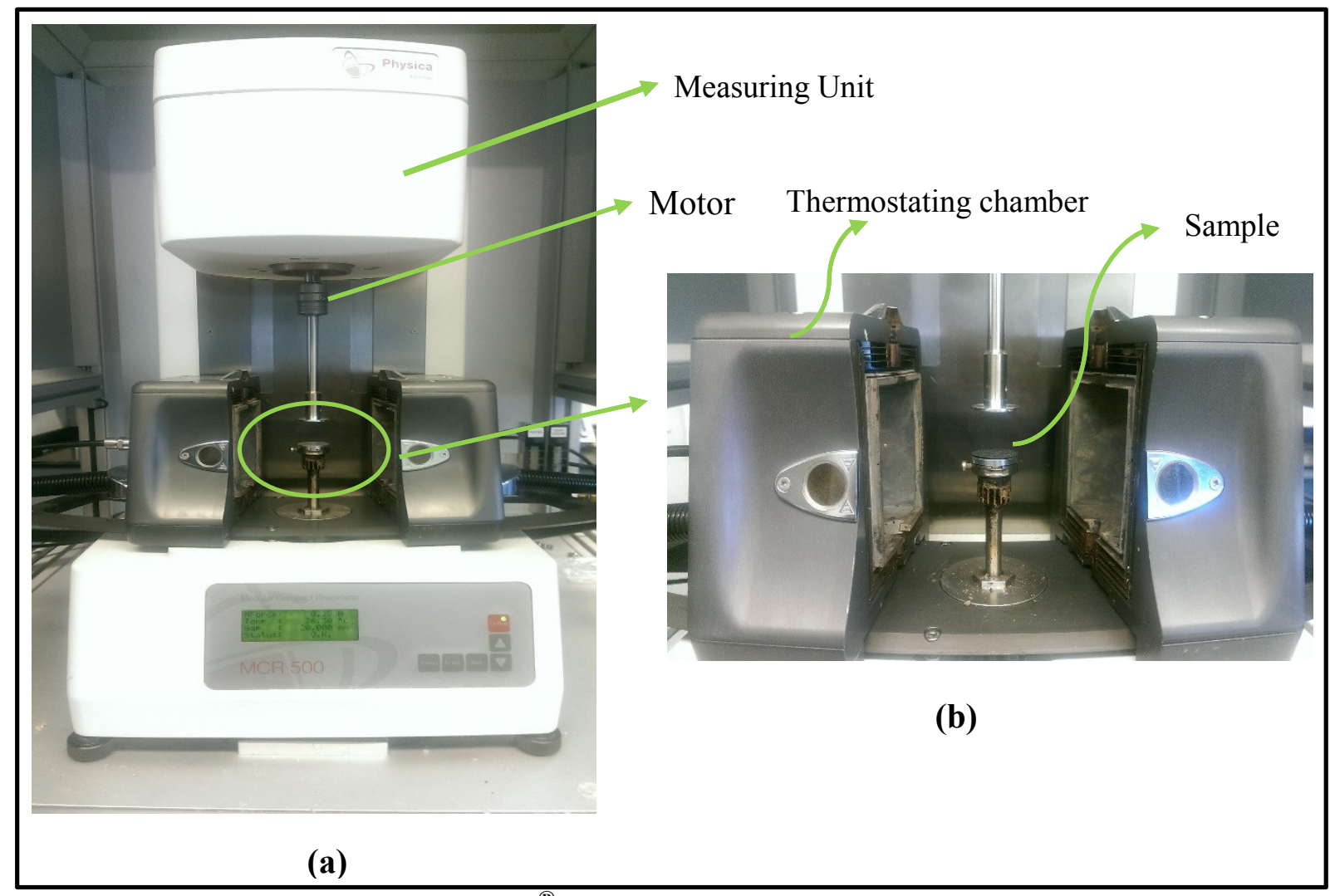

Figure 3.8 (a) MCR 500 ${ }^{\circledR}$ Rheometer and (b) Thermostating unit.

The upper plate of the Rheometer was driven by the synchronous motor and in turn the lower plate was kept stationary. The upper plates are found to be extremely precise to even small deformation caused by the specimen [53]. The measuring unit is capable of positioning of the plates and the adjusting the gap between them to its highest accuracy [53]. In addition, the rheometer is also equipped with the thermostating chamber which helps in characterizing the influence of temperature on the rheological flow behavior of the resin. The unit is capable of operating between a temperature ranges $-40^{\circ}$ to $+350^{\circ} \mathrm{C}$ [53]. In this case, nitrogen was used in order to enable the heating functionality of the unit.

The size of one layer prepreg sample was $25.4 \mathrm{~mm}$ in diameter and $0.55 \mathrm{~mm}$ thick. Since the thickness was very small, two layered prepreg, about $1 \mathrm{~mm}$ in thickness were used to improve 
the accuracy of the measurement. Initial tests were performed to determine the optimum testing conditions such as strain rate, frequency and gap between the plates. Based on the results, the optimum testing conditions were found to be; maximum strain rate of $10 \%$, a frequency of 0.2 $\mathrm{Hz}$ and a gap of $1 \mathrm{~mm}$. Tests were performed at both iso-thermal and dynamic sweep conditions.

\subsubsection{Iso- thermal condition}

During the iso-thermal tests, the chamber was first preheated to the desired temperature and stabilized at that temperature for half an hour. Later, the sample was placed inside the chamber and the test was started. On account of perceiving the resin behavior at elevated temperatures a

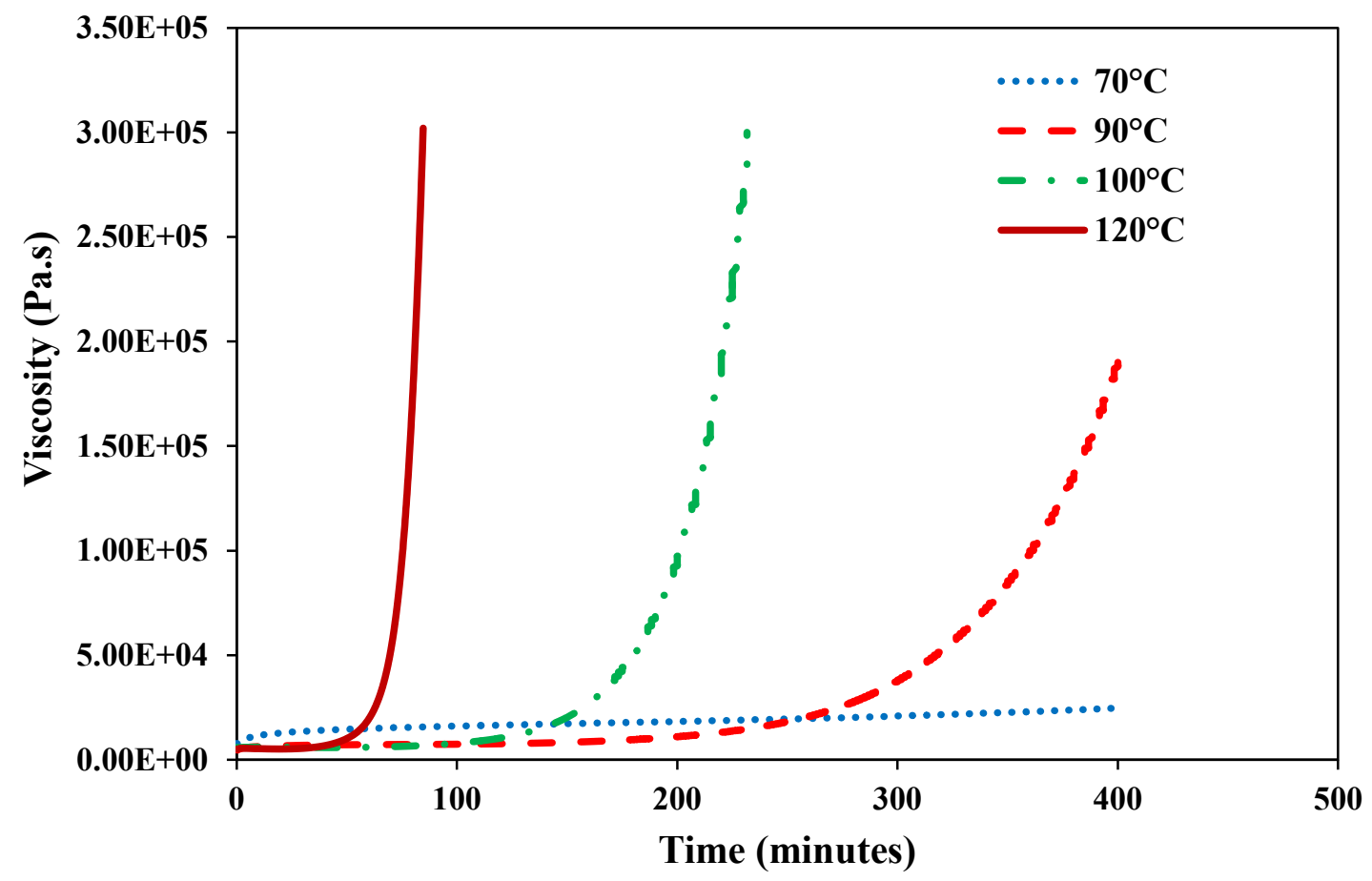

Figure 3.9 Experimental viscosity at selected isothermal temperatures.

viscosity vs time graph is plotted at different temperatures as in Figure 3.9. The graph shows that during the initial stages, viscosity decreases with the increase in temperature. The decrease in resin viscosity during the initial stages can be seen in detail in Figure 3.10. Results indicate that in the initial stages, viscosity of resin at $120^{\circ} \mathrm{C}$ to be much lesser than that at $100^{\circ} \mathrm{C}, 90^{\circ} \mathrm{C}$ and $70^{\circ} \mathrm{C}$. While later viscosity is found to drastically increase with the rise in temperature. This behavior is attributed to the transition of resin from gelled glass regime to vitrification regime as time proceeds [30]. 


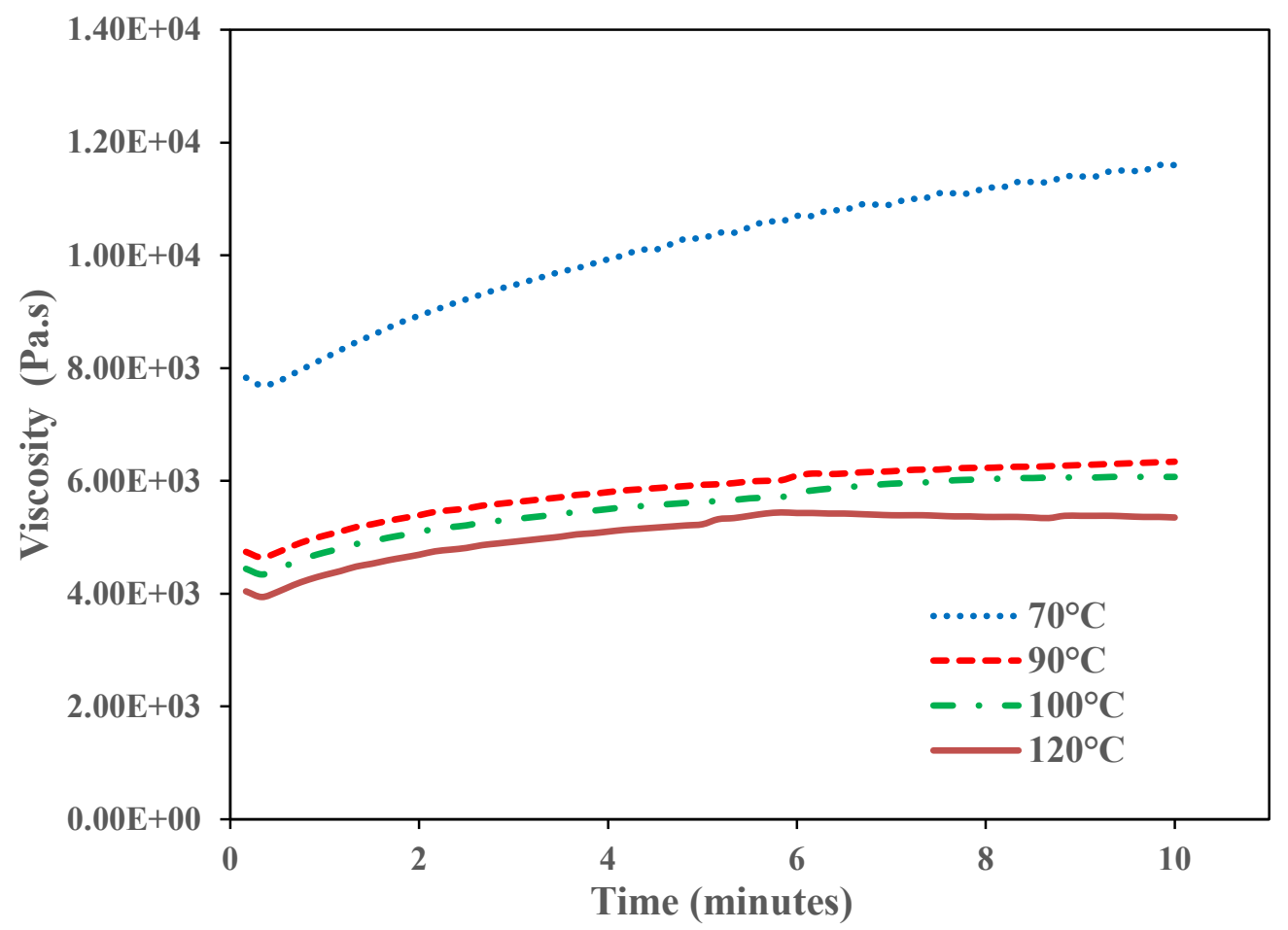

Figure 3.10 Variation of viscosity during the initial stage at selected temperatures.

Further, in order to determine the gelation time (time taken for the onset of cure) at different isothermal temperatures a graph is plotted between the storage modulus G' and loss modulus G' as depicted in Figure 3.11. It can be seen that during the initial stages, the loss modulus (G') is considerably higher than the storage modulus $\left(\mathrm{G}^{\prime}\right)$. But, later as the cure proceeds the loss modulus is found to decrease due to the transition of resin into a solid state. In contrast, the storage modulus increases with the cure process and eventually arrives at a plateau [52]. It is cited that the loss modulus increases with molecular weight and then decreases due to the solidification near the gel point. A similar observation was reported in literature [52].

The gel point denotes the onset of cross linking at where the transition of resin from a liquid to rubber state is witnessed. A more expert knowledge of the gel point helps to determine the optimum operating time at any iso-thermal temperatures during the forming operation. There are several methods to find the gel point, but the one used in our case is based on the criterion;

1. The point at which storage modulus $\left(G^{\prime}\right)$ and loss modulus (G') cross over each other $[52,54]$. The time required to reach the gel point is denoted as the 'gel-time' $\left(\mathrm{T}_{\mathrm{gel}}\right)$ as indicated in the Figure 3.11. 


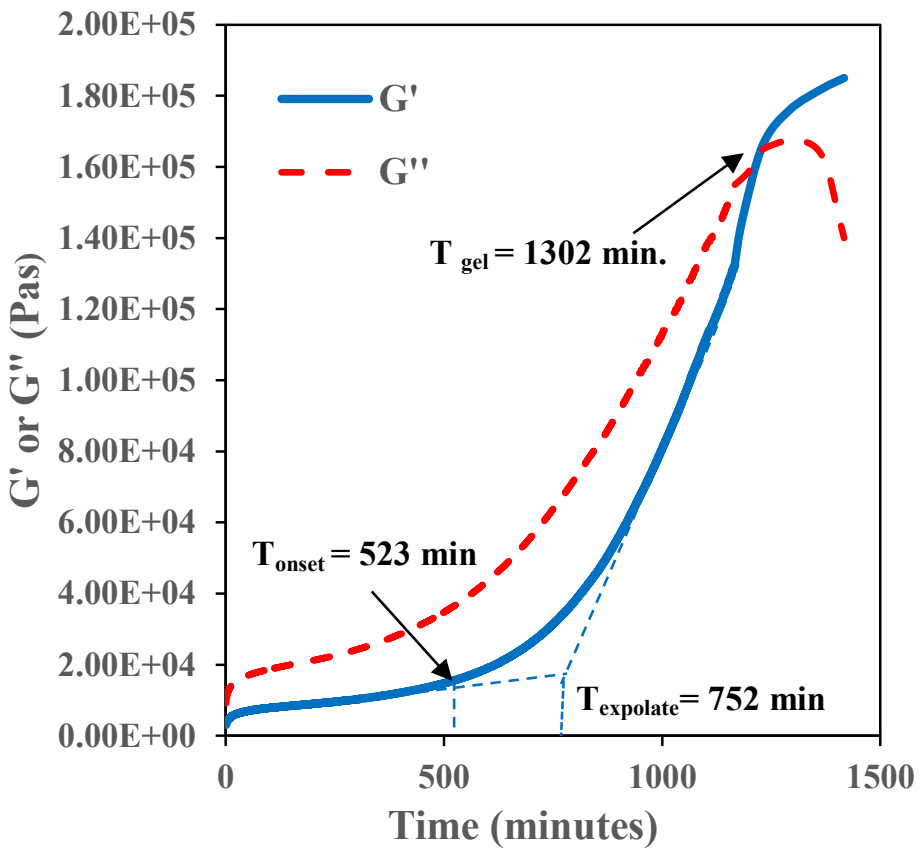

(a) $70^{\circ} \mathrm{C}$

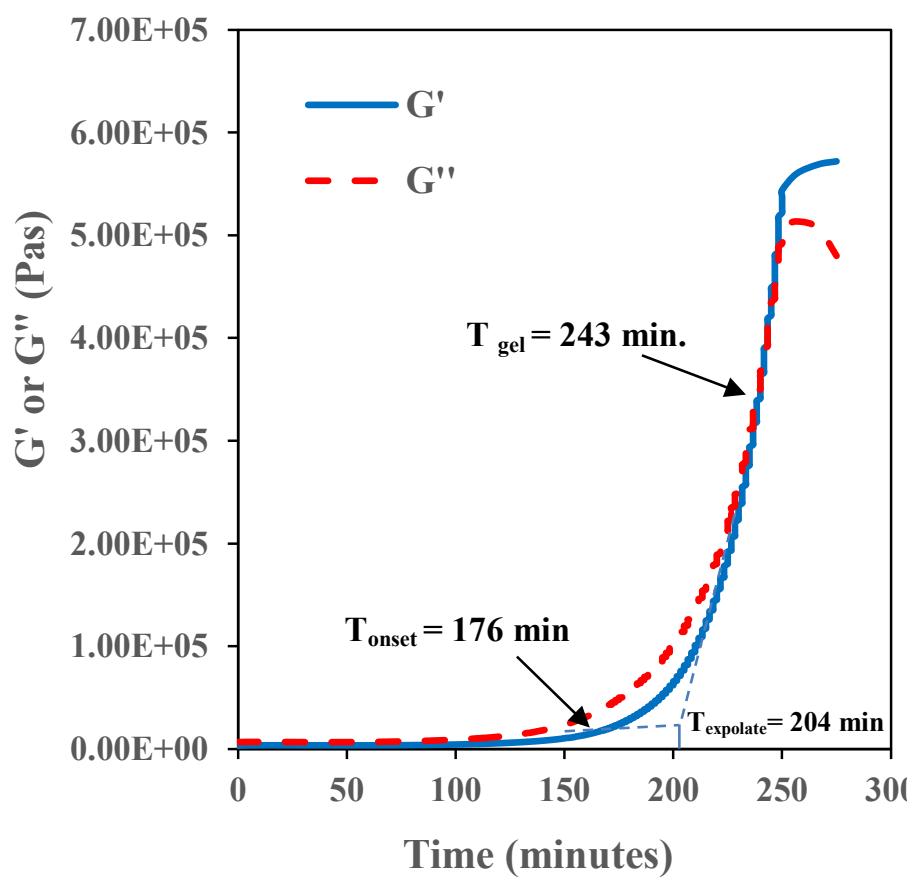

(c) $100^{\circ} \mathrm{C}$

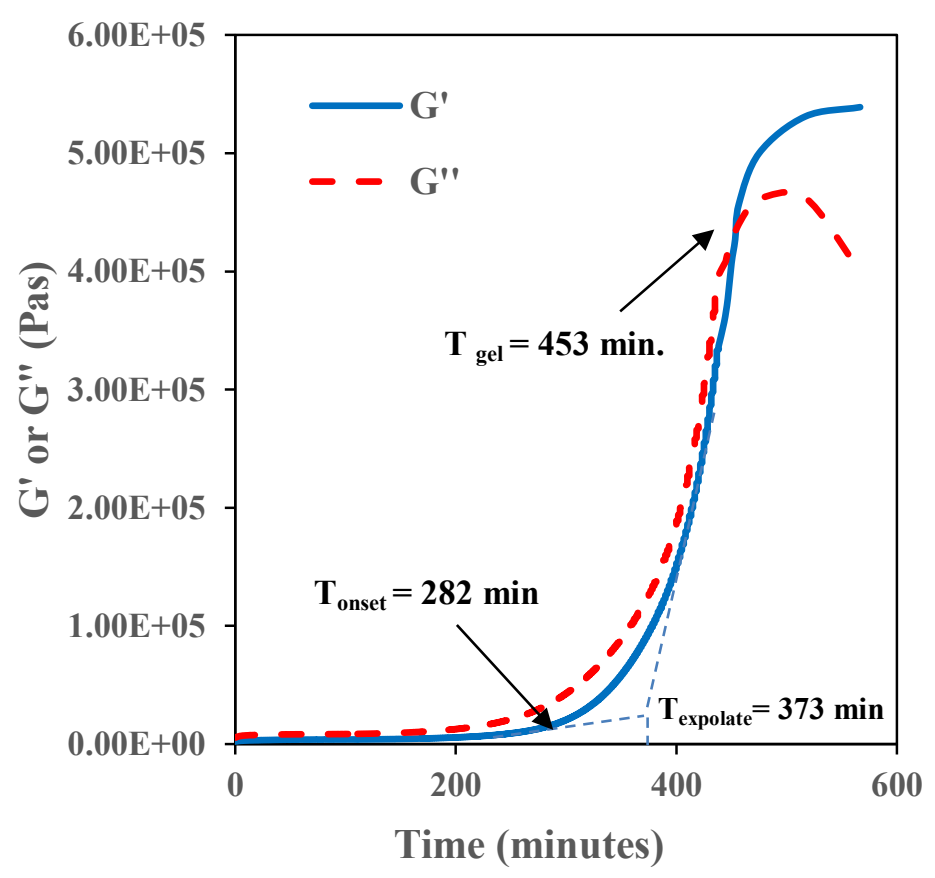

(b) $90^{\circ} \mathrm{C}$

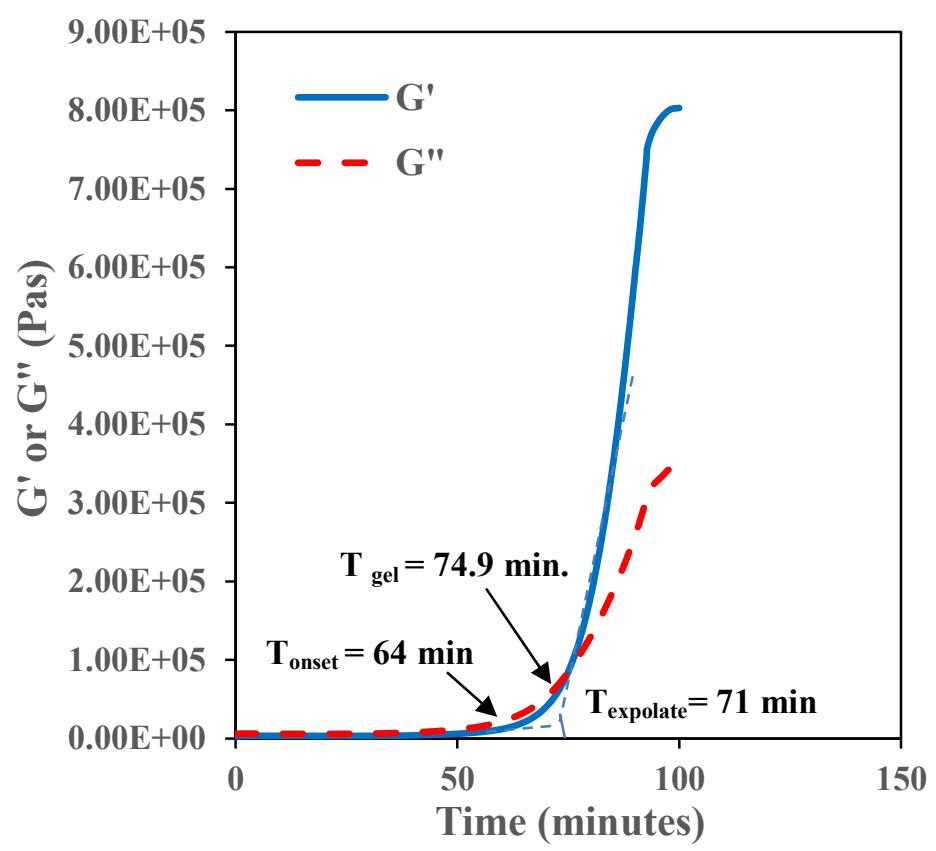

(d) $120^{\circ} \mathrm{C}$

Figure 3.11 Effect of storage modulus (G') and loss modulus (G') on time at various temperatures. 
The variation of the gel time with the isothermal temperature is summarized in Table 3.2. It can be seen that as the temperature increases the gel time decreases. This observation confirms the findings of Liangfeng [52] that the time for the transition of the resin from a liquid to rubbery state increases with the rise in isothermal temperature. In addition, $\mathrm{T}_{\text {onset }}$ marks the time taken for the onset of the chemical reaction and Table 3.2 shows that the onset time to be less than the gel time. Even though, gel time ( $\left.\mathrm{T}_{\text {gel }}\right)$ marks the onset of cure reaction, while forming it is much safer to stay with the $\mathrm{T}_{\text {onset }}$ regime to avoid curing during the forming operation.

Table 3.2 Gel time at different temperatures.

\begin{tabular}{ccccc}
\hline $\begin{array}{c}\text { Temperature } \\
\left({ }^{\circ} \mathbf{C}\right)\end{array}$ & $\mathbf{7 0}^{\circ} \mathbf{C}$ & $\mathbf{9 0}^{\circ} \mathbf{C}$ & $\mathbf{1 0 0}^{\circ} \mathbf{C}$ & $\mathbf{1 2 0}^{\circ} \mathbf{C}$ \\
\hline $\mathbf{T}_{\text {gel }}(\mathbf{m i n})$ & 1302 & 453 & 243 & 74.9 \\
$\mathbf{T}_{\text {onset }}(\mathbf{m i n})$ & 523 & 282 & 176 & 64 \\
$\mathbf{T}_{\text {extrapolated }}(\mathbf{m i n})$ & 752 & 373 & 204 & 71 \\
\hline
\end{tabular}

\subsubsection{Dynamic Cure Condition}

During the dynamic cure process, the samples were placed inside the chamber at room temperature and later heated at the desired rate. The variation of viscosity with temperature at a heating rate of $2^{\circ} \mathrm{C} / \mathrm{min}$ is plotted in Figure 3.12. The results observed during the dynamic condition is found to be different from that observed during the isothermal condition. It is noticed that during the initial stages of reaction, the drop in resin viscosity with the temperature is to dominate the resin behavior. A while later, as the cure reaction starts the resin viscosity is seen to drastically increase, projecting the degree of cure to be a dominant factor.

The temperature at which cure reaction starts and minimum viscosity temperature are found to be evidently visible from the Figure 3.12 . At the heating rate of $2^{\circ} \mathrm{C} / \mathrm{min}$, it is witnessed that the cure reaction starts at a temperature of $110.67^{\circ} \mathrm{C}$. To corroborate this, the measurements from the DSC had already shown us that the cure reaction starts at $113.5^{\circ} \mathrm{C}$ which is close to $110.67^{\circ} \mathrm{C}$ obtained from the rheometer. In summation, it is likewise reported that the resin reaches its minimum viscosity at $150.3^{\circ} \mathrm{C}$ at which it is prefigured to induce its maximum flowability. 


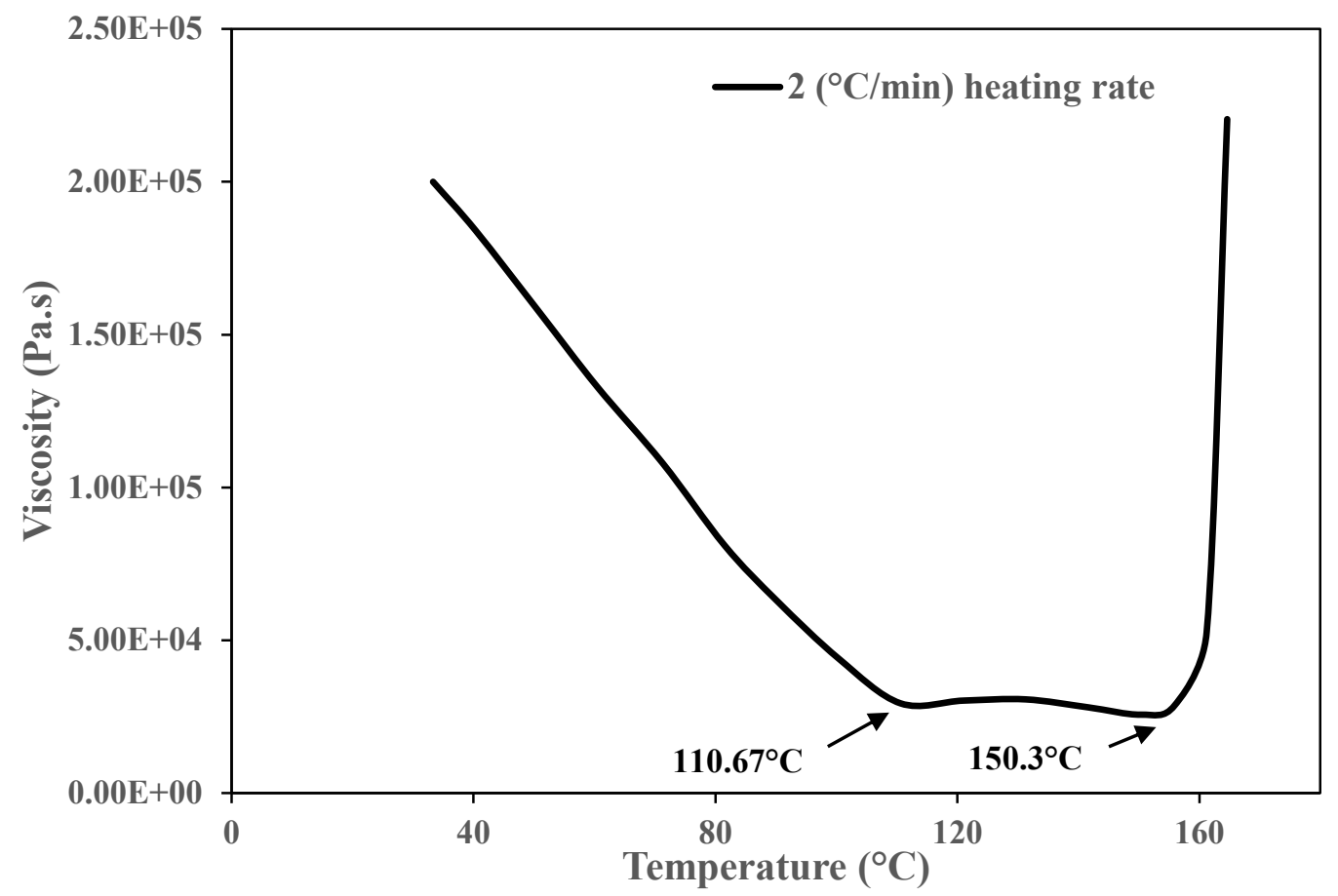

Figure 3.12 Viscosity vs. temperature at constant heating rate, $2^{\circ} \mathrm{C} / \mathrm{min}$.

Finally, to summarize the results from the rheometer, the tests performed under the isothermal condition showed that, time taken for the initiation of the cure reaction (gelation) decreases with the increase in temperature. This knowledge of the gel time of the resin system at varying elevated temperatures, facilitates to find the exposure time of the Cycom-5320 resin system, before any curing takes place during the actual forming operation.

\subsection{Structural Components}

\subsubsection{Design Requirement}

The rig (see Figure 3.13) was designed with following design requirements in mind:

(a) From the stress point of view, it should be able to withstand a force up to $20,000 \mathrm{~N}$ ( 20 $\mathrm{kN})$.

(b) The rig must be able to shear up to an angle of $70^{\circ}$.

(c) The rig must be able to handle samples of different thickness from 0.55 to $3.50 \mathrm{~mm}$.

(d) The rig must be able to handle samples of the cross section area $310 \times 310 \mathrm{~mm}^{2}$. 


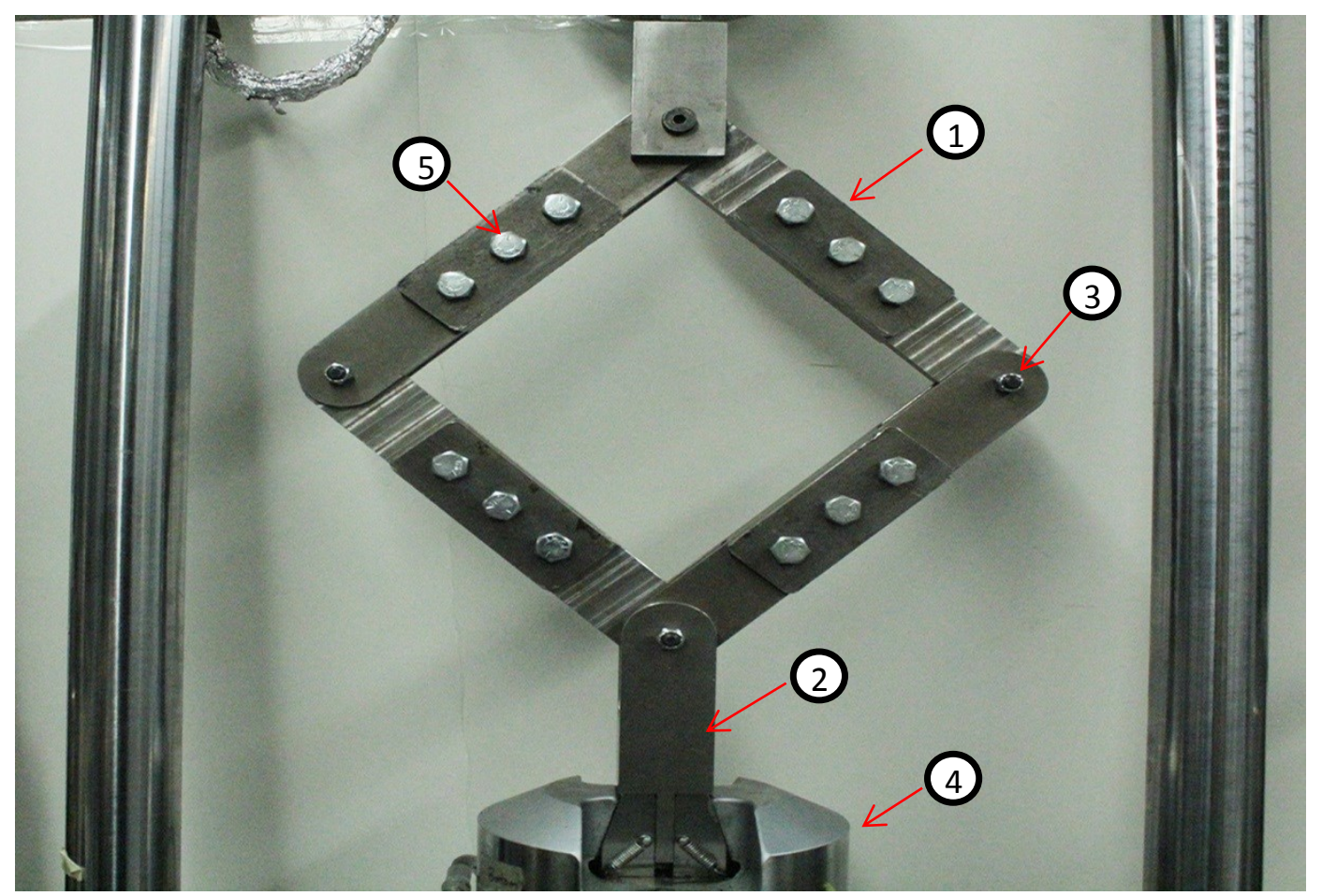

Figure 3.13 Structural outline of the test set up: 1- clamping plate, 2- clevis, 3- shoulder bolts, 4- lower jaw, 5- clamping bolts.

\subsubsection{Clamping plate}

The clamping plate as shown in Figure 3.14 is a component that enables to clamp the sample onto the frame. The upper plate of thickness 0.4 inches, while the lower is of 0.6 inch thickness. Each clamping plate is also supported by $4 \times \mathrm{M} 12$ bolts which helps in the firm clamping of the sample without any slippage. By this, it was also made sure that samples of various thickness were able to be clamped and tested in optimum conditions. But in this thesis, C-clamps have been employed as an alternative to bolts to facilitate firm clamping of the plates and also to ensure pure shear throughout the frame. The C-clamps (see Figure 4.1) have been used based on the recommendations of the previous work which reported that, clamped boundary conditions are preferable to impart pure shear deformation for prepreg materials [21]. 


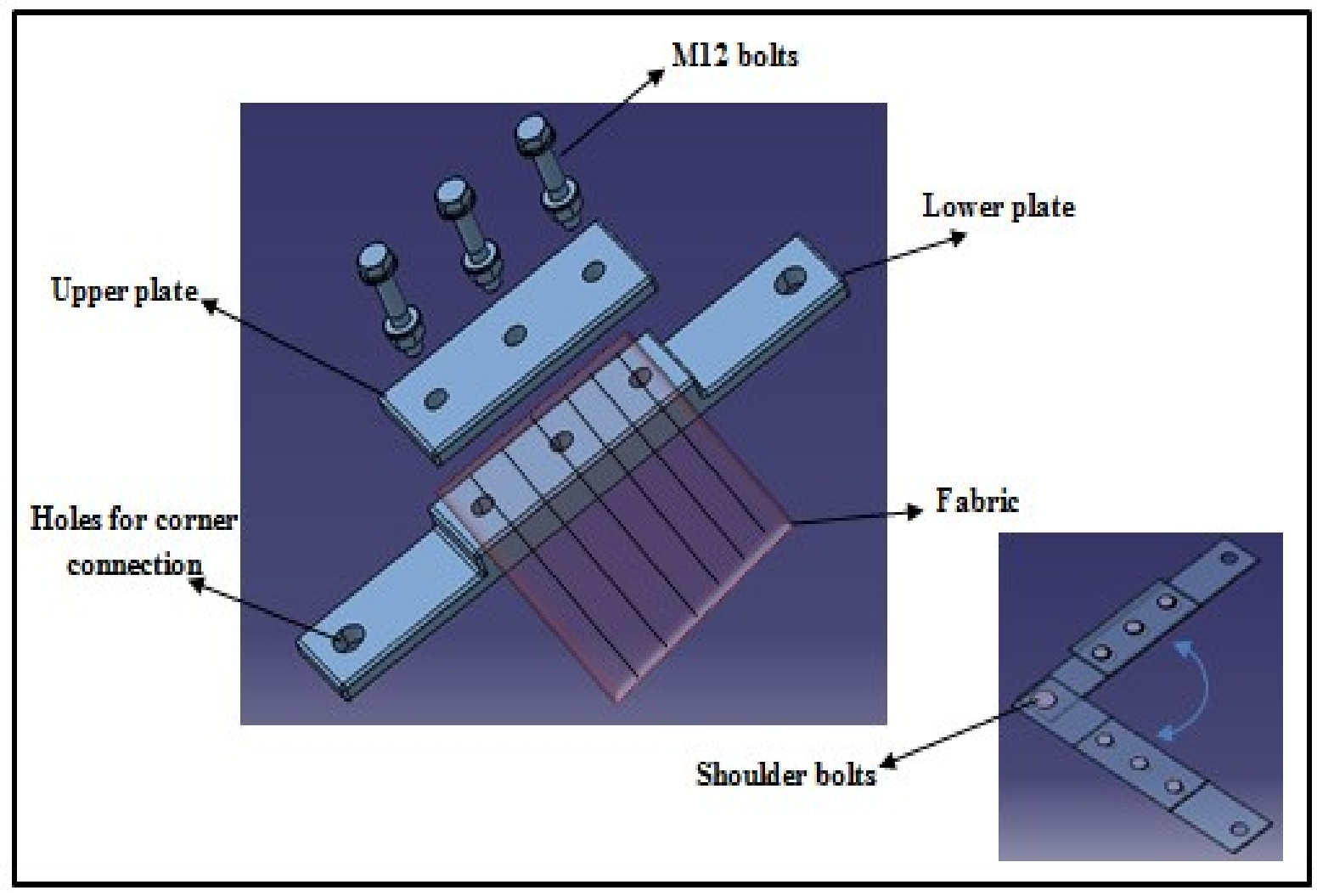

Figure 3.14 Design of clamping plate.

In a similar way, three other clamping plates were connected to each other by shoulder bolts at the ends, which helps in rotating the arms freely without any hindrance. A lot of picture frame set-ups have been designed in the past in-order to reduce the friction between the plates. By introducing the shoulder bolts into the setup, it acts as a bearing which helps to reduce the friction between the plates during testing. The plates are designed in such a way that they are able to shear up to an angle of $70^{\circ}$ before they come in contact with each other. The plates were made of stainless steel in order to make sure they withstand high temperature. 


\subsubsection{Clevis}

The installation of clevis on to the frame enable us to set up the frame onto the tensile machine. It acts as a connector (see Figure 3.15), connecting the frame onto the load cell which in turn records the amount of load experienced by the frame. The clevis is found to be made up of one

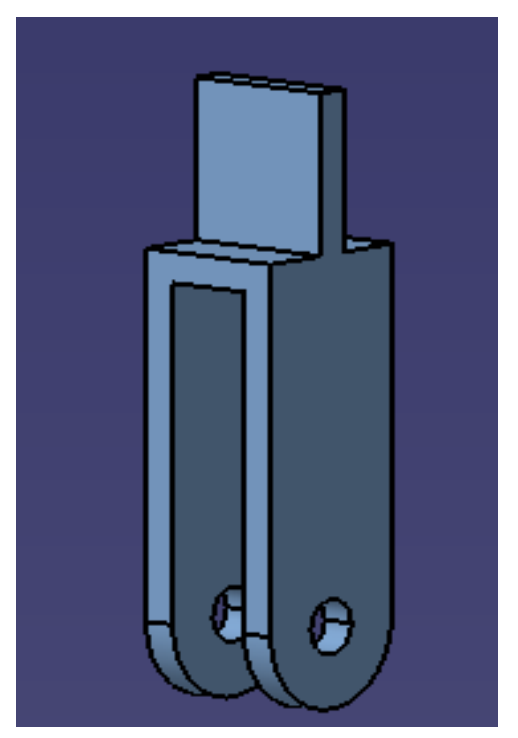

\section{Figure 3.15 Clevis.}

piece of steel in order to enhance the structural rigidity of the frame. Finally the clevis is fastened by pins which holds on to the frame firmly without any clearance.

\subsection{Summary}

From the iso-thermal tests performed using the DSC and rheological analysis the cure reaction of the Cycom-5320 OOA resin system was reported to start at a temperature between $110.67^{\circ} \mathrm{C}$ $113.5^{\circ} \mathrm{C}$. This helped to determine the operating temperature of the resin system by overcoming the curing during the forming process. Further, the picture frame rig was designed in a way that the arms are free to rotate around the hinges which help in imparting pure shear throughout the shear process. 


\section{CHAPTER 4: TEST RESULTS AND DISCUSSION}

This chapter aims to investigate the in-plane shear behavior of the out of autoclave (OOA) carbon epoxy thermoset prepreg using the picture frame test. Tests were performed at varying operating conditions (temperatures, displacement rates and lay-up sequences) in order to determine their contribution on the deformability of the fabric.

\subsection{Test method and results}

The 5HS and 8HS samples were cut cross shaped as shown in Figure 4.1 (a) and clamped onto the rig without any misalignment at an angle $\pm 45^{\circ}$ to the direction of the applied tensile force (see Figure 4.1(b)). The frame was then mounted onto the MTS tensile machine and a tensile load was applied at the cross heads resulting the frame to deform from its initial square configuration to rhomboid [41,55], as in Figure 4.1(c). This results in trellising behavior and the sample experiences pure shear throughout its surface [2].

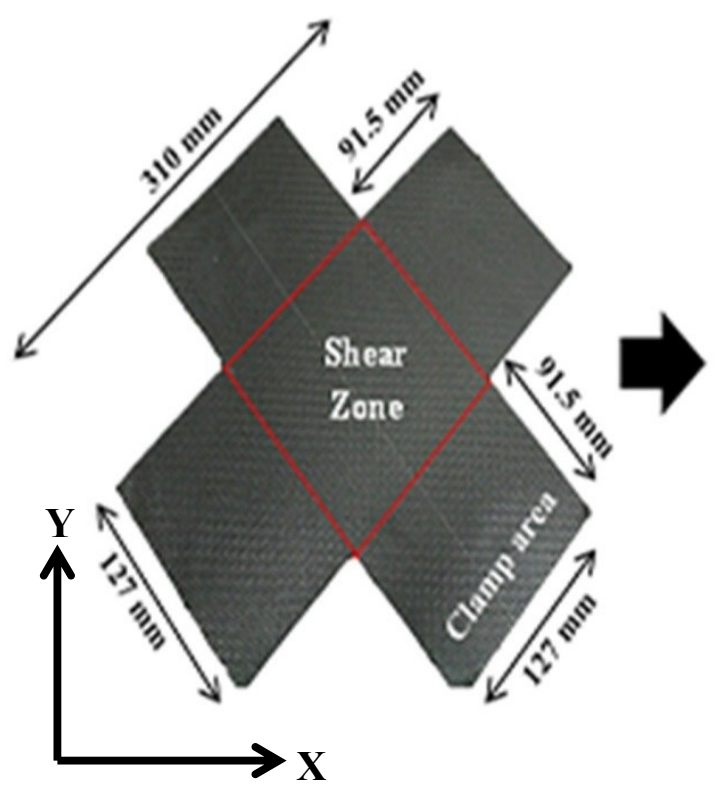

(a)

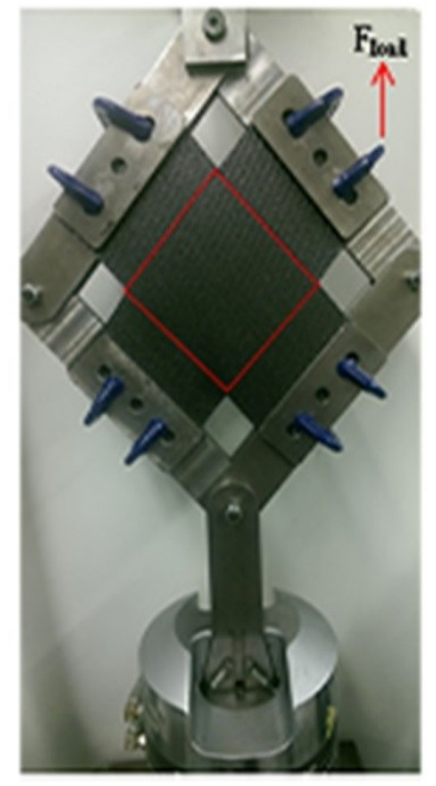

(b)

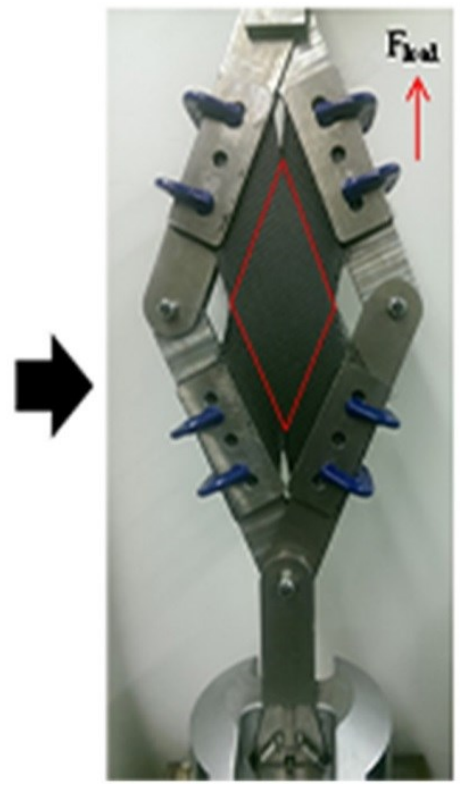

(c)

Figure 4.1 Set-up (a) initial sample, (b) un-deformed (square) frame and (c) deformed (rhomboid) frame. 
The cross head load required to deform the sample was recorded instantaneously by the MTS system with the help of a $2.5 \mathrm{KN}$ load cell. The test results discussed here are based on the loaddisplacement curves that were obtained from the tensile testing recordings. The tests were terminated at a displacement of $104 \mathrm{~mm}$. Figure 4.2, shows the typical load-displacement response of two layered $[0,90] 5 \mathrm{HS}$ and $8 \mathrm{HS}$ OOA carbon/epoxy prepreg at room temperature and constant displacement rate of $20 \mathrm{~mm} / \mathrm{min}$. The results show that the initial stiffness of both the samples are low up to a displacement of $60 \mathrm{~mm}$. However, on the whole, the stiffness of the $8 \mathrm{HS}$ sample is found to be greater than the $5 \mathrm{HS}$ during this range.

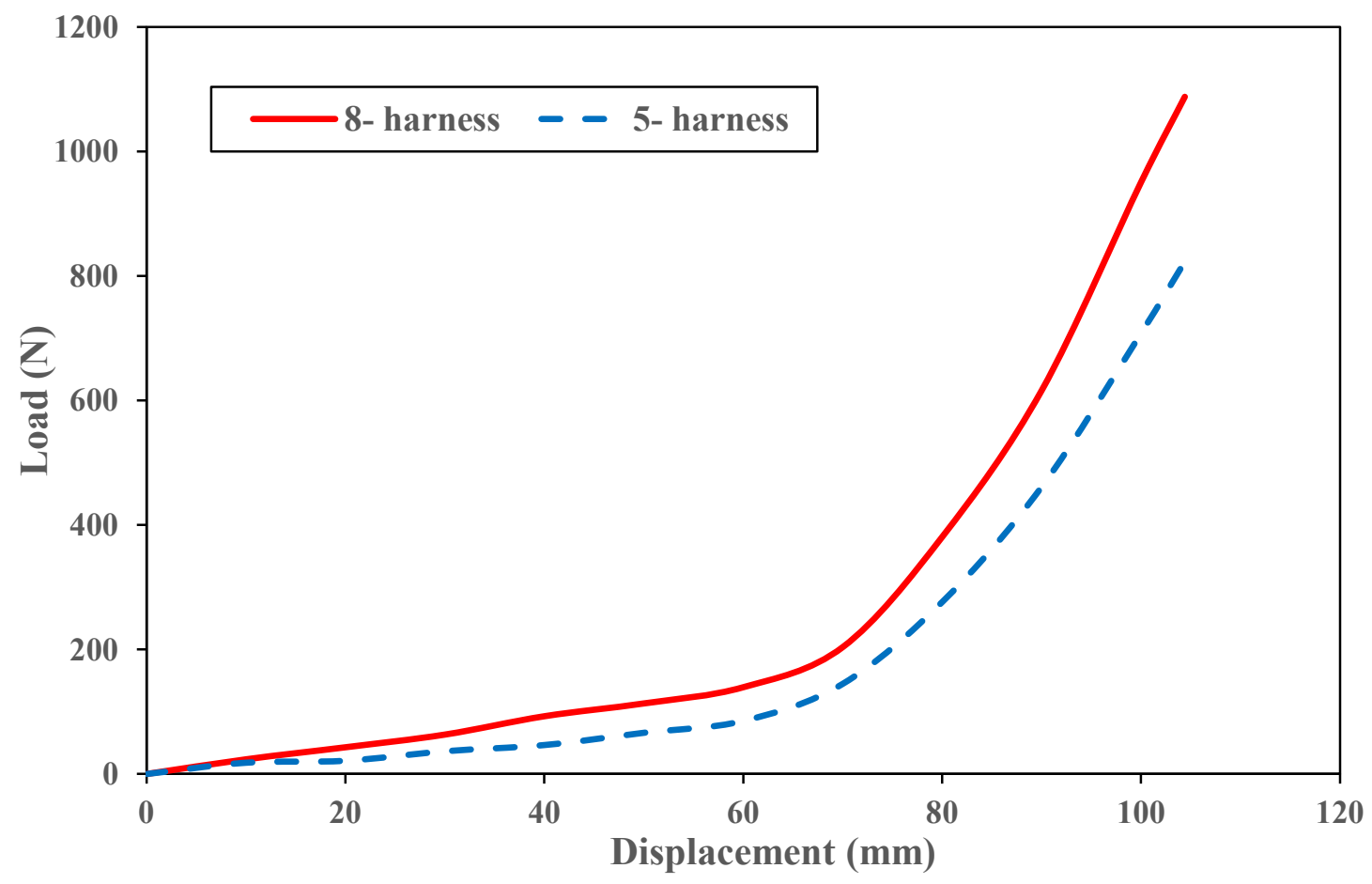

Figure 4.2 Load vs displacement curve at room temperature and $20 \mathrm{~mm} / \mathrm{min}$.

The amount of shear possible between the adjacent yarns before they come in contact with each other and limit the in-plane shear deformation (locking angle) were analyzed by comparing the shear force with the calculated shear angle. The shear force and the calculated shear angle at any state of deformation were resolved based on PJN assumptions from the equations 1.1 and 1.3. The shear force vs shear angle response of the 5HS and 8HS sample is plotted in Figure 4.3. It is seen that the curve exhibits three zones of deformation [2]: (zone: 1) the yarns tend to place each over the other and start to rotate at the crossover points (in-plane shear), (zone: 2) once the yarns come in contact with each other they restrict further deformation and tend to lock (locking angle) 
[2], (zone:3) further deformation results in the yarns to wrinkle out-of-plane. It is also visualized that during the initial stages of the deformation the shear load is relatively low. This is since, initially the adjacent yarns have much space to rotate in between them and also because at this stage only friction between the yarns serves as the major resistance to shear [39]. But, later as the deformation proceeds there is a sudden drastic increase in the shear load curve since yarns come in contact with each other. At this stage, the lateral compression serves as the major resistance $[4,39,40,46]$.The angle at which this response is observed is reported as the locking angle. Theoretically, this angle marks the onset of wrinkling. In this case, irrespective of the operating condition an extensive wrinkling was visible during the latter part of the test. So the prime objective of this study is to find the nominal operating conditions which postpones the onset of wrinkling.

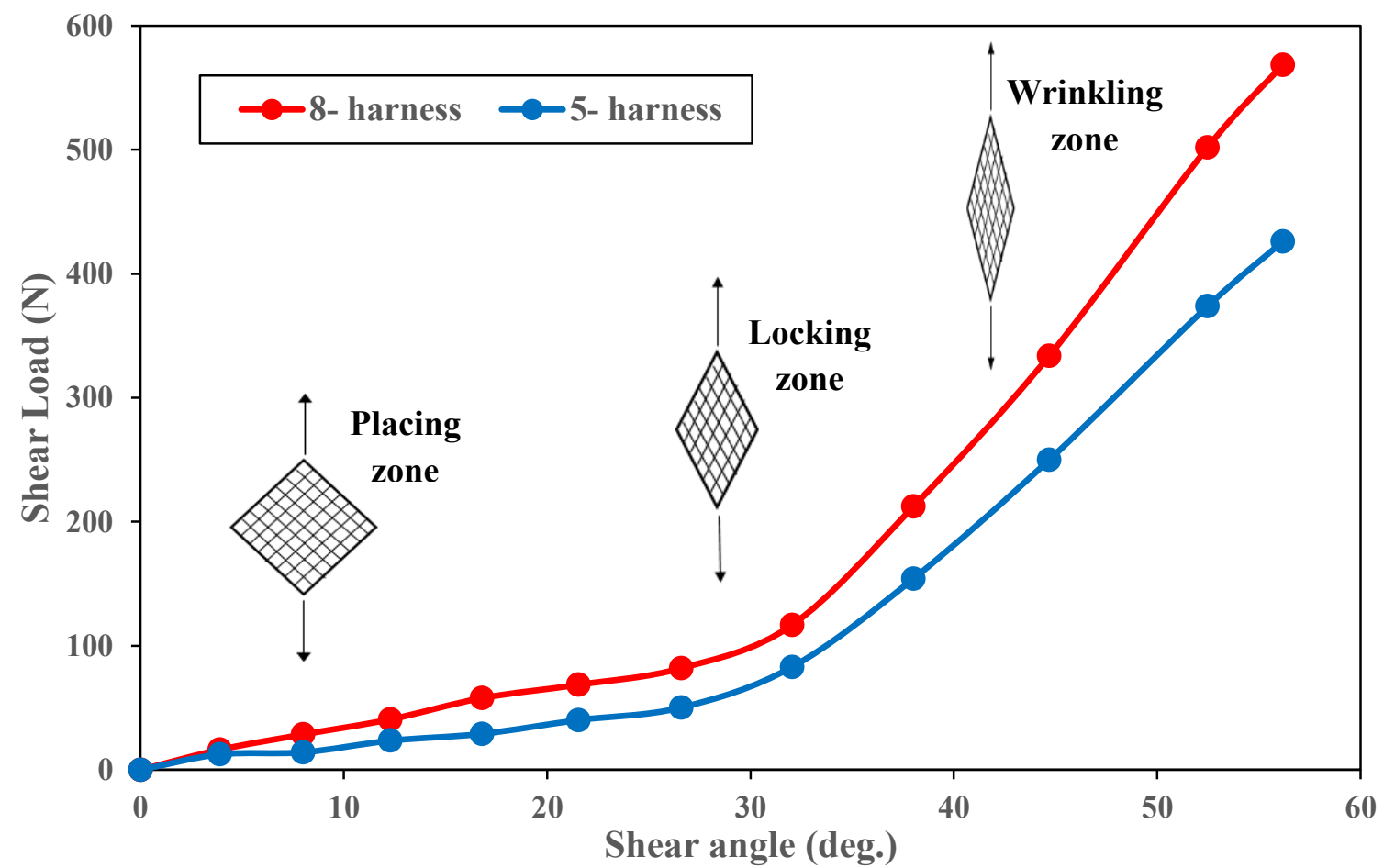

Figure 4.3 Shear load Vs calculated shear angle at room temperature and $20 \mathrm{~mm} / \mathrm{min}$.

The comparison between the calculated shear angle (based on PJN equation 1.3) and measured shear angle are plotted in Figures 4.4 and 4.5. The picture frame rig was equipped with a 3D digital image correlation (DIC) system (an image analysis device rigged with two high magnification cameras) which is capable of capturing images at various stages of deformation, as in Figure 4.18. The results from DIC are explained in detail in section 4.5. These sequential images from DIC were then imported into AutoCAD to measure the experimental shear angle. 


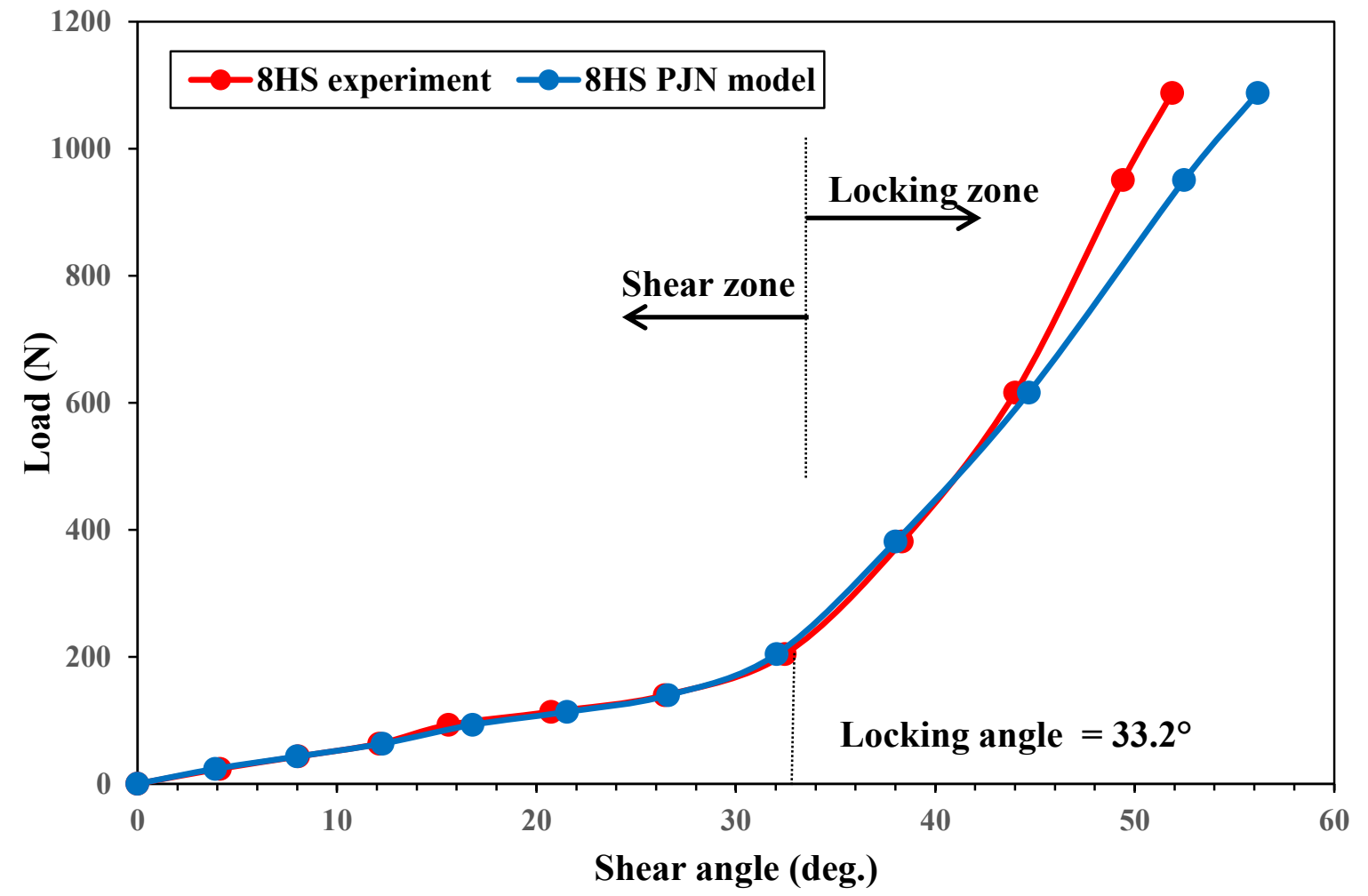

Figure 4.4 Comparison between calculated and experimental shear angle for 8HS.

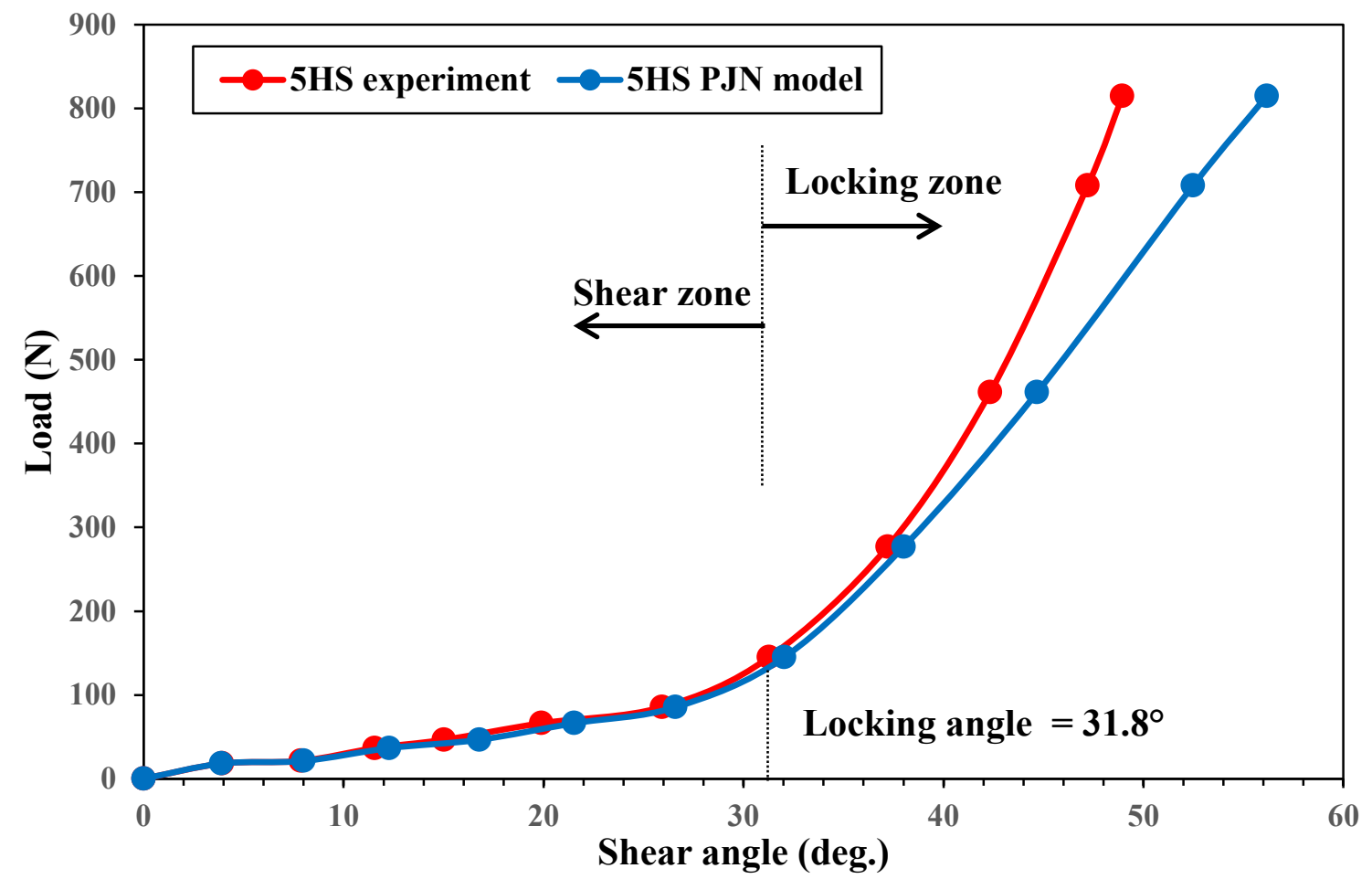

Figure 4.5 Comparison between calculated and experimental shear angle for 5HS. 
It is noticed that the experimental shear angle follows the theoretical shear angle during the initial stages of deformation. Then, as the deformation increases, it is observed at a shear angle of $30^{\circ}$ the calculated shear angle deviates from the experimental angle for both $8 \mathrm{HS}$ and $5 \mathrm{HS}$ samples. In addition, the locking angle is also found to be graphically plotted in Figure 4.4 and 4.5, as suggested by Scouter [45,56]. It is witnessed that the locking angle of the $8 \mathrm{HS}$ is approximately $33.2^{\circ}$, while for $5 \mathrm{HS}$ is $31.8^{\circ}$. The locking angle of the $8 \mathrm{HS}$ sample is found to be $4.4 \%$ higher than the 5HS sample even when sheared at same conditions (room temperature and $20 \mathrm{~mm} / \mathrm{min}$ ). This difference in locking angles between the samples may be attributed to their difference in weave style, yarn width and areal density, which are to be investigated in detail in forthcoming section 4.7. To facilitate the effect of elevated temperature on the in-plane shear behavior of the woven prepreg, the fabrics needs to be heated in a controlled and uniform manner. The next section discusses regarding the various facilities used to heat and monitor the temperature of the samples during the project.

\subsection{Heating facility}

In order to perform the tests at elevated temperatures a non-contact infrared heater manufactured by Watlow ${ }^{\circledR}$ of specification $5000 \mathrm{~W}$ and 240 Amps was used for investigation. The heater was capable of generating a maximum surface temperature of $1570^{\circ} \mathrm{C}$; however for this application,

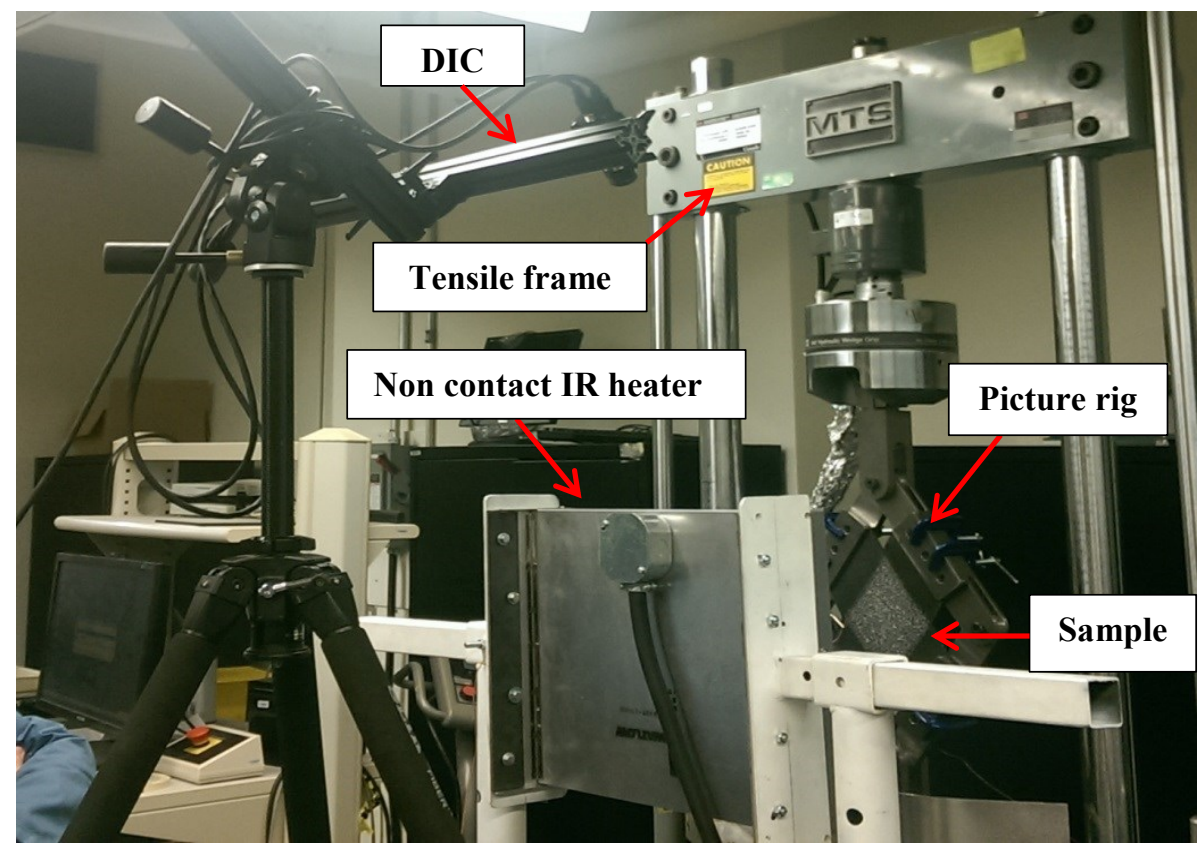

Figure 4.6 Positioning of the heating set-up. 
a much lower temperature of $90^{\circ} \mathrm{C}$ (maximum) was required, taking the forming operation into consideration. The positioning of the heaters with respect to rig is shown in Figure 4.6. Controllers were used to adjust and monitor the temperature of the heater. Thermocouples, sandwiched within the sample were used to monitor the temperature of the sample and the test was started only after the sample was held at processing temperature for 10 minutes. By this, it was made sure that uniform temperature was achieved throughout the sample. The data acquisition system; which is a temperature monitoring system enabled by a set of thermocouples was used to monitor the surface temperature of the sample. The thermocouples were positioned at three different locations as indicated in Figure 4.7 (a). It can be seen in Figure 4.7 (b) that the difference in temperatures recorded by the thermocouples placed at both sides (front and rear side) of the sample is almost negligible. This indicates, almost a uniform temperature is achieved throughout the prepreg during the test.
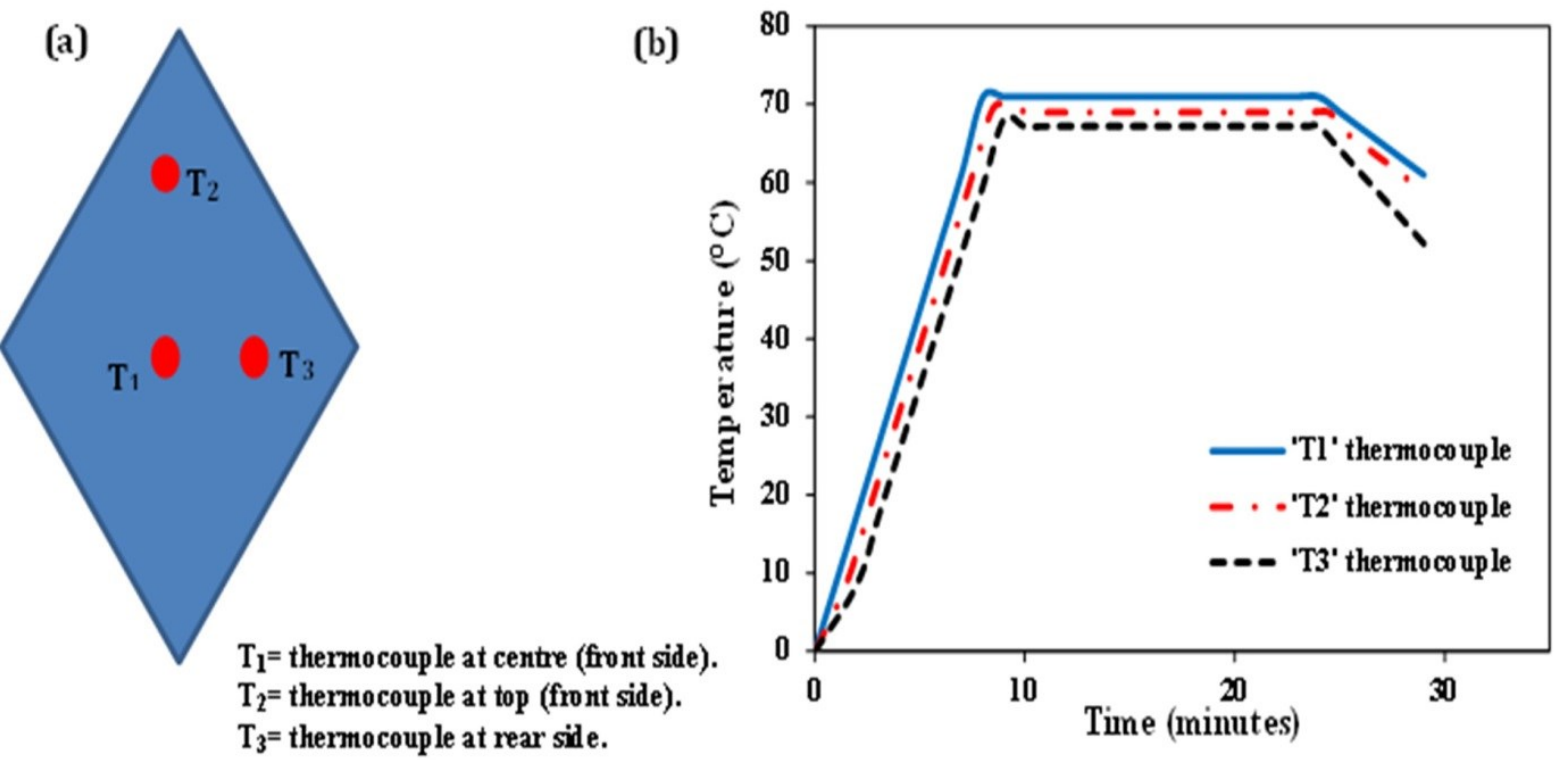

Figure 4.7 (a) Locations of thermocouples and (b) temperature recorded by thermocouples placed in three different locations on the prepreg.

In addition non-contact Mastercraft $\# 57^{\circledR}$ infrared temperature sensors and a FLIR T420 ${ }^{\circledR}$ infrared camera (see Figure 4.8) were used to monitor the temperature. The Figure 4.9 shows the output of the temperature gradient obtained by the FLIR $^{\circledR}$ infrared camera. The pictograph shows the surface heat and difference in temperature at two different points on the sample. 


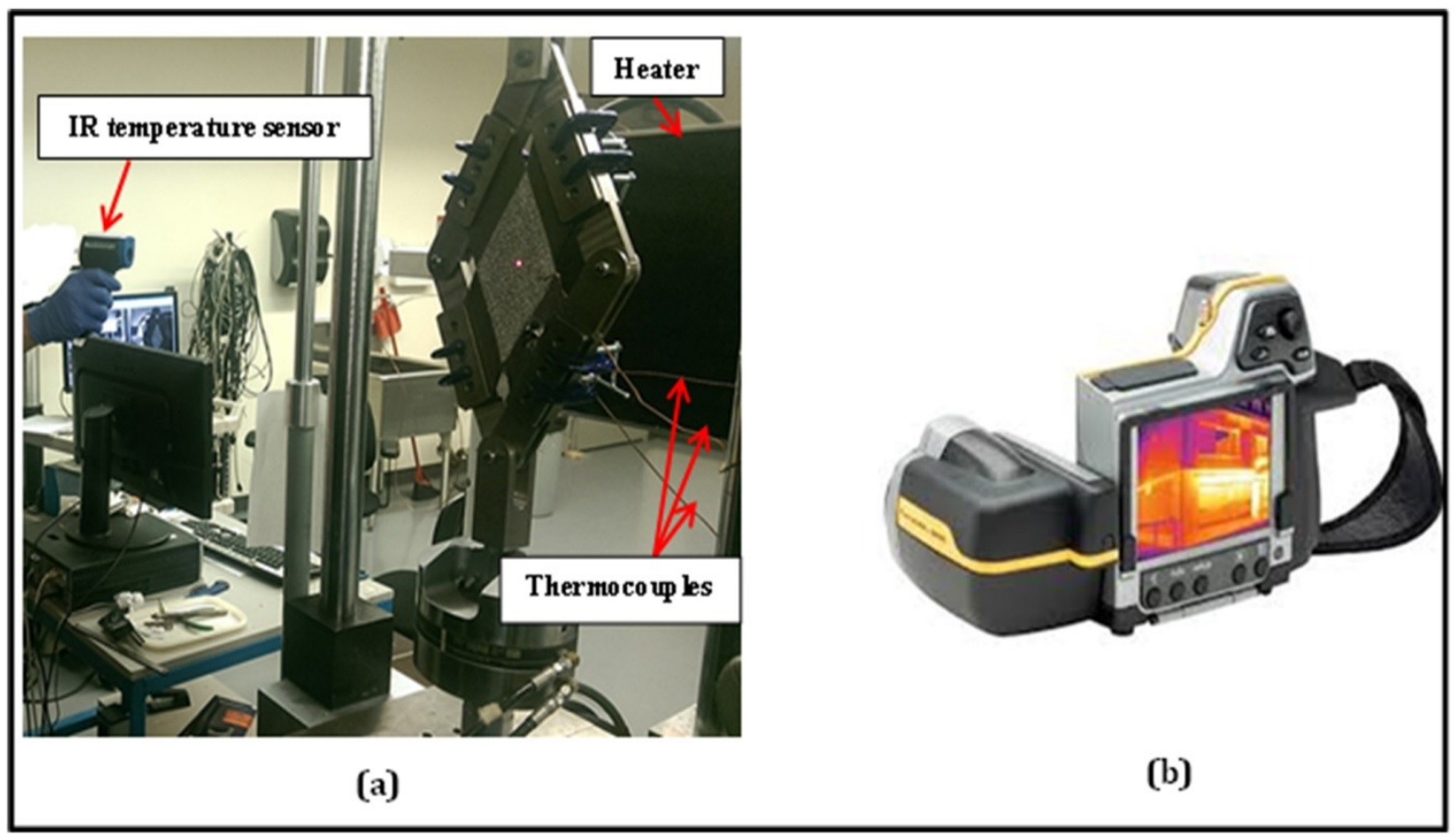

Figure 4.8 Photograph of the (a) Mastercraft $\# 57^{\circledR}$ IR temperature sensor and (b) FLIR T420® IR cameras (Courtesy: FLIR).

\section{FFLIR}

\begin{tabular}{l|l}
\hline Measurements & ${ }^{\circ} \mathrm{F}$ \\
\hline Sp1 & $193.3\left(89.6^{\circ} \mathrm{C}\right)$ \\
\hline Sp2 & $192.02\left(88.9^{\circ} \mathrm{C}\right)$ \\
\hline Difference & 1.28 \\
\hline Sp1-Sp2 & \\
\hline Parameters & \\
Emissivity & 0.95 \\
\hline Refl. temp. & $71.6^{\circ} \mathrm{F}$ \\
\hline
\end{tabular}

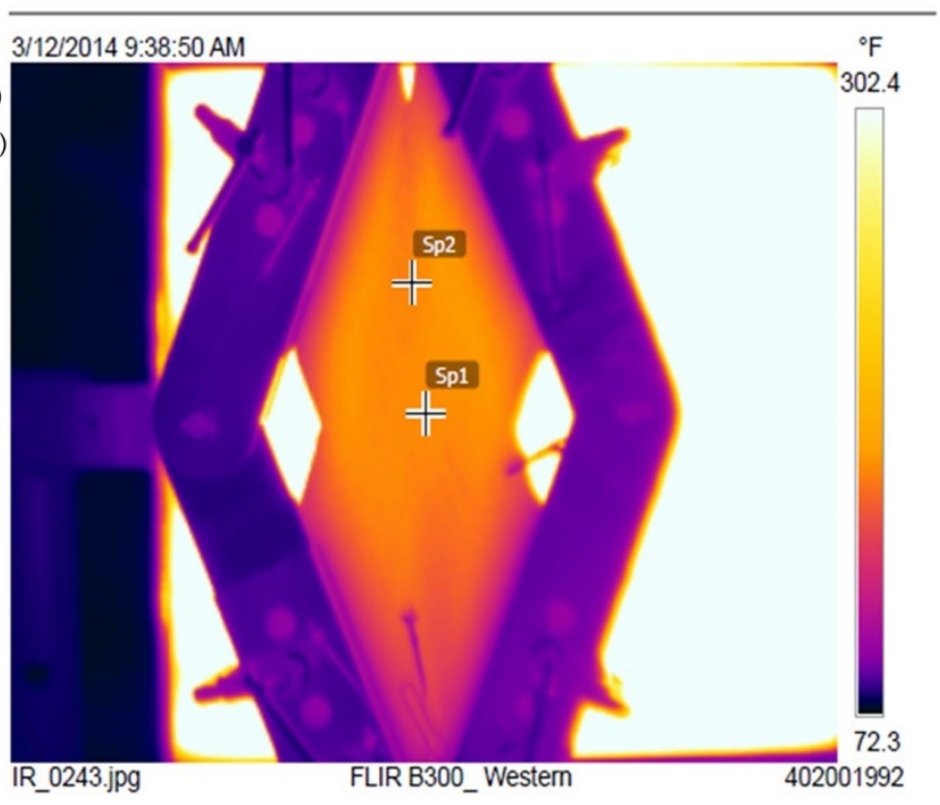

Figure 4.9 Temperature gradient from the FLIR® system. 


\subsection{Effect of temperature}

The actual forming operation takes place under high elevated temperature in order to ease the operation. The effect of operating temperature on the in-plane shear deformability of the fabric was investigated. Both $8 \mathrm{HS}$ and $5 \mathrm{HS}$ cross-ply laminates $[0,90]$ were investigated under constant cross head displacement rate of $20 \mathrm{~mm} / \mathrm{min}$ and varying operating temperatures $\left(50^{\circ} \mathrm{C}, 70^{\circ} \mathrm{C}\right.$ and $90^{\circ} \mathrm{C}$ ). Figures 4.10 and 4.11, the load Vs measured shear angle (using DIC) graph depicts the effect of operating temperature on the deformability of the fabric. The results show that the axial load decreases with the increase in temperature for both 8HS and 5HS samples, which is in accordance with the expected results. A similar result was found to be reported by B.Zhu et al. [3]. At lower temperature the load is seen to be high and later as the temperature increases the load is found to relatively decreasing. This behavior is attributed to the change in resin viscosity with the operating temperature as discussed earlier in the previous chapter. The results had shown us that during the initial stages, viscosity decreases with the increase in temperature. While later viscosity was found to drastically increase with the temperature. In this case, we are much curious regarding the first $10 \mathrm{~min}$, since the actual shear test (picture frame) was performed within this duration of time. To corroborate this the table 4.1 enlists the viscosity at varying operating temperatures during this period $(10 \mathrm{~min})$. Results indicate that in the initial stages, viscosity of resin at $100^{\circ} \mathrm{C}$ to be much lesser than at $90^{\circ} \mathrm{C}$ and $70^{\circ} \mathrm{C}$. Thus, on a whole, the rise in temperature decreases the amount of load required to shear the sample due to the transition of resin from un-gelled glassy state to a liquid state.

Table 4.1 Viscosity at elevated temperatures.

\begin{tabular}{ccc}
\hline Temperature $\left({ }^{\circ} \mathrm{C}\right)$ & Duration (min) & Viscosity (Pa.s) \\
\hline $70^{\circ} \mathrm{C}$ & 10 & $1.16 \times 10^{\wedge} 4$ \\
$90^{\circ} \mathrm{C}$ & 10 & $6.63 \times 10^{\wedge} 3$ \\
$100^{\circ} \mathrm{C}$ & 10 & $6.07 \times 10^{\wedge} 3$ \\
\hline
\end{tabular}




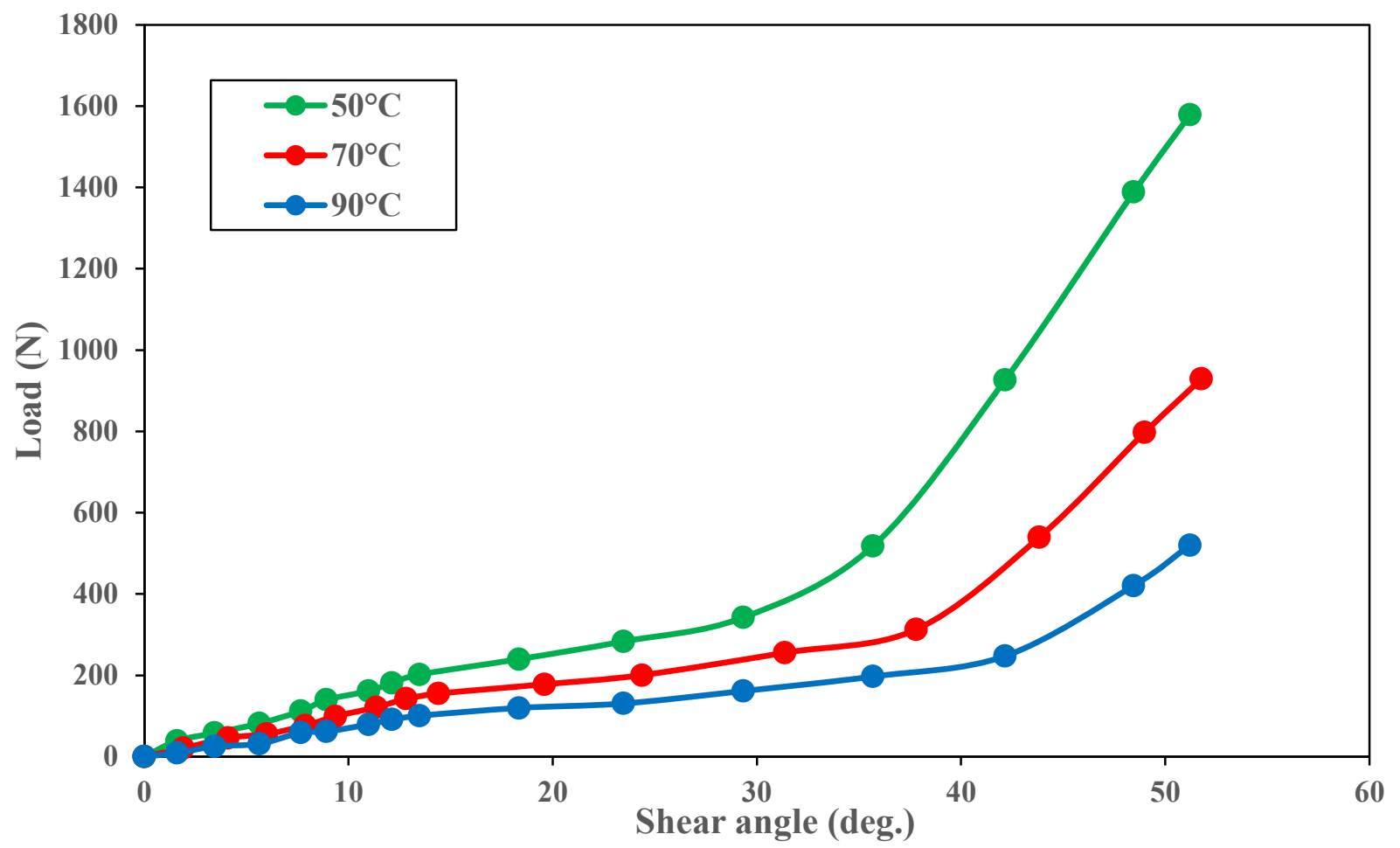

Figure 4.10 Picture frame on 8 harness at varying temperatures and $20 \mathrm{~mm} / \mathrm{min}$.

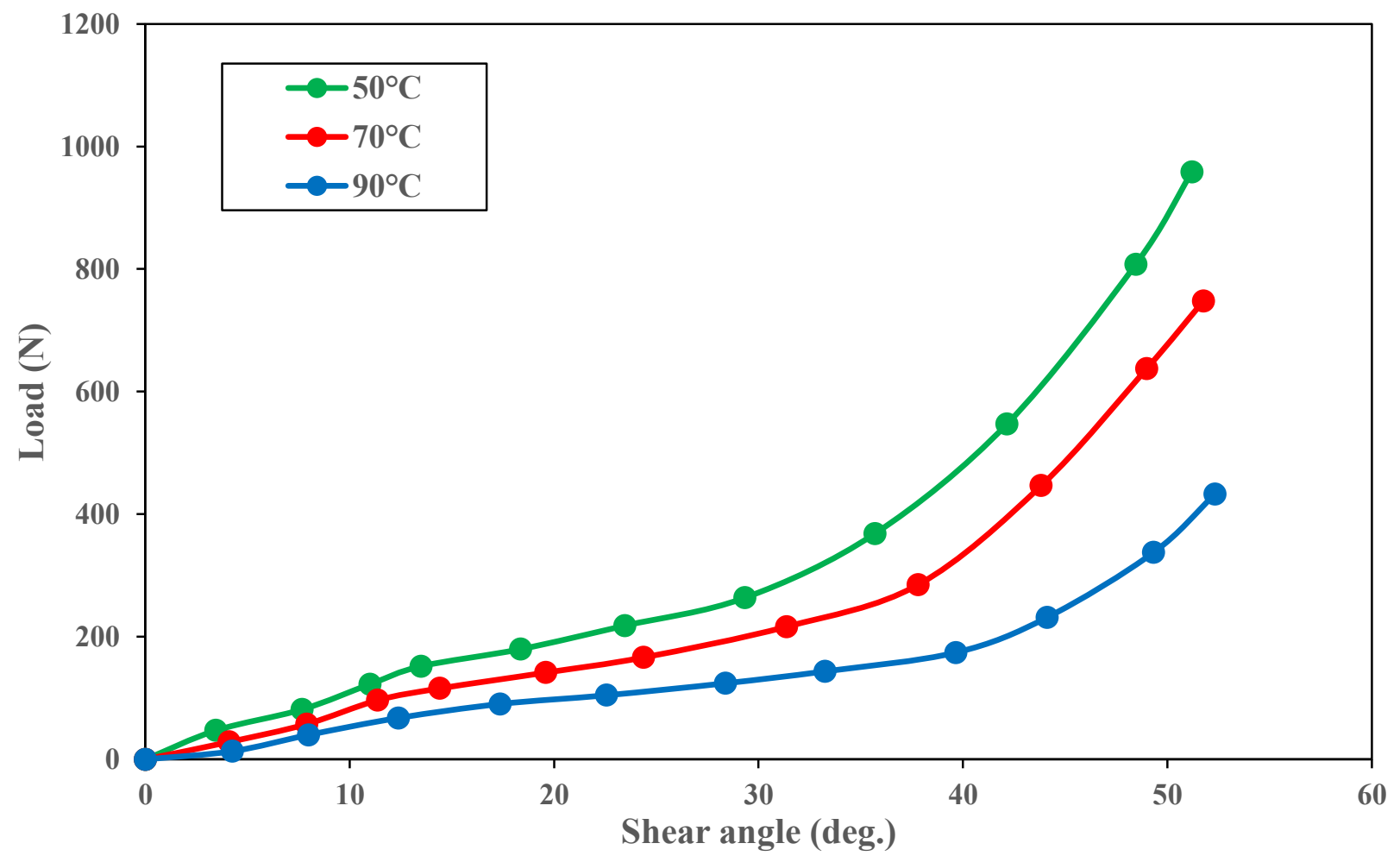

Figure 4.11 Picture frame test on 5 harness at varying temperatures and $20 \mathrm{~mm} / \mathrm{min}$. 
The same procedure used before to determine the locking angle is implemented here to determine the locking angles at elevated temperatures. Figure 4.12 compares the locking angles of both $8 \mathrm{HS}$ and $5 \mathrm{HS}$ samples at different elevated temperatures. Results show that, with the increase in operating temperature an increase in the locking angle is witnessed, which in turn would postpone the onset of wrinkling. In addition, the 8HS samples are found to have on a average $4.6 \%-7.3 \%$ higher locking angle than $5 \mathrm{HS}$ at all these conditions which suggest that 8 HS have better drapability than 5HS samples.

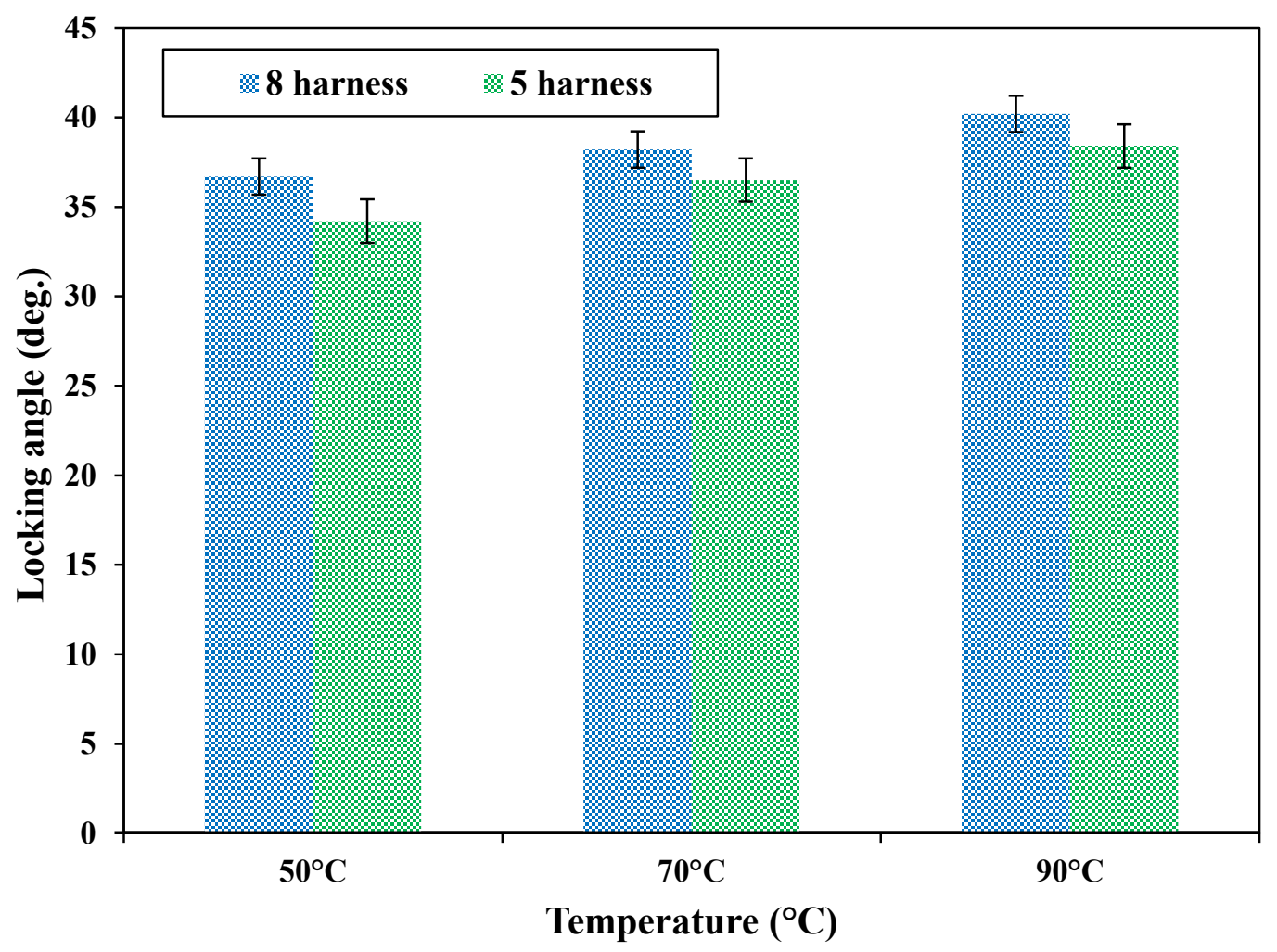

Figure 4.12 Locking angles of 8 harness and 5 harness at varying temperatures. 


\subsection{Effect of displacement rate}

In equal importance to the operating temperature the rate of forming is noticed to have a nominal effect on the forming process. The effect of forming rate on the in-plane shear deformability of

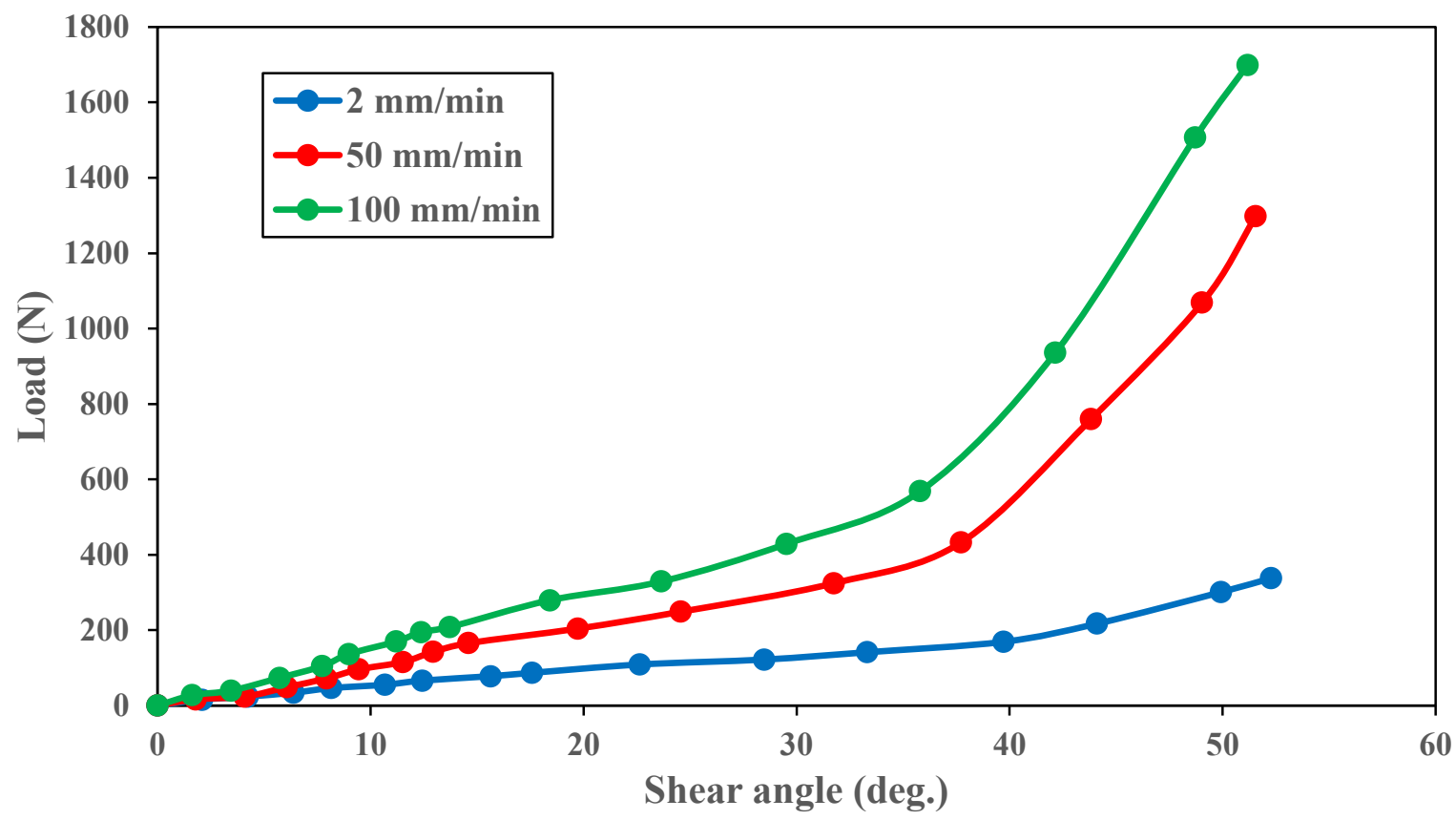

Figure 4.13 Picture frame test on 8 harness at varying ramp rates and $70^{\circ} \mathrm{C}$.

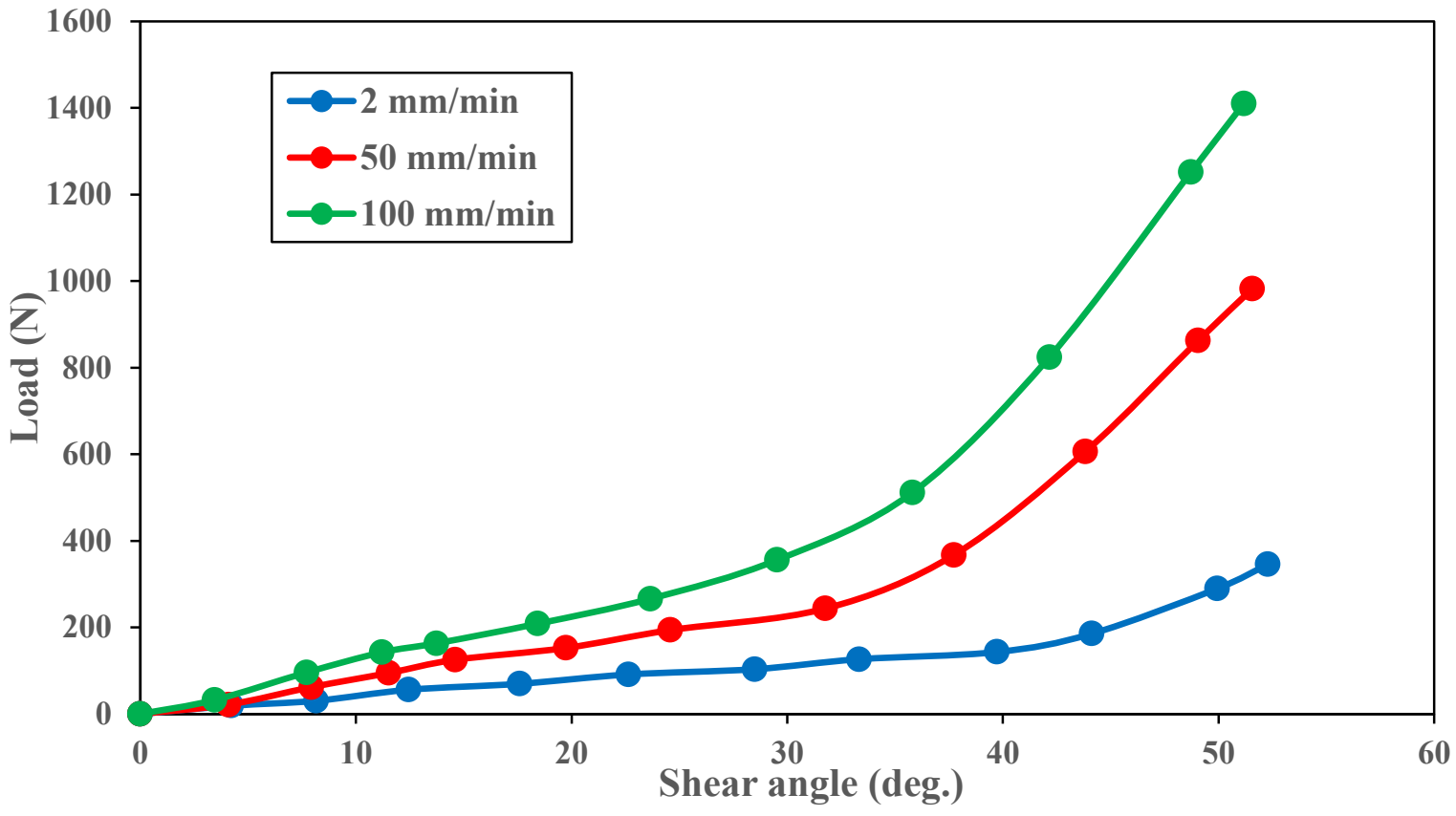

Figure 4.14 Picture frame test on 5 harness at varying ramp rates and $70^{\circ} \mathrm{C}$. 
the fabric at constant temperature $\left(70^{\circ} \mathrm{C}\right)$ and varying ramp rates $(2 \mathrm{~mm} / \mathrm{min}, 50 \mathrm{~mm} / \mathrm{min}, 100$ $\mathrm{mm} / \mathrm{min}$ ) are shown in Figure 4.13 and 4.14. It is evident from both graphs, for both 8HS and 5HS samples that increase in shear rate increases the load required to shear the sample at any given temperature. Photos taken during the test (see Figure 4.15) shows that wrinkling had started to initiate at almost half way through the test and became much severe at the latter stage.

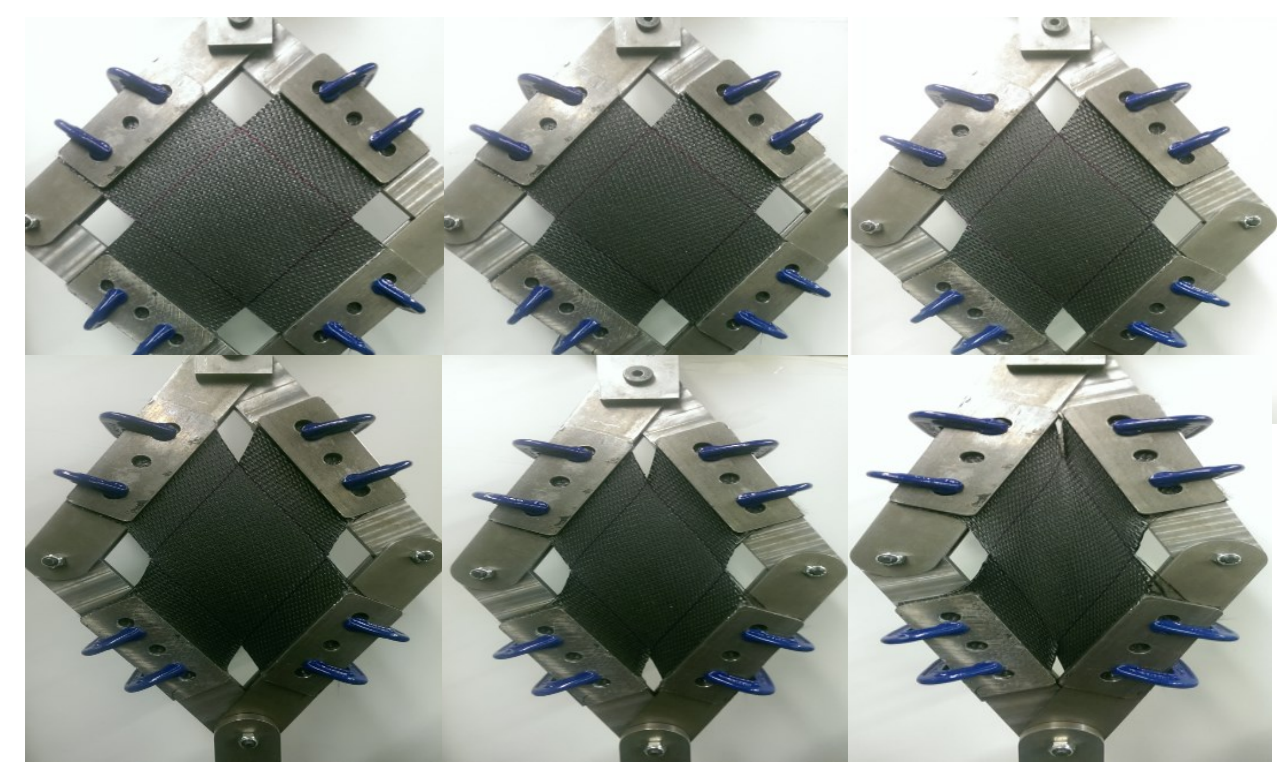

Figure 4.15 Photos taken during the picture frame test.

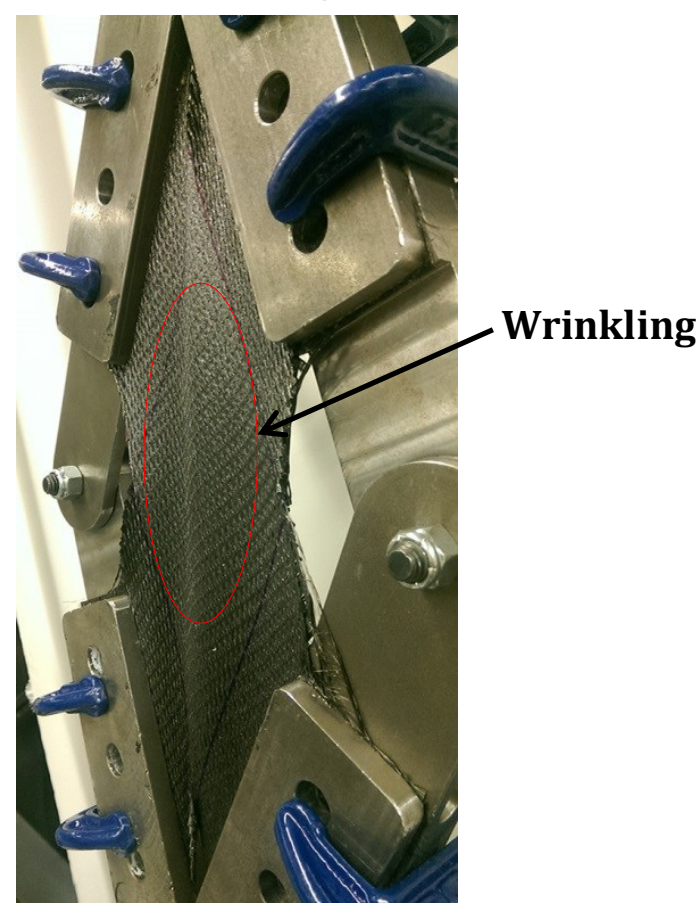

Figure 4.16, shows the side view of the final sample sheared at a rate of $100 \mathrm{~mm} / \mathrm{min}$ where prominent wrinkling is visible. For both $8 \mathrm{HS}$ and $5 \mathrm{HS}$ prepregs it is to be noted that, during the initial stages (up to a measured shear angle of $12^{\circ}$ ) there is found to be a $20 \%$ increase in load as the shear rate increases from 5 to $100 \mathrm{~mm} / \mathrm{min}$. But, later as the deformation proceeds (beyond $12^{\circ}$ shear angle) twice the increase in load is witnessed. Moreover, a similar response was also seen when sheared at room temperature. Figure 4.17 compares the locking angles of both 8HS and 5HS samples at

Figure 4.16 Onset of Wrinkling 
varying shear rates and $70^{\circ} \mathrm{C}$. Results show that locking angle decreases as the shear rate increase, which in turn resulted in serious wrinkling when sheared at high rate.

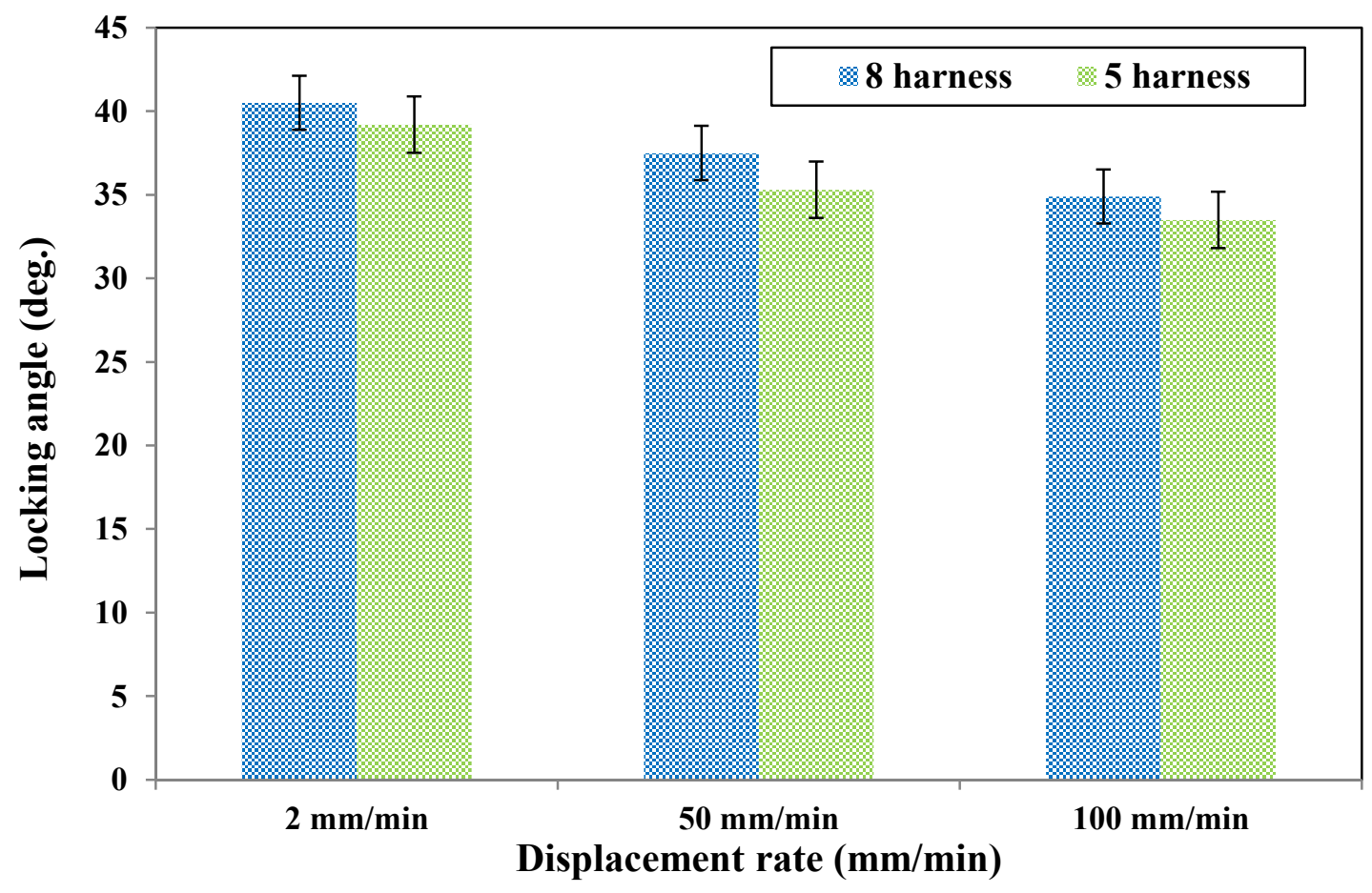

Figure 4.17 Locking angles of 8 harness and 5 harness at varying shear rates.

\subsection{Digital image correlation (DIC) analysis}

The picture frame rig was equipped with a 3D digital image correlation (DIC) system (Figure 4.18) which is capable of measuring the strain field and out of plane displacements at varying stages of deformation. The DIC is seen to be rigged with two high magnification cameras which is capable of capturing images during the test. In order to facilitate image analysis, random speckle patterns (white spots) were drawn on the surface of the sample. During the shear test, these patterns tend to deform from their original position to different point vectors. At the same time, the DIC starts to record the displacement of each facet point throughout the test. With the known reference vectors and the displacement vectors the strain at each stage can be calculated just by differentiating [57]. The major advantage that sets apart the DIC from other strain measuring devices is its ability of full field strain registration (overcoming the limitation of single point registration) and its ability to operate without being in contact with the sample surface $[57,58]$. 


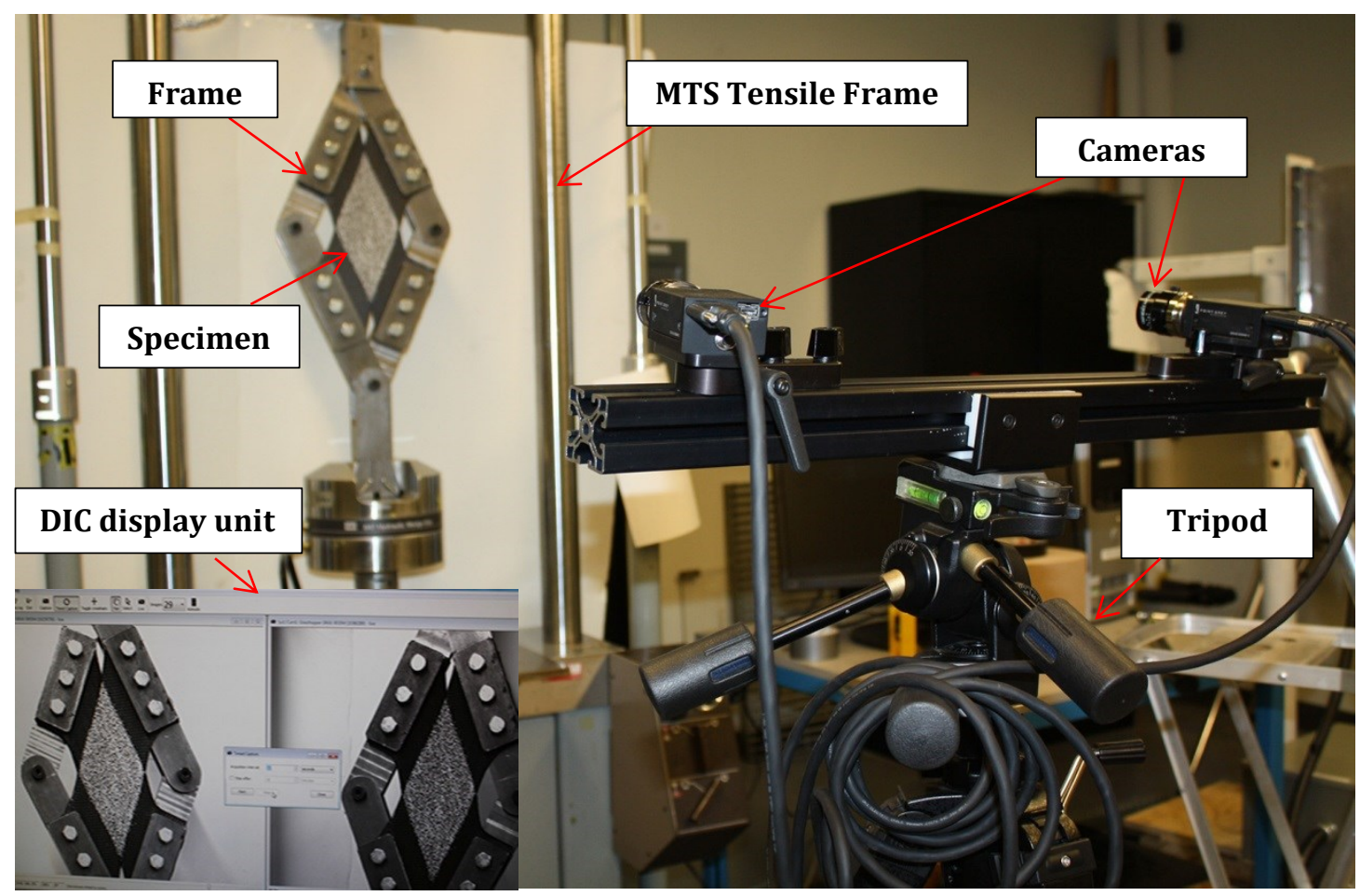

Figure 4.18 Experimental setup containing DIC and picture frame clamped on MTS.

\subsubsection{Strain results}

This section discuss regarding the variation of the various strain elements throughout the test process. The sequential images taken by the DIC were further post processed using VIC-2D correlated solution to determine the contour plot of the sample at the onset of wrinkling. The test was performed on 2- layered $8 \mathrm{HS}$ sample at an elevated temperature of $70^{\circ} \mathrm{C}$ and a rate of 20 $\mathrm{mm} / \mathrm{min}$. The contour plot of the axial strain $\left(e_{\mathrm{xx}}\right)$ at the end of the shear is shown in Figure 4.19 (a). As seen from the figure, the entire sample surface is seen to be under a compression (negative strain). This was expected since a tensile force is applied across the diagonally opposing ends (top side) of the frame. A maximum axial strain of $3415 \times 10^{-4}$ is seen to be observed at the two sides of the sample. This helps to predict the possible position of the onset of wrinkling (along the sides of the sample).

In contrast, the contour of the transverse strain $\left(e_{y y}\right)$ at the end of the shear shows the surface of the sample to be under tension (positive strain) throughout. This result is in accordance with the trellis behavior of the frame. A maximum transverse strain of $3340 \times 10^{-4}$ was witnessed at the 

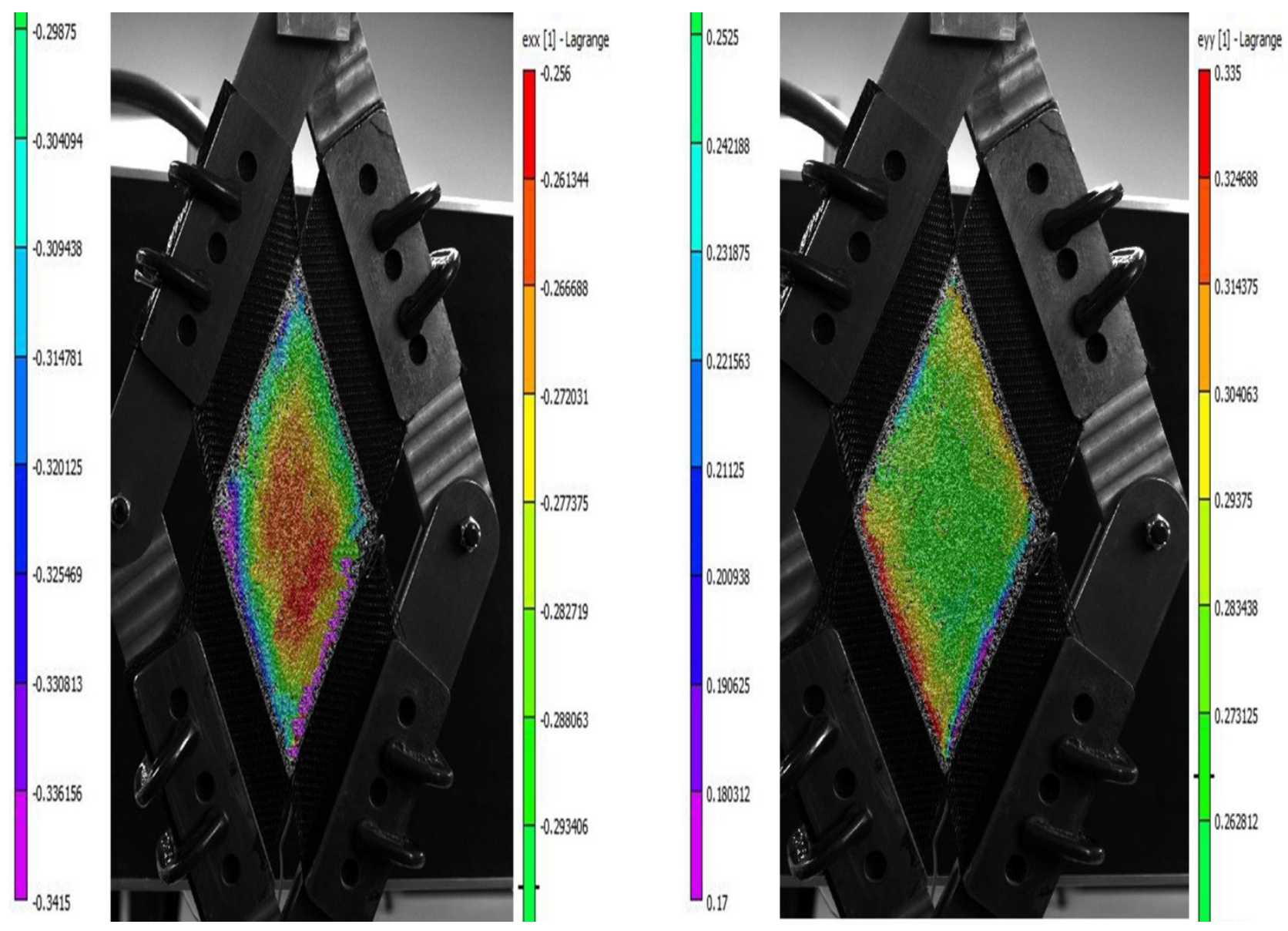

Figure 4.19 Strain fields at the end of the test (a) axial strain and (b) transverse strain.

side of the frame (see Figure 4.19 (b)). The contour plot of the shear strain field at various stages of deformation is plotted in Figure 4.20. Figure 4.20(a) shows that initially $\left(\gamma=12^{\circ}\right)$ shear strain is almost equal throughout the sample. But later, as the shear angle increases (see Figure 4.20 (b) and (c)) the magnitude of the shear strain is seen to increase throughout the sample. At a measured shear angle of $43^{\circ}$, the shear strain is seen to be maximum at the sides of the samples (the same location where the maximum axial strain was observed). This indicates, a possibility of onset of wrinkling near the side of the sample. However, VIC-2D ${ }^{\circledR}$ was not able to predict the exact point of onset of wrinkling. Earlier literature [59] had reported that VIC-2D ${ }^{\circledR}$ was not reliable to capture the onset of wrinkling. Therefore, further 3D analysis would help us to obtain a better idea regarding the exact location of onset of wrinkling. On account of performing 3D investigation, images from DIC were post processed using a VIC-3D ${ }^{\circledR}$ correlated solution. Visual inspection of the post processed images from DIC helps to plot the contour of the specimen- 


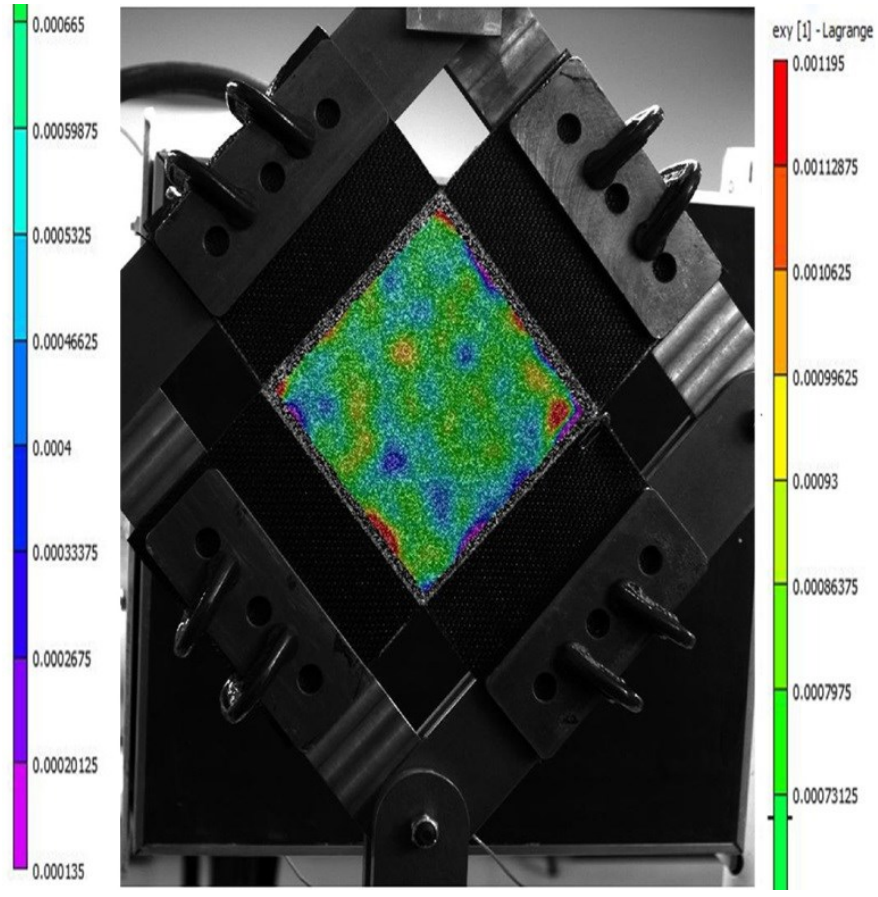

(a)
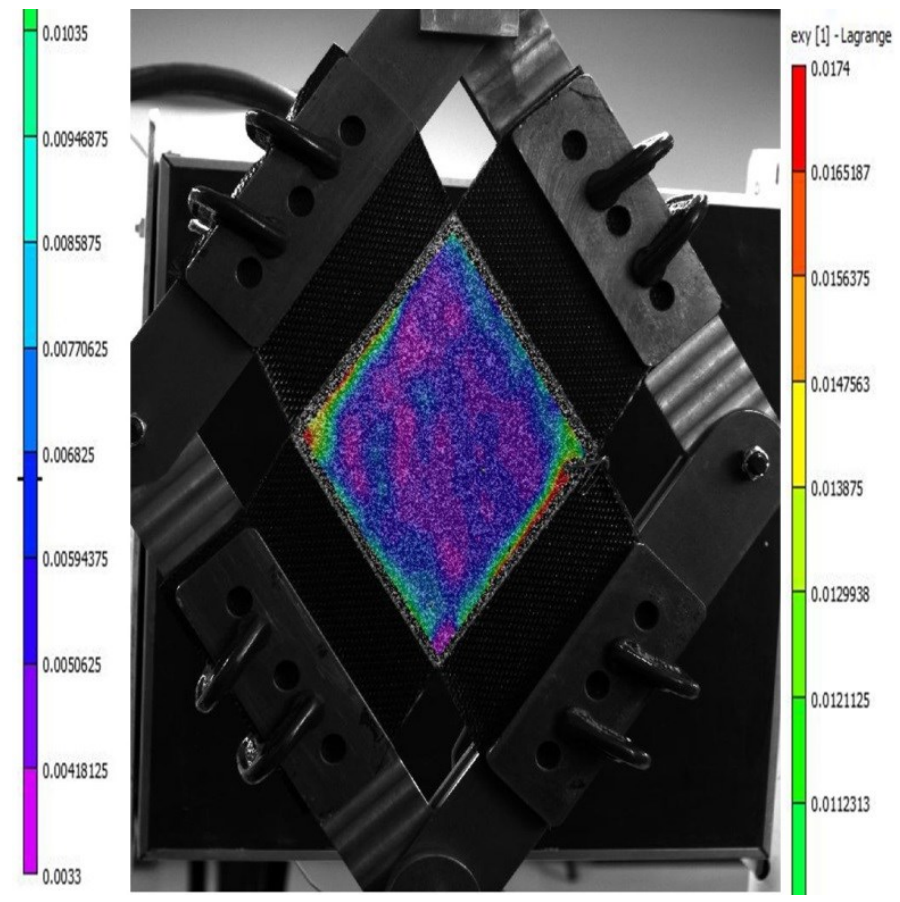

(b)

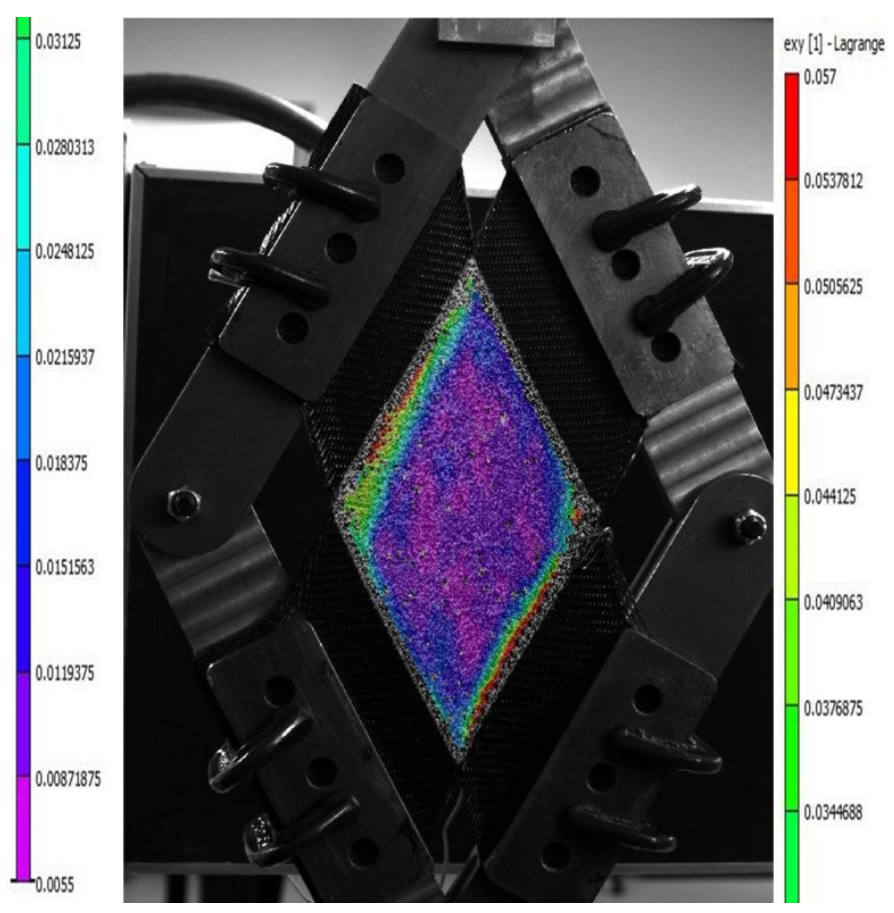

(c)

Figure 4.20 Shear strain field at varying measured shear angle (a) $\gamma \approx 8^{\circ},\left(\right.$ b) $\gamma \approx 18^{\circ}$ and (c) $\gamma \approx 37^{\circ}$. 

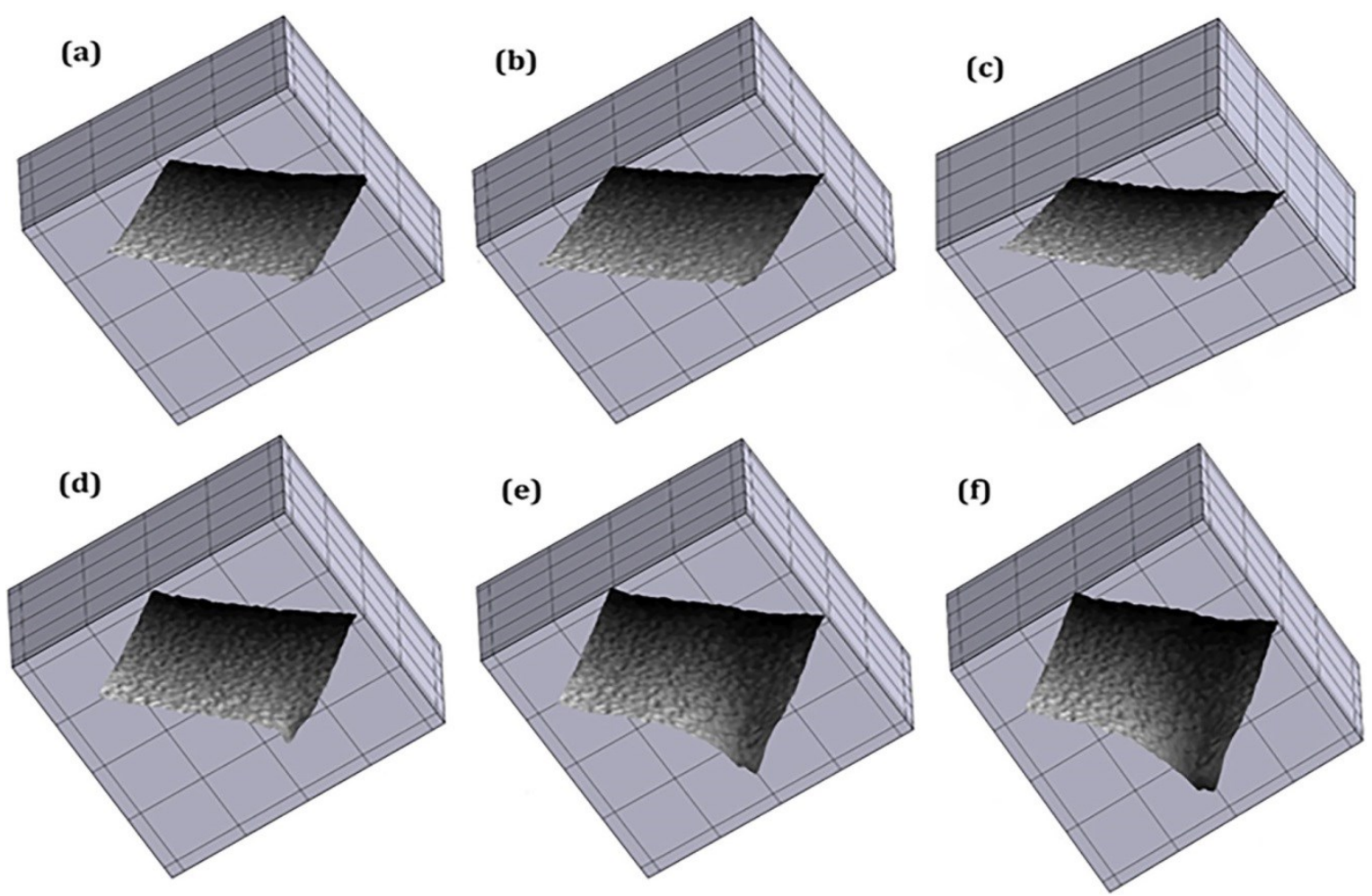

Figure 4.21 Post processed 3D images from DIC (a) $\gamma \approx 0^{\circ}$, (b) $\gamma \approx 8^{\circ}$, (c) $\gamma \approx 15^{\circ}$, (d) $\gamma \approx 27^{\circ}$, (e) $\gamma \approx 37^{\circ}$ and (f) $\gamma \approx 43^{\circ}$. [8HS prepreg at $\left.70^{\circ} \mathrm{C}\right]$.

at various stages of shear. Figure 4.21 (a) to (e) displays the sample undergoing shear as the deformation proceeds. It is evident distinctly in Figure 4.21 (e) that wrinkling initiates at the corners near the clamping area at a shear angle of $37^{\circ}$, and then propagates throughout the sample. This angle is noted to be $3.24 \%$ lower than the locking angle $\left(38.2^{\circ}\right)$ measured from the previous investigation. Even though the difference is not much, in depth analysis has revealed that actual wrinkling happens a bit earlier than the actual locking angle. However, in most other samples, especially samples tested at room temperature, the onset of wrinkling was observed exactly at locking angle. This variation might be due to the limitation of the DIC to operate at high elevated temperatures. This shows that locking angle can be only one of many reasons for wrinkling but not the sole factor [60]. This difference might also be due to other factors; layer compaction and ply bending which requires further investigation. However, on the whole; while forming it is much safer to stay within the locking angle to overcome the onset of wrinkling. Although the results seem good, one major disadvantage of this setup was that the DIC was not able to record the onset of wrinkling at all operating conditions, especially at high elevated 
temperatures $\left(90^{\circ} \mathrm{C}\right)$. This might be caused due to the distortion of the speckle pattern by the oozing of resin when operated at high temperatures. Therefore, it is preferably better to equip a DIC system for dry fabrics than for prepreg analysis.

\subsection{Influence of layer interaction}

Since, most forming operations are carried out on thicker samples to meet the requirements of day-to-day applications, the effect of the thickness (layer interaction) on the intra-ply shear behavior is to be investigated to obtain more reliable data. Tests were performed on $8 \mathrm{HS}$ samples at a constant temperature $\left(70^{\circ} \mathrm{C}\right)$ and displacement rate $(20 \mathrm{~mm} / \mathrm{min})$ varying the layer counts $(1$ layer, 2 layers and 4-layers). The laminates were sequenced as follow, 1- layer ([0]), 2- layer $([0,90])$ and 4 - layer $\left([0,90]_{\mathrm{s}}\right)$. In general, it is to be noted that areal density of the sample increases with the increase in layer count. By this it was made sure that a change in shear behavior with layer count (layer interaction) was characterized and plotted in Figure 4.22.

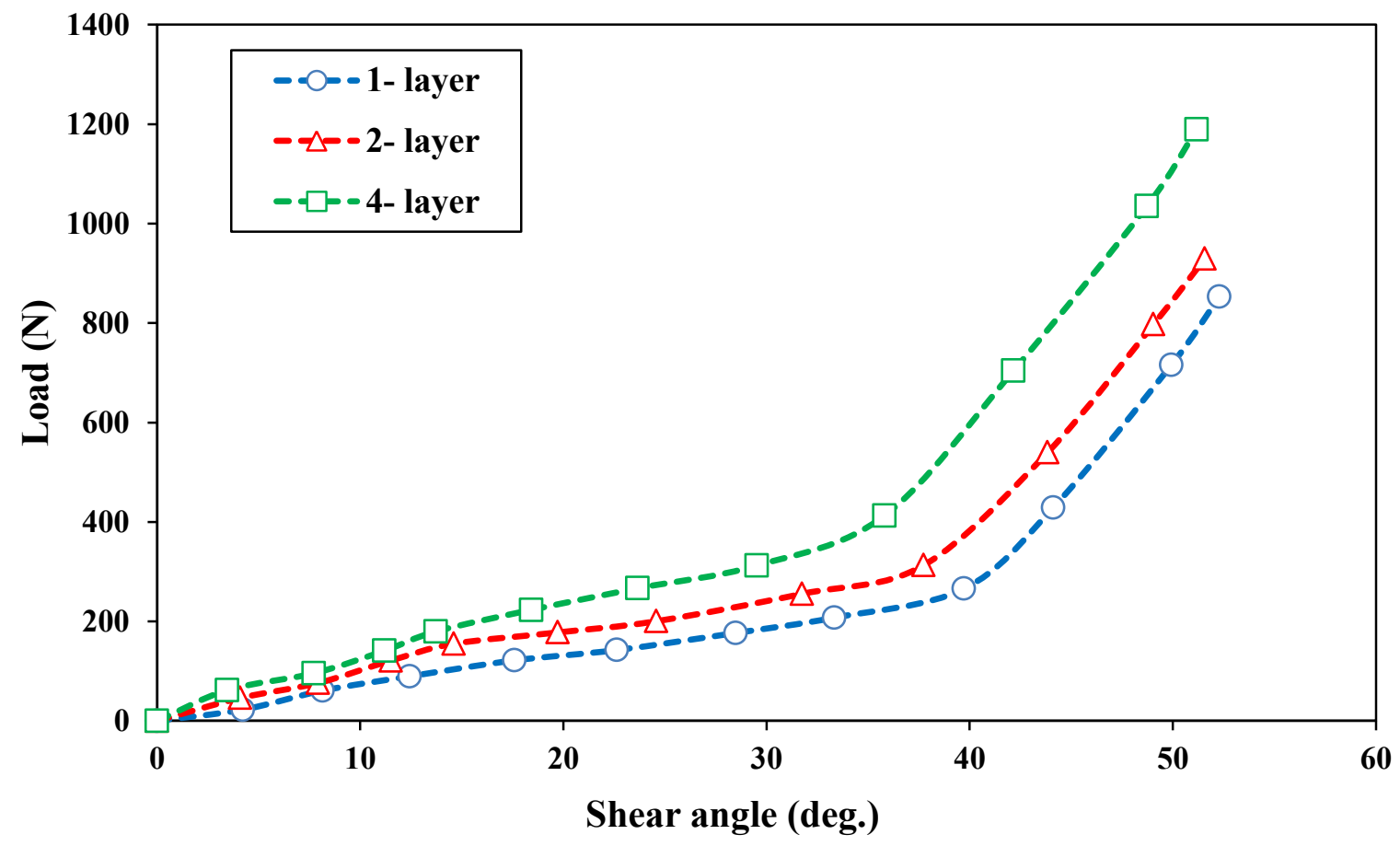

Figure 4.22 Effect of layer count on in-plane shear behavior.

It is witnessed that as the number of layers increase there is a considerable increase in load, due to the interaction of layers and nominal increase in areal density. Thicker samples (4-layers) with a high areal density require greater load for deformation and are seen to have lower locking angle 
as in Figure 4.23. In contrast, thinner samples (1- layer) with a lower areal density tend to have a higher locking angle. Thus, increase in layers results in interaction between the adjacent layers resulting in earlier interlocking. These observations confirm the findings of Taha et al. [45], who compared fibers of varying areal density. Hence, it can be concluded that lower the interaction between the layers ease the shear deformation which is eminent while forming.

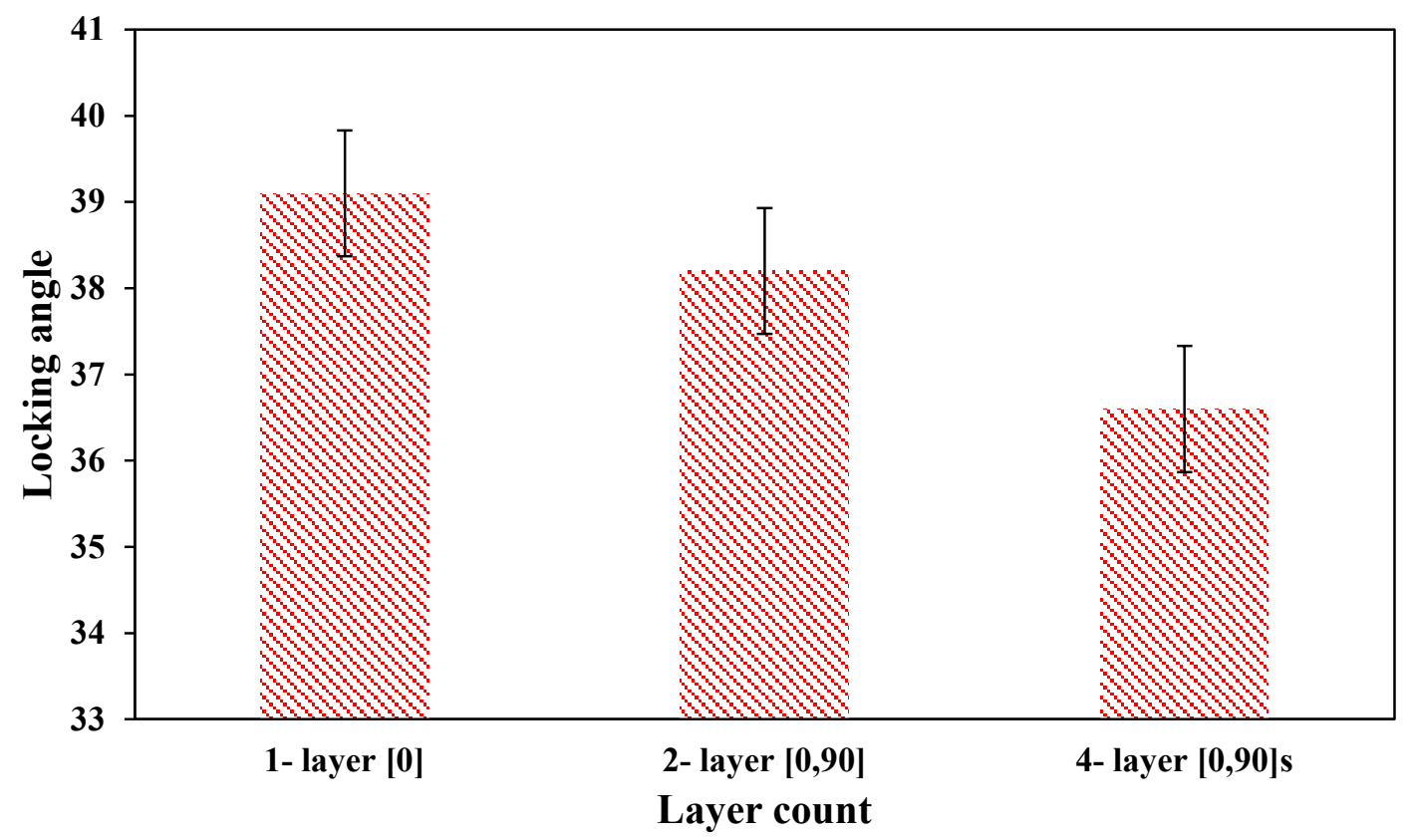

Figure 4.23 Locking angles of 8 harness at varying layer count.

\subsection{Samples Geometry Variation}

Throughout the shear process, a nominal change was observed in tow width and layer thickness. To investigate this variation, both layer thickness and tow width were measured using the digital caliper to an accuracy of $\pm 0.01 \mathrm{~mm}$ throughout the shear deformation.

\subsubsection{Thickness variation}

The thickness of the sample was measured at three different points on the specimen and on taking average of the results, a considerable variation was observed in thickness throughout the shear process. Results are reported based on tests performed on cross-ply [0,90] (5HS and 8HS) laminates at both room temperatures and elevated temperature $\left(70^{\circ} \mathrm{C}\right)$ as in Figure 4.24 . It is seen in Figure 4.24 that the thickness of the sample increases as the shear proceeds. At room temperature, Figure 4.24 (a), the thickness variation in 5HS is found to be higher than the $8 \mathrm{HS}$ sample. Initially, up to a shear angle of $13^{\circ}$ the difference in thickness between 8HS and 5HS is 
found to be small $\left(13.2^{\%}\right)$, but later beyond $13^{\circ}$, a drastic variation in thickness was observed between the samples. Finally, there was reported to be a $68.46 \%$ increase in initial thickness in $8 \mathrm{HS}$, while a $83.99 \%$ in $5 \mathrm{HS}$ sample at room temperature. The $5 \mathrm{HS}$ sample is seen to have increased almost twice its initial thickness; this behavior might be due to its high yarn width value which is to be discussed in detail in section 4.7. A similar observation was reported by Lomov et al. [47] who, while investigating the shear behavior of multi axial stitched preforms found that the thickness of the sample increases as the shear deformation proceeds in order to obtain a constant volume throughout the shear deformation.

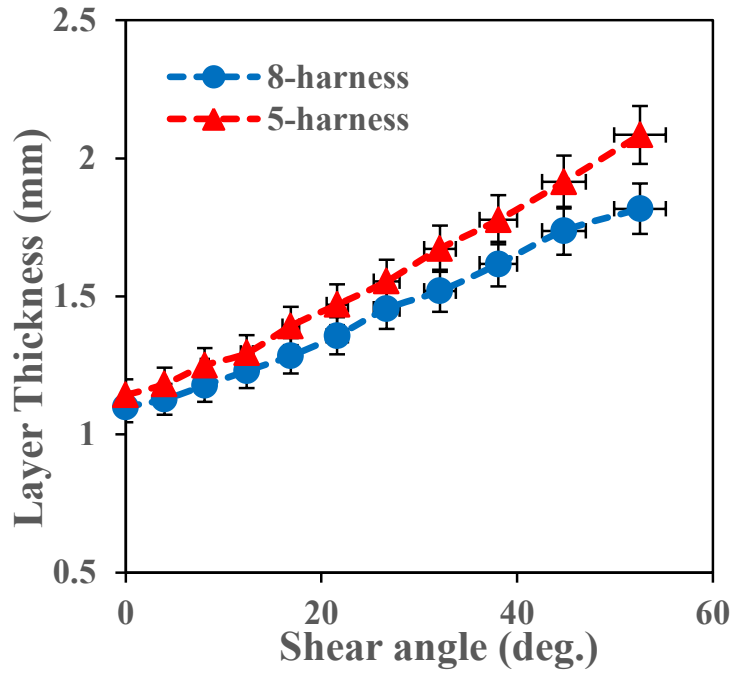

(a)

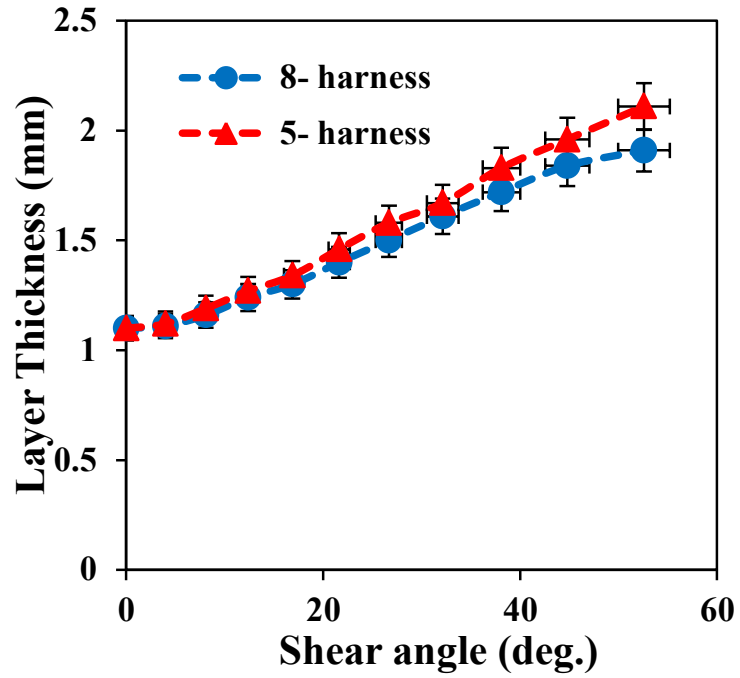

(b)

Figure 4.24 Variation of sample thickness in (a) room temperature and (b) $70^{\circ} \mathrm{C}$.

At elevated temperatures $\left(70^{\circ} \mathrm{C}\right)$ the same trend as in room temperature is witnessed. In this case, up to a shear angle of $33^{\circ}$, both samples are seen to have almost same thickness. Finally, there is a $79 \%$ increase in thickness for $8 \mathrm{HS}$ and a $92.1 \%$ for $5 \mathrm{HS}$ at elevated temperatures. This is found to be $10.54 \%$ higher than that at room temperature for $8 \mathrm{HS}$ and $8.11 \%$ higher for $5 \mathrm{HS}$ samples. Hence, based on the experimental results it is believed that the increase in thickness at elevated temperature is higher than when operated at room temperature. 


\subsubsection{Tow width variation}

In addition to the thickness variation of the samples, the change in tow width during the test is measured. Similar to the previous test, the yarn width was measured at three different points and average was taken. The variation of the yarn width with the measured shear angle at both room and elevated temperatures are discussed in Figure 4.25. In contrast to the layer thickness, the tow width is found to nominally decrease as the shear proceeds, for both $8 \mathrm{HS}$ and $5 \mathrm{HS}$ samples. In both the graphs, the measured yarn width is considered to be approximately low until a shear angle range between $33^{\circ}$ to $38^{\circ}$ (depending upon the material and operating conditions). Until this stage, the lateral compression is found to be low as the yarns have much space to rotate in between them. Beyond this point, it is observed to be a drastic decrease in the measured yarn width as the yarns come in contact with each other and tend to lock (locking angle). Finally, at the latter stages, between a shear angle range $48^{\circ}$ to $53^{\circ}$ (depending on the material and operating conditions) the yarn width is seen to stay constant with no further decrease, indicating the contact of adjacent yarns. This stage might indicate the onset of wrinkling [2]. Thus, we could see that yarn width variation serve as the one of the major reason for the onset of wrinkling.

Theoretically, Zhu et al. [2] proposed a relation between the shear angle and yarn width to determine the calculated yarn width,

$$
\mathrm{w}=\mathrm{w}_{0} \cos \gamma
$$

Where, ' $w$ ' is the calculated yarn width, ' $w_{0}$ ' is the initial yarn width and ' $\gamma$ ' is the measured shear angle. The comparison between the measured and calculated yarn widths at various shear angle is seen in Figure 4.25. At room temperature, Figure 4.25 (a), up to a shear angles of $33^{\circ}$ (8HS) and $29^{\circ}$ (5HS) the calculated yarn width is noted to be almost equal to the measured width. Beyond this, the calculated yarn width is seen to deviate largely from the measured yarn width. According to Zhu et al. [2], this point of deviation marks the onset of locking (locking angle). But, in this case experimentally the locking was witnessed at shear angles $35.5^{\circ}$ (8HS) and 33.4 (5HS). Even though the results don't exactly match, the variation is not so large (within $4.4 \%$ of variation). While at elevated temperature (see Figure 4.25 (b)), the yarn width variation

is observed to follow the same trend as the former. In this case, the variation between the measured and calculated yarn width is seen to be much larger. 


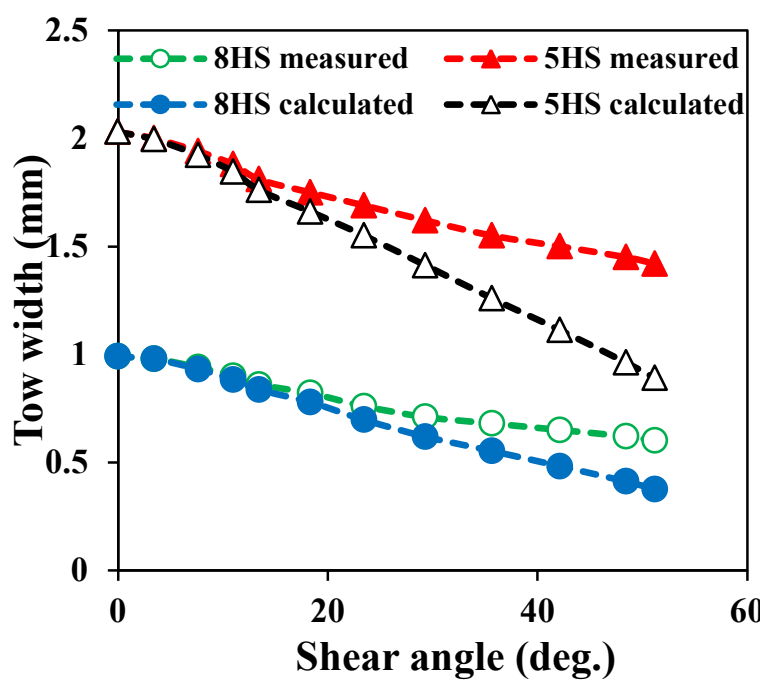

(a)

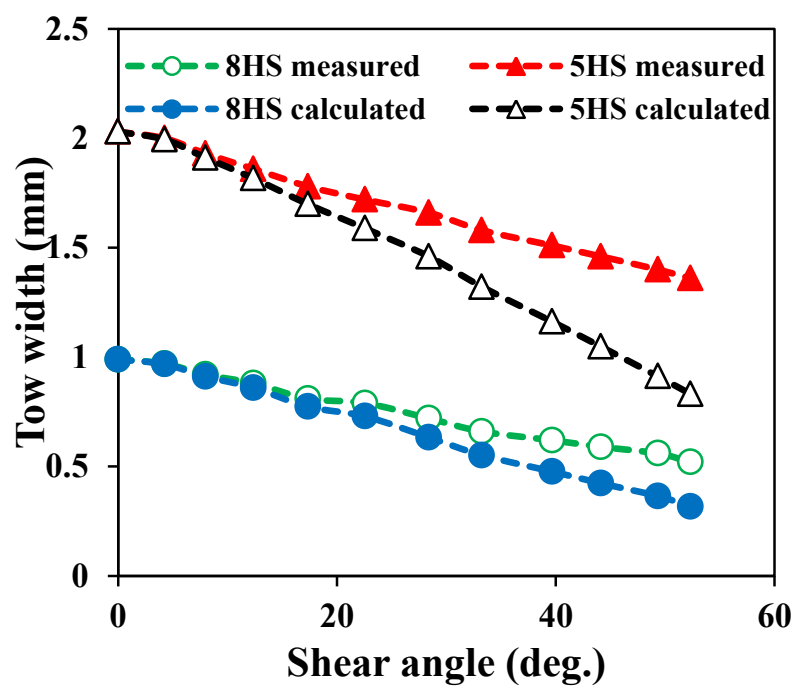

(b)

Figure 4.25 Variation of yarn width in (a) room temperature and (b) $70^{\circ} \mathrm{C}$.

In addition, on a whole, a $19 \%$ decrease in yarn width is observed for $8 \mathrm{HS}$ and a $25 \%$ decrease for $5 \mathrm{HS}$ at room temperature. Parallely, at elevated temperatures, a $27 \%$ decrease is witnessed for $8 \mathrm{HS}$ and a $34 \%$ decrease for $5 \mathrm{HS}$ samples. This confirms that the yarn width reduction at elevated temperature is much more than at room temperature. This behavior of prepreg requires further investigation which is discussed in detail in section 4.8 .

\subsection{Microscopic analysis}

Microscopic analysis was performed in order to visualize the mechanism of tow deformation within the fiber during the shear process. Both optical microscope and scanning electron microscope (SEM) were used to perform a detailed analysis. Specimens for the microscopic observation were prepared as follows. Firstly, the sheared samples were cured at $120^{\circ} \mathrm{C}$ for 3 hours in oven to restrict any distortion in the sheared geometry. Then, specimen of size $20 \times 15$

$\mathrm{mm}^{2}$ was cut from the cured samples and placed inside a mold. Finally, a mixture of resin (Epon $828^{\circledR}$ ) and hardener (Epikure $3046^{\circledR}$ ) mixed at a ratio 2:1, were poured into the mold and cured for 24 hours at room temperature, then for 1 hour at $100^{\circ} \mathrm{C}$. Further to facilitate keen observation surface specimens were grinded and polished by a Mecatech $234{ }^{\circledR}$ polishing machine as shown in Figure 4.26. The system was operated under at an optimum speed of 300 RPM with a force of 20 newtons applied to hold the samples to enable uniform grinding of the samples. Varying grades of finer paper $(180 \mu, 300 \mu, 600 \mu)$ were used for grinding and finally the samples were 
fine-tuned by diamond paste $(9 \mu, 3 \mu)$-polishing solution. By this it was made sure that the observation surface was free of any scratches and dirt to enable clear observation.

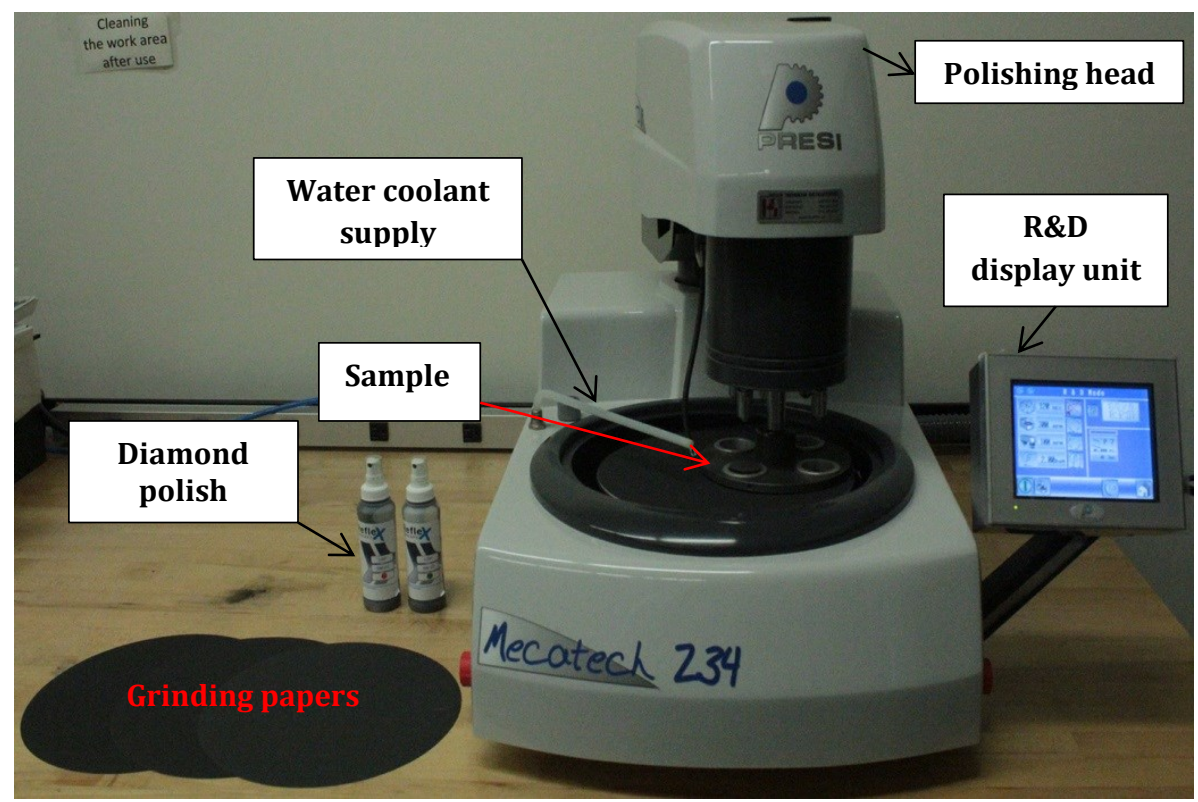

Figure 4.26 Mecatech 234® polishing machine.

Microscopic investigation on 5HS satin weave fabric was elaborately discussed by Chang et al. [61]. However, to date not much work has been conducted to characterize the change in tow geometry of OOA based prepregs during the shear process. Hence, microscopic observation was applied to measure the tow geometry such as: tow thickness ( $\mathrm{t}$ ), tow width (W), tow spacing $(\Delta \mathrm{X}, \Delta \mathrm{Y})$, amplitude (A) and wavelength $(\kappa)$ based on the same procedure followed by Chang et.al [61]. These parameters are schematically illustrated in Figure 4.27.

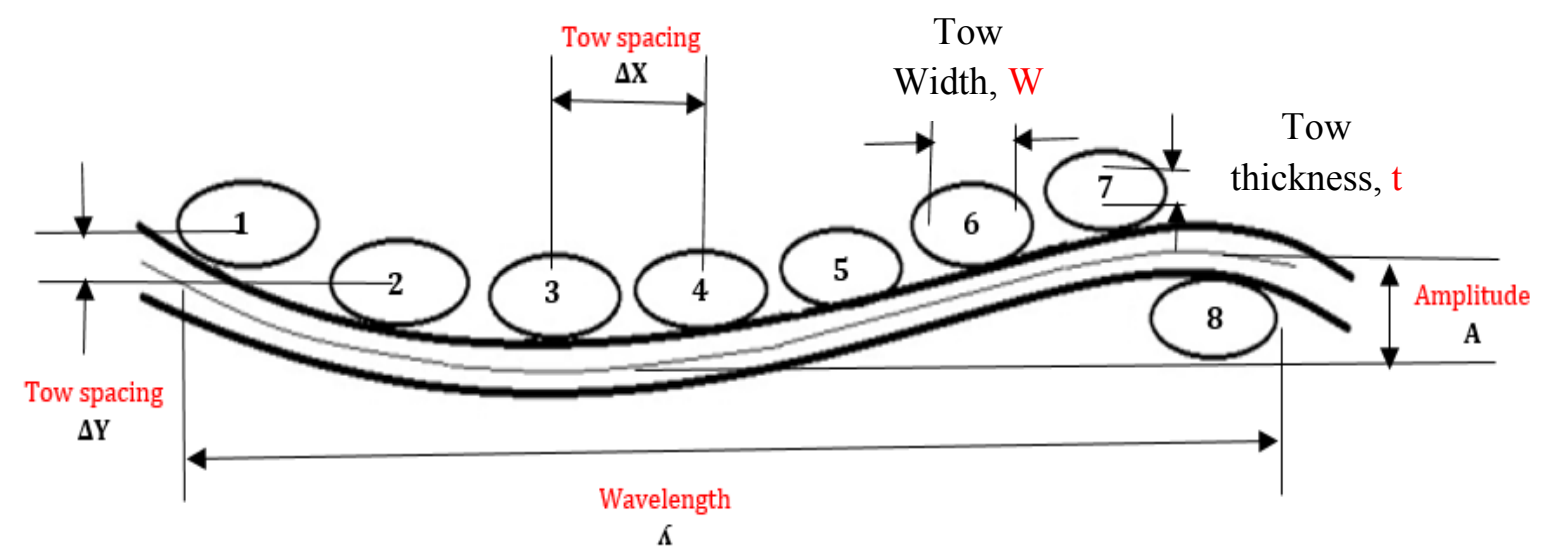

Figure 4.27 Tow geometry [61]. 


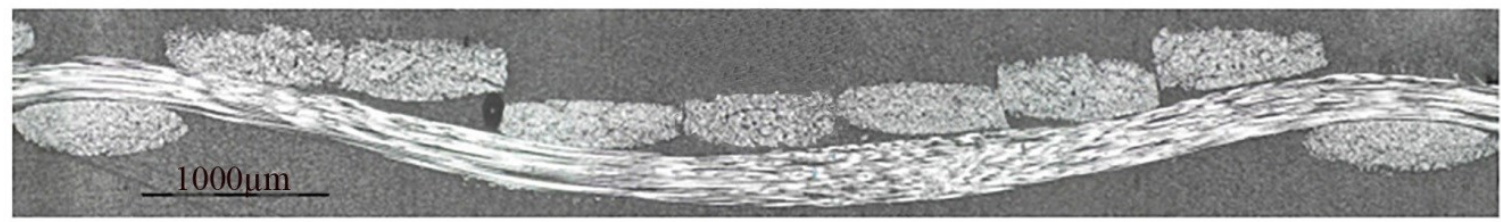

(a)

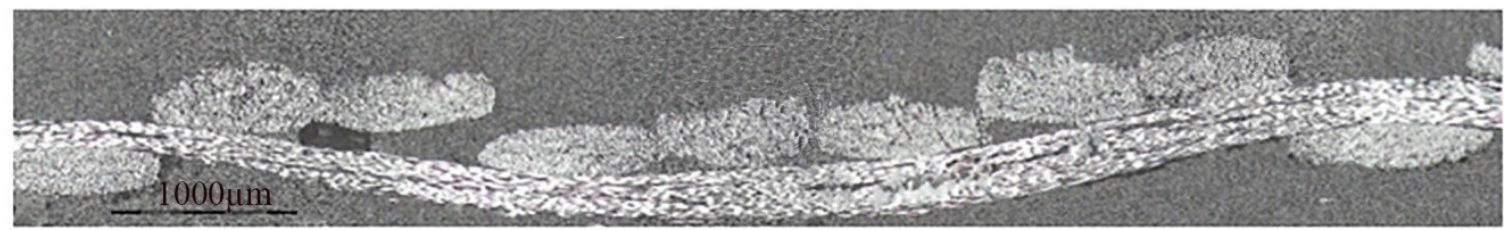

(b)

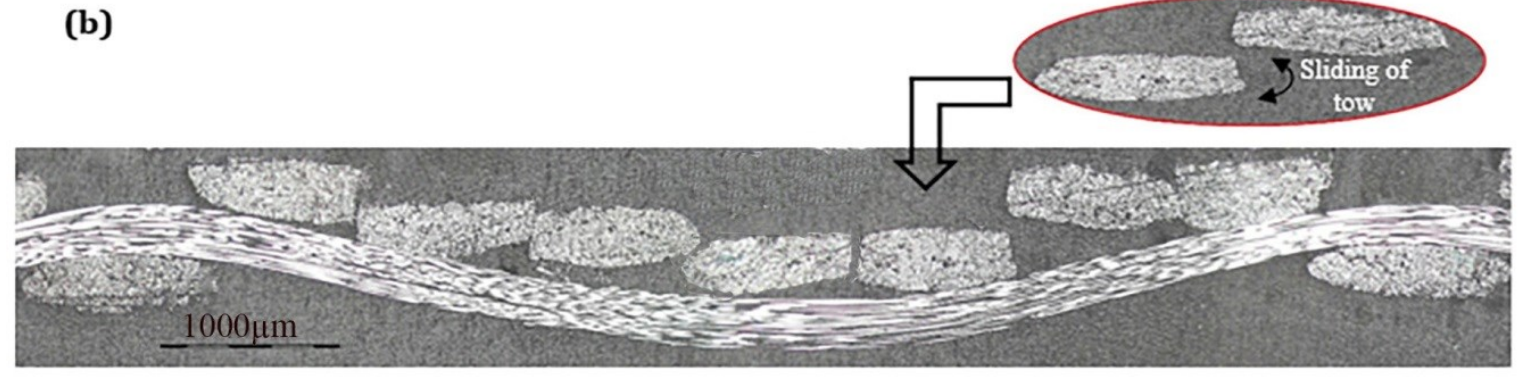

(c)

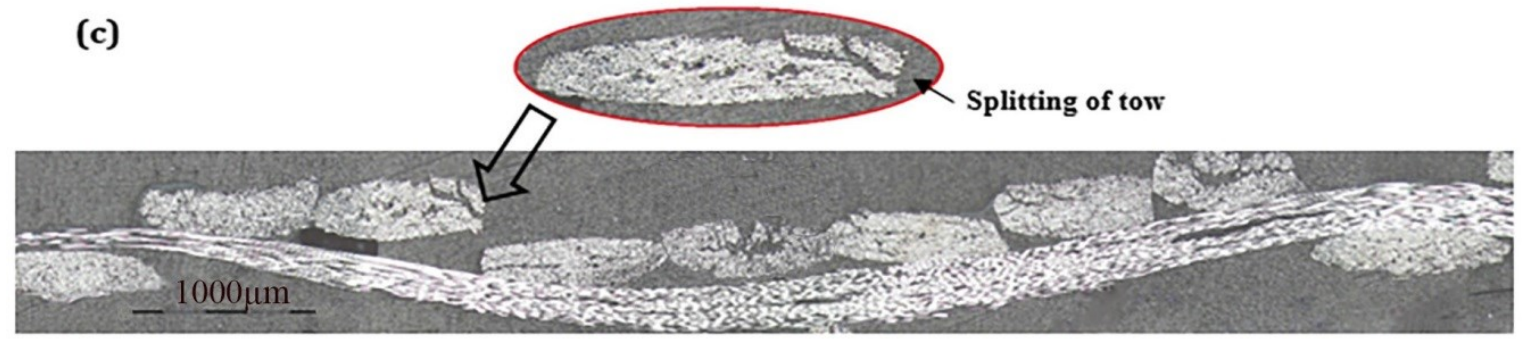

(d)

Figure 4.28 Microscopic image of the tow structure at various shear angles of 8HS samples (a) initial specimen, (b) $12^{\circ}$ sheared structure, (c) $24^{\circ}$ sheared structure and (d) $52^{\circ}$ sheared structure.

Figure 4.28, shows the microscopic images (5x magnification) during the various stages of shear deformation for the 8HS samples. At the start before shear, Figure 4.28(a), an orderly distribution of tows is witnessed; all tows are found to be of the same shape and evenly spaced from each other. While during the initial stages of shear $\left(\gamma \leq 20^{\circ}\right)$, Figure 4.28 (b and c), tows tend to relocate themselves by sliding over each other. But, at the later stages $\left(\gamma \geq 35^{\circ}\right)$ tows are seen to come in close contact with each other which eventually led to the split of tows [61] as shown in Figure 4.28(d). This phenomenon is found to be observed, due to deforming of the sample beyond its shear zone, which has led to the densification of the sample and in turn to the splitting of tows. Also on keen observation, a significant change in shape of tows is seen 
through, until the end of the shear process [61]. In contrast, there is not much change in tow geometry with respect to transverse tow ( $8^{\text {th }}$ tow) throughout the shear deformation. A similar observation was also reported in the literature [61]. This indicates that longitudinal tows are the ones which contribute more to the shear locking process.

\subsubsection{SEM analysis of samples}

SEM is used to observe the fine surfaces of the tow structure at high magnification. The Hitachi $\mathrm{S}-3400 \mathrm{~N}^{\circledR}$, a powerful SEM analyzer is used in this case to perform the observations.
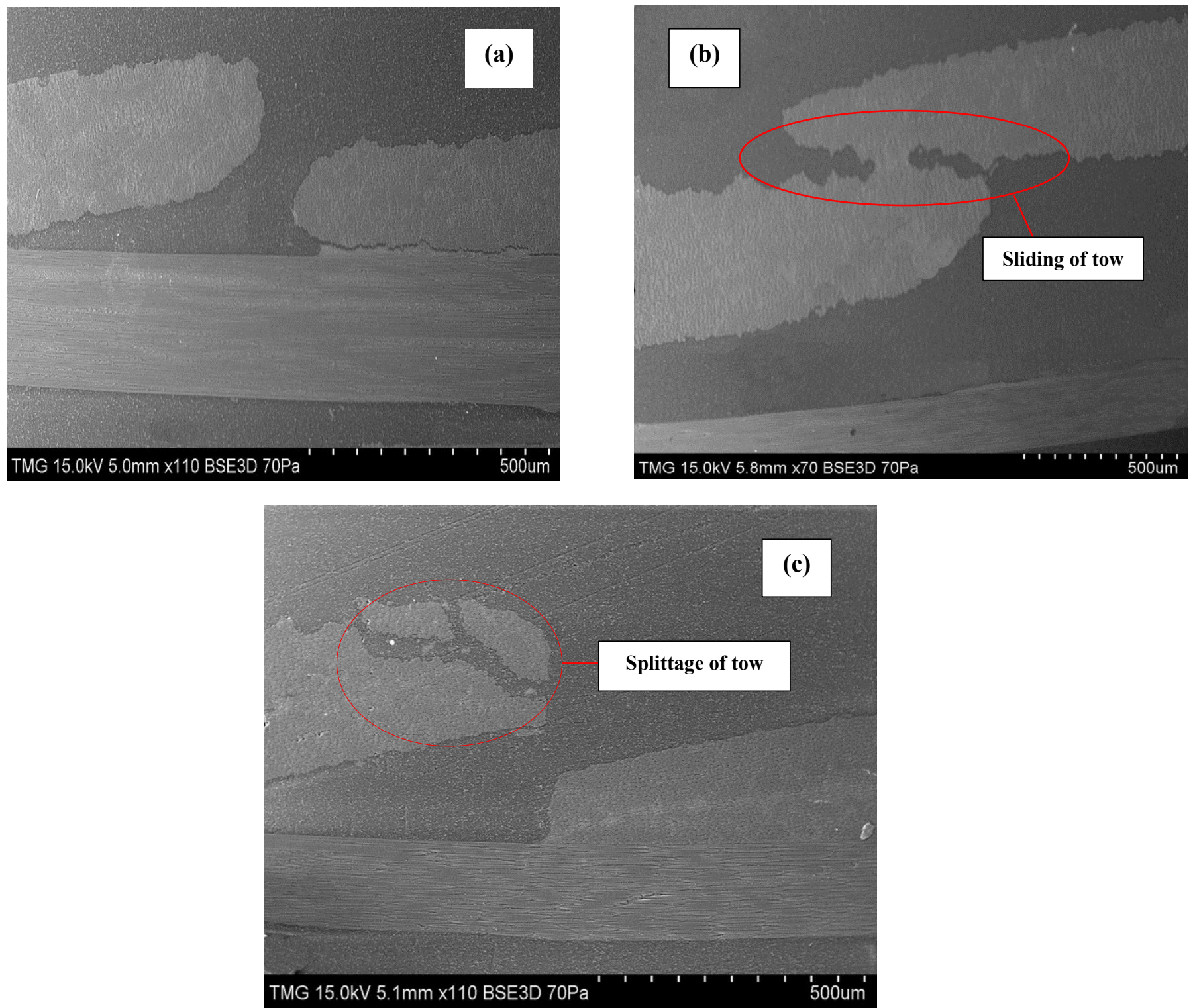

Figure 4.29 SEM images at various stages of shear (a) before shear, (b) $24^{\circ}$ sheared structure and (c) $52^{\circ}$ sheared structure (end of shear). 
The tests were performed at a variable pressure of $70 \mathrm{~Pa}$ with an alternating current of $15 \mathrm{kV}$. By this, the quality of the image obtained was much better than when performed at high vacuum (HVAC) conditions. The SEM images (Figure 4.29) taken at various stages of shear are quite similar to the results observed by an optical microscope. The sliding of tows during the shear process, $\left(\gamma=24^{\circ}\right)$ is clearly visible at high magnification (Figure 4.29 (a)). In turn, close contact between the tows had eventually led to the breakage of tows as in Figure 4.29 (c).

\subsubsection{Variation of structural parameters}

Tow geometry measured using the optic microscope at various stages of shear are listed in Table 4.2. From the microscopic images (see Figure 4.28) it was evident that the adjacent yarns come in contact with each other as the shear proceeds. In accordance with this, the results in Table 4.2

Table 4.2 Tow geometry parameters (8- harness)

\begin{tabular}{|c|c|c|c|c|c|c|c|}
\hline S. No & $\begin{array}{l}\text { Shear } \\
\text { angle } \\
\text { " } \gamma " \\
\text { (deg.) }\end{array}$ & $\begin{array}{c}\text { Tow } \\
\text { spacing } \\
" \Delta X " \Delta \% \\
(\mu \mathrm{m})\end{array}$ & 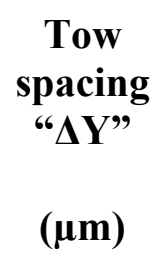 & 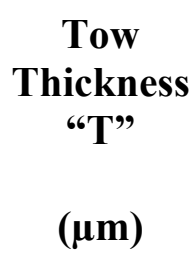 & $\begin{array}{c}\text { Tow } \\
\text { Width } \\
\text { "W" } \\
(\mu \mathrm{m})\end{array}$ & $\begin{array}{l}\text { Amplitude } \\
\text { “A" } \\
(\mu \mathrm{m})\end{array}$ & $\begin{array}{c}\text { Wavelength } \\
\text { “م" } \\
(\mu \mathrm{m})\end{array}$ \\
\hline 1. & $0^{\circ}$ & 1245.72 & 208.25 & 134.69 & 991.90 & 542.16 & 9932.81 \\
\hline 2. & $12^{\circ}$ & 1218.46 & 219.37 & 149.47 & 929.70 & 574.22 & 9722.71 \\
\hline 3. & $24^{\mathrm{o}}$ & 1189.90 & 249.21 & 167.53 & 889.36 & 582.15 & 9569.37 \\
\hline 4. & $52^{\circ}$ & 1181.58 & 282.71 & 177.96 & 852.46 & 662.46 & 9447.79 \\
\hline
\end{tabular}

shows that $\mathrm{x}$-directional tow spacing $(\Delta X)$ decreases with the increase in shear while the $\mathrm{y}$ directional tow spacing $(\Delta Y)$ increases. Further the tow thickness is seen to increase with the rise in shear while the tow width decreases as the shear proceeds. Graphically from Figure 4.30 (a) and (b) it can be further observed that there is a $32.12 \%$ increase in tow thickness while there is a $12.26 \%$ decrease in tow width at the end of the deformation. This due to the fact that as shear 

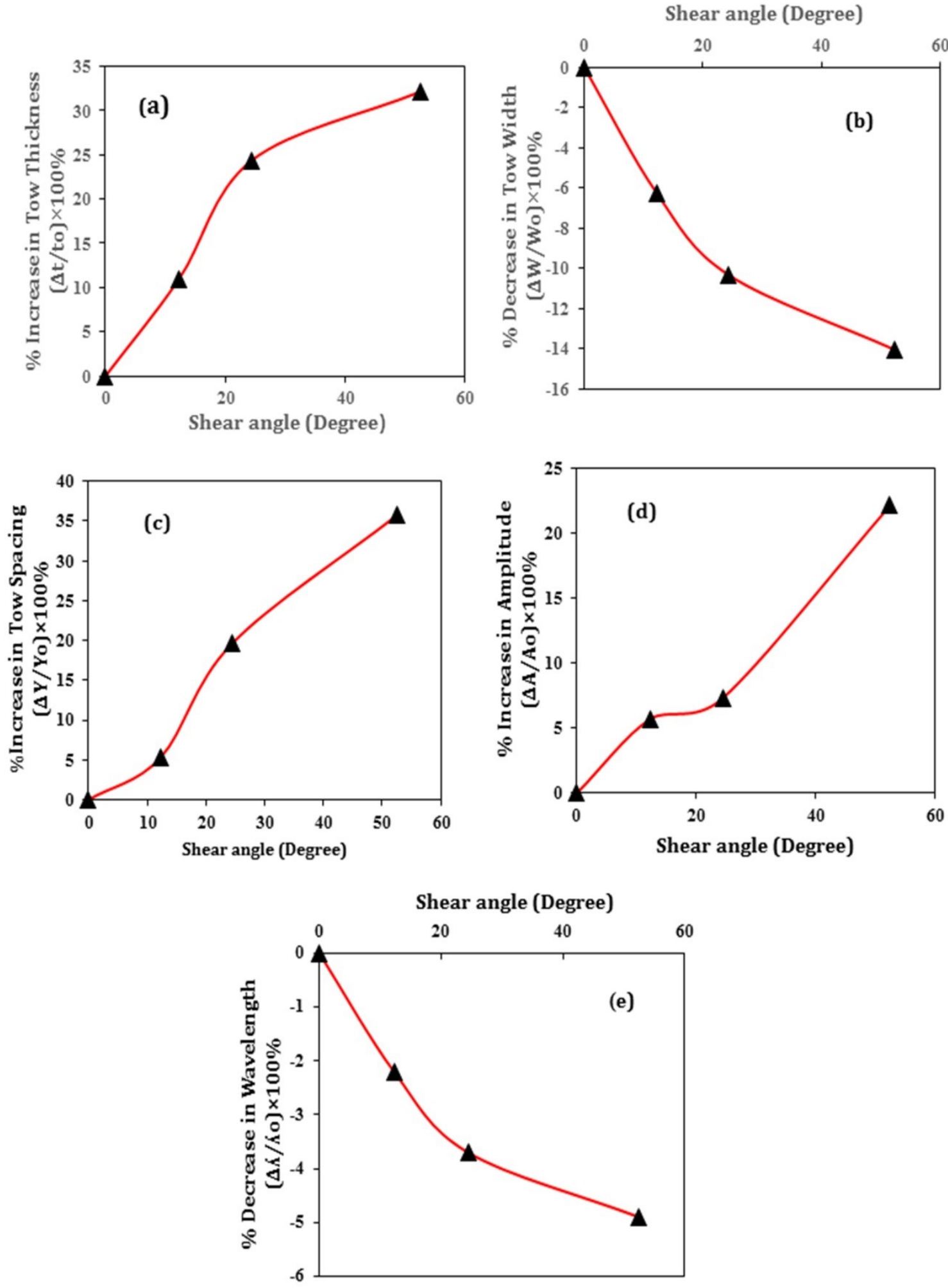

Figure 4.30 The percentage of variation of various factors with shear angle (8HS) (a) tow thickness, (b) yarn width, (c) tow spacing $(\Delta Y)$, (d) amplitude and (e) wavelength. 
increases adjacent yarns come in contact with each other, leading to lateral compression, which in turn increases the tow thickness and decreases the tow width. These results are in conformity to the manual measurements obtained with calipers during the test. In addition, on account of lateral compression, increasing with shear [61]; there is also observed to be a nominal increase amplitude $(22.1 \%)$ as the shear proceeds. In contrast, to counterpart the increase in amplitude a $4.9 \%$ decrease in wavelength $(K)$ is witnessed at the end of the shear process. Hence, these results show how the tows in the 8-harness samples reorganize themselves during the shear process.

\subsubsection{Microscopic analysis of 5 harness prepreg}

Similar to the $8 \mathrm{HS}$ samples, the sheared 5HS samples were prepared for microscopic analysis. The microscopic images obtained at various stages of shear are depicted in Figure 4.31. At start before the shear process, the tows are seen to be evenly arranged with one warp yarn over four fill yarns. During the initial stages of shear $\left(\gamma \leq 16^{\circ}\right)$ the tows are seen to relocate themselves with tows starting to slide.

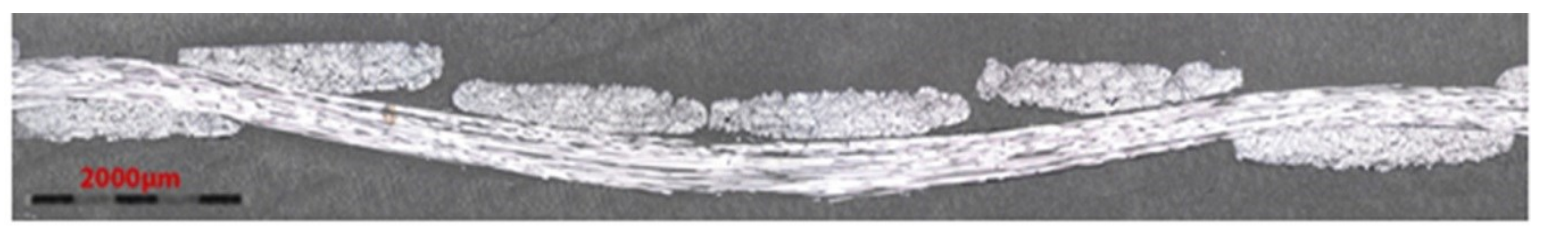

(a)
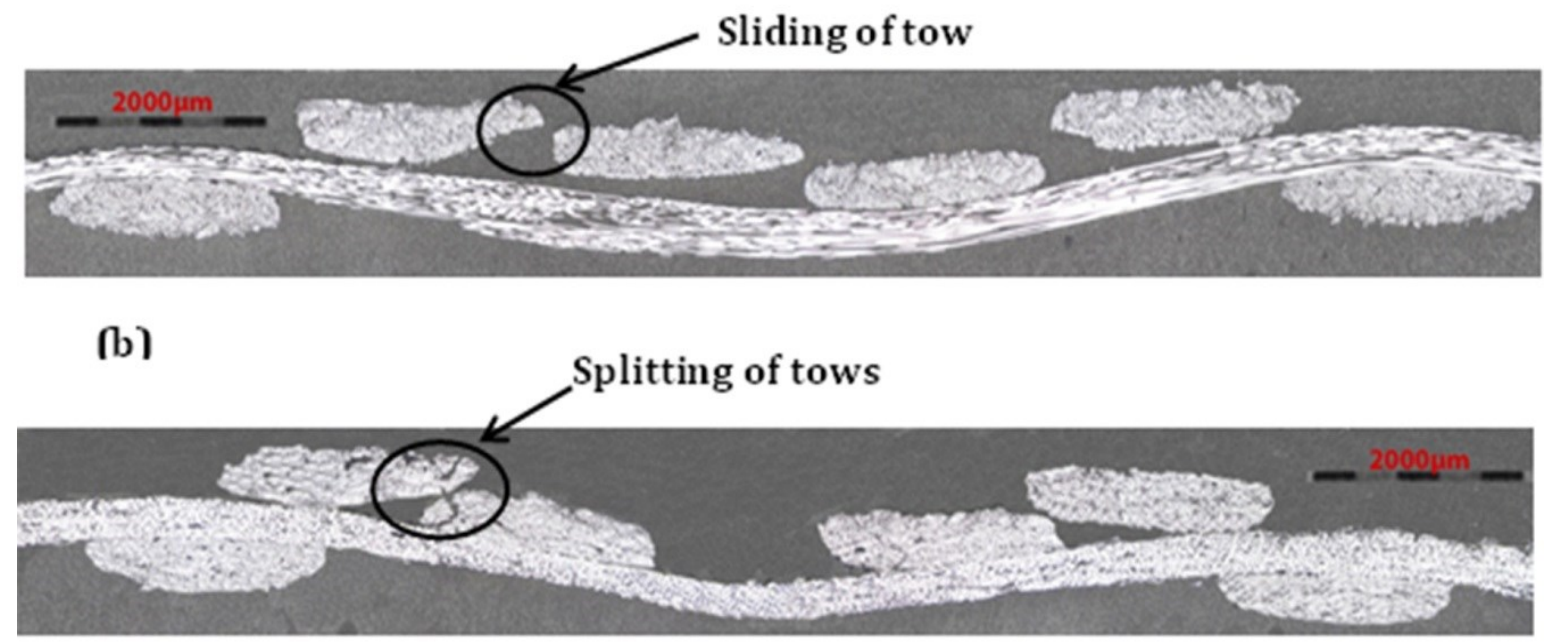

(c)

Figure 4.31 Microscopic image of the tow structure at various shear angles of 5HS samples (a) initial specimen, (b) $16^{\circ}$ sheared structure and (c) $38^{\circ}$ sheared structure. 
Further, at later stages $\left(\gamma \geq 30^{\circ}\right)$ the tows are seen to come in close contact with each resulting in splittage of tows [61]. A similar mechanism of tow deformation witnessed within the 8HS is visualized during the shear of the 5HS sample. The zone at which the splitting of tows is visualized, marks the start of the locking region. In the case of $8 \mathrm{HS}$, the splitting of tows was seen to initiate at a shear angle of $\gamma \geq 35^{\circ}$, whereas in case of the 5HS, it was witnessed at an angle of $\gamma \leq 35^{\circ}$. Hence, the 5HS samples are seen to lock at an earlier stage, while the 8HS sample locks relatively later. This corroborates our earlier investigation regarding; comparably higher locking angles of the 8HS samples than 5HS samples.

Table 4.3 Tow geometry parameters (5- harness)

\begin{tabular}{|c|c|c|c|c|c|c|c|}
\hline S.No & $\begin{array}{l}\text { Shear } \\
\text { angle } \\
\text { " } \gamma " \\
\text { (deg.) }\end{array}$ & $\begin{array}{c}\text { Tow } \\
\text { Spacing } \\
\text { " } \Delta \mathrm{X} " \\
(\mu \mathrm{m})\end{array}$ & $\begin{array}{c}\text { Tow } \\
\text { Spacing } \\
\text { " } \Delta Y Y^{\prime} \\
(\mu \mathrm{m})\end{array}$ & $\begin{array}{c}\text { Tow } \\
\text { Thickness } \\
\text { "T" } \\
(\mu \mathrm{m})\end{array}$ & $\begin{array}{c}\text { Tow } \\
\text { Width } \\
\text { "W" } \\
(\mu \mathrm{m})\end{array}$ & $\begin{array}{c}\text { Amplitude } \\
\text { "A" } \\
(\mu \mathrm{m})\end{array}$ & $\begin{array}{c}\text { Wavelength } \\
\text { " } \mathrm{N} " \\
(\mu \mathrm{m})\end{array}$ \\
\hline 1. & 0 & 1971.15 & 176.73 & 108.30 & 2011.97 & 431.15 & 9388.56 \\
\hline 2. & 23 & 1843.62 & 212.82 & 126.39 & 1865.92 & 483.16 & 9152.44 \\
\hline 3. & 36 & 1796.45 & 238.45 & 137.49 & 1676.66 & 537.86 & 8922.13 \\
\hline 4. & 48 & 1761.52 & 255.63 & 146.53 & 1521.41 & 555.37 & 8852.45 \\
\hline
\end{tabular}

Tow geometry at various stages of shear for 5HS is listed in Table 4.3. Graphically, it is noted that similar to the $8 \mathrm{HS}$ there is a nominal increase in the tow thickness $(35.3 \%)$ for $5 \mathrm{HS}$ which is observed to be $3.1 \%$ higher than the former (Figure 4.32). Whereas, there is seen to be $29.35 \%$ decrease in tow width, which in turn is $15 \%$ higher than $8 \mathrm{HS}$ sample. In addition, regarding the wavelength there is a $5.7 \%$ decrease observed at the end of the shear process. In contrast the tow amplitude is witnessed to increase by $28.8 \%$. On a whole, the percentage of variation of tow parameters with respect 5 harness sample is found to be higher than the 8 harness sample. 

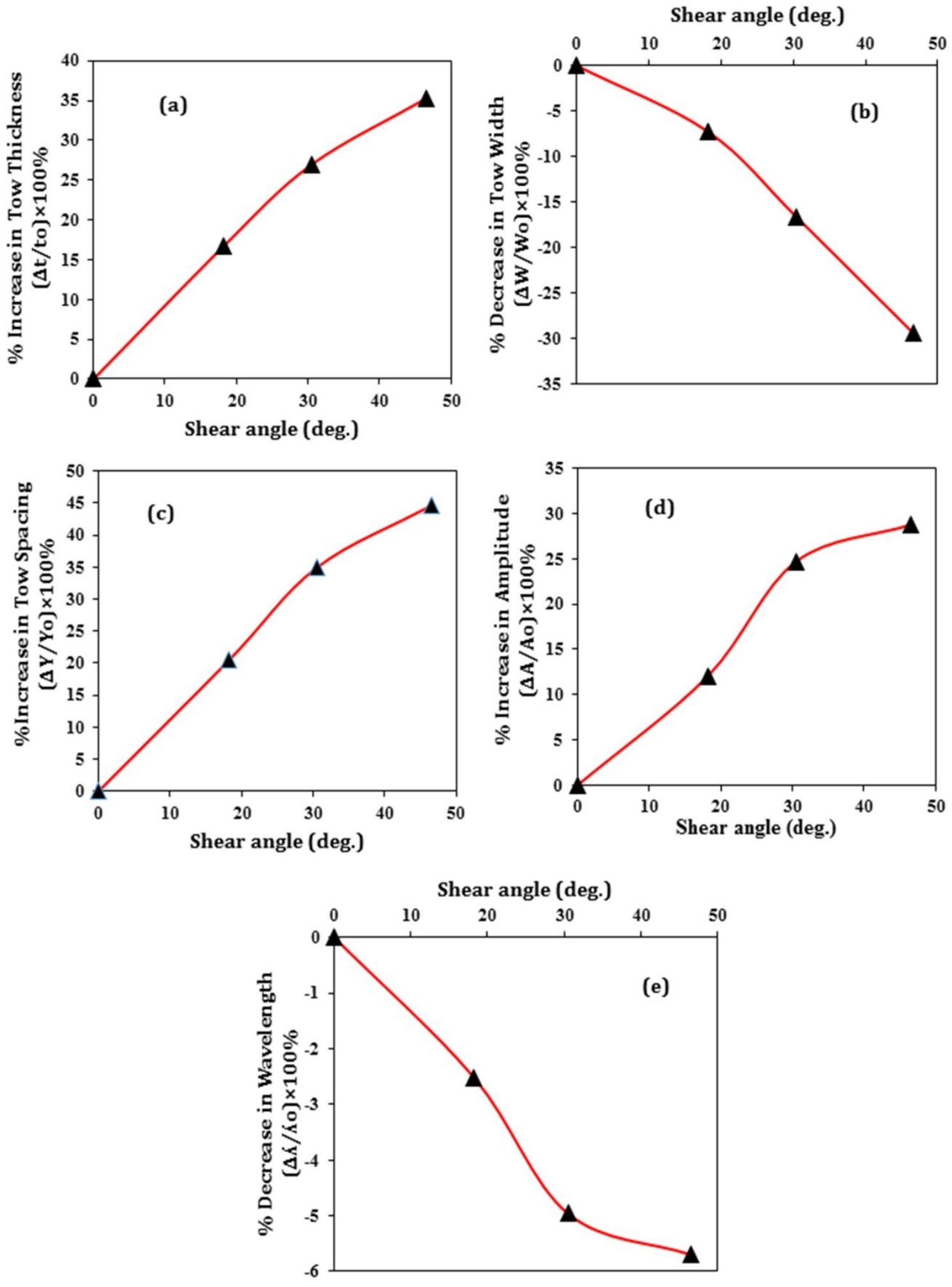

Figure 4.32 The percentage of variation of various factors with shear angle (5HS) (a) tow thickness, (b) yarn width, (c) tow spacing $(\Delta Y)$, (d) amplitude and (e) wavelength. 


\subsection{Unidirectional (UD) prepreg analysis}

To date, not much work has been performed to compare the drapability characteristics between the woven and UD laminates. In order to facilitate that, this section discusses regarding the characterizing of the intra-ply shear behavior of the cross-ply [0,90] unidirectional (UD) laminate when sheared at varying operating conditions. Tests were performed at different elevated temperatures and strain rates to observe the formability of the fabric. Figure 4.33, shows the shear mechanism involved when cross-ply laminates are indulged to shearing.
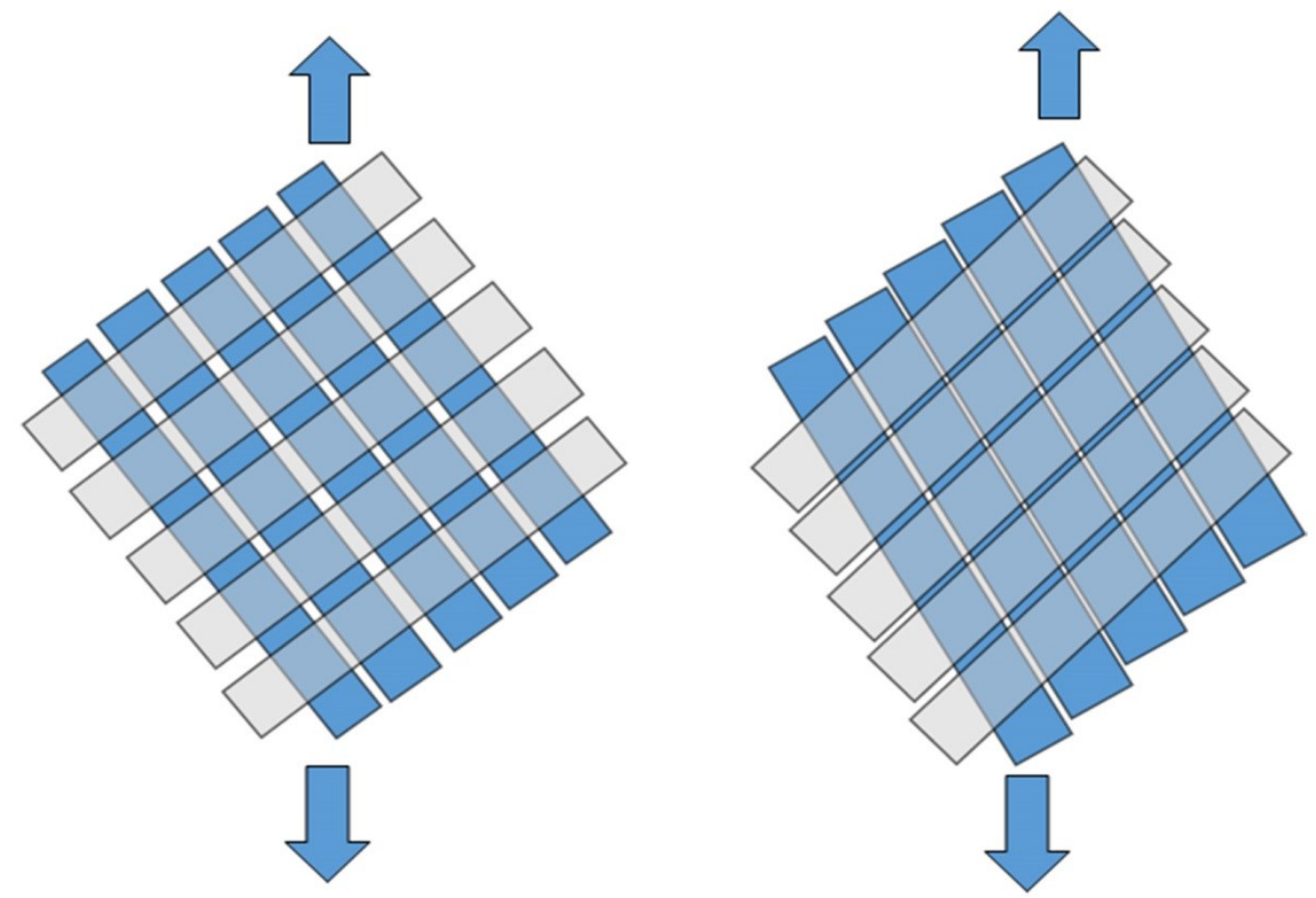

Figure 4.33 Schematic representation of cross-ply laminates during shear.

In order to make the comparison between the materials easier, tests were performed at same operating conditions as the former tests. Figure 4.34 depicts the effect of operating temperatures $\left(50^{\circ} \mathrm{C}, 70^{\circ} \mathrm{C}, 90^{\circ} \mathrm{C}\right)$ when performed at a constant displacement rate of $20 \mathrm{~mm} / \mathrm{min}$. A similar trend observed in woven fabric is seen to be replicated over here, i.e. the load is seen to decrease as the temperature increases, whereas a much lesser resistance is observed at higher temperature $\left(90^{\circ} \mathrm{C}\right)$. In contrast, since the UD laminates don't have any links connecting them similar to the woven fabrics the onset of locking angle seems to be meaningless for the UD prepreg. To 
support this, previous research by Potter [37] and Larberg et al. [11] had reported that no locking of fibers is possible for UD tape while they tend to wrinkle extensively indicating the limit of deformation. In our case, some serious wrinkling was clearly visible testing with the UD tape (see Figure 4.35). The fibers were observed to pile one over the other indicating the limit of deformation as in Figure 4.35 (a) [11]. In addition, in some trials, even splitting of fibers were visible at the end of the tests. These observations explain the exact complexity behind indulging the cross-ply UD prepregs into shear deformation. In order to reduce this complexity and also to observe the exact onset of winkling, the DIC was installed onto the setup, similar to the woven fabric analysis. Visual inspection of the images from the DIC reveals that the wrinkling starts to initiate at a way earlier stage than expected and also the piling up of the fibers (wrinkling) is seen to be much more severe during the latter stages.

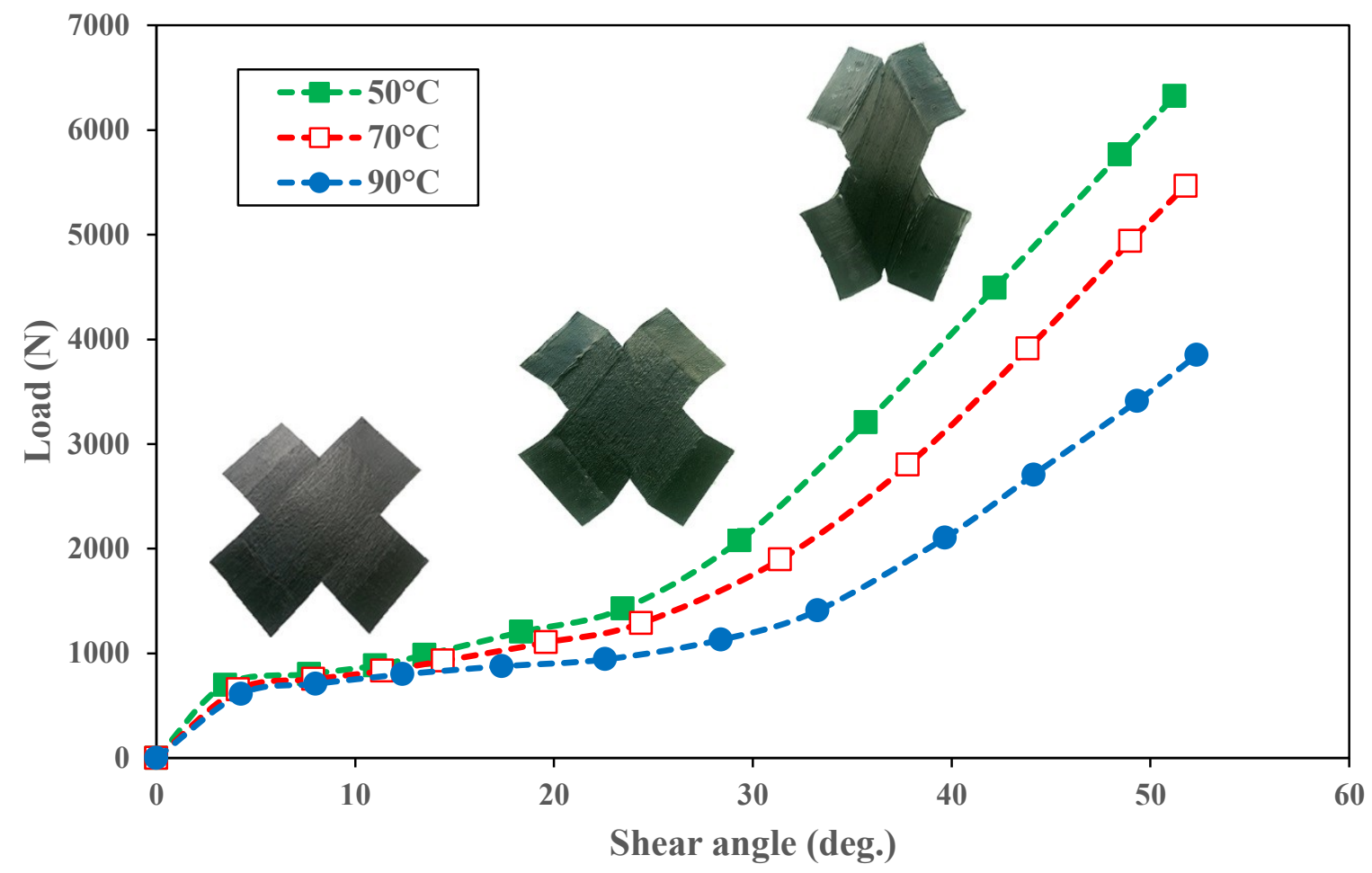

Figure 4.34 Picture frame with UD fabric at varying temperatures and $20 \mathrm{~mm} / \mathrm{min}$.

In addition, to determine the effect of displacement rates on the shear behavior, the UD prepreg was indulged to test at varying rates $(2 \mathrm{~mm} / \mathrm{min}, 50 \mathrm{~mm} / \mathrm{min}$ and $100 \mathrm{~mm} / \mathrm{min})$. Figure 4.36 , shows the load to increase as the rate of shear increases. Experimentally the onset of wrinkling was also observed to be postponed as the shear rate increases. 

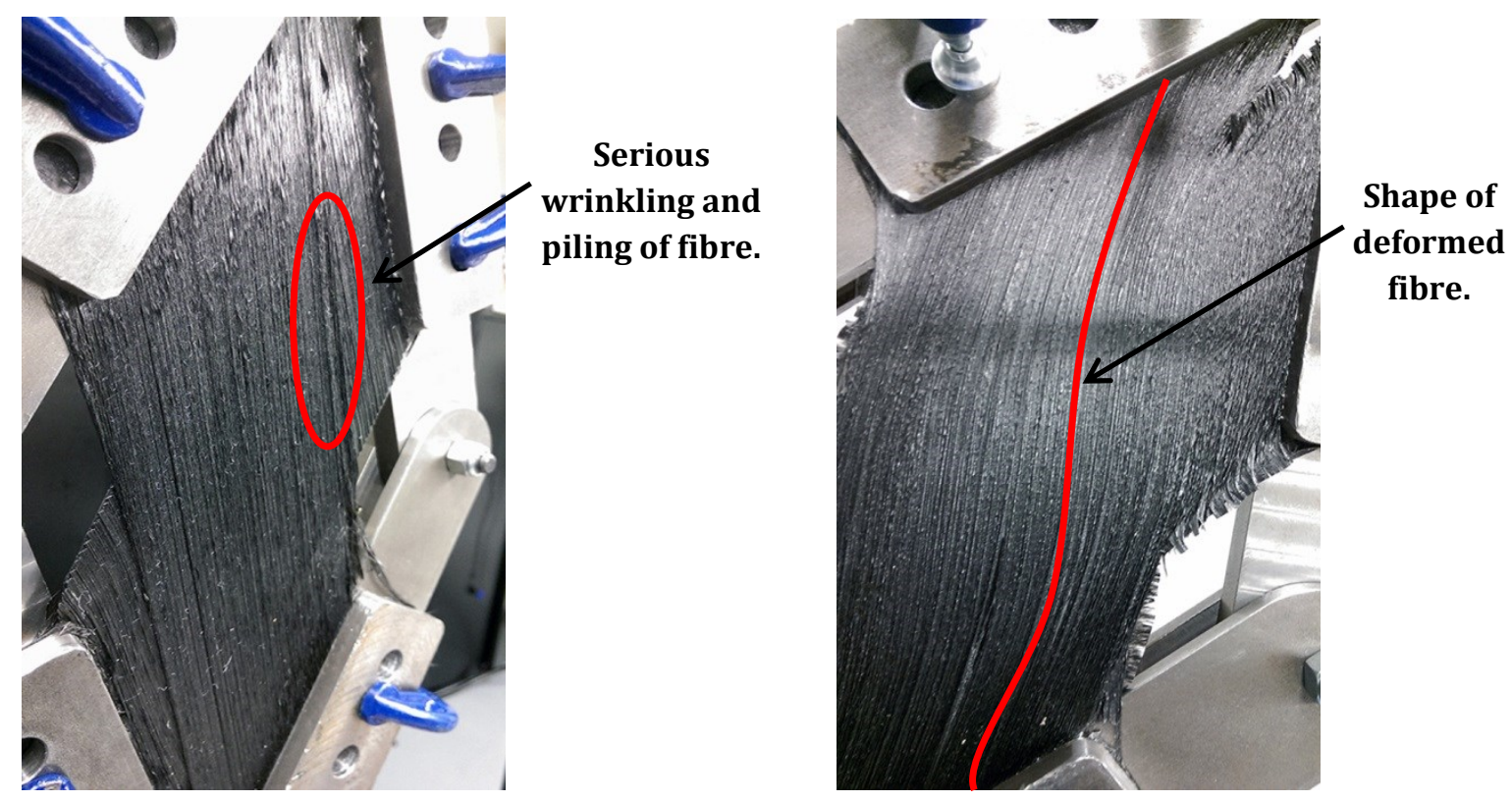

Figure 4.35 UD fabric (a) onset of wrinkling, and (b) shape of deformed sample.

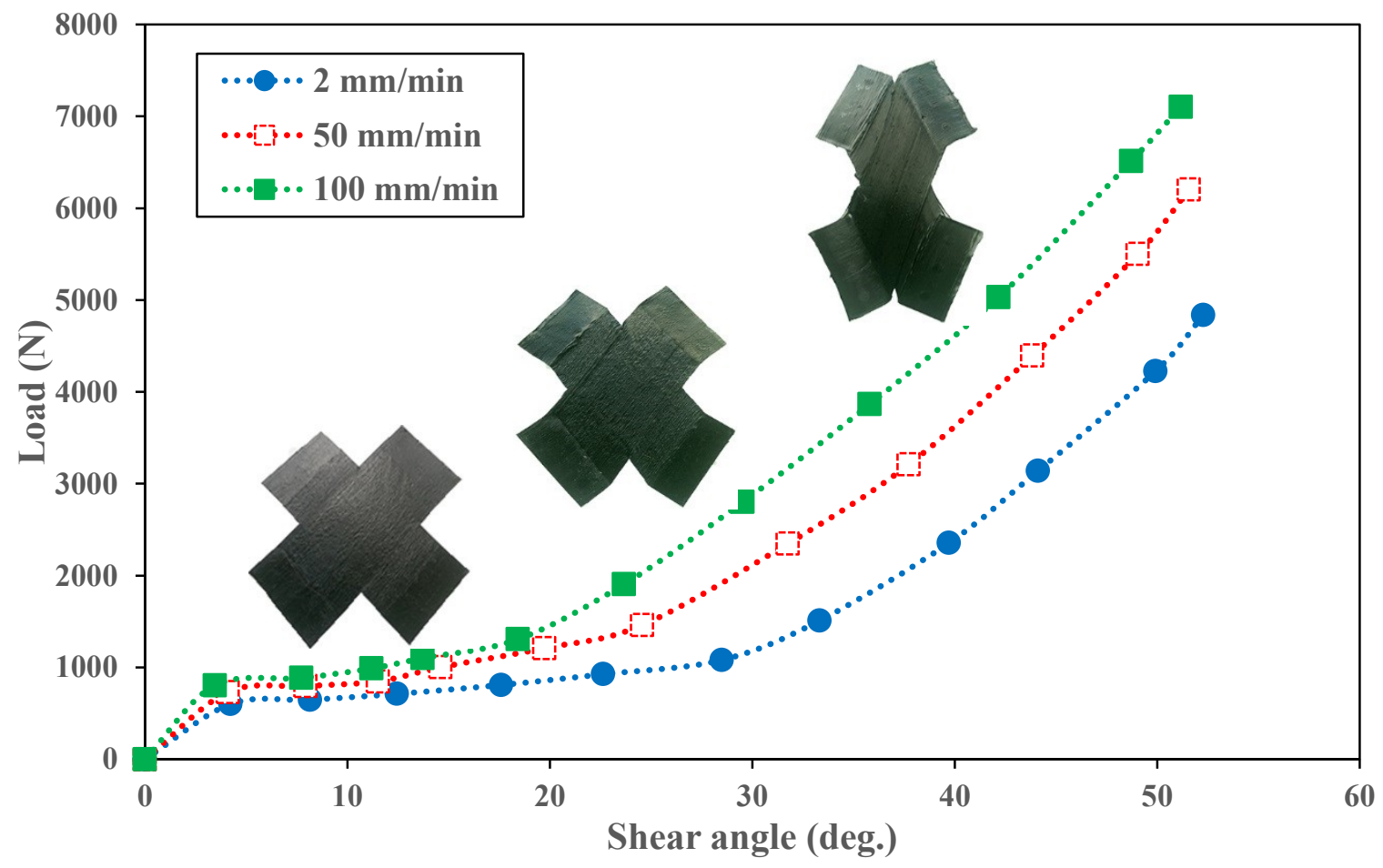

Figure 4.36 Picture frame with UD fabric at varying ramp rates and $70^{\circ} \mathrm{C}$. 
On the scale of comparison about the angle of onset of wrinkling between the woven and the UD fabrics at varying temperatures and displacement rates is plotted in Figure 4.37 and 4.38. The results show that UD tape tend to wrinkle at a much earlier stage than the 8 harness and 5 harness samples. The difference between wrinkling angles is seen to be maximized when tests are performed at high elevated temperatures $\left(90^{\circ} \mathrm{C}\right)$ and high rates $(100 \mathrm{~mm} / \mathrm{min})$. On an average, the UD fabrics are seen to wrinkle at $\left(5^{\circ}-8^{\circ}\right)$ earlier than the 8 harness samples and $\left(3^{\circ}\right.$ $6^{\circ}$ ) earlier than the 5 harness samples. This shows that the UD tape tends to have less deformability than the woven fabrics.

Thus, taking forming operation into account; it is much better to stick onto the woven fabrics than the UD fabrics when working on the complex contours. On a whole, even though previous research has reported UD tape to have high strength and stiffness, this study suggests that UD prepregs are not preferable for complex contour forming applications.

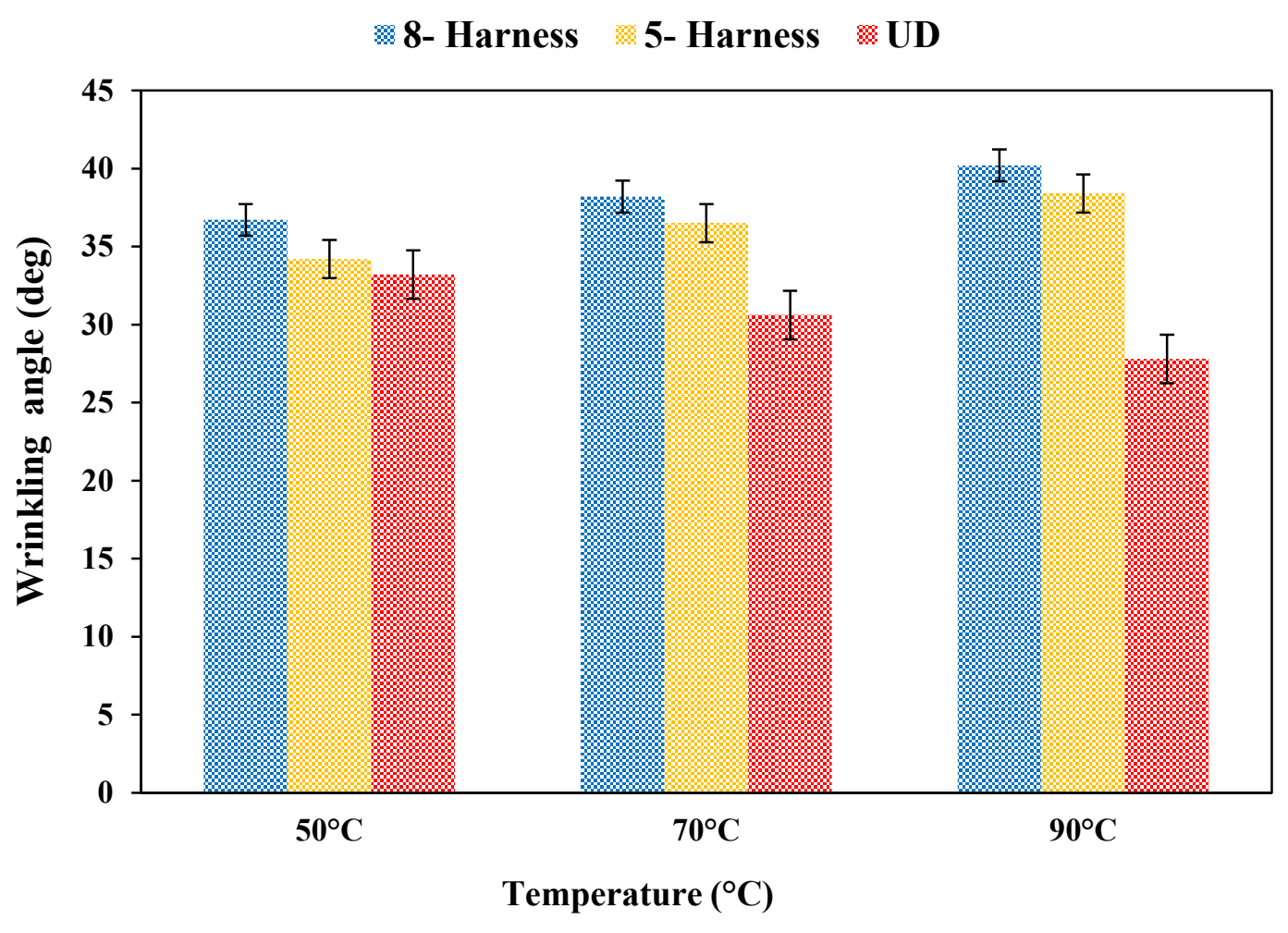

Figure 4.37 Wrinkling angles of 8HS, 5HS and UD at varying temperatures. 


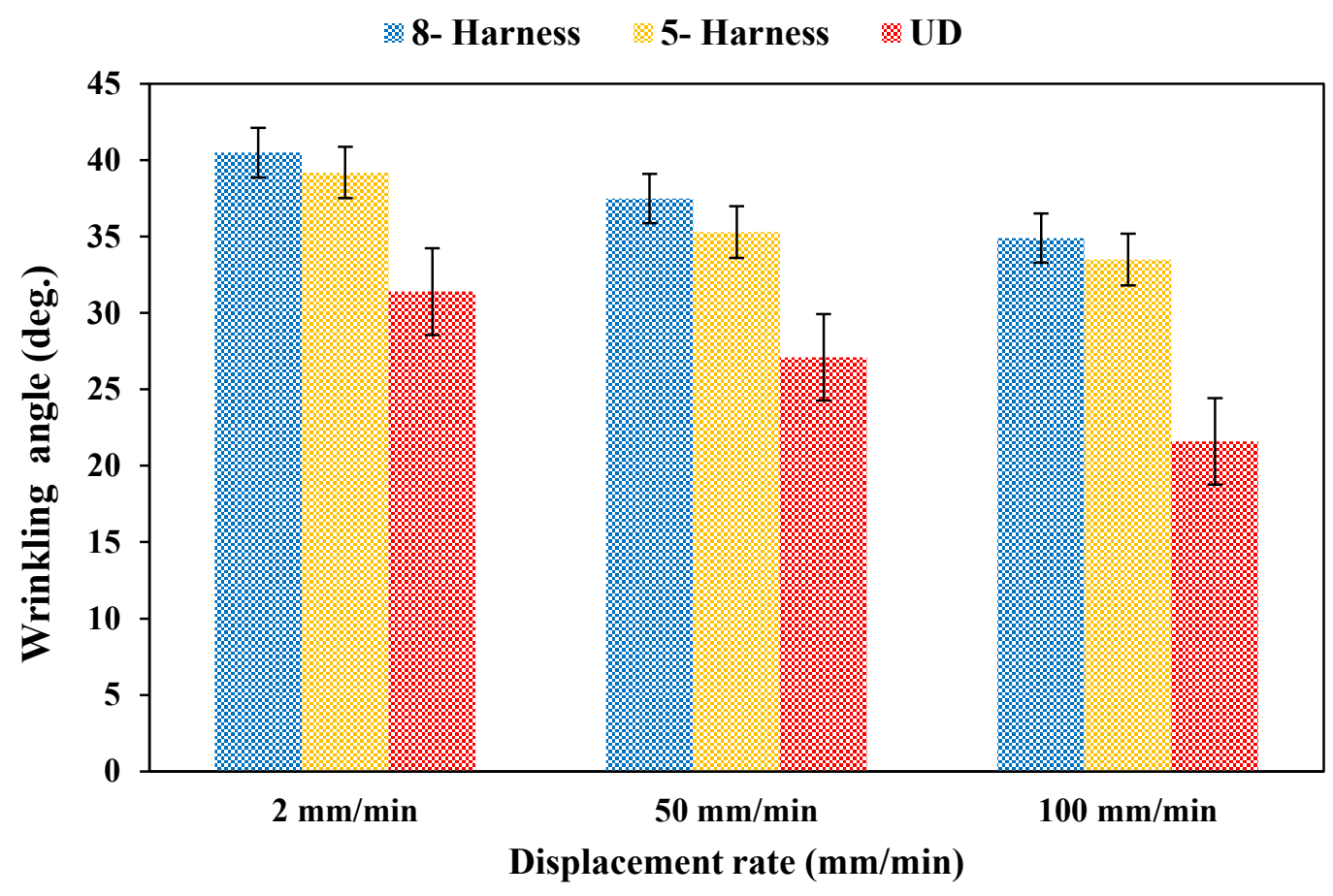

Figure 4.38 Wrinkling angles of 8HS, 5HS and UD at varying shear rates.

\subsection{Summary}

To summarize this chapter, by investigating the performance of the picture frame test at different elevated temperatures and displacement rates; it was reported that the onset of wrinkling was visible at a much earlier stage (also more severe) when forming at low temperatures and high displacement rates. In addition, on comparing the in plane shear behavior of both 8HS and 5HS prepreg it was visualized that $8 \mathrm{HS}$ have a better drapability than 5HS prepreg, making them favorable for forming operation.

In turn, the results of the microscopic investigation from both the prepregs (8HS and 5HS) suggested that, tow width and yarn amplitude decreases as the shear proceeds. Whereas, the tow thickness and yarn wavelength increase with the shear. Also, breakage of tows were visible at the end of the shear, indicating the tows were deformed beyond its locking zone.

Finally, the UD cross ply prepreg was indulged to shear analysis to characterize its ease to deformation. On analysis it was seen that UD prepregs have lesser deformability than woven fabrics making them not reliable for forming complex contours. 


\section{CHAPTER 5: Bias extension and optimization technique}

As discussed in chapter 2, the bias-extension test is also another test method used to characterize the intra-ply shear behavior of fabric. Even though a lot of research work has been carried out earlier using the bias extension test to characterize the shear behavior of the fabric. Some tests have been repeated in this thesis using the bias extension tests (at same operating conditions as the picture frame test) in a way that it is comparable to the picture frame test and also to make this thesis self-contained and independent. To demonstrate these, this chapter initially discusses the results from the bias extension test and further they are compared with the picture frame test. In the latter stage of this chapter, all the results from the picture frame test are optimized using the Taguchi and ANOVA (Analysis of variance) method to determine the optimum condition for forming based on the intra-ply deformation mechanism.

\subsection{Bias extension test}

The specimen used for the bias extension is seen of length $100 \mathrm{~mm}$ and width $50 \mathrm{~mm}$ as shown in Figure 5.1. Similar to the picture frame samples, random speckle patterns were also plotted in this sample to enable the use of the DIC to take sequential images at various stages of deformation. These images were then imported into Auto CAD to measure the shear angle at various stages. As discussed before in section 2.3.2, full deformation is observed only in 'Zone A' compared with 'Zone $\mathrm{B}$ and $\mathrm{C}$ ' due to their difference in boundary conditions. These conditions enable the measurement of the shear angle displaced by 'Zone A' to know the shear angle of the entire sample.

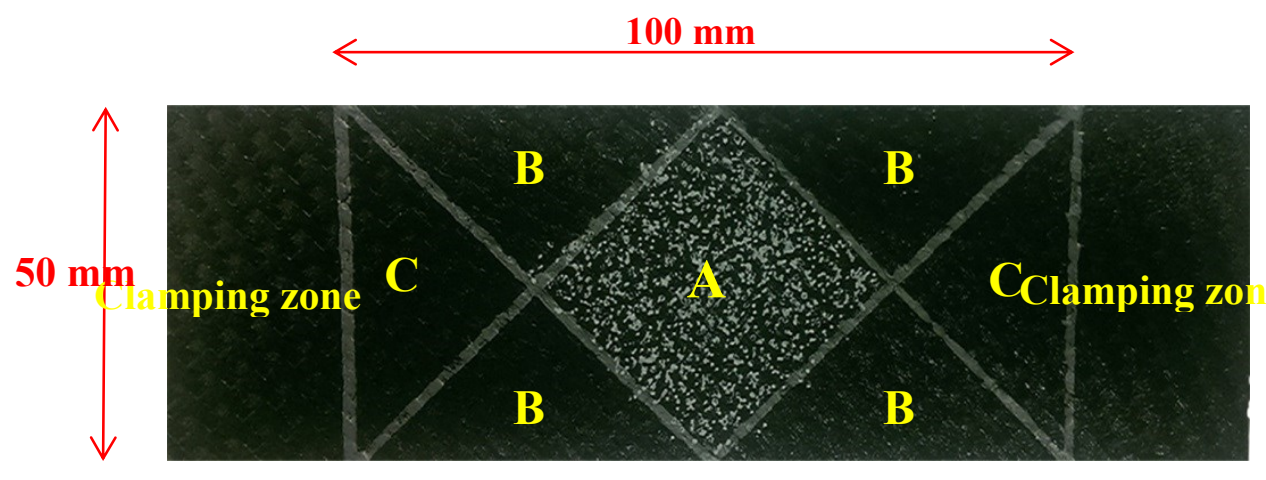

Figure 5.1 Bias extension sample [63] 
It is also made sure based on the previous works that the aspect ratio $(K=\mathrm{L} / \mathrm{W})$ is greater than or equal to two, in procedure for the samples to experience pure shear deformation $[37,62]$. In this case, both 8-harness and 5-harness samples were investigated for analysis at different operating conditions. All tests were carried out on 2- layered $\left[ \pm 45^{\circ}\right]$ oriented samples in a way enabling them to undergo shear, when a tensile load is applied across its cross heads. A photographic image of the test setup is shown in Figure 5.2.
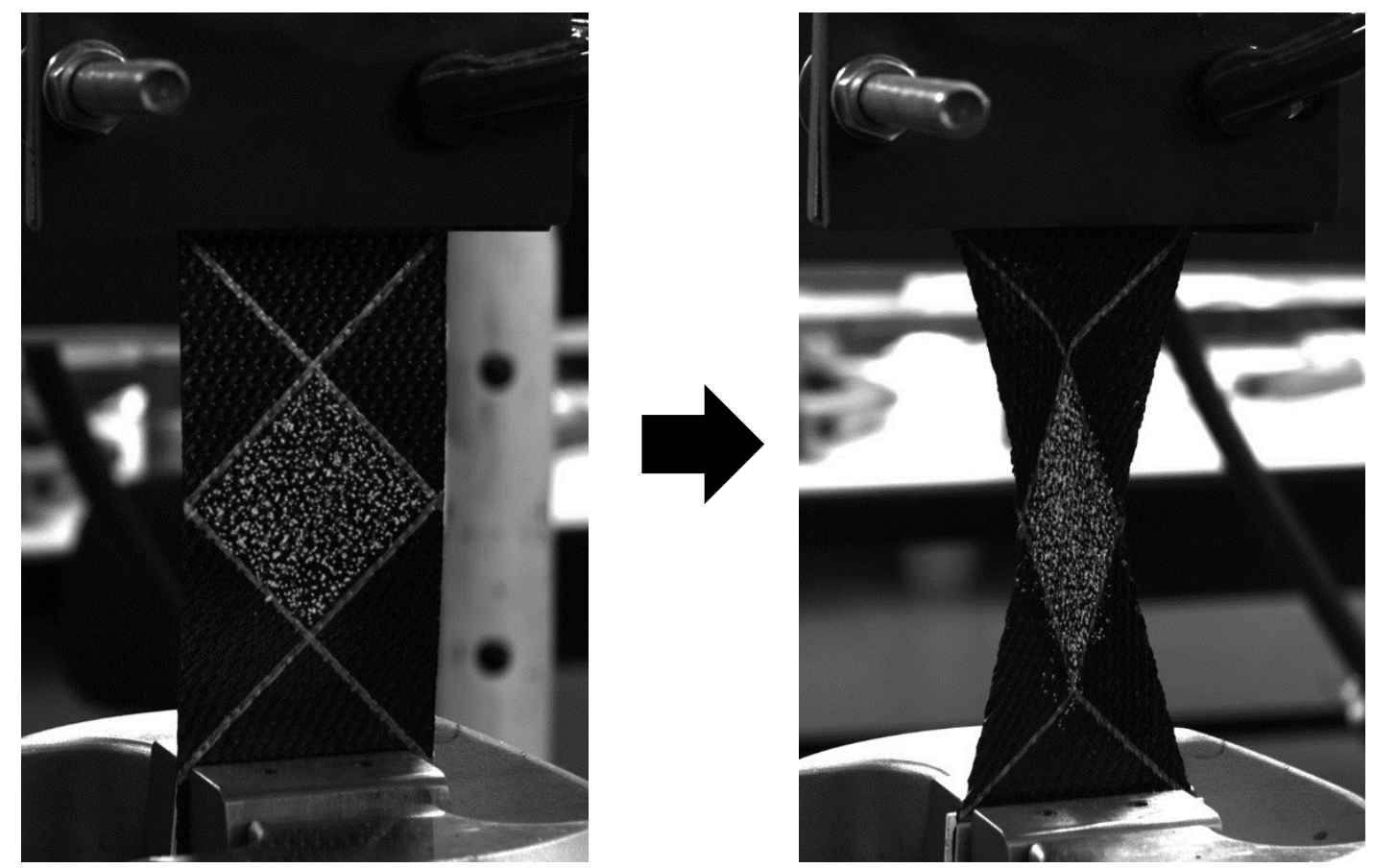

Figure 5.2 Photos taken during the bias extension test.

Bolts were used to clamp the samples in between the plates which were later attached to the tensile testing machine. A $2.5 \mathrm{kN}$ load cell was used to measure the load. Tests were carried out at different elevated temperatures (same as the picture frame test) to facilitate comparison with the picture frame results. The same non-contact infrared heater as in section 4.2 was used to heat the samples. It was made sure that the samples were held at a constant temperature for 10 mins before the start of the test. The effect of elevated temperatures $\left(50^{\circ} \mathrm{C}, 70^{\circ} \mathrm{C}\right.$ and $\left.90^{\circ} \mathrm{C}\right)$ and shear rates $(5 \mathrm{~mm} / \mathrm{min}, 50 \mathrm{~mm} / \mathrm{min}, 100 \mathrm{~mm} / \mathrm{min})$ on the bias results are explained in detail in the forthcoming section. At least two trials were performed under each condition. 


\subsubsection{Effect of elevated temperature}

In addition to the picture frame test, the effect of temperature on the in-plane shear behavior was re-authenticated by performing the bias extension test. The Figure 5.3 and 5.4 shows the effect

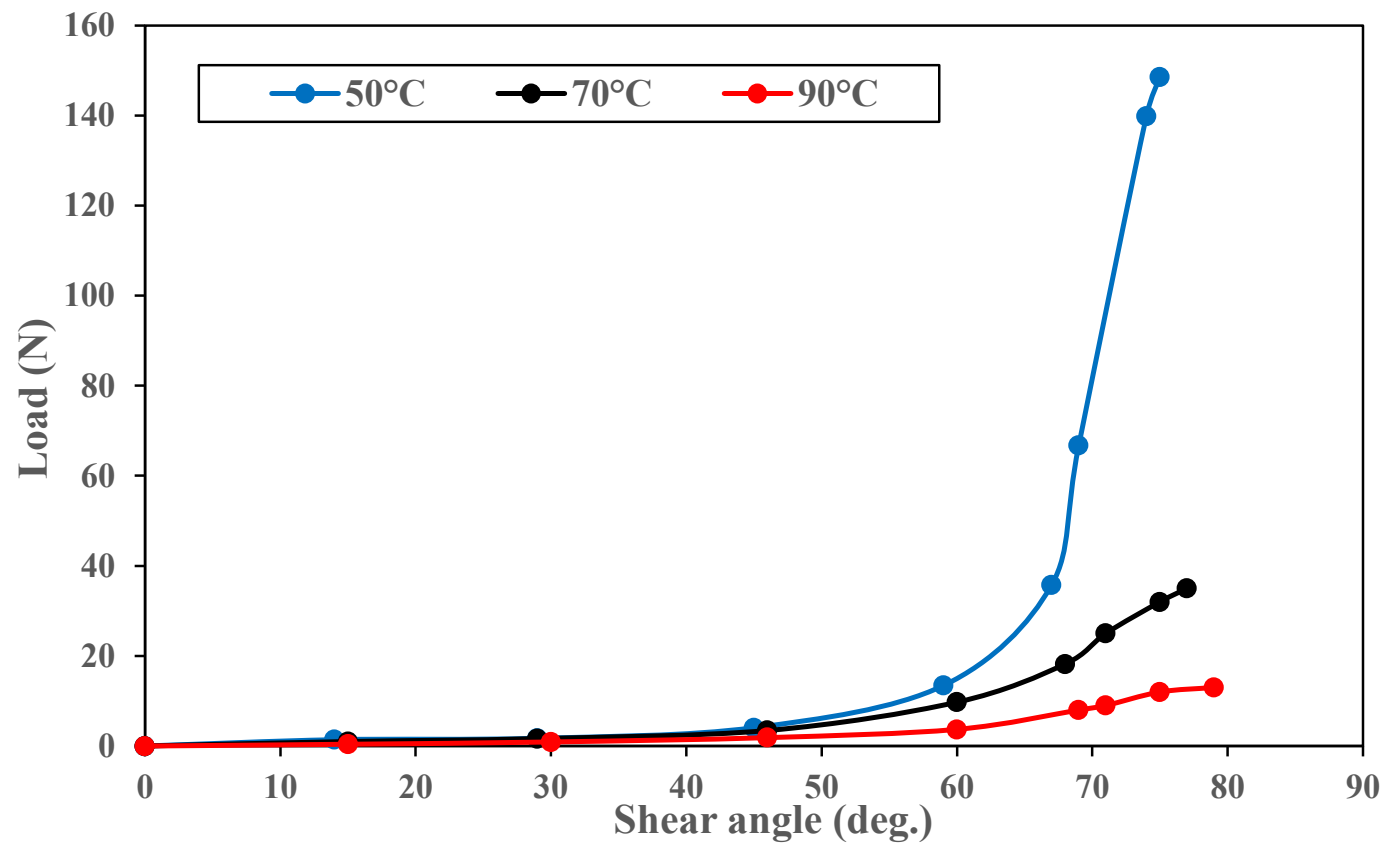

Figure 5.3 Bias extension test on 8 harness at varying temperatures and $20 \mathrm{~mm} / \mathrm{min}$ [63].

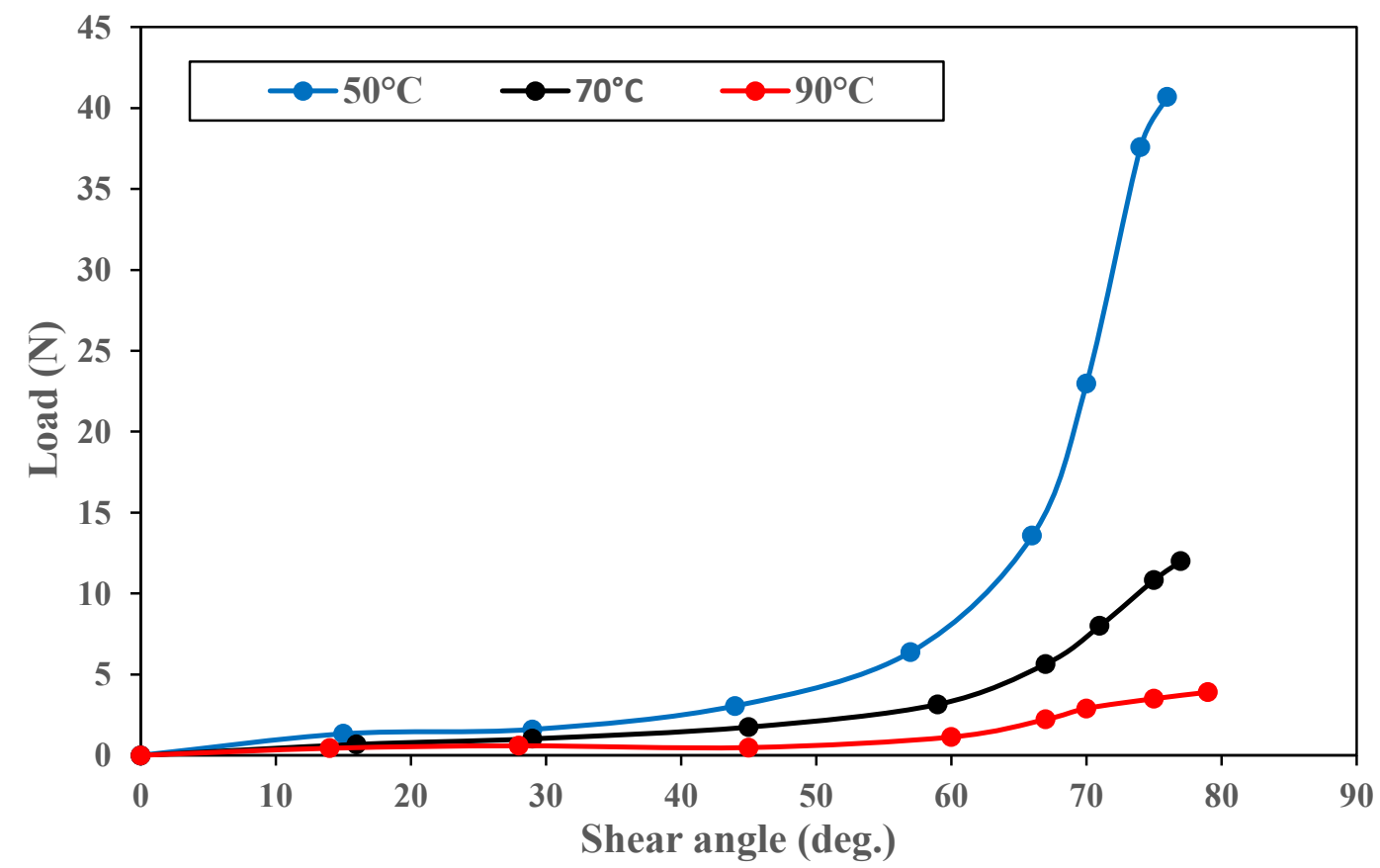

Figure 5.4 Bias extension test on 5 harness at varying temperatures and $20 \mathrm{~mm} / \mathrm{min}$ [63]. 
of temperature on the 8HS and 5HS samples. Moreover, the same trend observed over in Figure 4.10 and 4.11 under the influence of picture frame test can be visualized over here. The load is seen to increase with the increase in the measured shear angle. In contrast, the extent of deformation is seen to increase as the temperature increases [67]. This behavior is attributed to the decrease in resin viscosity with the raise temperature as discussed in section 3.4.2. The locking angle for the prepregs is determined by the same method outlined before in section 4.1 (the angle at which there is a drastic increase in load). It is observed that, as the temperature increases the locking angle is found to increase in turn postponing the onset of wrinkling. In addition, to validate the results from the picture frame test the 8HS prepregs under the bias extension test are reported to have higher locking angle than the 5HS sample under all operating conditions.

These observations reaffirm the results reported using the picture frame test. However, on the scale of comparison between the picture frame and bias extension tests, the load under the bias extension test seems to be much lower than the picture frame test results. Thus, in order to make a comparison between picture frame and bias extension tests much reliable, the results from both the tests need to be normalized, which is to be investigated in forthcoming section 5.2.

\subsubsection{Effect of displacement rate}

The effect of the displacement rate of the in-plane shear behavior of the bias- extension test is shown in Figures 5.5 and 5.6. It is witnessed that up to a shear angle of $44^{\circ}$ the loads under varying shear rates are observed to be almost equal for both $8 \mathrm{HS}$ and 5HS prepegs. Later, beyond $44^{\circ}$ a drastic increase in load (almost twice an increase) is visualized. In addition, similar to the picture frame test the load seems to increase with the increase in shear rate. In contrast, the deformation is seen to decrease as the shear rate proceeds.

The locking angles obtained at the varying shear rates show that locking angle decreases with the increase in shear rate for both 8HS and 5HS samples. Zhu et al. [3] performed the bias extension test using the plain woven fabric at different loading speeds and reported that the onset of locking is postponed as the displacement rate increases; thus confirming obtained results in this work. In addition, severe wrinkling and slippage of fibers were reported during shearing at high rates. Thus, based on the above discussion, it can be concluded that it is much better to deform samples at low rates to postpone the onset of wrinkling. 


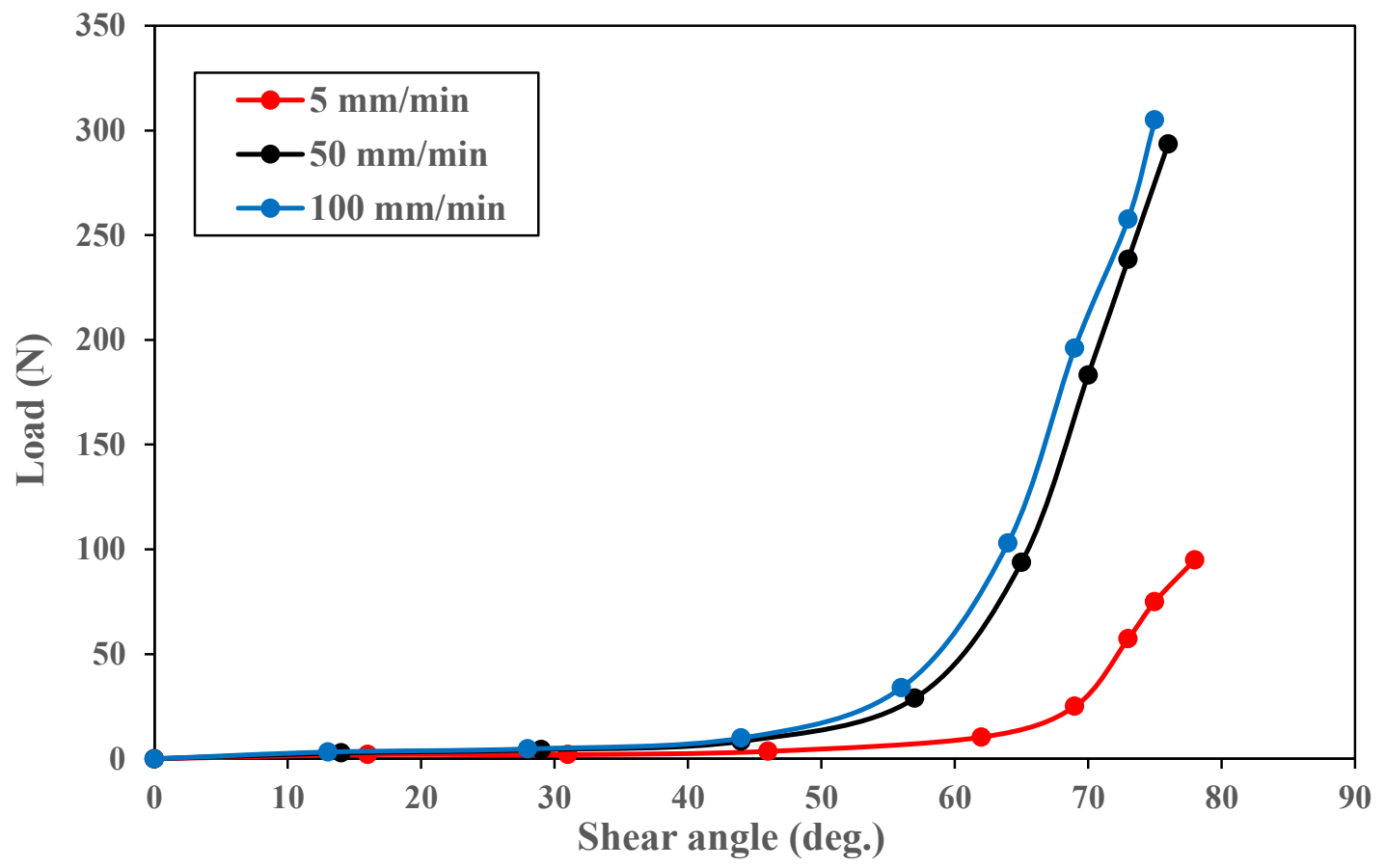

Figure 5.5 Bias extension test on 8 harness at varying ramp rates and $70^{\circ} \mathrm{C}$ [63].

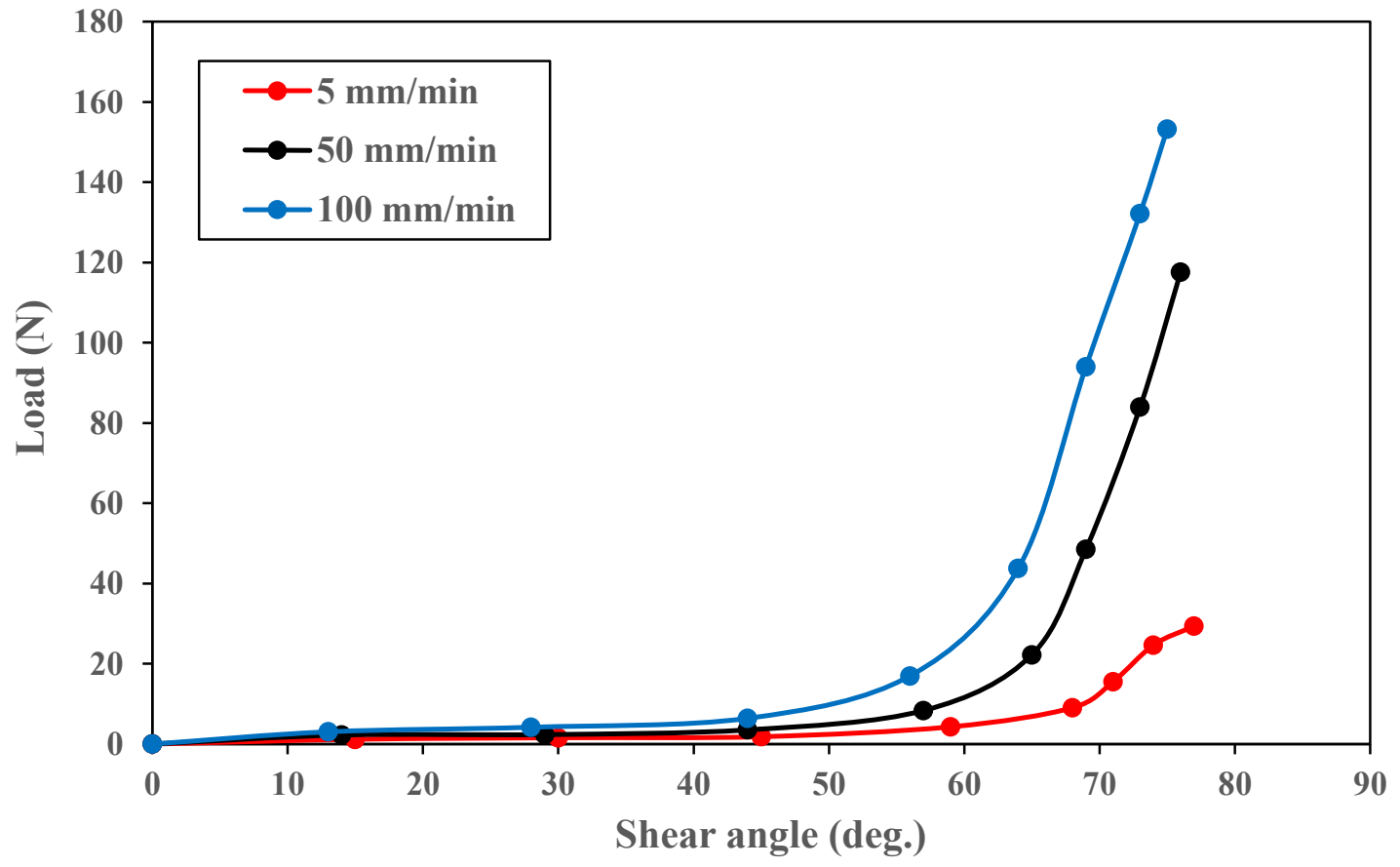

Figure 5.6 Picture frame test on 5 harness at varying ramp rates and $70^{\circ} \mathrm{C}[63]$. 


\subsection{Comparison of two tests}

Both the results obtained from picture frame test (section 4.3 and 4.4) and bias- extension test (section 5.1) are compared. Taking the variation between both these tests into consideration, a normalization needs to be performed.

\subsubsection{Area normalization}

Based on previous understanding, it is known that comparably picture frame test experience a pure shear deformation than the bias extension test (due to its three zones of deformation). However, it's been reported from previous literature $[3,37,41,42,55,65]$ that the Zone A experiences a pure shear due its free edges when compared with other two zones; which have at least one of their edges clamped. This helps to come to a conclusion that a comparison between these two tests must be made only based on the pure shear zones $\left(A_{1}\right.$ and $\left.A_{2}\right)$, as denoted in Figure 5.7. However, it could seen in the figures that area of pure shear in the picture frame test is much higher than that of the bias-extension test. Henceforth, the results of both the tests were normalized based on their area of shear [65] as discussed below.
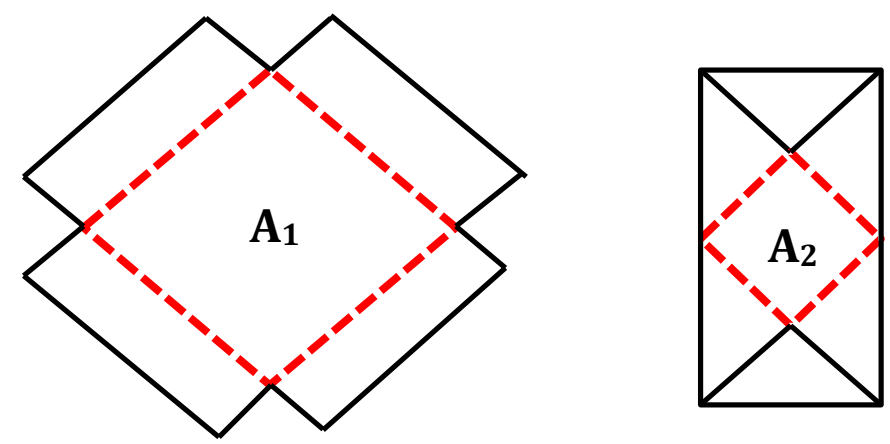

Figure 5.7 Indication of pure shear zones in picture frame and bias-extension samples.

The area of pure shear zones in the picture frame and bias extension tests is reported to be of dimension $16,129 \mathrm{~mm}^{2}$ and $2,500 \mathrm{~mm}^{2}$. The results were normalized as follows, [65]

$$
\mathrm{F}_{\text {norm }}=\frac{\mathrm{F}_{\text {load }}}{\text { Area of shear }}
$$

Where $F_{\text {load }}$ denotes the actual load from MTS device and $F_{\text {norm }}$ denotes the normalized load. The graph plotted between normalized load and shear angle for 8HS and 5HS is depicted in Figure 
5.8 and 5.9. The load is seen to be expressed in terms of ' $\mathrm{N} / \mathrm{mm}^{2}$, which makes the load value much lesser in a way to facilitate comparison.

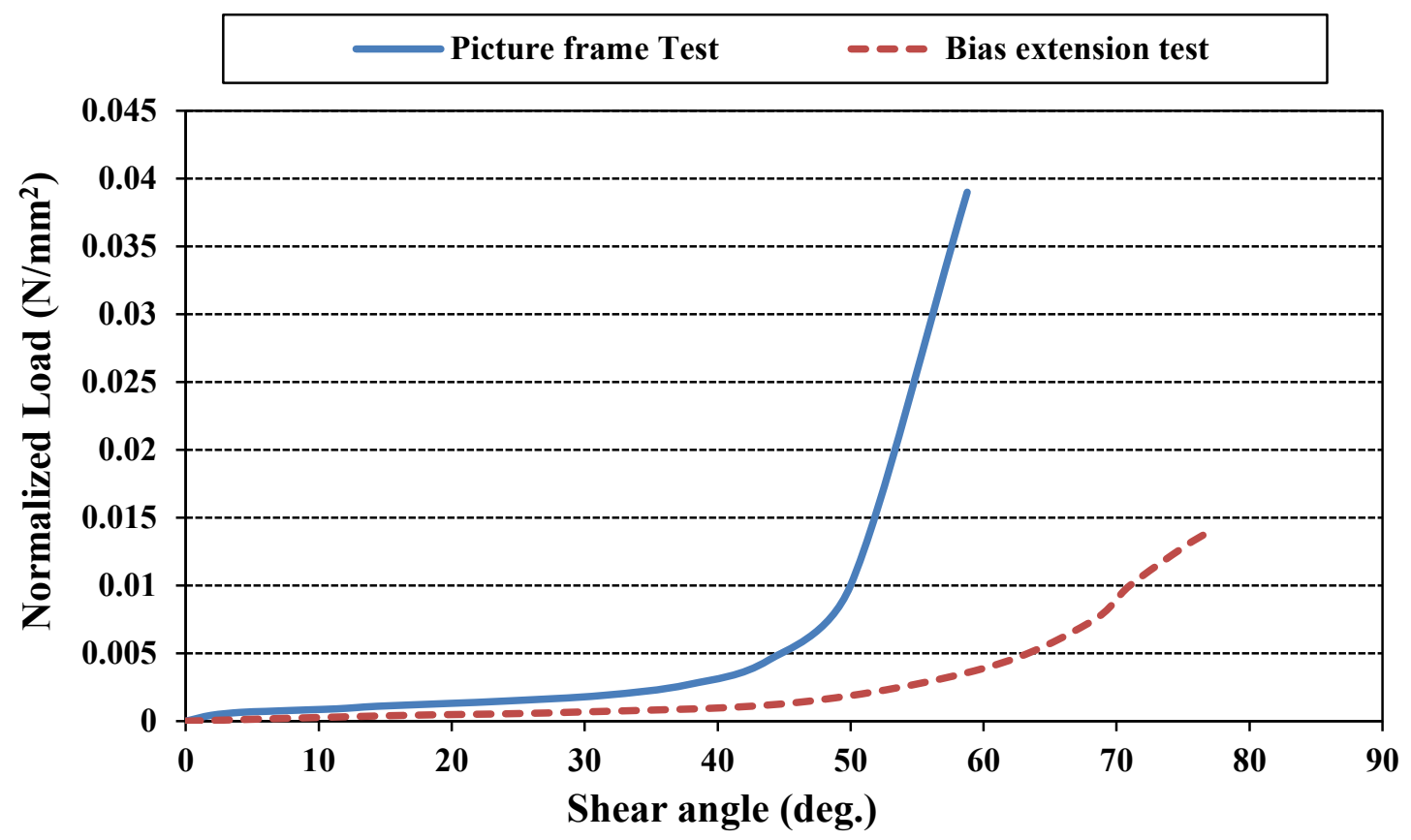

Figure 5.8 Comparison between picture frame and bias extension test for 8HS.

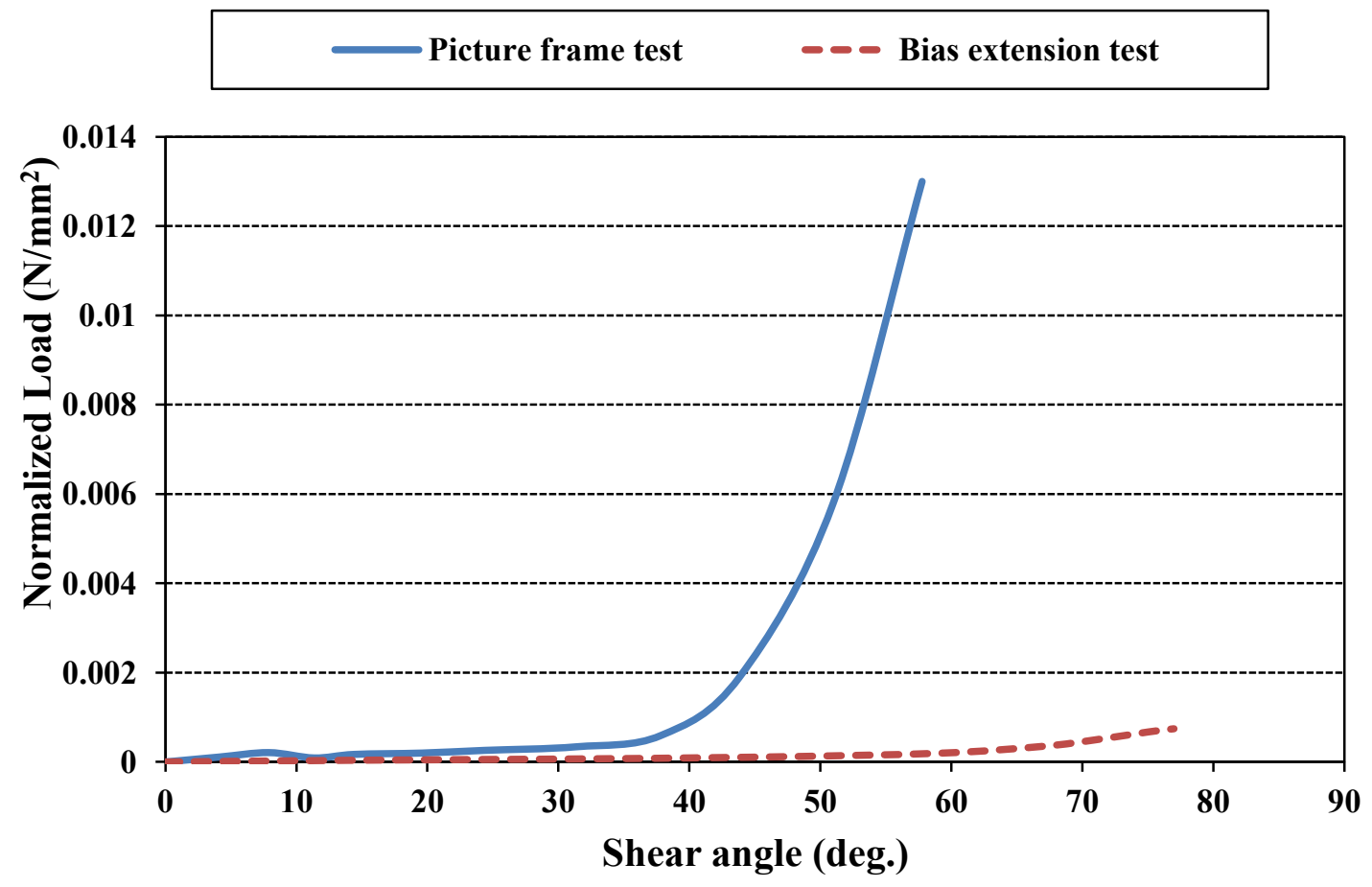

Figure 5.9 Comparison between picture frame and bias extension test for $5 \mathrm{HS}$. 
It is observed from both the graphs that normalization of the results has not changed the trend of the results reported before. In turn, the trend observed under the picture frame test is seen to be higher than the bias-extension test results. A similar results were reported in literature $[41,45]$. For the $8 \mathrm{HS}$ samples, only a $28 \%$ difference in normalized loads is observed between the picture frame and bias- extension results up to a shear angle of $30^{\circ}$. But, beyond this angle more than twice a difference between the loads is observed. While, for the 5HS samples the magnitude of difference in the normalized load between the two tests is much higher than the 8HS prepreg. These variations can come from the slippage of the tows during the bias extension test, which in turn would enable Zone A to not experience pure shear. These issues were also observed by Chen et al. [65] during his previous effort to compare both the tests.

In addition, for the 8HS prepreg, the difference in locking angles between both the tests is found to be only around $0.6^{\circ}$. This shows that bias extension test could be used at times as an alternative test to characterize the in plane shear behavior of the fabric. However, for the 5HS prepreg a much higher variation of $2.3^{\circ}$ was observed. Though, the variation in results between the samples looks susceptible a previous research by Launay et al. [4] had suggested that the difference might arise from the variation in manufacturing the sample. However, as a future work it is suggested to come up with an alternate way of normalization which takes into consideration, even the shear in the other two zones (Zone B and C). Based on the experimental procedure, Table 5.1 makes a comparison of the advantages and dis-advantages between both the tests.

Table 5.1 Comparison between picture frame and bias- extension test.

S.No Picture frame test Bias extension test

1. A complex rig setup which requires specialized design [41].

2. Pure shear deformation throughout the sample.

3. Misalignment of samples while clamping is a major issue.
Simple test with no rig required. But, requires specialized clamping.

Heterogeneous shear deformation in various zones [41].

In contrast, misalignment is observed during the test. 


\subsection{Process Optimization}

Till now we have discussed regarding the effect of varying parameters on the in-plane shear of OOA prepeg. However, it is needed to perform a number of trials before coming to a conclusion regarding the drapability of the fabric. Therefore, this section investigates regarding optimizing the test results from the picture frame test. In addition, to drive a conclusion on the significant parameter which influence wrinkling the most using the Taguchi and Analysis of Variance (ANOVA) method. The prime objective of this study is to characterize the drapabiliy of the low cost OOA prepreg at different parameter combinations by reducing the number of trials.

\subsubsection{Design of experiments}

The first step before the optimization is to select the parameters which influence the deformability of the fabric the most. In our case, the possible factors which have the most influence on the deformation are seen to be displacement rate, layer count and operating temperature. The three levels of each parameter subjected to the analysis are listed in Table 5.2

Table 5.2 Parameters and their levels [66]

\begin{tabular}{lllll}
\hline Symbol & Parameters & Level 1 & Level 2 & Level 3 \\
\hline $\mathrm{T}$ & $\begin{array}{l}\text { Temperature, A, } \\
\left({ }^{\circ} \mathrm{C}\right)\end{array}$ & 23 & 70 & 90 \\
$\mathrm{D}$ & $\begin{array}{l}\text { Displacement } \\
\text { rate, B, (mm/min) }\end{array}$ & 2 & 50 & 100 \\
$\mathrm{~N}$ & No. of. layers, C & 1 & 2 & 4 \\
\hline
\end{tabular}

Next it is needed to select an orthogonal array depending upon the levels of each parameter. Since there are three levels for each parameter $\left(3^{3}\right)$ we chose an L9 orthogonal array for further analysis. The L9 orthogonal array used for the analysis is listed in Table 5.3. The different levels of each parameter were selected based on the previous literature works.

\subsection{Taguchi method}

The Taguchi method is a powerful optimization technique used formidably for years to design an experiment. It is a simple, efficient and systematic tool used to select the optimum parameters [68]. 


\section{Table 5.3 L9 orthogonal array}

\begin{tabular}{llll}
\hline & \multicolumn{2}{l}{$\begin{array}{l}\text { Parameter } \\
\text { level }\end{array}$} & \\
\cline { 2 - 4 } Trial no & T & D & N \\
\hline 1. & 23 & 2 & 1 \\
2. & 23 & 50 & 2 \\
3. & 23 & 100 & 4 \\
4. & 70 & 2 & 2 \\
5. & 70 & 50 & 4 \\
6. & 70 & 100 & 1 \\
7. & 90 & 2 & 4 \\
8. & 90 & 50 & 1 \\
9. & 90 & 100 & 2 \\
\hline
\end{tabular}

In this case, this technique is used to determine the effect of each level of parameters and their combinations on the outcome of locking angles. The wrinkling which tends to occur during the composite forming has been considered as one of the unwanted defects. Even though the locking angle may not mark the exact point of 'onset of wrinkling', it is always better to deform a sample within its locking limit to avoid any unwanted defects. In addition, based on the results from the previous chapters, it is known that; higher the locking angle, postponed the wrinkling and better the formability of the fiber. Taguchi has come up with an equation to calculate the signal-tonoise $(\mathrm{S} / \mathrm{N})$ ratio for this case as listed below, [69]

$$
\left.\begin{array}{l}
\mathrm{S} / \mathrm{N}=-10 \log (\mathrm{MSD}) \\
(\mathrm{MSD})=\frac{1}{\mathrm{n}} \sum_{\mathrm{i}=1}^{\mathrm{n}}\left(\frac{1}{\mathrm{y}_{\mathrm{i}}^{2}}\right)
\end{array}\right\}
$$

Where MSD = Mean square deviation; $\mathrm{y}_{\mathrm{i}}=$ observations; $\mathrm{n}=$ no of tests in a trial. The $\mathrm{S} / \mathrm{N}$ values obtained for both 8HS and 5HS samples are summarized in Table 5.4. 
Table 5.4 Summary of results of locking angles and $\mathrm{S} / \mathrm{N}$ values

\begin{tabular}{|c|c|c|c|c|c|c|c|}
\hline & $\begin{array}{l}\text { Parameter } \\
\text { Level }\end{array}$ & & & $\begin{array}{l}\text { Locking angle } \\
\text { [L.c] (Degree) }\end{array}$ & & $\mathbf{S} / \mathbf{N}$ & \\
\hline Trial No & $\mathbf{A}$ & B & $\mathbf{C}$ & 8-Harness & 5-Harness & 8-Harness & 5-Harness \\
\hline 1. & 23 & 2 & 1 & 36.3 & 35.2 & 31.1981 & 30.9308 \\
\hline 2. & 23 & 50 & 2 & 31.3 & 29.6 & 29.9108 & 29.4258 \\
\hline 3. & 23 & 100 & 4 & 26.8 & 25.2 & 28.5626 & 28.0280 \\
\hline 4. & 70 & 2 & 2 & 40.5 & 39.2 & 32.1491 & 31.8657 \\
\hline 5. & 70 & 50 & 4 & 35.4 & 34.1 & 30.9800 & 30.6550 \\
\hline 6. & 70 & 100 & 1 & 35.6 & 34.5 & 31.0289 & 30.7563 \\
\hline 7. & 90 & 2 & 4 & 41.4 & 39.7 & 32.3400 & 31.9758 \\
\hline 8. & 90 & 50 & 1 & 39.1 & 36.9 & 31.8435 & 31.3405 \\
\hline 9. & 90 & 100 & 2 & 36.2 & 35.2 & 31.2220 & 30.9308 \\
\hline
\end{tabular}


Correlating the results from Table 5.4, it's seen that $8 \mathrm{HS}$ tend to have a higher locking angle than of the 5HS samples. This response has been attributed to the variation in areal density between the samples. Since, comparably the 5HS have higher density $\left(1178.62 \mathrm{~g} / \mathrm{m}^{2}\right)$ it tends to experience high shear resistance at smaller deformation which leads to earlier interlocking. Thus reduced areal density leads to postponed interlocking and wrinkling which is appreciable in terms of forming. These observations confirm the finding of Zhang et al. [39], who compared 3D woven preforms of varying areal density. This helps us to conclude that 8HS samples have better drapability than the 5HS samples $[63,66]$.

It is also witnessed in both $8 \mathrm{HS}$ and $5 \mathrm{HS}$ samples that increase in temperature leads to postpone interlocking which is appreciable in terms of draping complex contours. Increase in temperature from $23^{\circ} \mathrm{C}$ to $90^{\circ} \mathrm{C}$ has led to a phenomenal increase in locking angle. As discussed before in section 3.4.2.1, this is due to the decrease in resin viscosity with the raise in temperature, accompanied by the transition of resin from the rubbery to liquid state [30]. Thus, the effect of wrinkling is comparably much dominant while forming at low temperatures than at high temperatures $[64,67]$.

In contrast, increasing the speed rate has led to locking at an earlier stage resulting in smaller locking angles. Increasing the speed rate increases the rate at which adjacent yarns come in contact with each other, which in turn results to densification at smaller displacement. This causes locking at smaller displacements. On the other hand, at smaller speed rates densification tends to occur at later a stage of displacement which leads to postponed inter-locking. Hence, the impact of wrinkling is found to be much predominant during the forming at higher displacement rates. The response of the $\mathrm{S} / \mathrm{N}$ ratio (both $8 \mathrm{HS}$ and 5HS) to each parameter combination is listed in Table 5.5 and 5.6.

The best parameter combination can be selected based on $\mathrm{S} / \mathrm{N}$ ratio response in Table 5.5 and 5.6 by selecting the highest difference value (marked in red) of each parameter [69]. In turn, linear graphs in Figure 5.10 and 5.11, depicts the effect of varying levels of parameters on the locking angle for both 8HS and 5HS prepreg. Figure 5.10 (a) and 5.11 (a) suggest that the effect of temperature increases as the level proceeds from $23^{\circ} \mathrm{C}$ to $90^{\circ} \mathrm{C}$. In addition, the shift in temperature from $23^{\circ} \mathrm{C}$ to $70^{\circ} \mathrm{C}$ is seen to have a comparably a drastic influence on $\mathrm{S} / \mathrm{N}$ response than the shift from $70^{\circ} \mathrm{C}$ to $90^{\circ} \mathrm{C}$. 
Table 5.5 S/N response (8HS)

\begin{tabular}{|c|c|c|c|c|c|c|c|}
\hline Level & $A$ & B & $\mathrm{C}$ & Level & $A$ & B & C \\
\hline 1. & 29.8905 & 31.8957 & 31.3568 & 1. & 29.4615 & 31.5907 & 31.0092 \\
\hline 2. & 31.3860 & 30.9114 & 31.0939 & 2. & 31.0923 & 30.4737 & 30.7407 \\
\hline 3. & 31.8018 & 30.2711 & 30.6275 & 3. & 31.4157 & 29.9050 & 30.2196 \\
\hline Difference & 1.9113 & 1.6246 & 0.7293 & Difference & 1.9542 & 1.6857 & 0.7896 \\
\hline
\end{tabular}

Table 5.6 $\mathrm{S} / \mathrm{N}$ response (5HS)

While, from Figure 5.10 (b) and 5.11 (b) it is observed that the effect of the shear rate is seen to decrease as the levels proceeds from $2 \mathrm{~mm} / \mathrm{min}$ to $50 \mathrm{~mm} / \mathrm{min}$ and later to $100 \mathrm{~mm} / \mathrm{min}$. Figure 5.10 (c) and 5.11 (c) in turn indicates that the effect of the layer counts decreases as the no of layers increases from 1 to 4 layers.

Based on these outcomes from the Taguchi method, Table 5.7 summarizes the best parameter combinations recommended to reduce the onset of wrinkling during the forming operation. These results are based on the effect of locking angles on the in plane deformation of the fabric.

Table 5.7 Ideal parameter combinations

\begin{tabular}{cc}
\hline Factor & Values \\
\hline Temperature, A & $90^{\circ} \mathrm{C}$ \\
Displacement rate, $\mathbf{B}$ & $2 \mathrm{~mm} / \mathrm{min}$ \\
No.of.layers, $\mathbf{C}$ & 1 layer \\
\hline
\end{tabular}

In addition, based on the differences in $\mathrm{S} / \mathrm{N}$ values listed in Table 5.5 and 5.6 it can be noted that the difference created by temperature is much higher than the difference created by other two parameters. Hence, these results from Taguchi method indicate that influence of temperature on the locking angle is much significant than other two parameters (displacement rate and layer 
count). These outcomes from the Taguchi method is further verified by performing the Analysis of Variance (ANOVA) to determine the percentage of contribution of each parameter on the onset of wrinkling (locking angle).
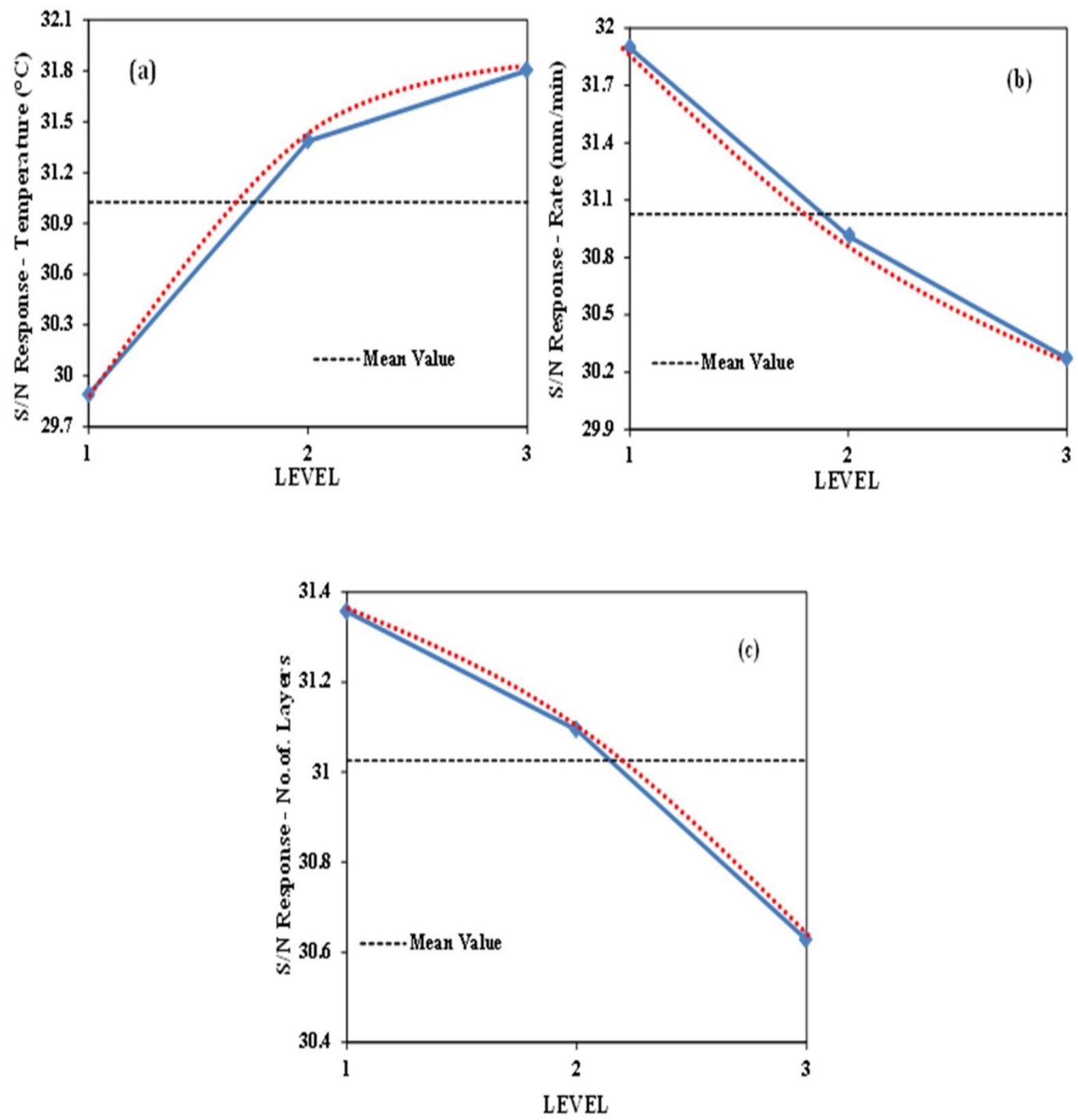

Figure 5.10 Combination of parameters of 8HS at different levels (a) Temperature, (b) displacement rate and (c) layer counts. 

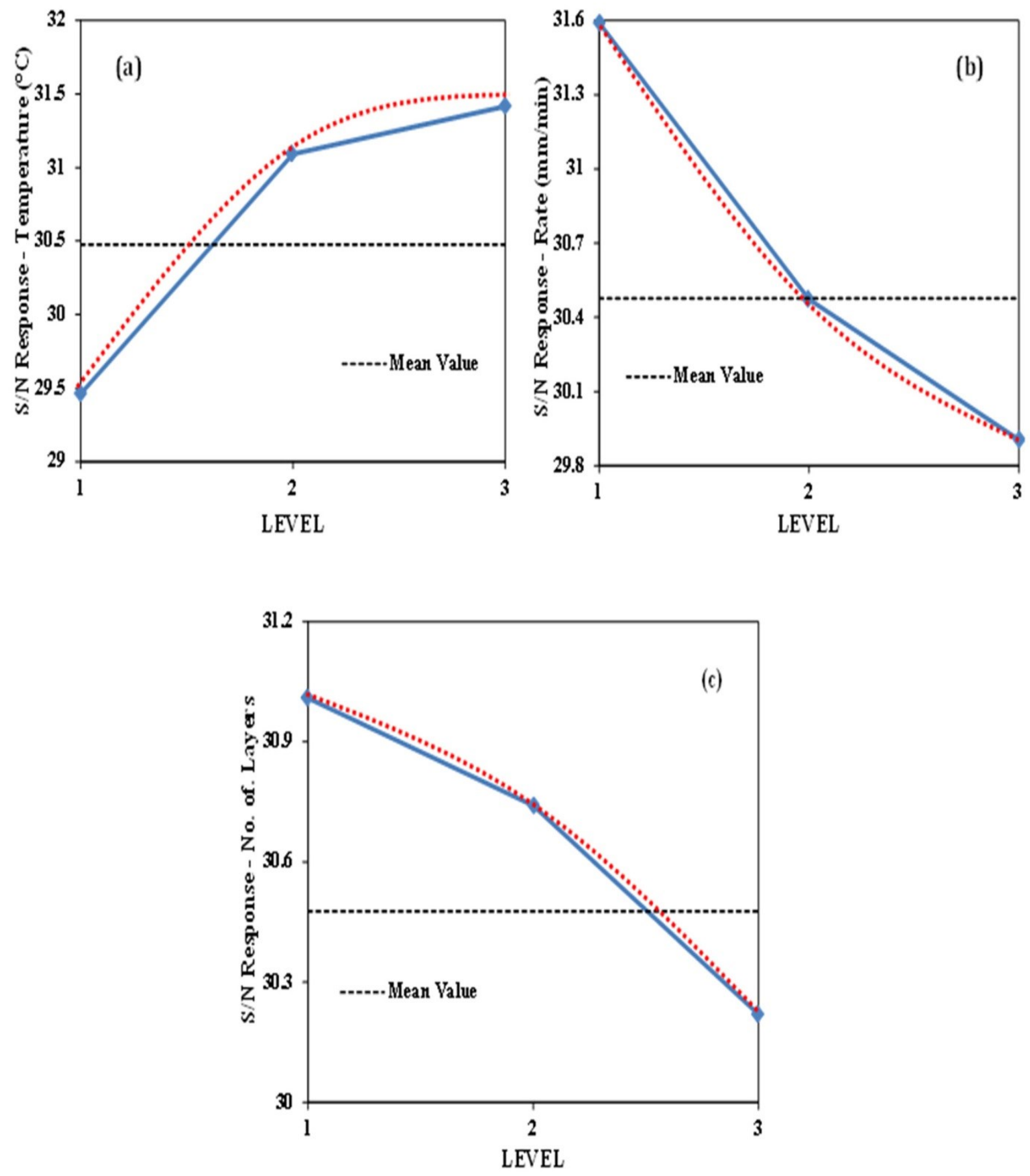

Figure 5.11 Combination of parameters of 5HS at different levels (a) Temperature, (b) displacement rate and (c) layer counts. 


\subsection{Analysis of Variance}

The results were further analyzed using Analysis of Variance (ANOVA) method to determine the percentage of contribution of each parameter [70]. The percentage of contribution by each parameter on both 8HS and 5HS is shown in Table 5.8 and 5.9.

ANOVA calculates the sum of squares $\left(\mathrm{S}_{\mathrm{T}}\right)$ of all parameter based on the following equations, [69]

$$
\mathrm{S}_{\mathrm{T}}=\left(\mathrm{Lc}_{\mathrm{a} 1}^{2}+\mathrm{Lc}_{\mathrm{a} 2}^{2}+\cdots+\mathrm{Lc}_{\mathrm{aN}}^{2}\right)-\frac{\left(\mathrm{Lc}_{\mathrm{a} 1}+\mathrm{Lc}_{\mathrm{a} 2}+\cdots+\mathrm{Lc}_{\mathrm{aN}}\right)^{2}}{\mathrm{~N}}
$$

Where $\mathrm{Lc}_{\mathrm{a} 1}, \mathrm{Lc}_{\mathrm{a} 2}, \ldots$ are the locking angles at varying parameter levels. Further, the square of each parameter is calculated by, [69]

$$
\mathrm{S}_{\mathrm{A}}=\frac{\left(\sum \mathrm{A}_{1}\right)^{2}}{\mathrm{~K}_{\mathrm{A}}}+\cdots+\frac{\left(\sum \mathrm{A}_{3}\right)^{2}}{\mathrm{~K}_{\mathrm{A}}}-\frac{\left(\mathrm{Lc}_{\mathrm{a} 1}+\mathrm{Lc}_{\mathrm{a} 2}+\cdots+\mathrm{Lc}_{\mathrm{aN}}\right)^{2}}{\mathrm{~N}}
$$

The term $\mathrm{S}_{\mathrm{A}}$ denotes the sum of the parameter ' $\mathrm{A}$ ', and finally the percentage of contribution of each parameter on the outcome is equated as shown, [69]

$$
\mathrm{P}_{\mathrm{A}}=\frac{\mathrm{S}_{\mathrm{A}}}{\mathrm{S}_{\mathrm{T}}} \times 100 \%
$$

This enables us to determine the percentage of contribution of each parameter on the onset of wrinkling. The results in tables 5.8 and 5.9 suggest that, temperature contributes the most on the onset of wrinkling by $54.60 \%(8 \mathrm{HS})$ and $53.95 \%$ (5HS). Even though the difference in the contribution by temperature between both the samples might be small it reveals that, comparably the influence of operating temperature is higher on the 8HS than the 5HS prepreg. Whereas, secondly the displacement rate is seen to contribute $39.42 \%$ (8HS) and $38.94 \%$ (5HS) to the onset of wrinkling. Finally, the layer counts are seen to contribute the least to the outcome.

This confirms our previous investigation from the Taguchi analysis that; operating temperature (resin viscosity) is the most significant factor which influence the onset of wrinkling in both 8HS and 5HS prepreg. Displacement rate and thickness only have a small effect on wrinkling by contributing less to the overall percentage of dependence. 
Table 5.8 ANOVA (8 harness)

\begin{tabular}{|c|c|c|c|c|}
\hline Parameters & $\begin{array}{l}\text { Degree of } \\
\text { freedom, f }\end{array}$ & $\begin{array}{c}\text { Sum of } \\
\text { square, } S\end{array}$ & $\begin{array}{l}\text { Variance, } \\
\text { V }\end{array}$ & $\begin{array}{l}\text { Contribution, } \\
\%\end{array}$ \\
\hline Temperature, A $\left({ }^{\circ} \mathrm{C}\right)$ & 2 & 90.749 & 45.37 & 54.60 \\
\hline $\begin{array}{l}\text { Displacement Rate, B } \\
(\mathrm{mm} / \mathrm{min})\end{array}$ & 2 & 65.520 & 32.76 & 39.42 \\
\hline No. of. Layers & 2 & 9.236 & 4.61 & 5.55 \\
\hline Error & 2 & 0.685 & 0.34 & 0.41 \\
\hline Total & 8 & 166.19 & 83.09 & 100 \\
\hline
\end{tabular}

Table 5.9 ANOVA (5 harness)

\begin{tabular}{|c|c|c|c|c|}
\hline Parameters & $\begin{array}{l}\text { Degree of } \\
\text { freedom, } f\end{array}$ & $\begin{array}{c}\text { Sum of } \\
\text { square, } S\end{array}$ & Variance, V & $\begin{array}{l}\text { Contribution, } \\
\%\end{array}$ \\
\hline Temperature, A $\left({ }^{\circ} \mathrm{C}\right)$ & 2 & 89.780 & 44.89 & 53.94 \\
\hline $\begin{array}{l}\text { Displacement Rate, } \\
\text { B }(\mathrm{mm} / \mathrm{min})\end{array}$ & 2 & 64.813 & 32.40 & 38.94 \\
\hline No. of. Layers & 2 & 9.943 & 4.97 & 5.97 \\
\hline Error & 2 & 1.904 & 0.95 & 1.14 \\
\hline Total & 8 & 166.44 & 83.2 & 100 \\
\hline
\end{tabular}




\subsection{Summary}

Firstly, this chapter reported that bias-extension results follow the same trend as the picture frame test results during the shear analysis. The results of both the tests were normalized based on their shear area to make the results comparable. These results from both the tests explains the prime reason behind the picture frame and the bias extension tests being formidably selected to characterize the intra-ply shear behavior of the fabric.

Later, based on the Taguchi and ANOVA methods of optimization it was reported that high temperature integrated with lower displacement rate serves as an optimum condition to perform the forming operation, avoiding the onset of wrinkling. In addition, it was also reported that temperature serves the most prominent parameter which influence the onset of wrinkling during the forming operation. 


\section{CHAPTER 6: CONCLUSION}

Conclusions drawn from the research work presented in the preceding chapters are summarized as follows:

I. From the DSC analysis used to characterize the material, it was found that the Cycom5320 OOA carbon epoxy prepreg starts to cure at a temperature of $113.5^{\circ} \mathrm{C}$ when heated at a rate of $2^{\circ} \mathrm{C} / \mathrm{min}$. These results were further verified by performing the rheological analysis, which suggested that the curing reaction starts at $110.67^{\circ} \mathrm{C}$ when heated at a rate of $2^{\circ} \mathrm{C} / \mathrm{min}$. This result suggested that the material should be handled within this temperature in order to avoid it from curing during the forming operation. Hence, taking this into account, the operating temperatures $\left(50^{\circ} \mathrm{C}, 70^{\circ} \mathrm{C}, 90^{\circ} \mathrm{C}\right)$ were chosen to characterize the in-plane shear behavior of the OOA prepreg.

II. The rheological analysis of the resin system showed that, during the initial phase of transition, viscosity of the resin at $90^{\circ} \mathrm{C}$ is much lower than that at $70^{\circ} \mathrm{C}$ and $50^{\circ} \mathrm{C}$. In addition, the gelation time (time to cure) at different temperature were reported as, 243 $\min \left(100^{\circ} \mathrm{C}\right), 453 \mathrm{~min}\left(90^{\circ} \mathrm{C}\right)$ and $1302 \mathrm{~min}\left(70^{\circ} \mathrm{C}\right)$. This helped to conclude that the gelation time decreases with the increase in temperature. By performing the rheological analysis, we were able to investigate the amount of time we had for forming before any curing (gelation) happens.

III. On investigating the in-plane shear behavior of OOA prepreg by subjecting them to different elevated temperatures and displacement rates, it was concluded that; the onset of wrinkling is postponed while forming during high temperatures and low displacement rates. The wrinkling was experimentally found to be observed at the locking angle when samples were tested at room temperature. However, in-depth inspection of the onset of wrinkling at elevated temperatures using the DIC concluded that the onset of wrinkling was visible marginally before the locking angle. This variation might be due to the distortion of the speckle pattern by the oozing of resin from the prepreg, when operated at high temperatures. 
IV. From the microscopic analysis, the sliding of the tows was clearly visible during the shear deformation. The tows were seen to relocate themselves making a severe contact as the shear increases. In turn, splittage of tows was visible at the end of the deformation indicating the tows were sheared beyond its locking zone. Even a phenomenal change in the shape of the tows throughout the shear process was reported during the analysis. The SEM analysis also depicted the same results.

V. In addition, the microscopic analysis also revealed that the tow width decreases with the increase in shear angle indicating that change in tow width has a major role to play in the onset of wrinkling. While, the thickness of the tows was seen to increase as the shear proceeds. In contrast, the wavelength of the yarn cross section was seen to decrease with the increase in the amplitude to compensate these variations in tow size.

VI. On a scale of comparison between the $8 \mathrm{H}, 5 \mathrm{HS}$ and UD prepreg to characterize their formability; it was concluded that $8 \mathrm{HS}$ (3K thickness) has the maximum deformability of the lot by postponing the onset of wrinkling. Following, the 5HS (6K thickness) is seen to have a reasonable deformability but not as high as the $8 \mathrm{HS}$ prepreg. While, the UD prepreg is observed to have the least deformability making them least preferable for forming of complex contours. Hence it was concluded that the UD prepreg have less deformability than the woven prepregs.

VII. The results of the in-plane shear characterization were further optimized using Taguchi method to determine the effect of various parameters (temperature, shear rates and layer count) on the onset of wrinkling. Based on the Taguchi method the optimum parameter combinations for forming were concluded as follows,

- Optimum temperature $=90^{\circ} \mathrm{C}$;

- Optimum displacement rate $=2 \mathrm{~mm} / \mathrm{min}$;

- Optimum layer count = 1- layer.

VIII. Further on analysis using the ANOVA technique (to determine the percentage of contribution of each parameter on the onset of wrinkling), it was concluded that the temperature is the most significant parameter which influence the wrinkling the most; followed by displacement rate and layer count. In addition, it was seen that the influence of the temperature on wrinkling is marginally higher in the 8HS (54.60) than the 5HS (53.94\%) prepreg. 


\section{CHAPTER 7: FUTURE WORK}

As for further investigation the effect of other modes of deformation; inter-ply shear, friction between plies, ply bending and layer compaction on the forming operation needs to be investigated. Further, taking all these deformation modes into consideration a model needs to be created to characterize the deformation of the prepreg before proceeding with the actual forming operation. The actual forming operation needs to be simulated using Aniform ${ }^{\circledR}$ prior to performing it experimentally. In addition, the various challenges associated with the double diaphragm forming process need to be overcome. By this, it can be made sure that a high quality product without any defect (wrinkling and slippage) is formed. 


\section{REFERENCES}

[1] A. C. Long (editor), Design and manufacture of textile composites, CRC press. 2005.

[2] B. Zhu, T. Yu, and X. Tao, "An experimental study of in-plane large shear deformation of woven fabric composite," Composites Science and Technology, vol. 67, no. 2, pp. 252261, Feb. 2007.

[3] B. Zhu, T. X. Yu, and X. M. Tao, "Large deformation and slippage mechanism of plain woven composite in bias extension," Composites Part A: Applied Science and Manufacturing, vol. 38, no. 8, pp. 1821-1828, Aug. 2007.

[4] Jean Luanaya, Gilles Hiveta, Ahn V.Duonga and Phillipe Boisseb," Experimental analysis of the influence of tensions on in plane shear behavior of woven composite reinforcements,"Composites Science and Technology, vol. 2, June. 2007.

[5] P. Boisse, K. Buet, A. Gasser, and J. Launay, "Meso/macro-mechanical behaviour of textile reinforcements for thin composites," Composites Science and Technology, vol. 61, no. 3, pp. 395-401, Feb. 2001.

[6] T. Centea and P. Hubert, Modelling the effect of material properties and process parameters on tow impregnation in out-of-autoclave prepregs. Composites Part A: Applied Science and Manufacturing. 2012; 43: 1505-13.

[7] K.S. Madhok, "Comparative Characterization of Out-of-Autoclave Materials Made by Automated Fiber Placement and Hand-lay-up Processes. Master thesis," Concordia University, September, 2013.

[8] L. Repecka and J. Boyd, "Vacuum-Bag-Only-Curable Prepregs That Produce Void FreeParts," presented at the 47th International SAMPE Symposium, 2002.

[9] A. C. Long (editor), Composites forming technologies, CRC press. 2007. 
[10] J. Cao, P. Xue, X. Peng, and N. Krishnan, "An approach in modeling the temperature effect in thermo-stamping of woven composites," Composite Structures, vol. 61, no. 4, pp. 413-420, Sep. 2003.

[11] Y. R. Larberg, M. Akermo, and M. Norrby, "On the in-plane deformability of cross-plied unidirectional prepreg," Journal of Composite Materials, vol. 46, no. 8, pp. 929-939, Oct. 2011.

[12] M. Sherburn, "Geometric and Mechanical Modelling of Textiles,"PhD. Thesis, University of Nottingham . July, 2007.

[13] S. V. Hoa, Principles of the manufacturing of composites materials,DEStech publication. 2009.

[14] A. P. Mouritz, M. K. Bannister, P. J. Falzon, and K. H. Leong, "Review of applications for advanced three-dimensional fibre textile composites," Composites Part A: Applied Science and Manufacturing, vol. 30, no. 12, pp. 1445-1461, Dec. 1999.

[15] Reedy ED, Guess TR. Additional comparisons of interlocked fabric and laminated fabric Kevlar 49/epoxy composites; "Journal of Composite Technology and Research" $1986 ; 8: 163-168$.

[16] Tucker CL., "Forming of advanced composites," In: Gutowski TG, editor. Advanced compossites manufacturing. New York: Wiley, pp. 297-372, 1997.

[17] C. M. O'Bradaigh, "Sheet Forming of Composites Materials," in Flow and Rheology in Polymer Composites Manufacturing, Advani, S. G., ed., pp.517-569, Elesvier, Amsterdam, 1994.

[18] Christopher.B.Munro,'Technological Advances in Double Diaphragm Formingof Advanced and Uniform Short Fiber Composites using Fixed and Reconfigurable Tooling,’PhD.Thesis, Rensellaer Polytechnic Institute. August, 2006. 
[19] H. E. N. Bersee, S. Lindstedt, G. Niño, and A. Beukers, "Diaphragm forming of thermoset composites," 16th International conference on composite materials, pp. 1-11, 2007.

[20] Samuel.P. Truslow, "Permanent press, no wrinkles : reinforced double diaphragm formings of advanced thermoset composites. Master Thesis," Massachusetts Institute of Technology, May, 2000.

[21] J. Wang, "Predictive Modelling and Experimental Measurement of Composite Forming Behaviour,"PhD. Thesis, University of Nottingham. August, 2008.

[22] J. Krebs, K. Friedricha, and D. Bhattacharyyab, "A direct comparison of matched-die versus diaphragm forming," Composites Part A, 29A, pp. 183-188, pp. 183-188, 1998.

[23] D. Laroche and T. Vu-Khanh, "Forming of Woven Fabric Composites," Journal of Composite Materials, vol. 28, no. 18, pp. 1825-1839, Dec. 1994.

[24] G. Lebrun, M. N. Bureau, and J. Denault, "Evaluation of bias-extension and picture-frame test methods for the measurement of intraply shear properties of PP/glass commingled fabrics," Composite Structures, vol. 61, no. 4, pp. 341-352, Sep. 2003.

[25] K. Potter, "Beyond the pin-jointed net: maximising the deformability of aligned continuous ${ }^{\circledR}$ bre reinforcements," vol. 33, 2002.

[26] K. Vanclooster, "Forming of Multilayered Fabric Reinforced Thermoplastic Composite,"PhD. Thesis, Katholeike University,Belgium, 2009.

[27] K. a. Fetfatsidis, D. Jauffrès, J. a. Sherwood, and J. Chen, "Characterization of the tool/fabric and fabric/fabric friction for woven-fabric composites during the thermostamping process," International Journal of Material Forming, vol. 6, no. 2, pp. 209-221, Nov. 2011.

[28] Y. R. Larberg and M. Åkermo, "On the interply friction of different generations of carbon/epoxy prepreg systems," Composites Part A: Applied Science and Manufacturing, vol. 42, no. 9, pp. 1067-1074, Sep. 2011. 
[29] J. Sun, M. Li, Y. Gu, D. Zhang, Y. Li, and Z. Zhang, "Interply friction of carbon fiber/epoxy prepreg stacks under different processing conditions," Journal of Composite Materials, no. February, Feb. 2013.

[30] Ersoy N, Potter K, Wisnom MR and Clegg MJ. An experimental method to study the frictional processes during composites manufacturing. Composites Part A: Applied Science and Manufacturing. 2005; 36: 1536-44.

[31] E. Bilbao, D. Soulat, G. Hivet, and a. Gasser, "Experimental Study of Bending Behaviour of Reinforcements,” Experimental Mechanics, vol. 50, no. 3, pp. 333-351, Mar. 2009.

[32] W. R. Yu, M. Zampaloni, F. Pourboghrat, K. Chung, and T. J. Kang, "Analysis of flexible bending behavior of woven preform using non-orthogonal constitutive equation," Composites Part A: Applied Science and Manufacturing, vol. 36, no. 6, pp. 839-850, Jun. 2005.

[33] K. Bilisik and G. Yolacan, "Experimental determination of bending behavior of multilayered and multidirectionally-stitched E-Glass fabric structures for composites," Textile Research Journal, vol. 82, no. 10, pp. 1038-1049, Apr. 2012.

[34] ASTM D1388-08, "Standard Test Method for Stiffness of Fabrics," ASTM International, 2012.

[35] Ylva Larberg, "Forming of Stacked Unidirectional Prepreg Material,"PhD. Thesis, KTH Royal Institute of Technology,Sweden, 2012.

[36] Mark c. and Taylor H.M., "The fitting of woven cloth to surfaces," Textile Inst., vol. 47, pp. 477488, 1956.

[37] K. Potter, "Bias extension measurements on cross-plied unidirectional prepreg," Composites Part A: Applied Science and Manufacturing, vol. 33, no. 1, pp. 63-73, Jan. 2002.

[38] A.G.Prodromou and J.Chen," On the Relationship Between Shear Angle and Wrinkling Textile Composites",Composites Part A ,no 28A,pp.491-503,1997. 
[39] Y. Zhang, F. Sun, Y. Wang, L. Chen, and N. Pan, "Study on intra/inter-ply shear deformation of three dimensional woven preforms for composite materials," Materials \& Design, vol. 49, pp. 151-159, Aug. 2013.

[40] S. V. Lomov, "Picture Frame Test of Woven Composite Reinforcements with a Full-Field Strain Registration,” Textile Research Journal, vol. 76, no. 3, pp. 243-252, Mar. 2006.

[41] P. Harrison, M. J. Clifford, and a. C. Long, "Shear characterisation of viscous woven textile composites: a comparison between picture frame and bias extension experiments," Composites Science and Technology, vol. 64, no. 10-11, pp. 1453-1465, Aug. 2004.

[42] J. Cao, R. Akkerman, P. Boisse, J. Chen, H. S. Cheng, E. F. de Graaf, J. L. Gorczyca, P. Harrison, G. Hivet, J. Launay, W. Lee, L. Liu, S. V. Lomov, a. Long, E. de Luycker, F. Morestin, J. Padvoiskis, X. Q. Peng, J. Sherwood, T. Stoilova, X. M. Tao, I. Verpoest, a. Willems, J. Wiggers, T. X. Yu, and B. Zhu, "Characterization of mechanical behavior of woven fabrics: Experimental methods and benchmark results," Composites Part A: Applied Science and Manufacturing, vol. 39, no. 6, pp. 1037-1053, Jun. 2008.

[43] A. S. Milani, J. A. Nemes, G. Lebrun, and M. N. Bureau, "A Comparative Analysis of a Modified Picture Frame Test for Characterization of Woven Fabrics,'Polymer Composites, vol. 0, pp.561-568, 2010.

[44] A. S. Milani, J. a. Nemes, R. C. Abeyaratne, and G. a. Holzapfel, "A method for the approximation of non-uniform fiber misalignment in textile composites using picture frame test," Composites Part A: Applied Science and Manufacturing, vol. 38, no. 6, pp. 1493-1501, Jun. 2007.

[45] I. Taha, Y. Abdin, and S. Ebeid, "Comparison of picture frame and Bias-Extension tests for the characterization of shear behaviour in natural fibre woven fabrics," Fibers and Polymers, vol. 14, no. 2, pp. 338-344, Mar. 2013.

[46] A. Willems, S. V Lomov, Z. Yingbo, I. Verpoest, and D. Vandepitte, "Deformability characterization of fabrics using large and small scale full field optical strain measurements," pp. 1-8. 
[47] S. V. Lomov, M. Barburski, T. Stoilova, I. Verpoest, R. Akkerman, R. Loendersloot, and R. H. W. te. Thije, "Carbon composites based on multiaxial multiply stitched preforms. Part 3: Biaxial tension, picture frame and compression tests of the preforms," Composites Part A: Applied Science and Manufacturing, vol. 36, no. 9, pp. 1188-1206, Sep. 2005.

[48] T.G. Gutowski, G. Dillon, S. Chey, and H. Li, "Laminate wrinkling composites scaling laws for ideal,"Composites Manufacturing, vol. 6, no. 3, pp. 123-134, 1995.

[49] P. Boisse, N. Hamila, E. Vidal-Sallé, and F. Dumont, "Simulation of wrinkling during textile composite reinforcement forming. Influence of tensile, in-plane shear and bending stiffnesses," Composites Science and Technology, vol. 71, no. 5, pp. 683-692, Mar. 2011.

[50] http://www.compositesworld.com/articles/out-of-autoclave-prepregs-hype-or-revolution, Composites World.

[51] https://www.cytec.com/businesses/aerospace-materials/products/cycom-5320-1/technical data sheet.

[52] Liangfeng Sun, “Thermal Rheological Analysis of Cure Process of Epoxy Prepreg”. PhD Dissertation,” Lousiana State University, May, 2002.

[53] http://www.pcimag.com/ext/resources/PCI/Home/Files/PDFs/Virtual_Supplier_Brouchures/ Anton_Paar.pdf.

[54] Tung and Dynes. Relationship between Viscoelastic Properties and Gelation in Thermosetting Systems. Journal of Applied Polymer Science. 1982; 27: 569-74.

[55] P. Harrison, J. Wiggers, and A. C. Long, "Normalization of Shear Test Data for Rateindependent Compressible Fabrics," Journal of Composite Materials, vol. 42, no. 22, pp. 2315-2344, Aug. 2008.

[56] Scouter BJ. "Effect of fiber architecture on formability of textile preforms"; $\mathrm{PhD}$ Dissertation,University of Nottingham, UK, 2001. 
[57] F. Shadmehri, "Buckling of Laminated Composite Conical Shells; Theory and Experiment,"; PhD Dissertation, Concordia University, Canada, 2012.

[58] "Deformation Measurment," Correlated Solutions, I., "http://www.correlatedsolutions.com/data/vic2d-vic3d-flyer.pdf,". [Online].

[59] A. Willems, S. V. Lomov, I. Verpoest, and D. Vandepitte, "Drape-ability characterization of textile composite reinforcements using digital image correlation," Optics and Lasers in Engineering, vol. 47, no. 3-4, pp. 343-351, Mar. 2009.

[60] Gereke T, Döbrich O, Hübner M and Cherif C. Experimental and computational composite textile reinforcement forming: A review,"Composites Part A: Applied Science and Manufacturing, vol.46, pp. 1-10, 2013.

[61] S. H. Chang, S. B. Sharma, and M. P. F. Sutcliffe, "Microscopic investigation of tow geometry of a dry satin weave fabric during deformation,"Composites Science and technology, vol. 63, pp. 99-111, 2003.

[62] Härtel, F., \& Harrison, P. (2014). Evaluation of normalisation methods for uniaxial bias extension tests on engineering fabrics. Composites Part A: Applied Science and Manufacturing, 67(November), 61-69. doi:10.1016/j.compositesa.2014.08.011.

[63] H. Alsharani, P. M. Rahul and M. Hojjati, " Experimental investigation of in-plane deformability of out of autoclave satin weave fabric prepreg". Applied Composite Materials,submitted.

[64] H. Alshahrani, P.M. Rahul, M. Hojjati," Evaluation of in-plane shear deformation of outof-autoclave carbon/epoxy prepregs using bias extension test” CAMX/SAMPE/ACMA, Orlando, Florida, USA, October 13-16, (2014).

[65] Chen, J., Lussier, D. S., Cao.J and Peng X.D., "Materials characterization methods and material models for stamping of plain woven composites."Journal of Forming", 2001. 
[66] Rahul P.M., A. Hassan, M. Hojjati "Influence of intra-ply shear behavior of out-ofautoclave carbon/epoxy prepreg". Journal of composite materials, submitted.

[67] Rahul P.M., A. Hassan, M. Hojjati "The Effect of Processing Parameters on Intra-ply Shear Property of Out-Autoclave Carbon/Epoxy Prepreg" in the proceedings of $10^{\text {th }}$ Canada-Japan Workshop on Composites, Vancouver, Canada, August 19-21 (2014).

[68] Davidson, M. J., Balasubramanian, K., \& Tagore, G. R. N. (2008). Experimental investigation on flow-forming of AA6061 alloy-A Taguchi approach. Journal of MaterialsProcessingTechnology,200(1-3),283-287.

[69]. Ghazali M, Shayfull Z, Shuaib A, Nasir SM and Salleh MM. Injection mould analysis in reducing warpage nylon PA66 side arms using taguchi method and anova. International Journal of Basics and Applied Sciences. 2011; 01: 55-60.

[70]. Balamugundan, B., Karthikeyan, L., \& Senthilkumar, V. S. (2012). Multi Characteristics Optimization During Milling of Friction Stir Processed Glass Fiber Reinforced Plastic Composites. Procedia Engineering, 38, 1276-1285. 